
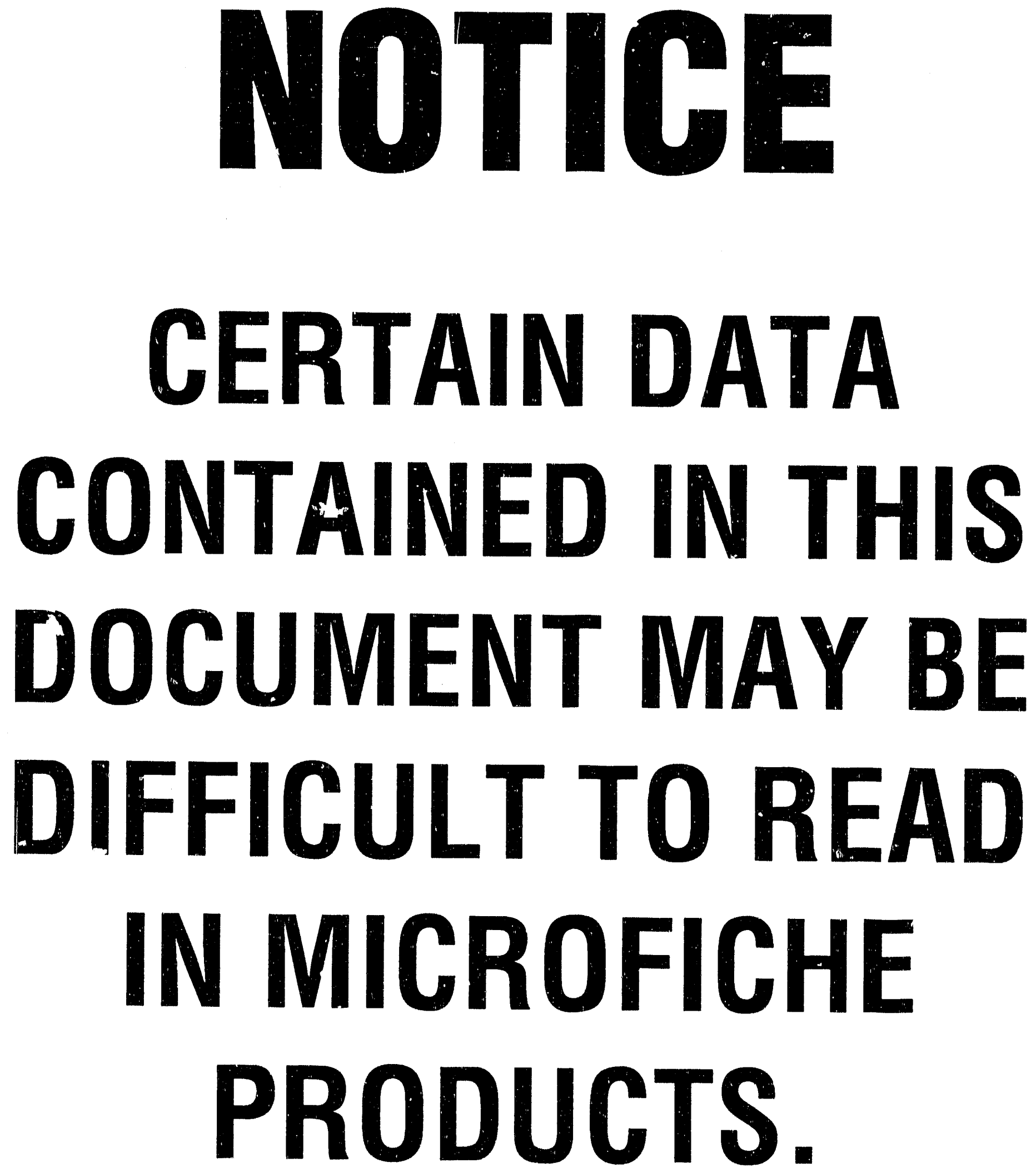
DOE/PC/88868-T5

(DE91004164)

CHARACTERIZATION AND MODIFICATION OF PARTICULATE PROPERTIES TO ENHANCE FILTRATION PERFORMANCE

Final Report

By

Todd R. Snyder

P. Vann Bush

Michael S. Robinson

June 1990

Work Performed Under Contract No. AC22-88PC88868

For

U.S. Department of Energy

Pittsburgh Energy Technology Center

Pittsburgh, Pennsylvania

By

Southern Research Instltute

Birmingham, Alabama 


\section{DISCLAIMER}

This report was prepared as an acoount of work sponsored by an agency of the United States Government. Neither the United States Government nor any agency thereot. nor any of their employes, makes any warranty, express or implied, or assumes any legal liability or responsibiluty for the accuracy, completeness, or usefulness of any information, apparatus, product, or process disclosed. or represents that its use would not infringe privately owned rights. Reference herein to any specific commercial product, process, or service by trade name. trademark, manufacturer, or otherwise does not necessarily constitute or imply is endorsement, recommendation. or favoning by the United States Government or any agency thereof. The views and opinions of authors ex. pressed herein do not necessarily state or reflect those of the United States Governinent or any agency thereor.

This report has been reproduced directly from the best available copy.

Available to DOE and DOE contractors from the Office of Scientific and Technical Information, P.O. Box 62, Oak. Ridge, TN 37831; prices available from $(615) 576.8401$, FTS 626.8401 .

Available to the public from the National Technical Information Service, U.S. Deparment of Commerce, 5285 Port Koyal Rd., Springfield, VA 22161. 


\title{
CHARACTERIZATION AND MODIFICATION OF PARTICULATE PROPERTIES TO ENHANCE FILTRATION PERFORMANCE
}

\section{FINAL REPORT}

\section{Contract No. DE-AC22-88PC88868}

SRI Project No. 6666

June, 1990

\author{
Todd R. Snyder \\ P. Vann Bush \\ Michael S. Robinson \\ SOUTHERN RESEARCH INSTITUTE \\ Post Office Box 55305 \\ 2000 Ninth Avenue South \\ Birmingham, Alabama 35255-5305
}

\section{Prepared for}

U.S. DEPARTMENT OF ENERGY Pittsburgh Energy Technology Center Post Office Box 10940, MS 920-L Pittsburgh, Pennsylvania 15236

Perry D. Bergman, Project Manager 


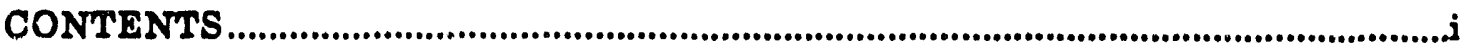

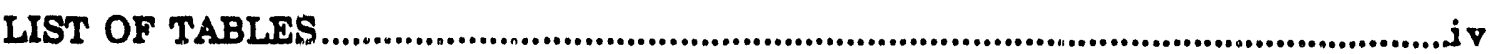

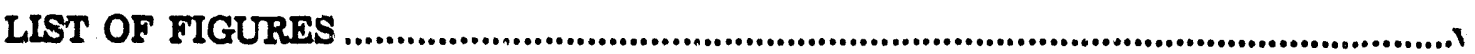

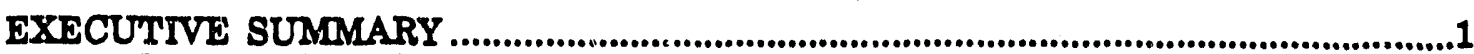

CONCLUSIONS ...

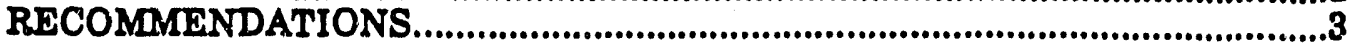

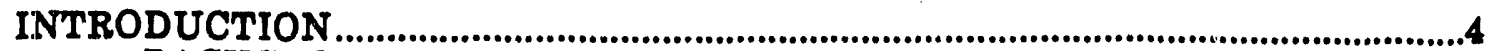

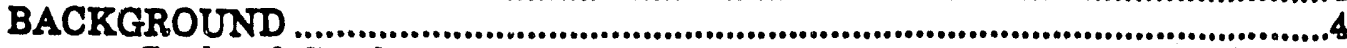

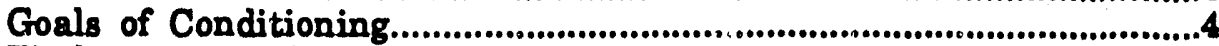

Findings from Prior Work...................................................................4.4

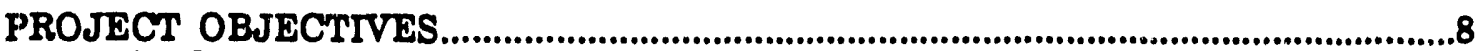

PROJECT ORGANIZATION

PARAMETRIC TESTS OF ASHES AND FABRICS..................................................11

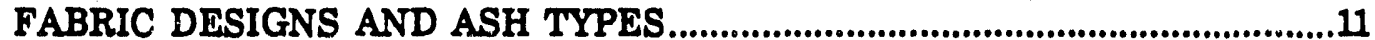

LABORATORY EQUIPMENT AND PROCEDURES .........................................11

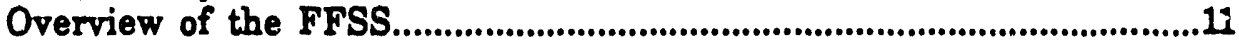

Filtration Cabinet. ..................................................................11

Data Acquisition and Analysis System......................................15

MEASUREMENT OF ASH COHESIVITY.....................................................15

LABORATORY ANALYSES OF HOPPER ASHES.........................................15

RELATIONSHIPS BETWEEN ASH PARTICLE SIZE AND SHAPE, ASH

COHESIVITY, AND FABRIC DESIGN..........................................................

Exfect of Particle Shape............................................................................29

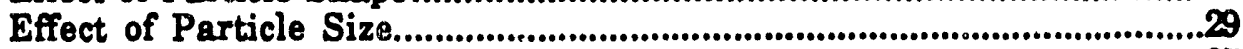

Effect of Ash Cohesivity ............................................................................35

Effect of Fabric Design ............................................................................35

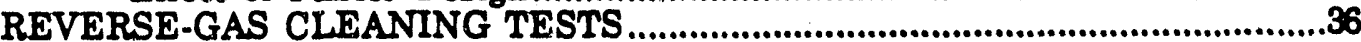

SUMMARY OF PARAMETRIC TESTS OF ASHES AND FABRICS..................42

SURVEY OF METHODS TO MODIFY PARTICLE FILTRATION PROPERTIES......43

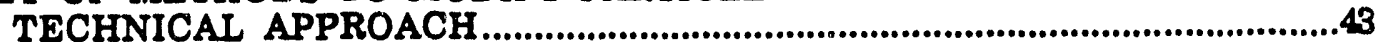

FINDINGS FROM THE LITERATURE REVIEW

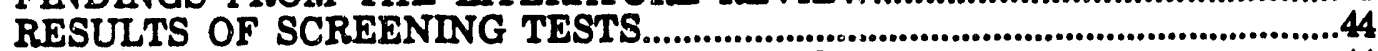

Conditioning Fly Ashes with Dry Powders............................................44

Mixing Ashes with Dry Powders in the Miring and

Conditioning Chamber ...........................................................................44

Mixing Ashes with Dry Powders in a Blender......................................47

Mixing Ashes with Dry Powders by Manual Shaking .............................49

Characteristics of Aluminum Silicate ....................................................49

Investigaticn of Ammonia/Sulfur Trioxide Reactions ...........................54

SUMMMARY OF SURVEY OF METHODS TO MODIFY PARTICLE

FILTRATION PROPERTIES. 
PROOF-OF-CONCEPT TESTS OF METHODS TO MODIFY PARTICLE

FILTRATION PROPERTIES.................................................................................68

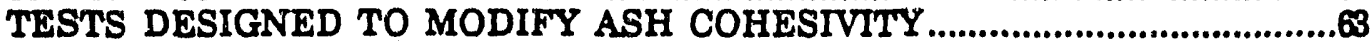

Fine Powders as Conditioning Agents.....................................................6马

Formation of Liquid Bridges to Condition Ashes ...................................67

Elevated Humidity Levels........................................................................69

Fine Oil Mist ...................................................................................69

Reactants Formed from Ammonia or Triethylamine

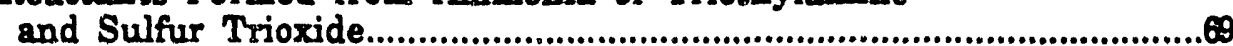

TESTS DESIGNED TO MODIFY THE FILTERING SURFACE..................72

SUMMARY OF PROOF-OF-CONCEPT TESTS OF METHODS TO MODIFY

PARTICLE FILTRATION PROPERTIES ........................................................74

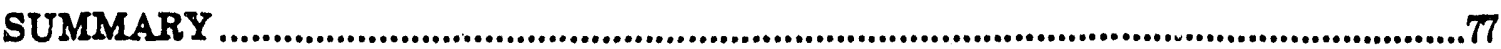

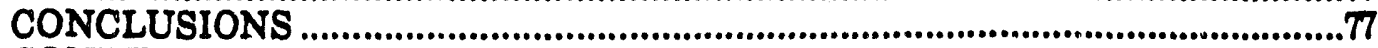

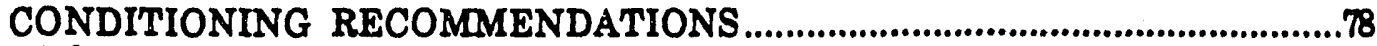

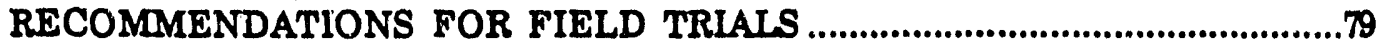

Inherent Limitations of the Laboratory Environment.............................79

Technical Questions Addressed by On-Site Sidestream Testing ............79

Proposed Field Trials at Monticello...............................................................79

Site Description ..........................................................................79

Proposed Tests..........................................................................................79

Proposed Field Trials at Scholz..................................................................80

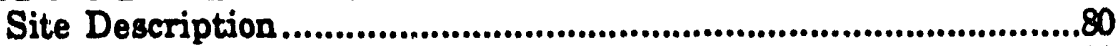

Proposed Tests................................................................................80

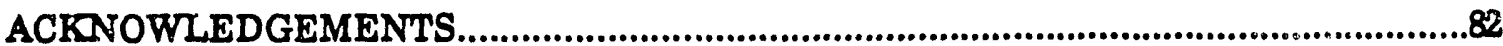

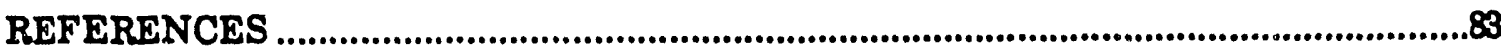

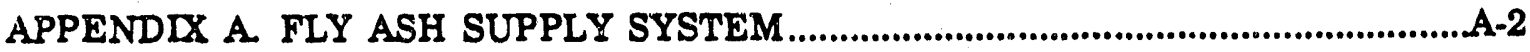

APPENDDX B. DESIGN AND OPERATION OF THE FABRIC FILTER SAMPLING SYSTEM.

APPENDIX C. TECHNIQUES USED TO ANALYZE FABRIC FILTER SAMPLING SYSTEM DATA.

APPENDIX D. LABORATORY TESTS USED TO CHARACTERIZE FLY ASH TAMPLES.

APPENDIX E. ADDITIONAL DATA FOR FILTRATION TESTS OF UNCONDITIONED ASHES

APPENDIX F. PROCEDURES AND PARAMETERS USED TO GENERATE THE LITERATURE SEARCH.

APPENDIX G. SUMMARY OF PERTINENT ARTICLES AND ADDITIONAL INFORMATION OBTAINED THROUGH THE LITERATURE SEARCH

APPENDIX H. DESCRIPTION OF MIXING AND CONDITIONING CHAMBER

APPENDIX I. PROCEDURES USED FOR PRODUCING CONDITIONED MIXTURES OF T'WO FLY ASH TYPES IN THE MIXING AND CONDITIONING CHAMBER 
APPENDEX J. CHARACTERISTICS OF ASHES COLLECTED FROM THE MIXING AND CONDITIONING CHAMBER DRY POWDER CONDITIONING TESTS

APPENDIX $\mathrm{K}$ TEST PROCEDURES FOR THE CONDITIONING OF FLY ASH WITH CAB-O-SIL SILICA IN THE MIXING AND CONDITIONING CHAMBER.

APPENDIX L. TEST PROCEDURES FOR THE CONDITIONING OF BASE FLY ASH WITH FINE POWDERS IN THE WARING BLENDORTM

APPENDIX M. SUMMARY OF ANALYSES OF MIXTURES PRODUCED

IN THE BLENDER A-44

APPENDIX N. PROCEDURES USED FOR PRODUCING CONDITIONED MIXTURES OF ASH AND VARIOUS POWDERS WITH MANUAL SHAKING $A-47$

APPENDIX O. SUMMARY OF ANALYSES OF HAND-SHAKEN MIXTURES $A-48$

APPENDIX P. TEST PROCEDURES FOR THE CONDITIONING OF FLY ASH WITH AMMONIUM SULFATE IN THE MIXING AND CONDITIONING CHAMBER.

APPENDIX Q. ADDITIONAL DATA FOR PROOF-OF-CONCEFT FILTRATION TESTS

APPENDIX R. PROCEDURES USED IN PROOF-OF-CONCEPT FILTRATION TESTS OF SULFUR TRIOXIDE COMBINED WITH AMMONIA AND SULFUR TRIOXIDE COMBINED WITH TRIETHLYAMINE 
1. DESCRIPTION OF FABRICS AND ASHES ................................................

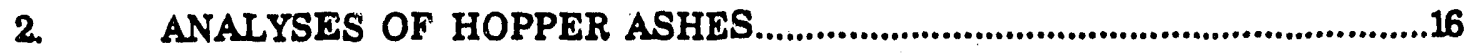

3. TASK 2 FILTRATION PERFORMANCE AND DUSTCAKE ASH CHARACTERISTICS

4. CHARACTERISTICS OF DRY POWDER CONDITIONING AGENTS EVALUATED IN TASK 3 .............................................................46

5. MEDIAN DIAMETEISS OF UNCONDITIONED ASH SAMPLES ..............47

6. SELECTED ANALYSES OF HAND-SHAKEN MEXTURES.........................52

7. TEST RESULTS OF GAS-PHASE REACTIONS BETWEEN

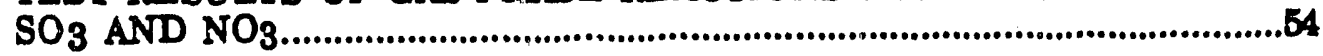

8. TASK 4 FILTRATION PERFORMANCE AND DUSTCAKE ASH CHARACTERISTICS.......................................................................6465

9. MONTICELLO GIDESTREAM TRIALS..............................................80

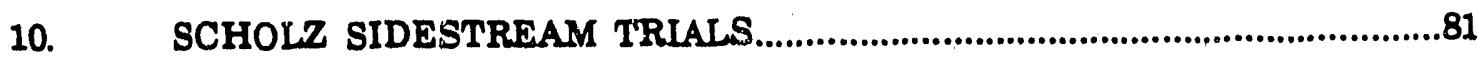




\section{FIGURES}

1. Stages in the evolution of coal into residual dustcake including two approaches to improving filtration performance by conditioning........5

2. Schematic cross-sections illustrating the effects of fabric precoating on the fabric/dustcake interface...................................................6

3. Idealized plot of drag as a function of areal density showing the definitions of $\mathbf{K}_{2}$ and $S_{4}$

4. Schedule of project tasks............................................................................... I)

5. Faotographs illustrating fabric characteristics: a) backlit - 0\% EST

b) backlit - 25\% EST c) backlit - 100\% EST d) SEM - 0\% EST and e) SEM - 100\% EST

6. SEM photographs of dustcake ashes from the three source plants..................13

7. SEM photographs of Monticello hopper ash at magnifications of a) $100 x$ b) $500 x$ c) $1000 x$ and d) $5000 x$.

8. SEM photographs of Scholz hopper ash at magnifications of a) $100 \times$ b) $500 x$ c) $1000 x$ and d) $5000 x$

9. SEM photographs of AFBC hopper ash at magnifications of a) $100 x$ b) $500 x$ c) $1000 x$ and d) $5000 x$.

10. Aerodynamic size distributions of the Monticello, Scholz, and AFBC hopper ashes measured with a Bahco classifier.

11. Volumetric size distribution of the AFBC hopper ash measured with a Coulter Counter.

12. Mass probability distributions of Monticello inlet ashes measured with a University of Washington Mark V impactor.

13. Mass probability distributions of Scholz inlet ashes measured with a University of Washington Mark V irapactor.

14. Mass probability distributions of AFBC inlet ashes measured with a University of Washington Mark V impactor.

15. Volumetric size distributions measured with a Coulter Counter of Monticello dustcake ashes collected on the fabric with 0\% EST .26

16. Volumetric size distributions measured with a Coulter Counter of Scholz dustcake ashes collected on the fabric with U\% EST.

17. Volumatric size distributions measured with a Coulter Counter of AFBC dustcake ashes collected on the fabric with 0\% EST. . .28 
18. Morphology factor as a runction of volumetric median particle size for Monticello, Scholz and AFBC dustcake ashes collected in the parametric tosts.

19. $\mathrm{K}_{2}$ values as a function of the median volumetric particle size for Monticello, Scholy and AFBC dustcake ashes collected on the fabric with $0 \%$ EST in the parametric tests.

20. $\mathrm{K}_{2}$ values as a function of the median volumetric particle size for Monticello, Scholz and AFBC dustcake ashes collected on the fabric with $100 \%$ EST in the parametric tests.

21 S $S_{e}$ values as a function of the median volumetric particle size for Monticel!'o, Scholz and AFBC dustcake ashes collected in the parametric tests..

22. Drag as a function of areal density for the parametric tests of Monticello ash modified by inlet cyclone $\$ 1$ and inlet cyclone $\$ 2$.........38

23. Drag as a function of areal density for the parametric tests of Scholz ash modified by inlet cyclone $\# 1$ and inlet cyclune \#2.

24. Drag as a function of ereal density for the parametric tests of AFBC ash modified by inlet eyclone $\# 1$ and inlet cyclone \#2.

25. Drag as a function of time for reverse-gas cleaning tests of Monticello, Scholz and AFBC ashes collected on fabric with 25\% EST.

26. Schematic drawing showing the bond between two particles enhanced by the presence of a liquid bridge.

27. Uncompacted bulk porosity of wall ash samples as a function of the Schoiz ash content of the ash mixture loaded into the mixing and conditioning chamber.

28. Results of uncompacted bulk porosity measurements of mixtures produced in the Waring blendor ${ }^{7 m}$ of Monticello ash and selected conditioning agents.

29. Results of uncompacted bulk porosity measurements of mixtures produced in the Waring bleador ${ }^{\mathrm{TM}}$ of Monticello ash and sodium bicarbonate.

30. SEM photographs of the gluminum silicate powder taken at a) $100 x$ b) $500 x$ c) $1000 x$ and d) $5000 x$

31. System used for generating gaseous $\mathrm{SO}_{3}$ from temperaturecontrolled fuming sulfuric s,cid. 
33. SEM photogrephs taken at a magnification of $100 x$ of reaction products of tests a) 1, b) $2, c) 4$, d) 5 .

34. SEM photographs talsen at a magnification of $1000 \mathrm{x}$ of reaction products of tests a) 1, b) 2, c) 4 , d) 5 .

35. Phase diagram showing the effects of temperature and stoichiometric ratios on the types and phases of reactants produced from the combination of $\mathrm{SO}_{3}$ and $\mathrm{NH}_{3}$. The diagram shows three different solid compounds: 1:1 or $\mathrm{NH}_{4} \mathrm{HSO}_{4}$ (ammonium bisulfate), 2:1 or $\left(\mathrm{NH}_{4}\right)_{2} \mathrm{SO}_{4}$ (ordinary ammonium

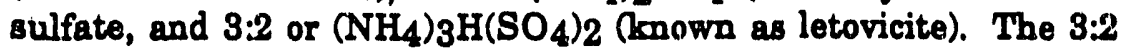
compound has two different crystalline modifications: $\alpha$ and $\beta$.

36. Effect of $\mathrm{SO}_{3}+\mathrm{NH}_{3}$ conditioning on the porosity and relative gas flow resistance of Monticello ash. The largest increase in porosity was observed for the experiment during which ammonium bisulfate and later ammonium sulfate formed on the surfaces of the ash particles.

37. Photographs showing pinholes in the dustcake comprising Monticello ash conditioned with $0.2 \%$ EH5 silica collected on fabric with 0\% EST. (Ruler divisions shown on the bottom of the photograph are 0.01 inches.)

38. Drag as a function of areal density for the Monticello and Scholz ashes unconditioned, and conditioned with $1.0 \% \mathrm{w} / \mathrm{w}$ aluminum silicste.

39. Drag as a function of areal density for filtration tests of unconditioned Monticello ash; Monticello ash conditioned at an elevated relative humidity (RH) of $54 \%$; and Monticello ash conditioned at an elovated relative humidity of $69 \%$.

40. Schematic of the systems used for the proof-of-concept tests of $\mathrm{SO}_{3}$ and $\mathrm{NH}_{3}$, and $\mathrm{SO}_{3}$ and triethylamine. 71

41. Drag as a function of areal density for filtration tests at $300^{\circ} \mathrm{F}$ of unconditioned Moaticello ash; Monticello ash conditioned with $\mathrm{SO}_{3}$ and $\mathrm{NH}_{3}$; and Monticello ash conditioned with $\mathrm{SO}_{3}$ and triethylamive.

42. Drag as a function of areal density for filtration tosts of Monticello ash with no precoat and two different precoating materials...... T5

43. Effects of precoating fabric with 25\% EST with aluminum silicate.............76

A-1. Schematic diagram of the SFI wind tunnel, ash injection system and FFSS. 
A-2. Photograph of the inlet cyclone \#2 sampling train arrangement. The dust-laden sample air passed through the inertial separator, inlet cyclone $\# 2$, and finally into the FFSS...................................................4

B-1. Schematic diagram of the FFSS filtration cabinet...........................................7

E-1. Schematic diagram of the mixing and conditioning chamber located in the thermally controlled oven............................................................36

E-2. Photograph of the mixin and conditioning chamber located

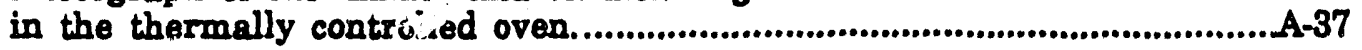


This project was based on a Program Research and Development Announcement issued by the Dispartment of Energy in February, 1987 that requestod a "fundprental study to determine how thie collection of fines ind cleaning of the filters [in baghousen in 20al-fired power plants] are effected by particle characteristics, gas phase dynamics, gas particle interaction, and surface particle charecteristics." Southern Research Institute's (SRI) response to this requast was a proposal for an eighteen-month-long project with two opecific objectives:

\section{Charactorise the pariculate properties that determine the filtration performance of fabric filters, and \\ 2 - Investigate methods for modifying these particulate properties to enhance Gltzation performance.}

These projeci oojectives wrere lesigned to provide thi fundamental information describing the effest of particle characteriatics on filtration, and to improve the performance of fabric filters by nortify $\mathrm{ng}$ these particle eharacteristics. Filtration performance includes both flow resistarice ad collection efficiency. Our wark in this project has focused on flow resistance performence.

A series of parametric tests of threc distinct types of fly ash wes performed to characterize the key particulate properies that determine filtration performance. Literature reviews were combined with laboratory screening tests to ic'antify primary mexternisms and potential agents for the modification of these key ny ash properties. Proof-of-concept filtration tests were then used to evaluate and verify the benefits of various approaches. Several successful conditioning approaches were ideutified through this process, resuiting in substantial improvements in filtration performance. Furthermore, modification of the fabric filtering surface by precoating also yielded significant i=provements in filtration performance. We have identified other cunditioning agents and processes which warrant further study.

\section{CONCLUSIONS}

The literature review identified particle size and shape, van der Waals forces (governed by partirle size, shape, closeness and contact area), and adsorbed surface films as the primary factors determining fly ash cohezivity.

The parametric tests verified that, for a given filtration fabric, inherent ash cohesivity is primarily determined by ash particle shape and size. The relationship between particle shape and flow resistance is relatively complex, involving the competing effects of altered particle roughness on specific surface area and dustcake porosity. The benefits of high inherent ash cohesivity on dustcake porosity (high cohesivity produces relatively high dustcake porosity) can be mitigated by too much particle surface area. The low surface aress characteristic of smooth particles are normally associated with the formation of dustcakes having relatively low porosities, but would yield very low filtering flow resistance if dustcake porosity could be kept high.

Nonuniform flow through the dustcake or filtering medium can override the effect of ash properties in determizing flow resistance. This is evident when filtering ash with clean fabric: in this case, flow resistance is much more dependent on the size and arrangement of pores in the fabric than on the characteristics of the collected ash. The influence of fabric design is also evident when the collected dustcake is very thin, or when the combination of low ash cohesivity and fabric pore characteristics generate a nonuniform dustcake structurc containing pinholes. 
Appropriate modification of the anh can result in substantial improvements in filtration performance. Improper modification of the ash can sigrificantly degrade filtration performence. Furthermore, modification of the fabric filtering surface by precoating can elso yield improvements in filtration performance.

Fine powders, particle wetting agents, and shemicals with specific bonding traits were identified in the literature reviow a candidates for modifying anh properties. Prospective dry powder conditioning agents identified in the literature review included fly ashes, fine silica, lime, and aluminum silicate. Particle wetting agents identified in the literature review included ammonium bisulfate, v/ater vapor, and reaction py ducts of triethylamine and sulfur trioxide. Several categories of chemically-active agente were identified: amine sulfates, surfactanta/dinpersants, flocculating or coagulating agents, silanes, and deliquescent compounds. Work in this projest gres limited to the evaluation of powders and particle wetting agents.

In general, the higher the surface area of a dry powder conditioning agent, the greater its effect on cohesivity. Dry powders have the greatest conditioning effect on relatively smooth, spherical particle\%. Surface irregularities tend to obscure the effects of dry powder condivioning agents. Bleading very small amounts of fine silica with ash generally decreased bulk ash porosity. The fine particles acted as lubricants, separating particles and decreasing the van der Waals attractive force. Dustcukes comprising ashos conditimned with fine silica often contained pinholes, indicative of the lowered ash cohesivity. Blending very small amounts of fint aluminum silicate flakes with ashes incrensed bulk ash porosity.

Adsorbed surface films generally increase particle cohesivity by causing liquid bridges between particles at their points of contact. Tests were conducted with fine vil droplets, water rapor, and the reaction products of ammonia and triethylamine with sulfur trioxide. One objective of these tests was to determine if liquid bridging was the mechanism by which ammonia or amines, when reacted with sulfur trioxide, results in modified ash properties. Ash pre-conditioned by exposure to sulfur trioxide reacted with ammonia gas in $300^{\circ} \mathrm{F}$ environment resulting in increased bulk ash cohesivity, whereas exposure to dry ammonium sulfate fume was less effective for increasing ash cohesivity. This finding suggests that liquid bridging is the mechanism by which ammonia and sulfur trioxide conditioning alter filtration performance: at $300^{\circ} \mathrm{F}$ ammonium bisulfate, the initial reaction product, is a liquid that wets the particles and increases the adhesive forces.

Filtration tests showed that conditioning with sulfur trioxide and ammonia, or sulfur trioxide and triethylamine, increased ash cohesivity. The increased aub cohesivity prevented pinhole formation and resulted in higher dustcake porosity, both of which improved the filtering characteristics of the ash.

Filtration tests also showed that oil droplets and increased levels of relative humidity can significantly decrease filtering flow resiatance.

The use of powders as precoating material was evaluated as a means of reducing the component of flow resistance associated with the fabric/dustcake interface. An aluminum silicate powder with low surface area and high bulk porosity significantly reduced this flow resiatance. 


\section{RECOMOMENDATIONS}

We foel that several approaches studied in this project merit further investigation. Liquid bridges were appartiaily successfully created between Monticello ash particles through the introduction of increased relative humidity levels. Additional laboratory evaluations of variors humidity levels followed by field trials are recommended to pursue this potentially benefic I approach. In full-scale applications the reduction in flue gas temperature that would be as siated with wate: injection to incresse relative humidity would also decrease total flue Bh I Feline. Reducing the gas volume flow rate would reduce filtering pressure drop. An additional benefit would result from a reduction in the viscosity of the flue g.as due to the drop in temperature (pressure drop is proportional to gas viscosity). Although the full implications of conditioring with increased bumidity levels need to be examined in more detail, this approach hold significent promise.

The application of a suitable precoat material to the clean fabric was shown to successfully reducs the flow resistance associated with the fabric dustcake interface. Precoating materials may be alsi, be capable of protecting the fabric surface and residual dustcake from the detrimental effects of condensation often associated with cyclic behavior. Field trials of this technology are 1 ecommended to test its viability in flue gas environments and for repeated clearing and filtration cycles.

We slso recorsaiend the evaluation of additional chemicals as conditioning agents. Compounds identified in the literature review utay be able to alter ash cohe:ivity by inducing chemical bonds between fly ash particles. 


\section{INTRODUCTION}

Although many fabric filters operate efficiently with rensonable pressure drop coste, certain types of anh can cause high emissions, excessive pressure drops, or both. Because of increaningly broad application of fabric filters to flue gas cleanup at coal-nired power plants, and the potential for application to new combv kion processes, it is important to insure that fabric filter technology is optimized to provide the roost effective particulate sollection at the lowest operating cost.

\section{BACKGROUND}

Baghouse performance has varied widely from one installation to another. Pilot- and full-scale studies have identified the residual dustcakes that build on the fabric as the most critical component in determining baghorse performance (1-4). The factors that determine the characteristics of the residual dustcake are shown in figure 1. Improved fabric designs and optimized cleaning methods have been examined by many different researchers. Fundamental understanding of fly asb characteristics and their influence on the residual dustcake $(5,6)$ provides the foundation for a logical investigation of fly ash conditioning alternatives. Studies of the influence of the fabric/residual dustcake interface on baghouse performance provide the background for the evaluation of fabric precoating materials.

\section{Goals_ of Conditioning}

Two approaches to conditioning are illustrated in figure 1 . One approach is to add agents that modify fly ash properties in order to increase the ash cohesivity. The other is to add agents that modify the ash/fabric interface in order to optimize the filtering surface. An optimized filtering surface contains a high density of relatively small pores. Small pores are easily bridged over and their presence in relatively large numbers minimizes the local air velocity through each pore. As a supplement to fabric design, precoat materials can be applied to the clean fabric surface to provide the desired pore structure. Characteristics of the ideal precoat material include the ability to bridge large pores, and a tendency to produce a highly porous structure with low resistance to gas flow. Figure 2 demonstrates how a precoat material modifies the filtering surface of the fabric.

Increased ash cohesivity causes the ash particles to form a more porous dustcake structure. Even small increases in the porosity of a dustcake significantly reduce resistance to gas flow through the cake. When ash particles are made stickier through conditioning, any tendency uf particles to break loose from the dustcake structure and slip through the dustcake and fabric is reduced. Ash cohesivity can be increased by increasing the attractive forces between particles. These forces depend on the inherent characteristics of the ash particles and the additional effects introduced by conditioning processes or materials.

\section{Findings from Brior Work}

Southern Research Institute (SRI) has participated in a comprehensive research program funded by the Electric Power Research Institute (EPRI) to evaluate fabric filter technology for application to utility coal-fired power plants. Several areas of this research yielded results that have direct bearing on the development and evaluation of conditioning alternatives. Laboratory and field tests have verified that fabric construction influences the filtering drag, residual dustcake weight and the collection efficiency of a baghouse. Th: size of the pores through the fabric and the inherent ability of the initially collected ash particles to bridge them over influence both the filtering drag and the collection efficiency of the system. Smooth, 


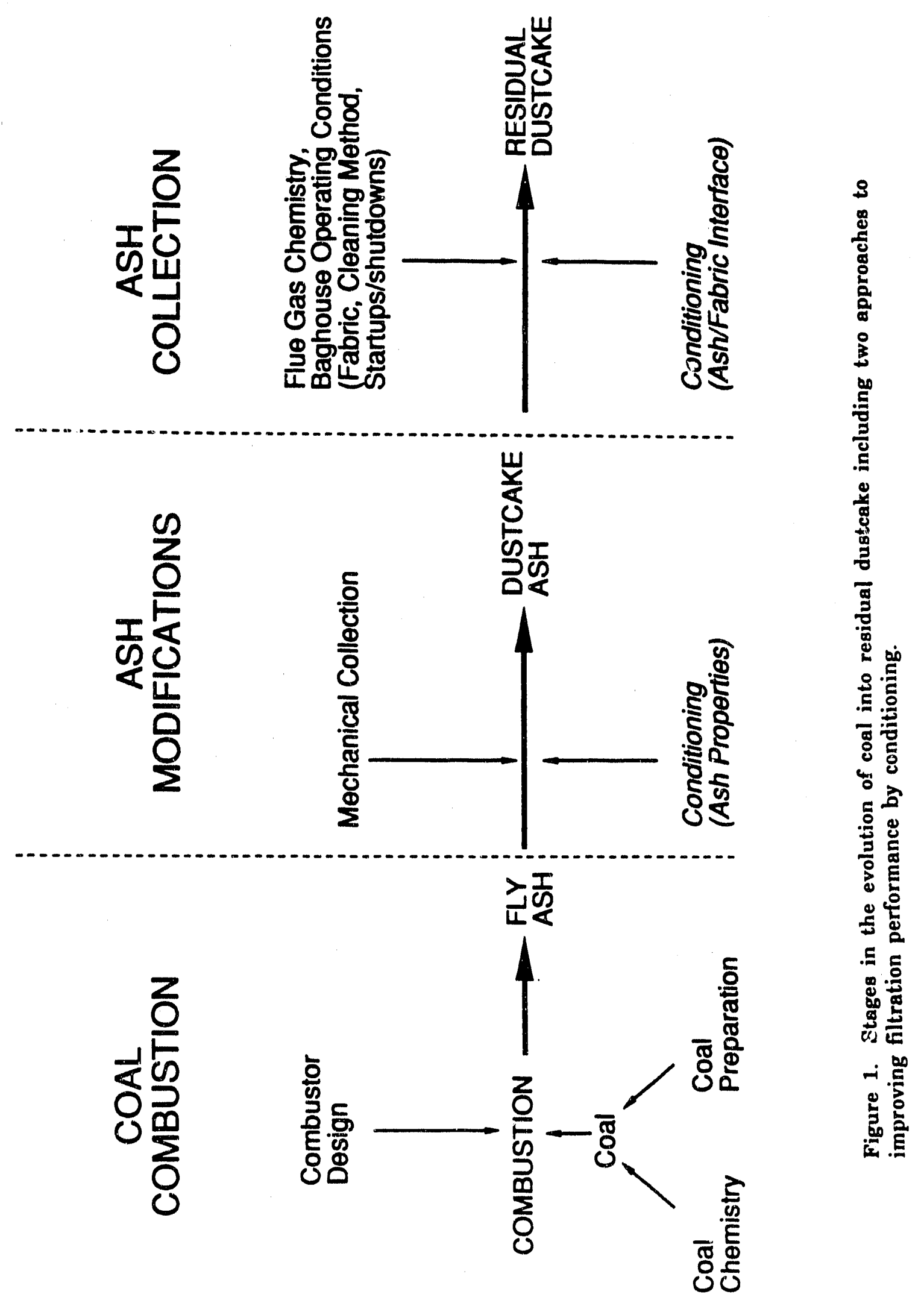




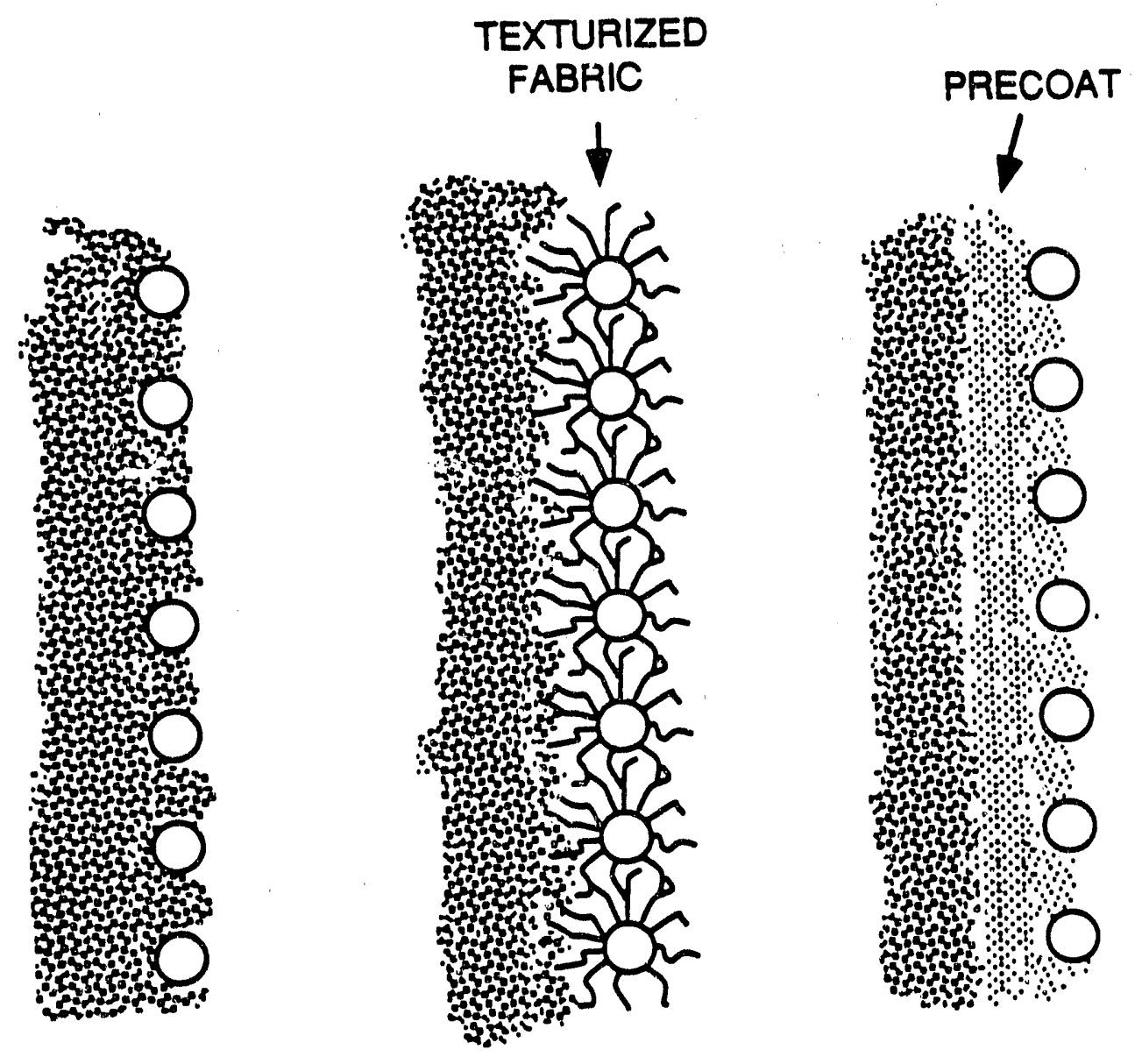

Figure 2. Schematic cross-sections illustrating the effects of fabric precoating on the fabric/dustcake interface. 
spherical ash particles have low inherent cohesivity and tend to infiltrate and even penetrate the fabric pores.

Semi-empirical models have been developed to describe the effects of dustcake porosity and particle characteristics on filtering drag (7). Empirical models based on correlations of data from pilot- and full-scale baghouses predict the influences of physical and chemical properties of ash or coal on filtration performance (6). Mechanistic interpretations of the empirical correlations have not been developed, though alkali and sulfur reactions are implicated.

Gas flow resistence and dustcake areal density have bees related to the exposure to dew points. The effects on filtration performance of allowing fabric filters to pass through acid and water dow points were observed shortly after SRI began operating the EPRI pilot-scale fabric filter test facilities in the late 1970 's and early $1980^{\prime} \mathrm{s}$. The mechanisms for the changes in flow resistance and penetration have not been verified. Insreased dustcake porosity and the presence of adsorbed surface films on the ash particles were believed to induce these changes. Consistently, fabric filters collecting ash downstream of spray dryers have shown lower flow resistance and ash cohesivity than might be expected from the physical characteristics the dustcake ash. The mechanisms responsible for these beneficial changes may be applicable to fabric filters collecting other types of ash.

EPRI sponsored testing beginning in 1982 at the Monticello Station of TU Electric to evaluate ammonia injection to reduce ash bleedthrough by increasing ash cohesivity. The tests showed a more than 10-fold reduction in penetration ( $3.2 \%$ to $0.2 \%$ penetration) as a result of ammonia injection. Compartment-scale tests have been completed, and a full-scale demonstration program ip under way at Monticello. SRI has also tested ammonia injection at the EPRI High - Sulfur Fabric Filter Pilot Plant located at Gulf Power's Plant Scholz, and in sidestream and compartment-scale tests at the Pennsylvania Power and Light Brunner Island Station. In all cases, the flow resistance of the ash has been reduced as a result of $\mathrm{NH}_{3}$ injection. These effects of $\mathrm{NH}_{3}$ injection have also been confirmed at the University of North Dakota in testing sponsored by the Department of Energy (8).

Not all ashes perform equally in fabric filters, and we know of some materials and processes that alter the filtration properties of the ash. Therefore it may be possible to modify the less desirable characteristics of certain ashes to improve their filtration performance. 
Tha specific objectives of this project are to characterize the particulate properties that determine the filtration performance of fabric filters, and to investigate methods for modifying these particulate properties to enhance filtration performance. Inherent in these objectives is the development of an experimental approach that will lead to full-scale implementation of beneficial conditioning processes identified during the project. The general approach has included a large number of laboratory evaluations to be followed by optional field tests of a few successful conditioning processes performed on a sidestream device.

Figure 3 illustrates how two quantities, $S_{0}$ and $K_{2}$, are used to quantify filtering behavior during a filtration cycle. Advantages in filtering drag can be obtained by roducing either $S_{0}$ or $\mathbf{K}_{2}$. Lower $S_{\odot}$ or $K_{2}$ of the collected ash results in lower average drag over a given filtration period. Alternatively, lower $S_{\theta}$ or $K_{2}$ permits longer filtration periods between cleaning cycles for a given average drag. Improvements in collection efficiency are obtained by altering the characteristics of the fabric/dustcake aggregate, which serves as the collection medium for most applications, or by altering the characteristics of difficult-to-collect ash particles.

\section{PROJECT ORGANIZATION}

This project was divided into five tasks. The schedule followed for these tasks is shown in figure 4. Tasks 2 and 3 each focus on one of the two complementary parts of the project. Task 2 Parametric Tests of Ashes and Fabrics, evaluates the degree to which ash properties and fabric design determine filtration performance. Task 3 Survey of Methods to Modify the Particle Filtration Properties, provides a literature review and laboratory study of techniques to modify ash properties. The results of these two tasks were used in Task 4 Proof-of-Concept Tests of Methods to Modify Particle Filtration Properties to demonstrate the effects on filtration performance of modifying ash properties. The findings of all the tasks are summarized in this Final Report. 


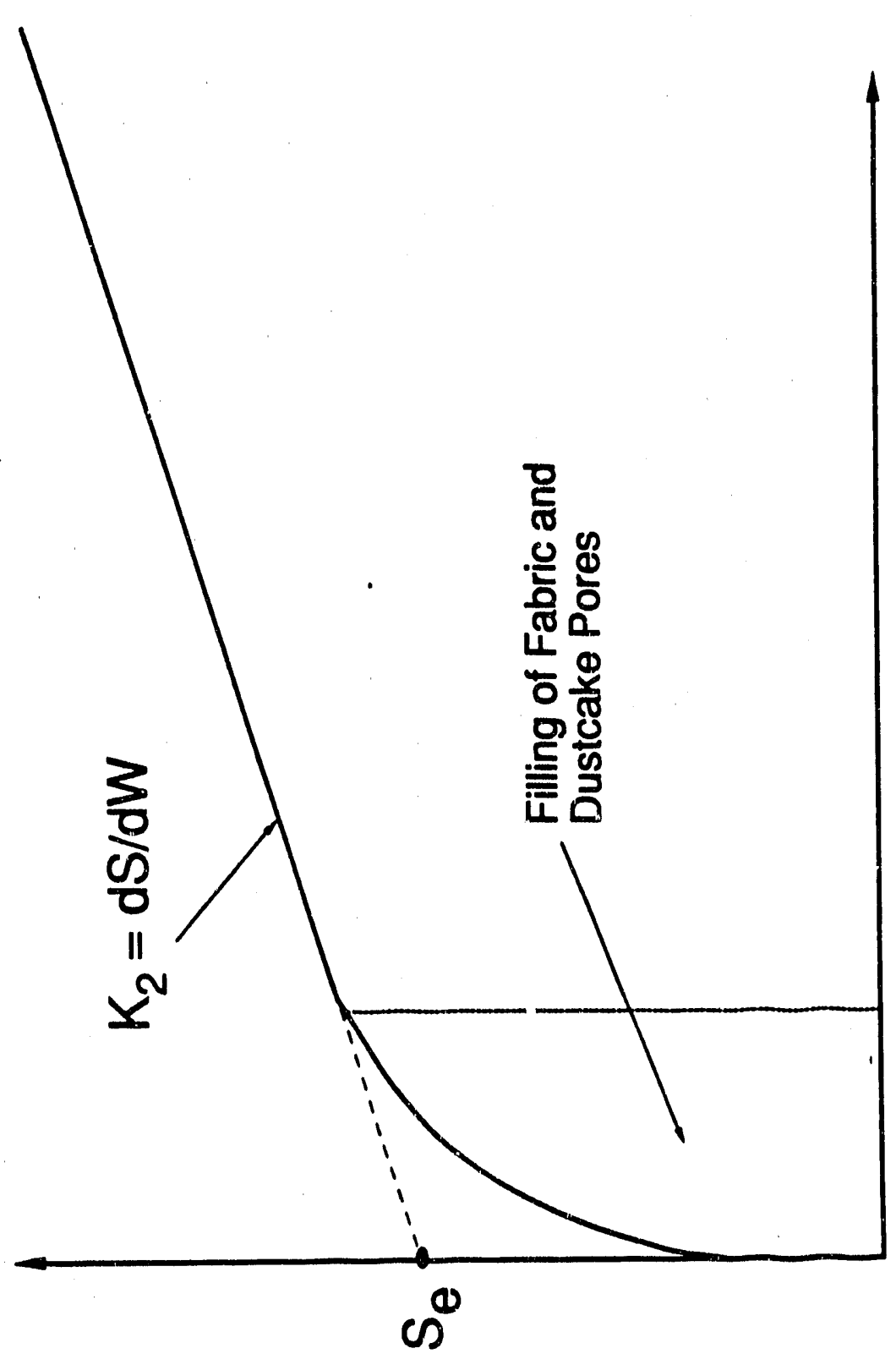

焉

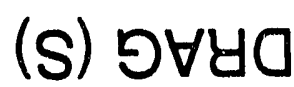




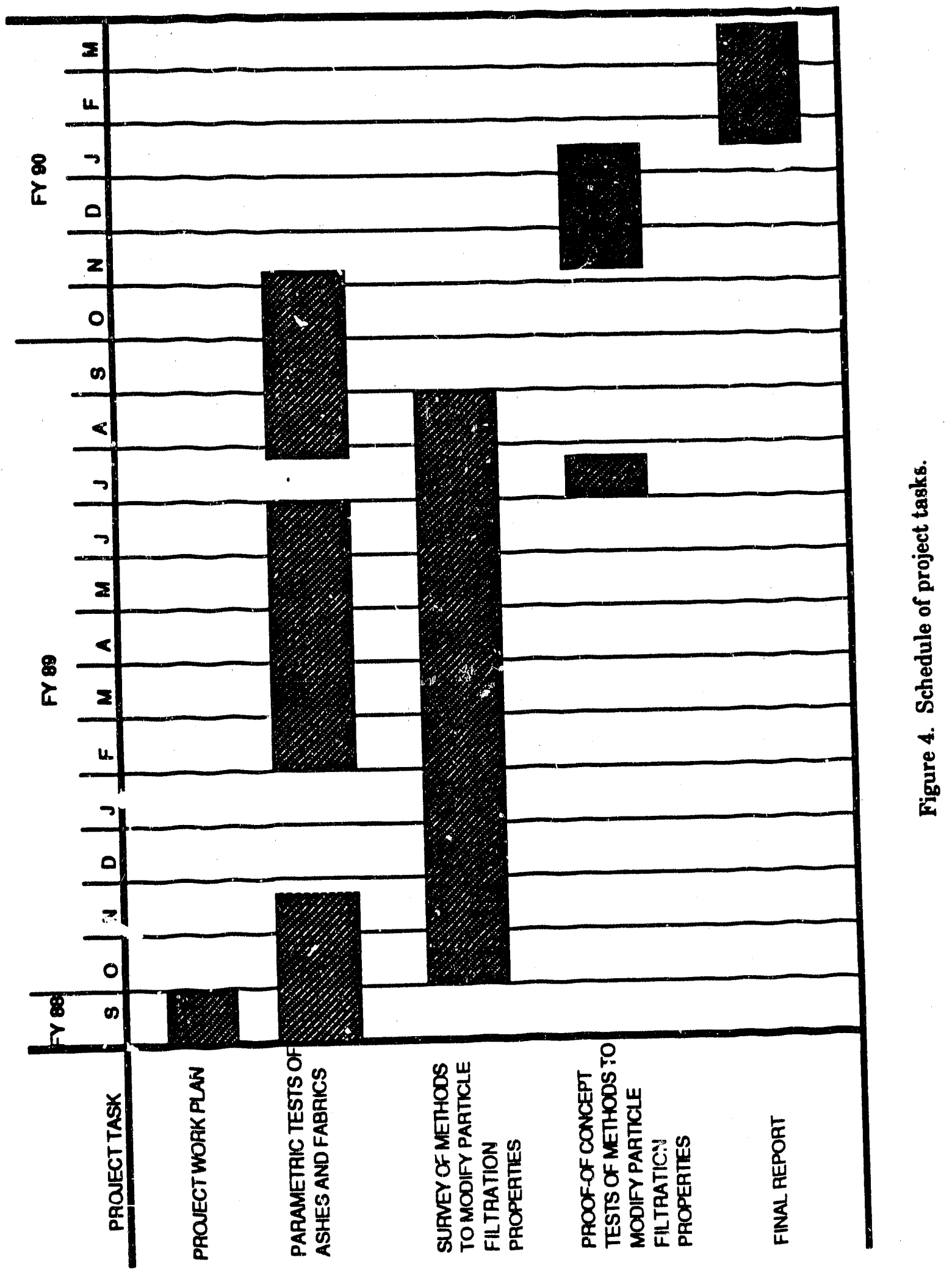


The parametric tests performed under Task 2 were designed to assess filtration performance for ashes and fabrics having widely different characteristics. Differences in filtcation performance were then correlated with the characteristics of the ashes and fabrics to improve our understanding of the effects of these characteristics on filtering pressure drop and collection efficiency. This understanding aids in the selection and evaluation of various conditioning agents and methods intended to enhance filtration performance.

\section{FABRIC DESIGNS AND ASH TYPES}

Field experience has indicated that the exposed surface texturization (EST) of filtering fabric can significantly influence residual dustcake weight and collection efficiency (2). Texturization and weave pattern determine the size and distribution of pores through the filtering fabric. The two woven fiberglass fabrics selected for the parametric tests represent extremes of EST and weave. SEM and backlit photographs of these fabrics shown in figure 5 illustrate the differences in their design. (Figure 5 also contains pictures of fabric with 25\% ESI used in somo of the Task 4 tests.)

Two of the ashes selected for the parametric tests, Monticello and TVA AFBC, represent the extremes of ash characteristics encountered in the studies of utility baghouses performed for EPRI (5). The appearances of these two ashes are shown in figure 6 along with Scholz ash, which has intermediate chara.tieristics. Table 1 includes brief descriptions of the ashes and fabrics shown in figures 5 and 6.

\section{LABORATORY EQUIPMENT AND PROCEDURES}

In Tasks 2 and 4 an ash injection system and wind tunnel were used to provide a gas stream containing redispersed fly ash. Ash feed rate and wind tunnel velocity were monitored and controlled to generate a stable fly ash concentration for isokinetic sampling by the Fabric Filter Sampling System (FFSS). Prior to the entry of the ash-laden gas stream into the FFSS, optional size modification of the suspended $8 \mathrm{sh}$ particles was performed by one of two inlet cyclone configurations. Detailed descriptions of the ash injection system, wind tunnel design and operation, and optional cyclones for inlet ash size modification are contained in Appendix A.

\section{Qverview of the EFSS}

The FFSS is used to simulate the operation of a fabric filter with reverse-gas cleaning. The FFSS consists of modules for holding the filter media, for controlling and monitoring flow and temperature in the system, for cooling and drying the flue gas after it has been filtered, and for data acquisition and analysis. A brief description of parts of the FFSS is provided below. More detailed descriptions of the design and operation of the FFSS are contained in Appendix B.

Eiltcation Cabinet. A flue gas sample is extracted isokinetically through a sample probe and enters the FFSS through a port centrally located in the rear of the sampling transform in the filtration cabinet. The gas is passed through a circular swatch of labric, 11 inches in diameter, mounted opposite the inlet port. A second inlet port is availabie on the sampling transform for the injection of conditioning agents. Flue gas velocity is reduced in the transform from the duct velocity to the desired filtering face velocity at the fabric sample. Residence time and volume expansion in the transform permits the mixing of flue gas, ash, and conditioning agents upstream of the fabric and dustcake. 

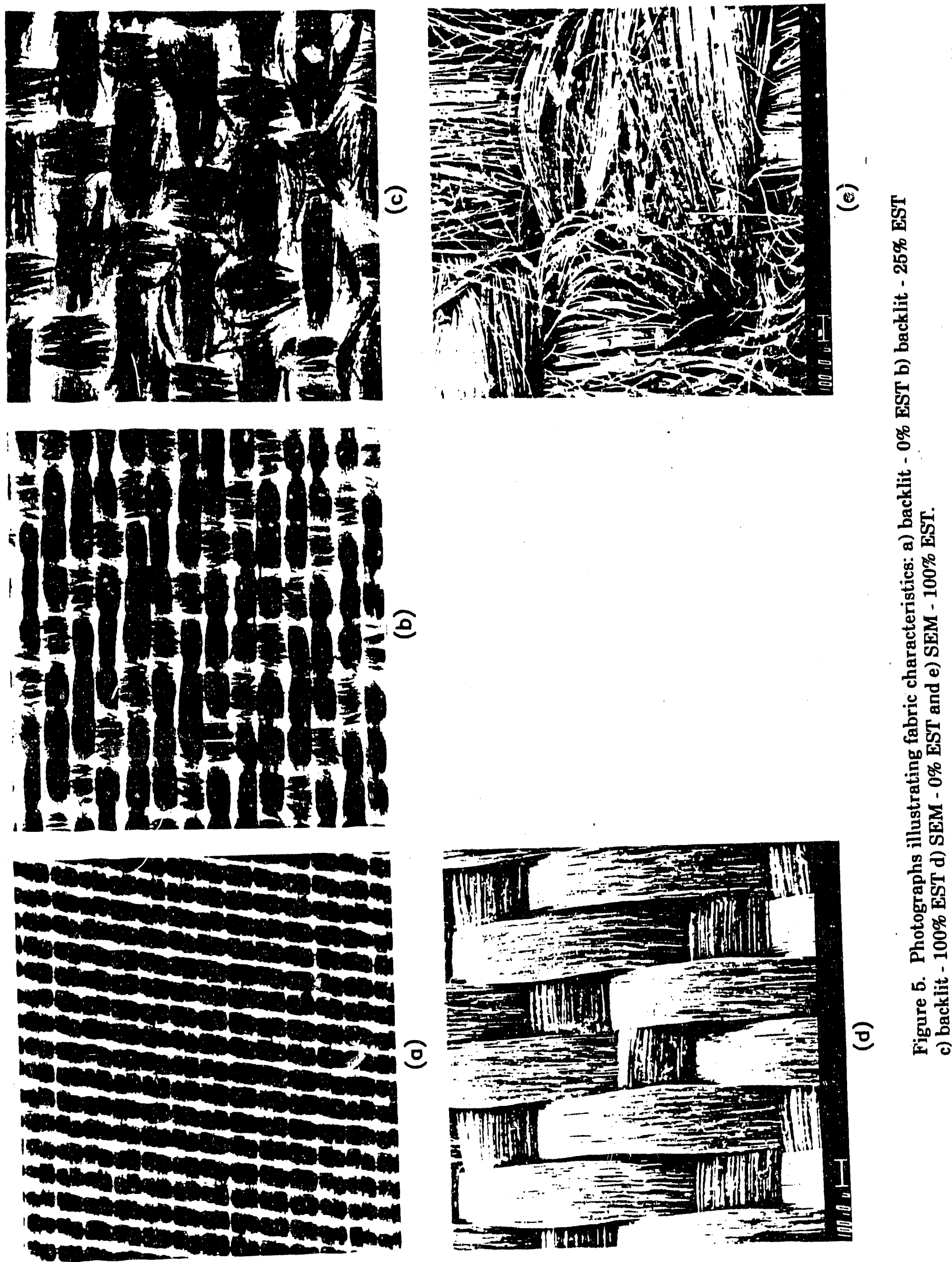


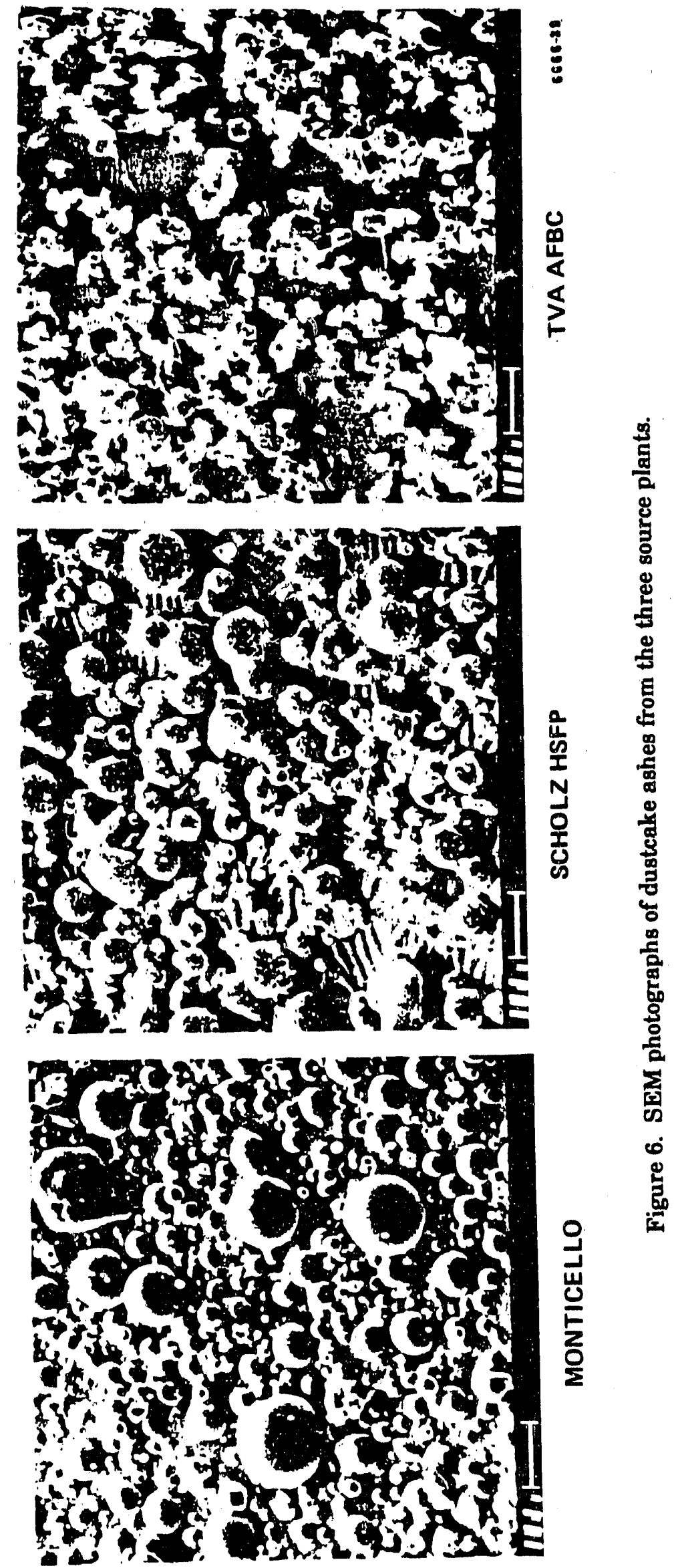




\section{Table 1}

\section{DESCRIPTIONS OF FABRICS AND ASHES}

FABRICS: 1) Woven fiberglass, double warp weave, $48 x 30$ count, 16 oz/yd $\mathrm{d}^{2},{ }^{2} 0 \%$ Teflon B finish, $100 \%$ EST.

2) Woven fiberglass, 4 harness satin weave, $100 x 60$ count, 5 oz/ $\mathrm{yd}^{2}, 6 \%$ Teflon B finish, 0\% EST.

3) Woven fiberglass, $3 \times 1$ twill weave, $48 \times 30$ count, $9.50 x / y d^{2}, 10 \%$ Teflon B finisk, 25\% EST.

ASHES: $\quad$ 1) Monticello - Teras lignite coal ash, smooth surface, spherical particles, non-cohesive.

2) Schole - high sulfur, eastern bituminous coal ash, rough surface, spherical particles, relatively cohesive.

3) AFBC - atmospheric fluidized bed ash and sorbent, rough, nonspherical particles, very cohesive. 
Data_Acauisition and_Analyzis Syatem. A computer utilizing Labtech Notebook 8 software serves as a data acquisition system for the FFSS. The orifice static pressure, pressure drop across the orifice, end orifice (filtration cabinet) temperature are continuously monitored and used to calculate the flow rate and the air-to-cloth ratio. The pressure drop across the fabric is also monitored continuously and, along with the air-to-cloth ratio, is used to calculate the drag. These values are displayed on the computer monitor during the test along with a trend graph of drag as a function of time.

At the conclusion of each laboratory test, $3.8 \mathrm{~h}$ samples from the inlet cyclone (if used), FFSS transform hopper, dustcake, and outlet cyclone were collected and weighed. Techniques used to analyze the FFSS data are fully discussed in Appendix C.

\section{MEASUREMENT OF ASH COHESIVTTY}

Cohesivity of bulk powders can be defined as the degree to which the component particles stick together. Cohesivity, defined in this way, is a property for which there are numerous measurable quantities. Among these are tensile strength, shear strength, bulk porosity, angle of repose, and compressibility. There are well-known analytical techniques for determining several of these quantities. Each of these measurable quantities describe the cohesivity of the bulk powder, and can be related to one another. There are also numerous derived quantities to describe powder coherivity; for example, cohesion, flow factor, and effective angle of internal friction.

The techniques and quantities used to describe the cohesivity of a bulk powder must be chosen based on the way cohesivity is manifested in the process being evaluated. For example, hopper design favors the use of shear strength tests and flow factors calculated therefrom. Civil engineers use compressibility, porosity, and shear strength tests in foundation design. In filtration of particulate matter, the key parameters that manifest the ash cohesivity are dustcake porosity and residual dustcake thickness.

Two of the techniques we have used to measure the cohesivity of ashes are shear strength and bulk porosity tests. Shear strength measurements are widely used to characterize the cohesivity of powders. The shear strength tests are made with the SRI Ring Shear Device which has annular sample and load cells. A series of shear tests are run on each sample at three compressive loads. The shear stress data d " ne yield loci and Mohr circles (9). The angle of the effective yield locus is culled the effectiv angle of internal friction and can be used as the measure of ash cohesivity derived from shear strength tests. We have found that the effective angle of internal friction of an ash correlates to the porosity of a dustcake of that ash and to the residual dustcake areal density (5).

Bulk porosity is measured on uncompacted and compasted samples of ash. Uncompacted bulk porosities of ashes agree reiatively well with the measured porosities of fabric filter dustcakes from which the bulk ash samples are taken. Ash samples compacted in a cylinder under a specific compressive load $\left(446 \mathrm{lb} / \mathrm{in}^{2}{ }^{2}\right)$ have resultant porosities that are strongly correlated to dustcake porosities (5). Bulk porosity tests provide the most direct assessment of ash cohesivity when evaluating the effect of ash cohesivity on sltration performance.

\section{LABORATORY ANALYSES OF HOPPER ASHES}

Hopper ashes obtained from three plants were characterized with the range of laboratory tests described in Appendix D. The results of these tests are presented in table 2. The compacted bulk porosity, uncompacted bulk porosity, and shear tests performed on these ashes indicate that, as expected, the Monticeilo ash is the least cohesive of the ashes, and the AFBC ash has the bighest cohesivity of the three ashes. SEM photographs of these hopper ashes are presented in figures 7, 8, and 9. The irregular shapes of the AFBC ash particles evident in figure 9 are also indicated by the relatively high morphology factor measured for this ash. Results of 


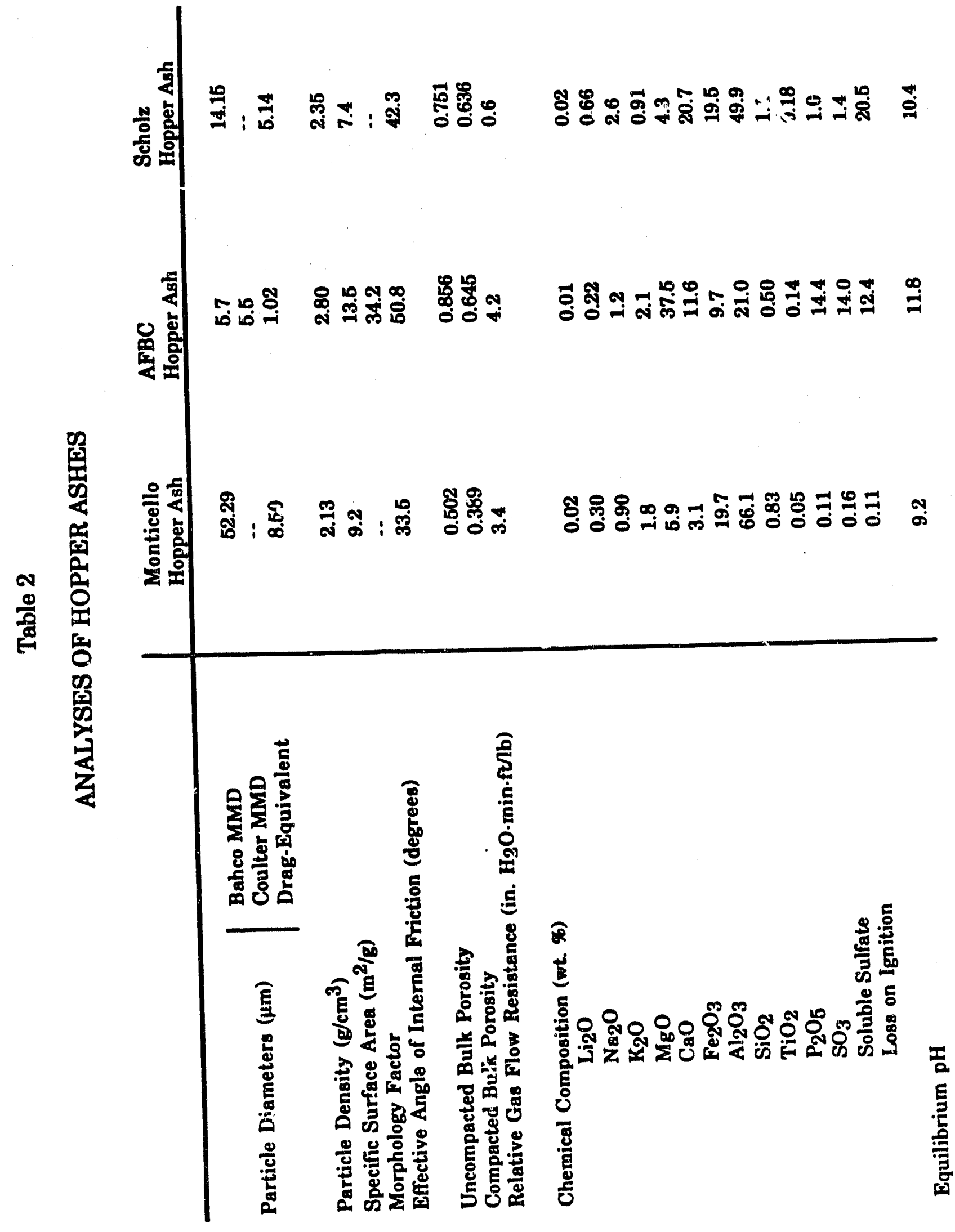




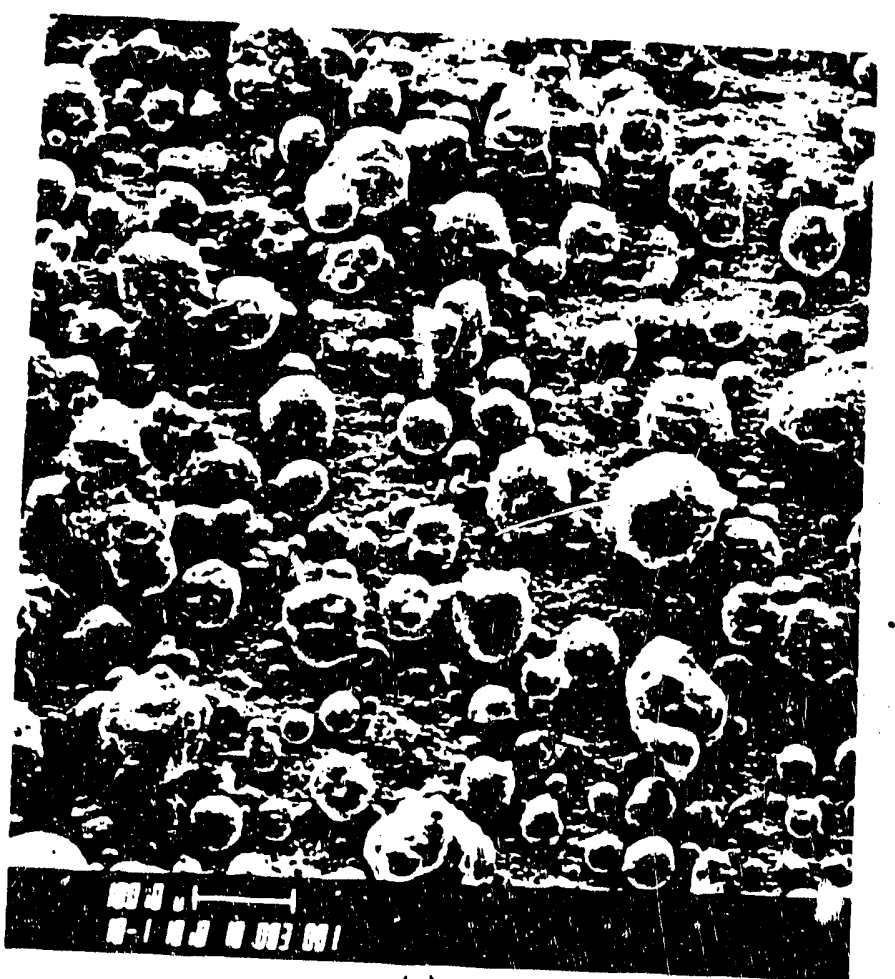

(a)

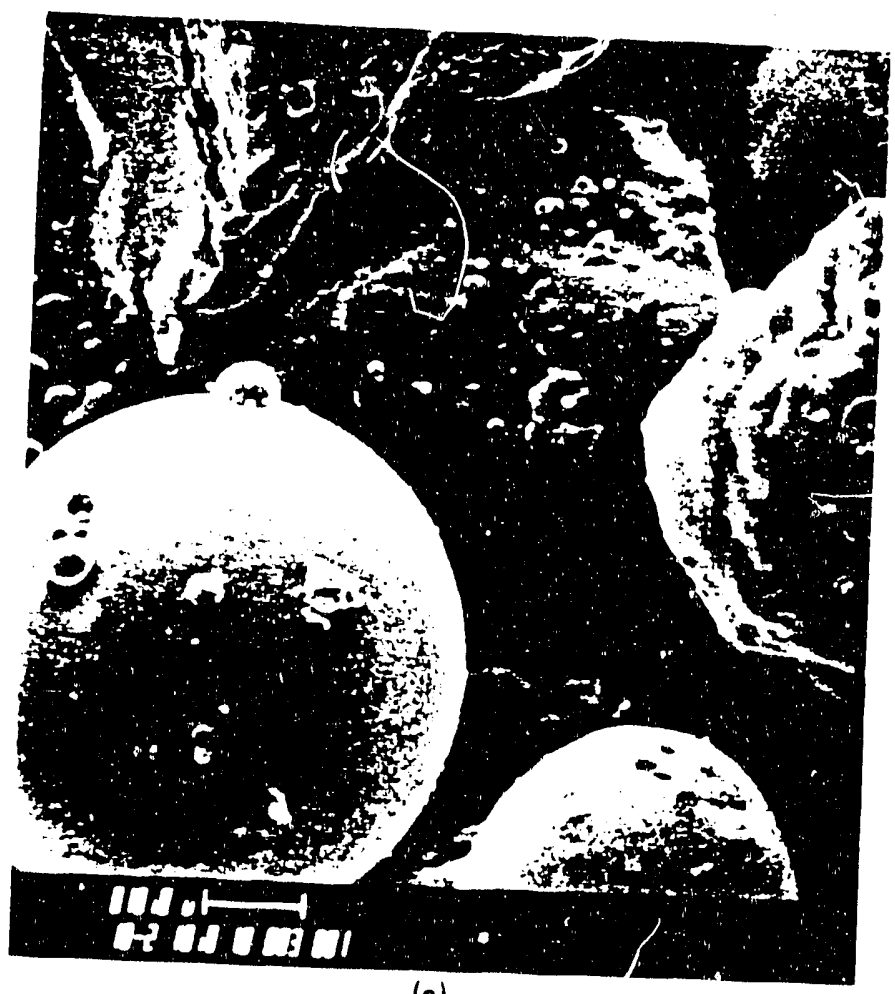

(c)

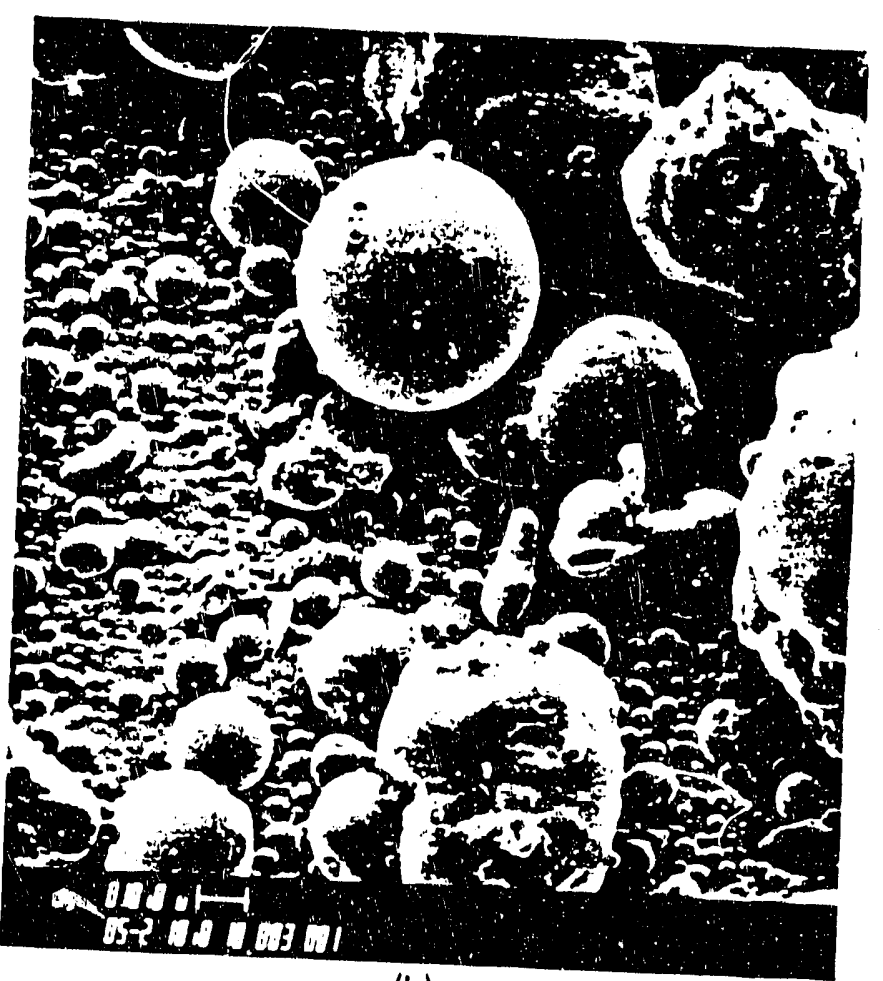

(b)

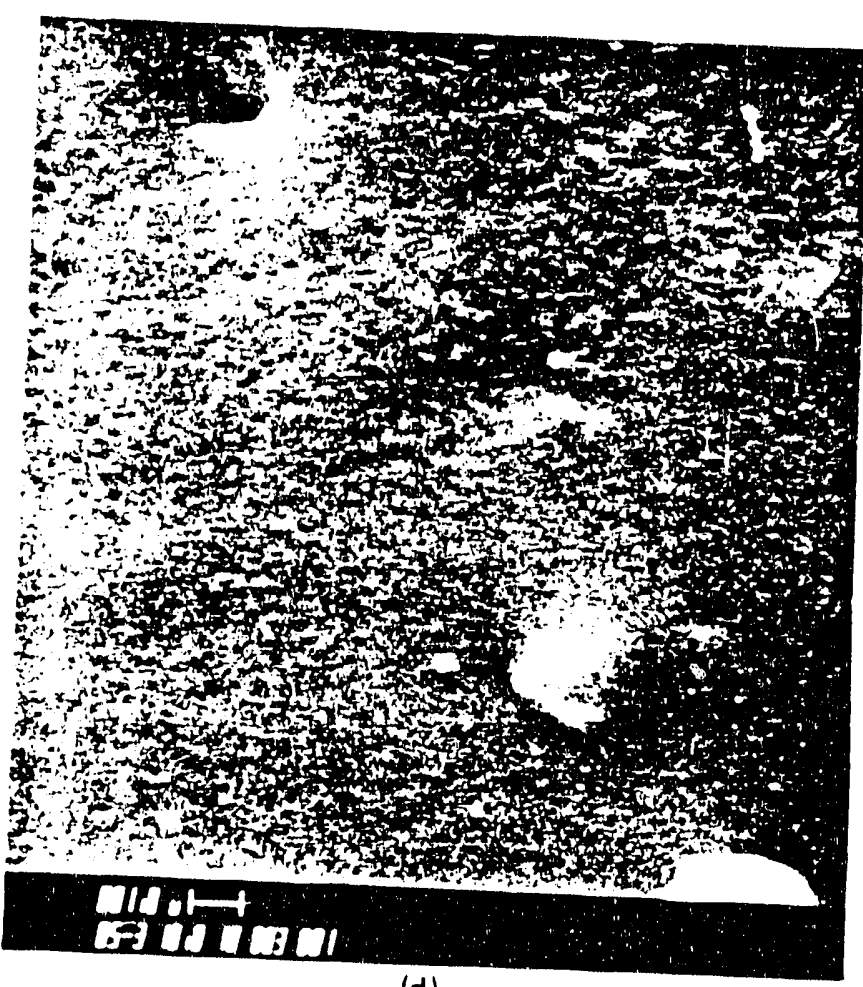

(d) and d) $5000 x$. 


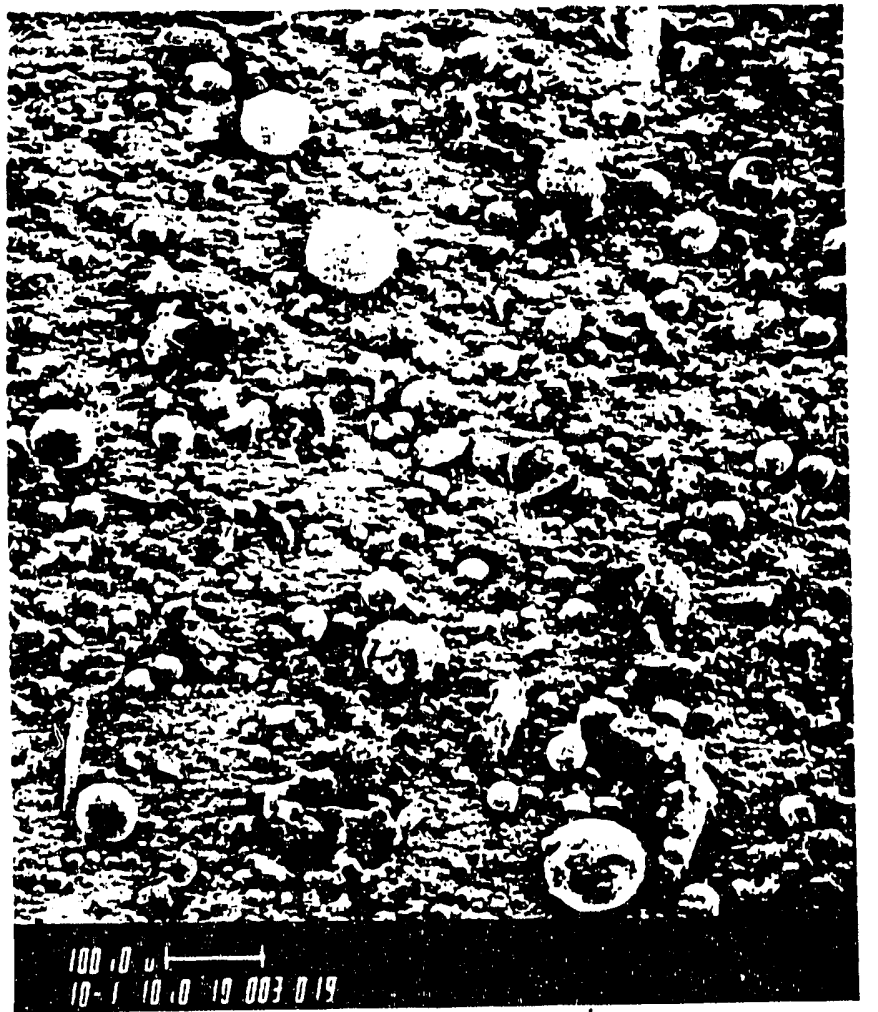

(a)

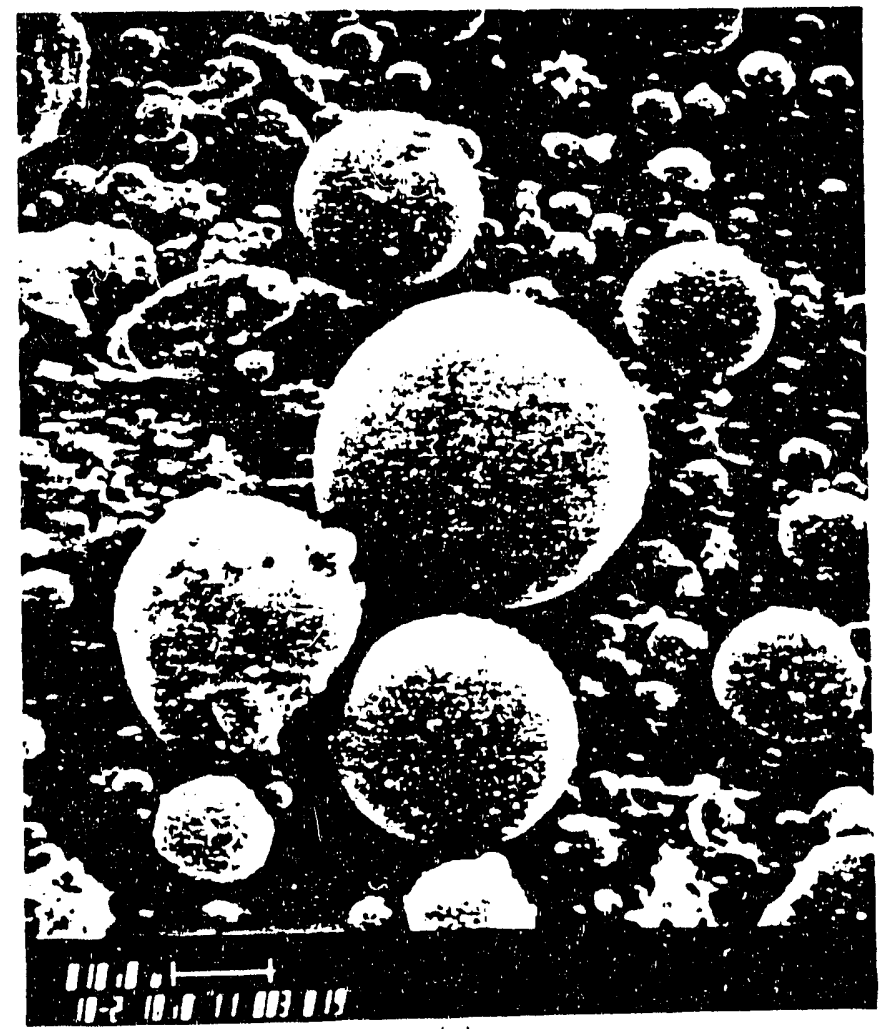

(c)

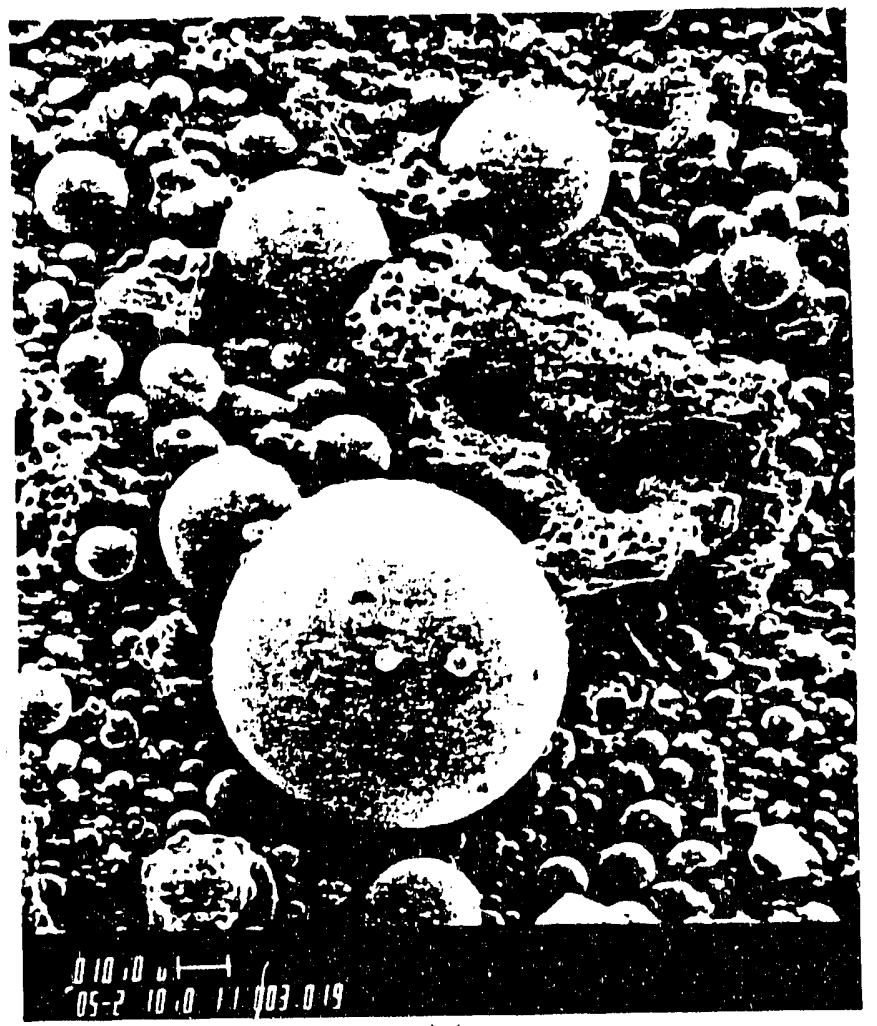

(b)

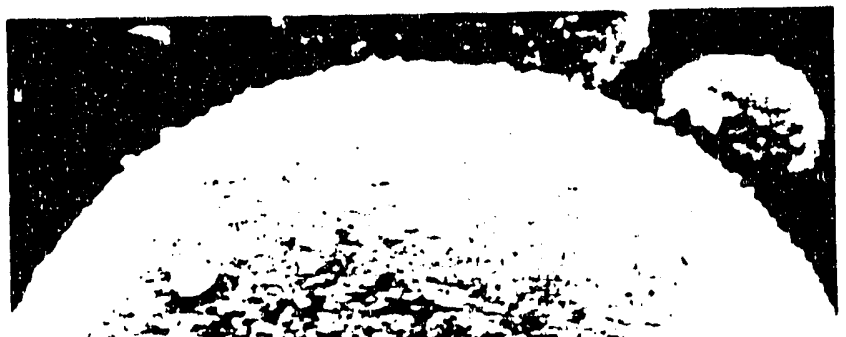

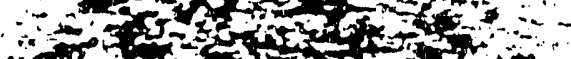

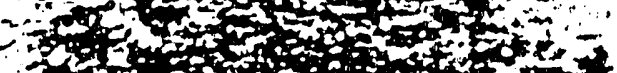

20

-

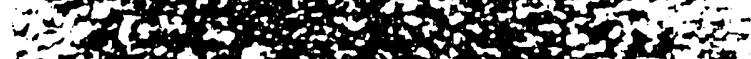

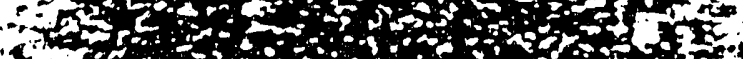
(14

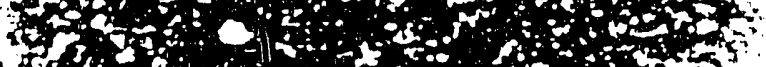

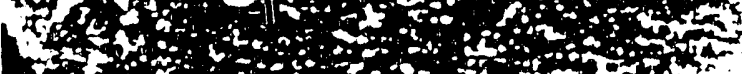

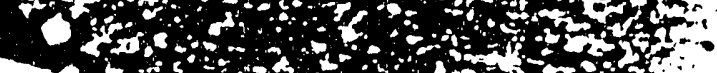
(4)

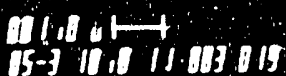

Figure 8. SEM photographs of Scholz hopper ash at magnifications of a) $100 \mathrm{x}$ b) $500 \mathrm{x} \mathrm{c}$ ) $1000 \mathrm{x}$ and d) $5000 x$. 


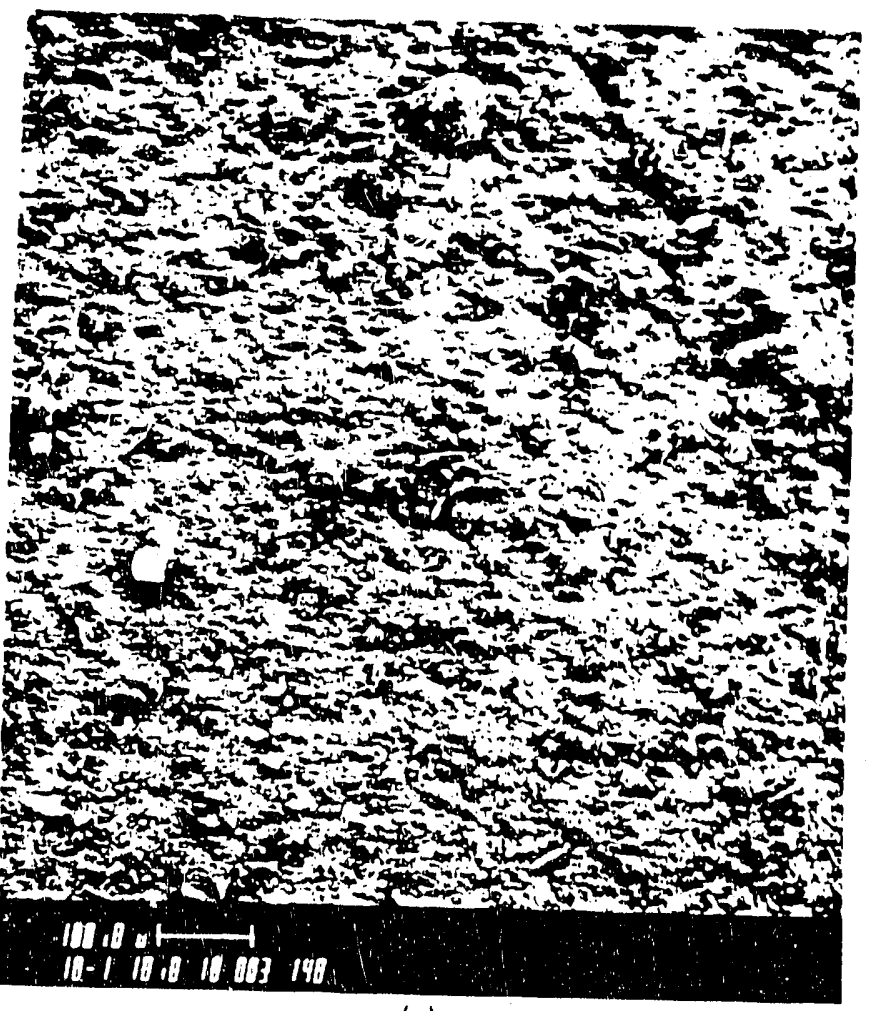

(a)

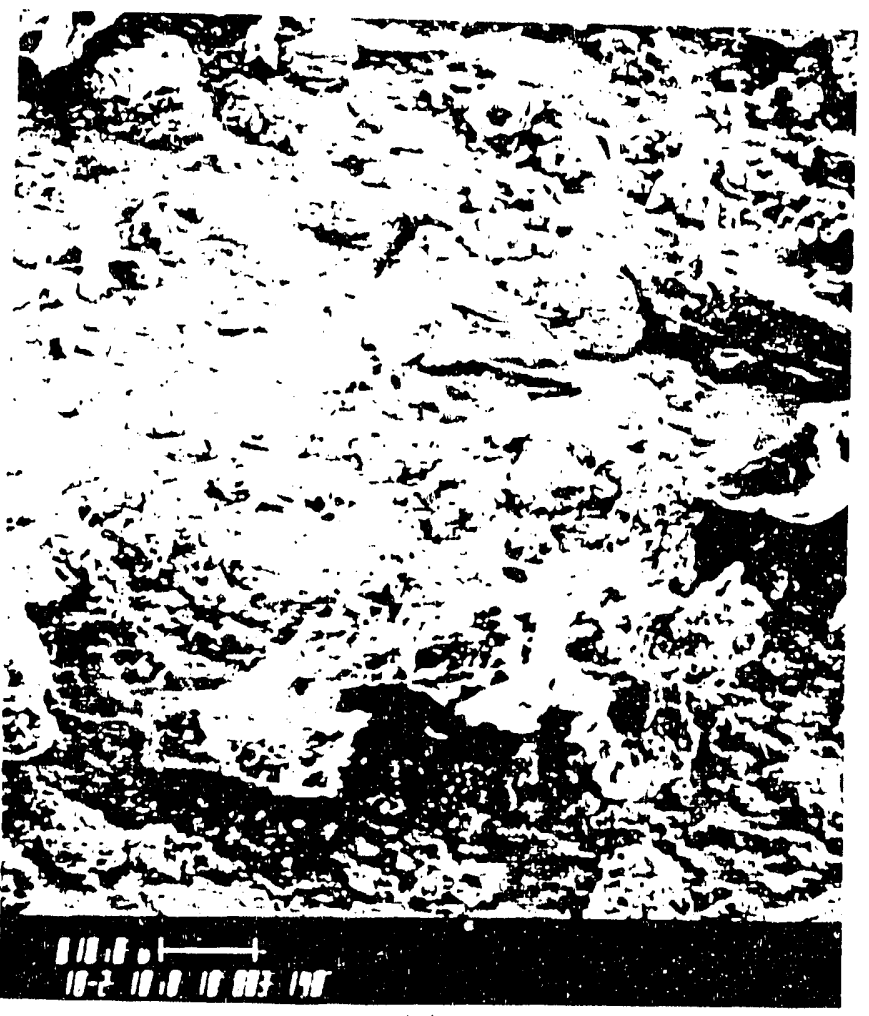

(c)

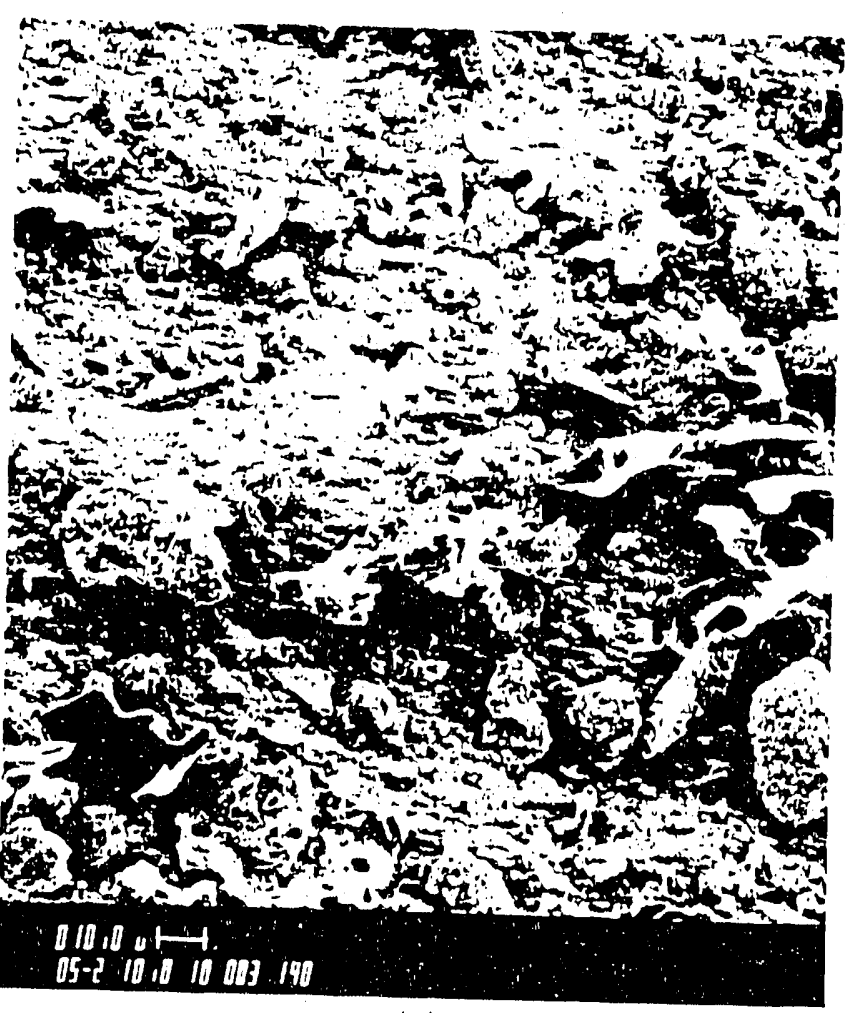

(b)

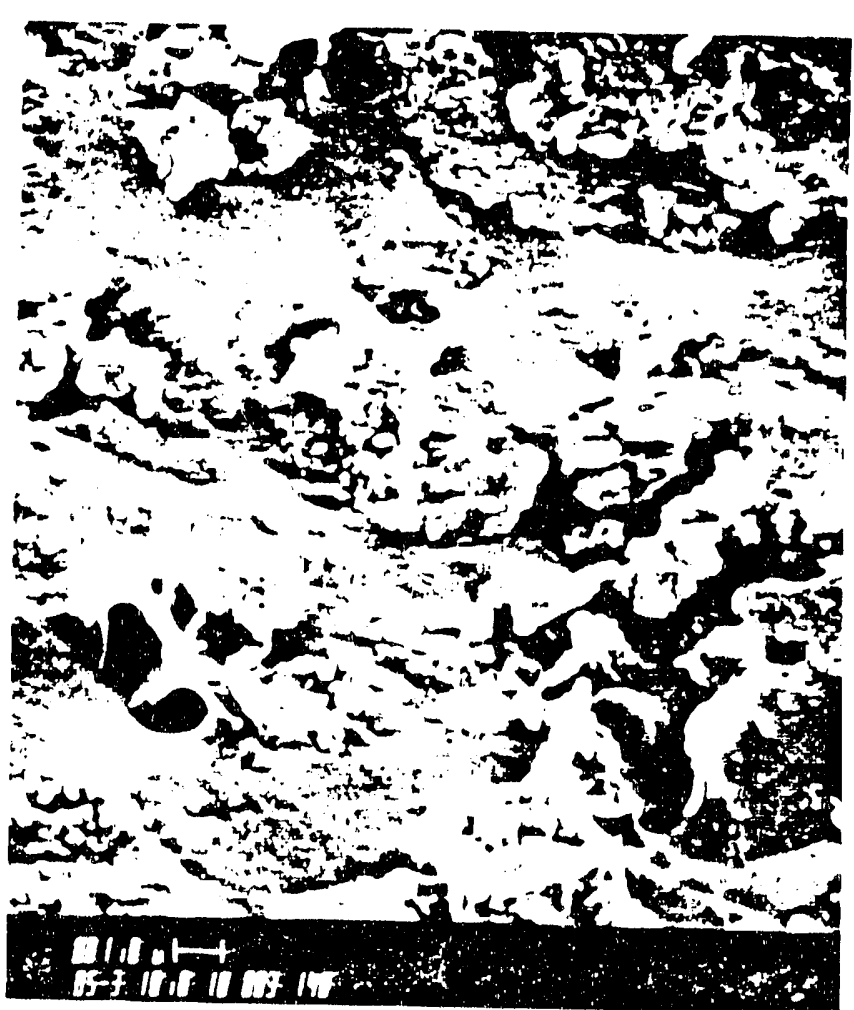

(d)

Figure 9. SEM photographs of AFBC hopper ash at magnifications of a) $100 \mathrm{x}$ b) $500 \mathrm{x}$ c) $1000 \mathrm{x}$ and $6666-23$ d) $5000 \mathrm{x}$. 
aerodynamic classifications of these ashes are presented in figure 10. The volumetric size distribution of the AFBC ash measured with the Coulter Counter is presented in figure 11. (Coulter Counter measurements of the Monticello and Scholz ashes were not possible because of their large median sizes.) The AFBC ash is significantly finer than the two PC ashes as a result of the recycle cyclones used in the bubbling bed AFBC process (10).

\section{RELATIONSHIPS BETWEEN ASH PARTICLE SIZE AND SHAPE, ASH COHESIVITY, AND FABRIC DESIGN}

Ash cohesivity is affected by the size and shape of the ash particles, and also by the surface chemistry of the ash. Ash surface chemistry is a result of the interaction between components of the flue gas and the chemical compounds on the surface of the ash particles. In the testing performed in the FFSS under Task 2, the cohesivity of the collected ash is dominated by the inherent cohesivity, or the cohesivity due only to the sizes and shapes of the ash particles. (Modification of the inherent ash cohesivity with such processes as the addition of wetting agents, chemically active powders, or sufficient amounts of relatively inert dry powders will be discussed under Tasks 3 and 4.)

In order to evaluate the effects of particle size distribution on filtration performance we performed FFSS tests of each ash unaltered, and modified with the two inlet cyclone configurations. The size distributions of the ashes entering the FFSS were measured using University of Washington Mark V cascade impactors, and the size distributions of the dustcake ashes were measured using a Coulter Counter. The effects of the inlet cyclones on the ashes from the three plants are shown in the results of impactor measurements presented in figures 12,13 and 14. Representative size distributions of the ashes reaching the fabric are shown in figures 15,16 , and 17.

Mathematical filtration models of idealized homogeneous dustcakes indicate the strong influences dustcake porosity and ash particle size and shape have on $R$, the relative gas flow resistance. $R$ is the laboratory analog of $K_{2}$. Southern Research Institute developed an empirical filtration model describing filtration through uniform dustcakes under a research project with the Electric Power Research Institute (equation 1).

$$
\begin{aligned}
P= & \left(\mu U / D p^{2}\right) \cdot[W /(p(1-\varepsilon)]] \cdot(1-\varepsilon)^{2} / \varepsilon \\
& {\left[30.0+36.2(1-\varepsilon)-143(1-\varepsilon)^{2}+2240(1-\varepsilon)^{3}\right] }
\end{aligned}
$$

where

$$
\begin{aligned}
& P=\text { pressure drop, dynes } / \mathrm{cm}^{2} \\
& \mu=\text { gas viscosity, poise } \\
& U=\text { face velocity of the gas, } \mathrm{cm} / \mathrm{s} \\
& W=\text { areal mass loading, g/cm } 2 \\
& P=\text { average particle density, } g / \mathrm{cm}^{3} \\
& \varepsilon=\text { porosity or void fraction }
\end{aligned}
$$

The effects of ash particle size and shape on filtering drag are accounted for in equation 1 by the drag-equivalent diameter of the ash. Experience with full-scale baghouses has shown that the ash collected in each baghouse exhibits characteristic values of drag-equivalent diameter and dustcake porosity.

Each parametric filtration test began with a clean fabric surface. $\mathrm{K}_{2}$ values from the parametric tests were expected to reflect differences in ash shape, size and cohesivity. Differences in $S_{e}$ between tests were expected to reflect differences in fabric design and ash characteristics. For essentially uniform dustcakes such as those formed in these FFSS tests, $\mathrm{K}_{2}$ is determined primarily by the size and shape of the dustcake ash particles and the porosity of 


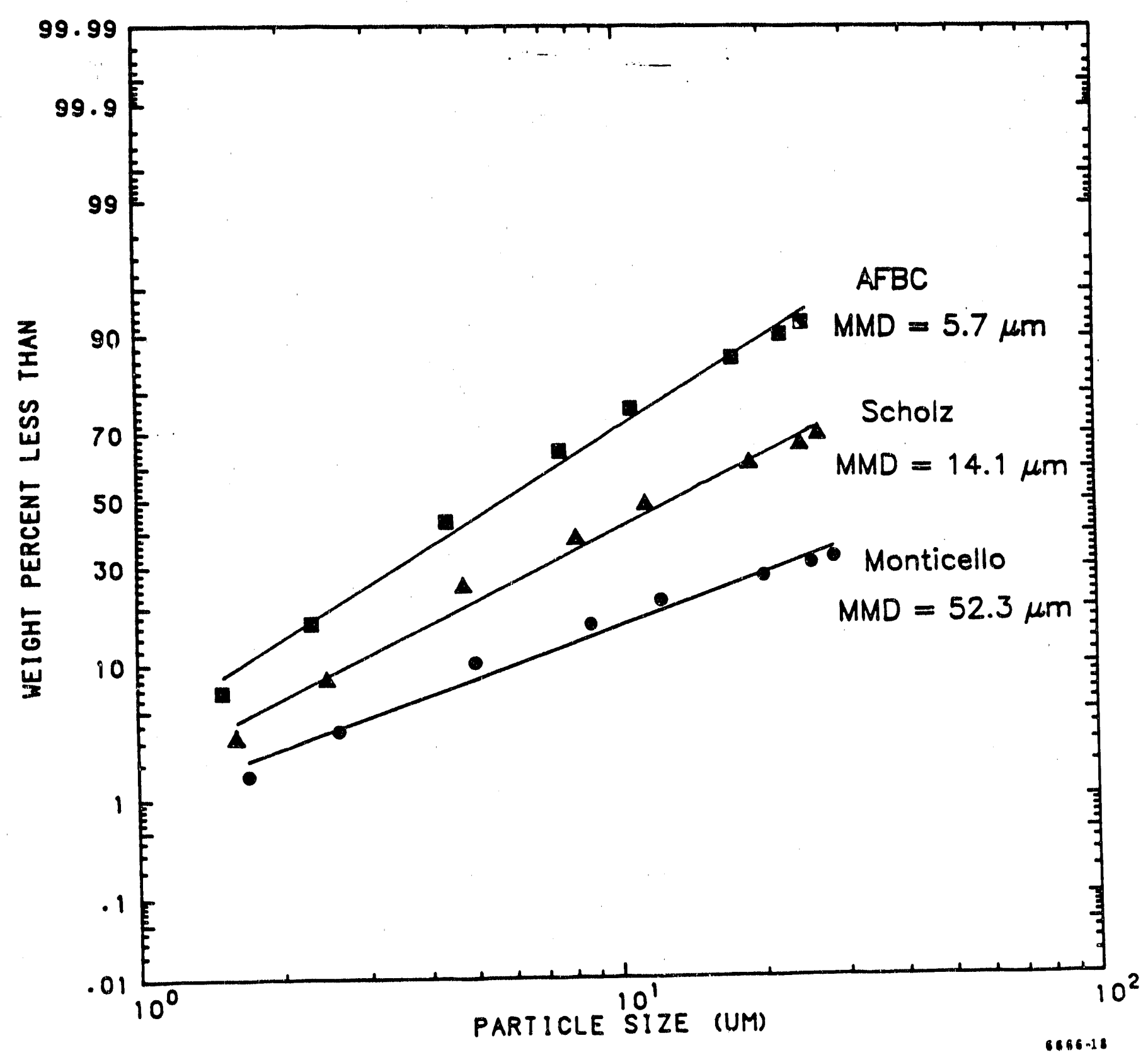

Figure 10. Aerodynamic size distributions of the Monticello, Scholz, and AFBC hopper ashes measured witt Bahco classifier. 


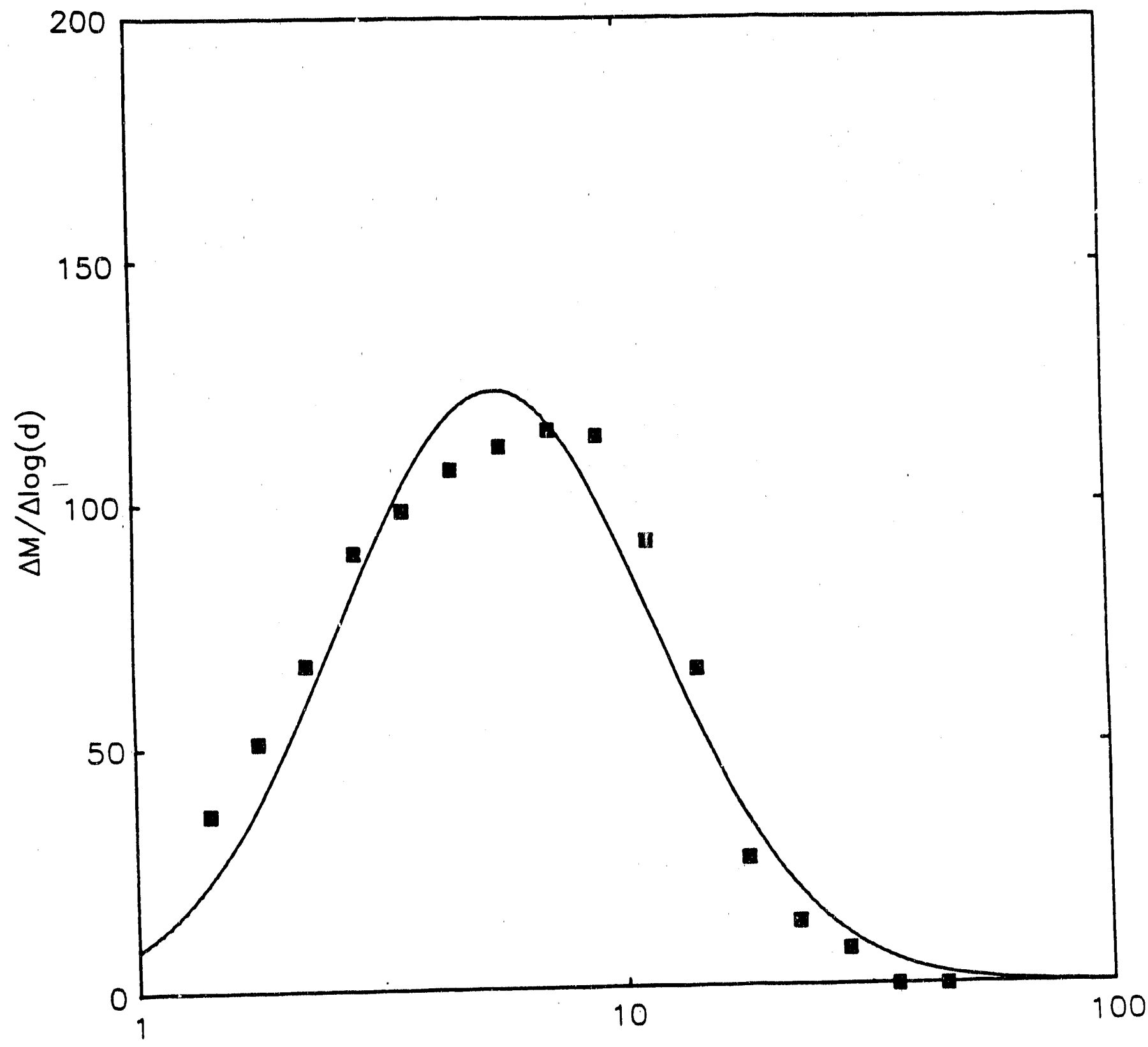

Particle Diameter, $\mu \mathrm{m}$

6666488

Figure 11. Volumetric size distribution of the AFBC hopper ash measured with a Coulter Counter. 


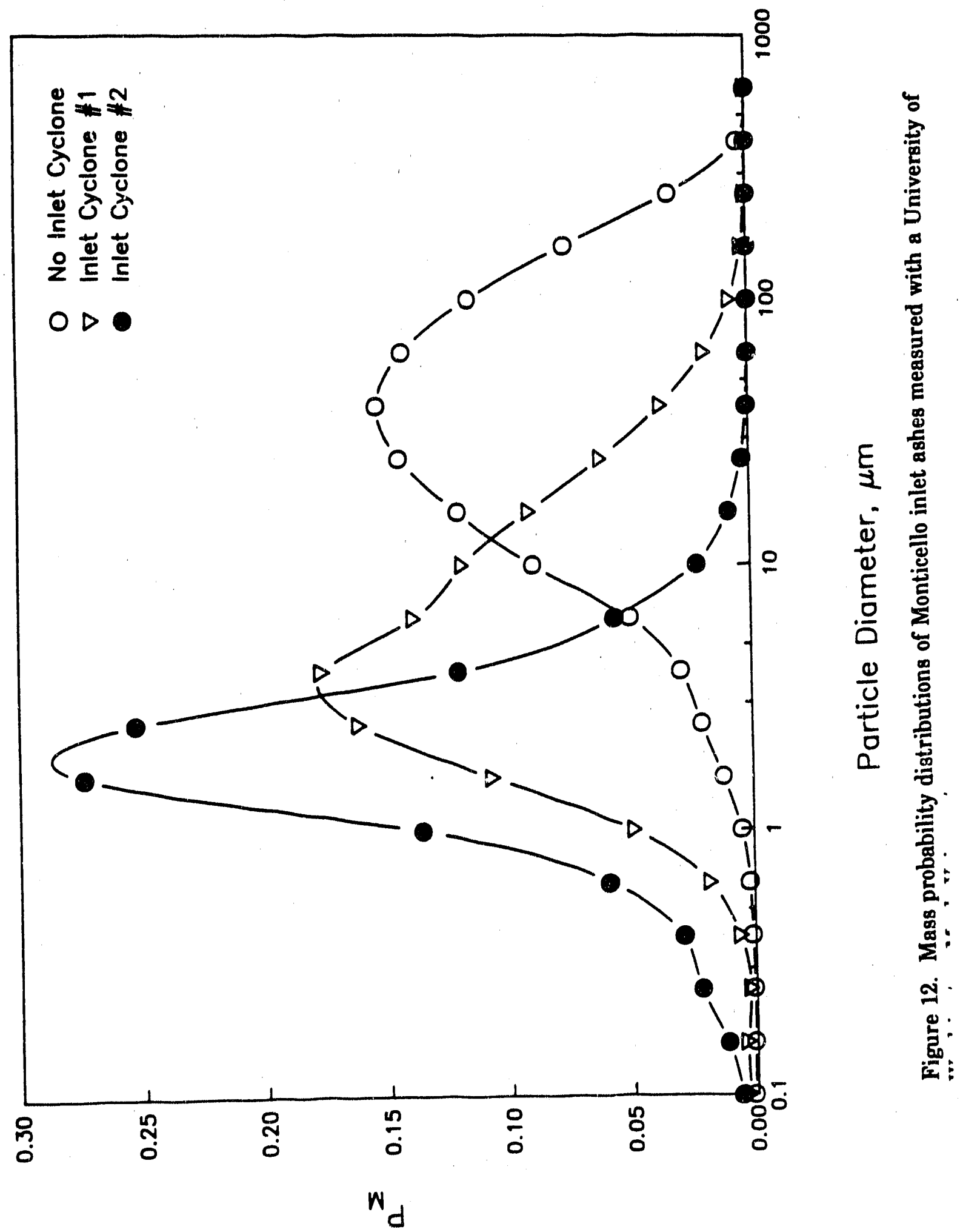




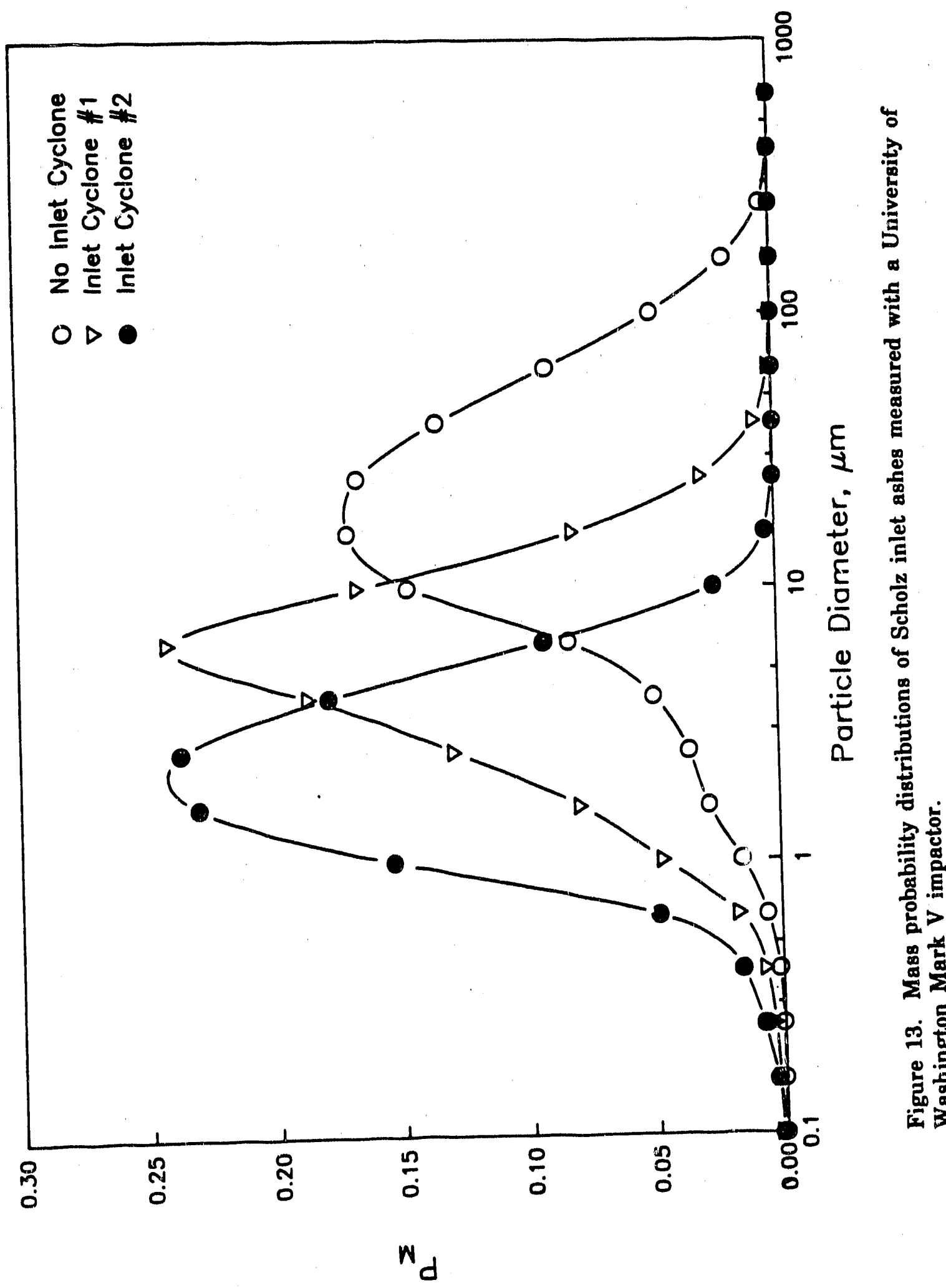




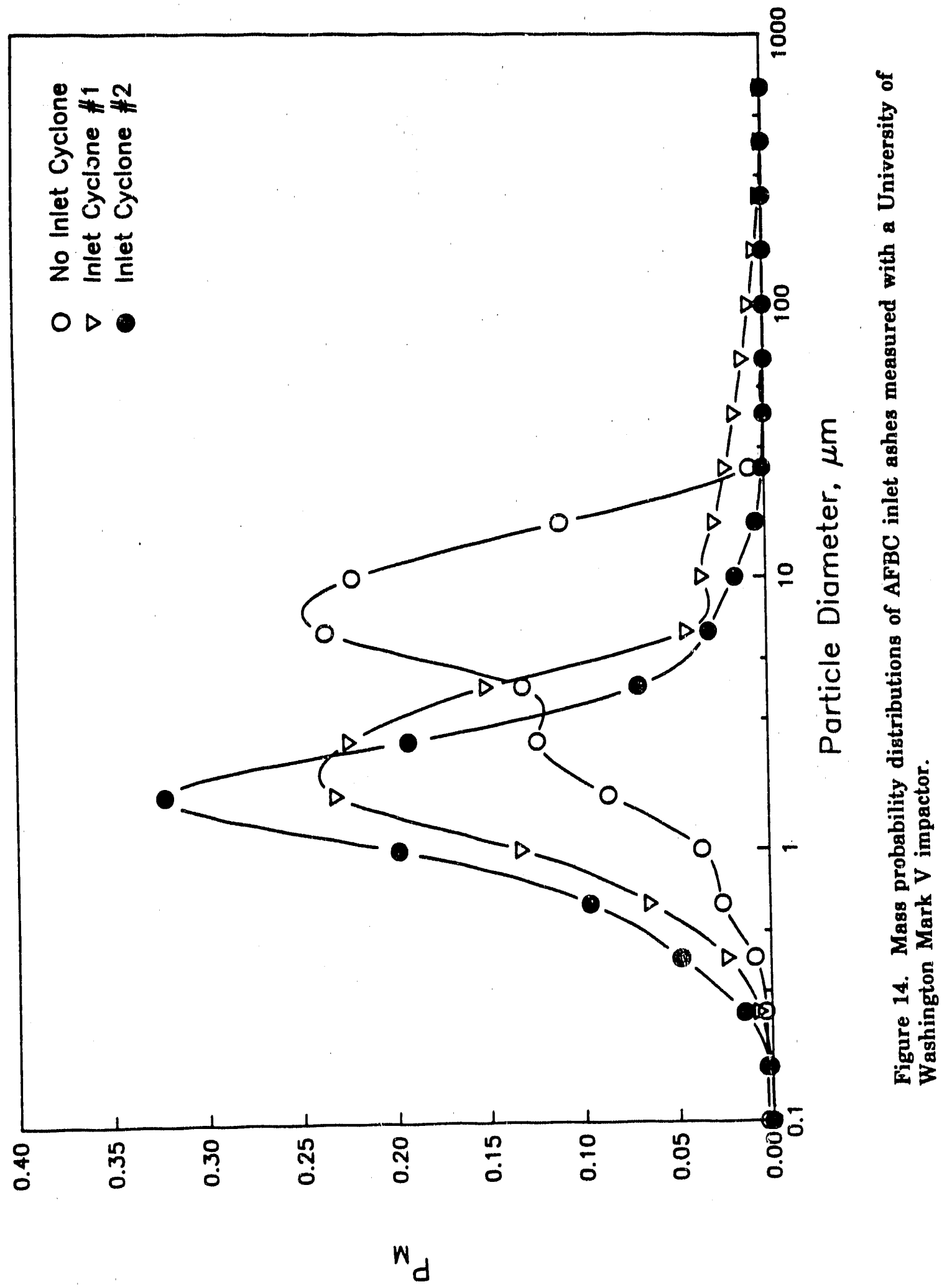




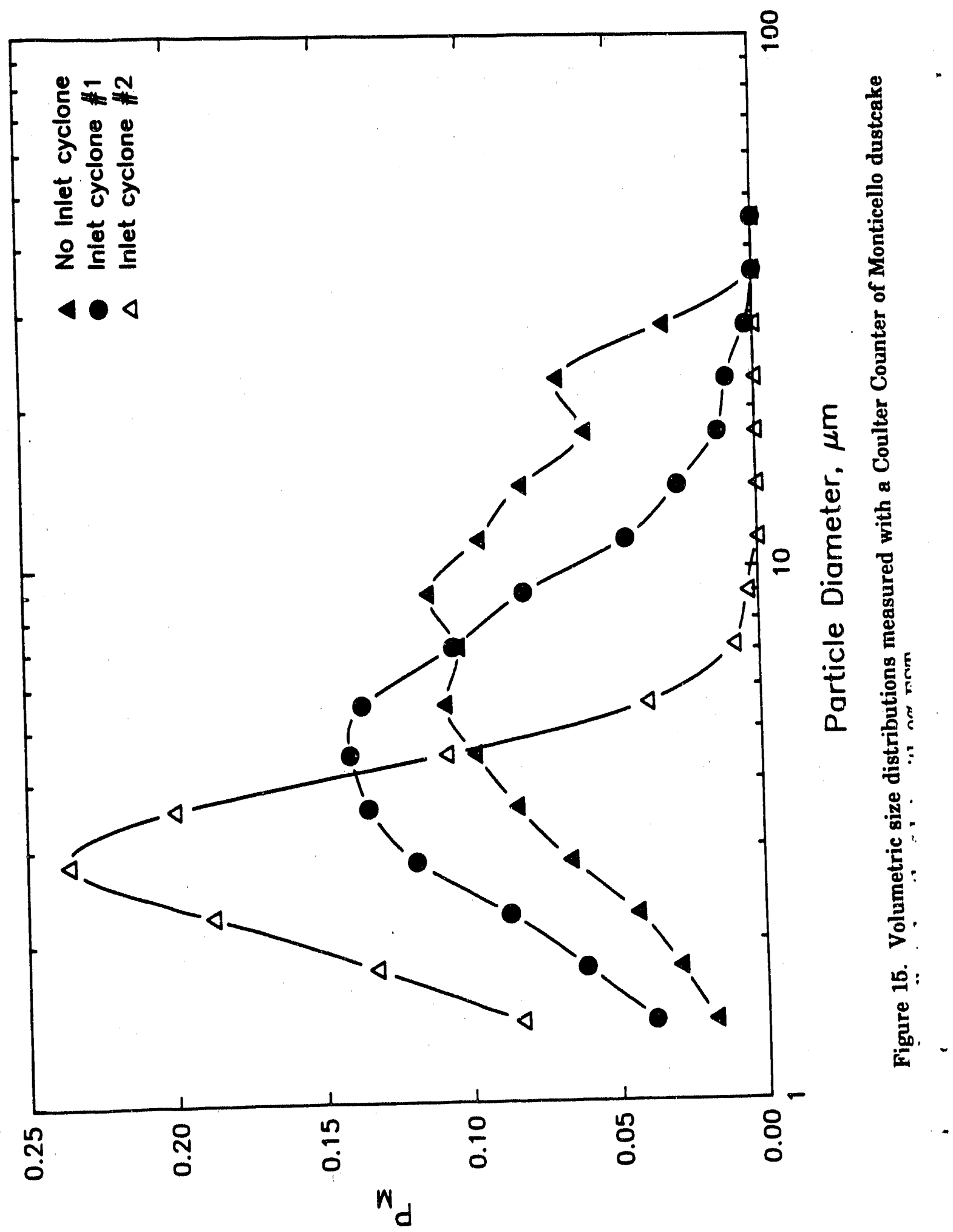




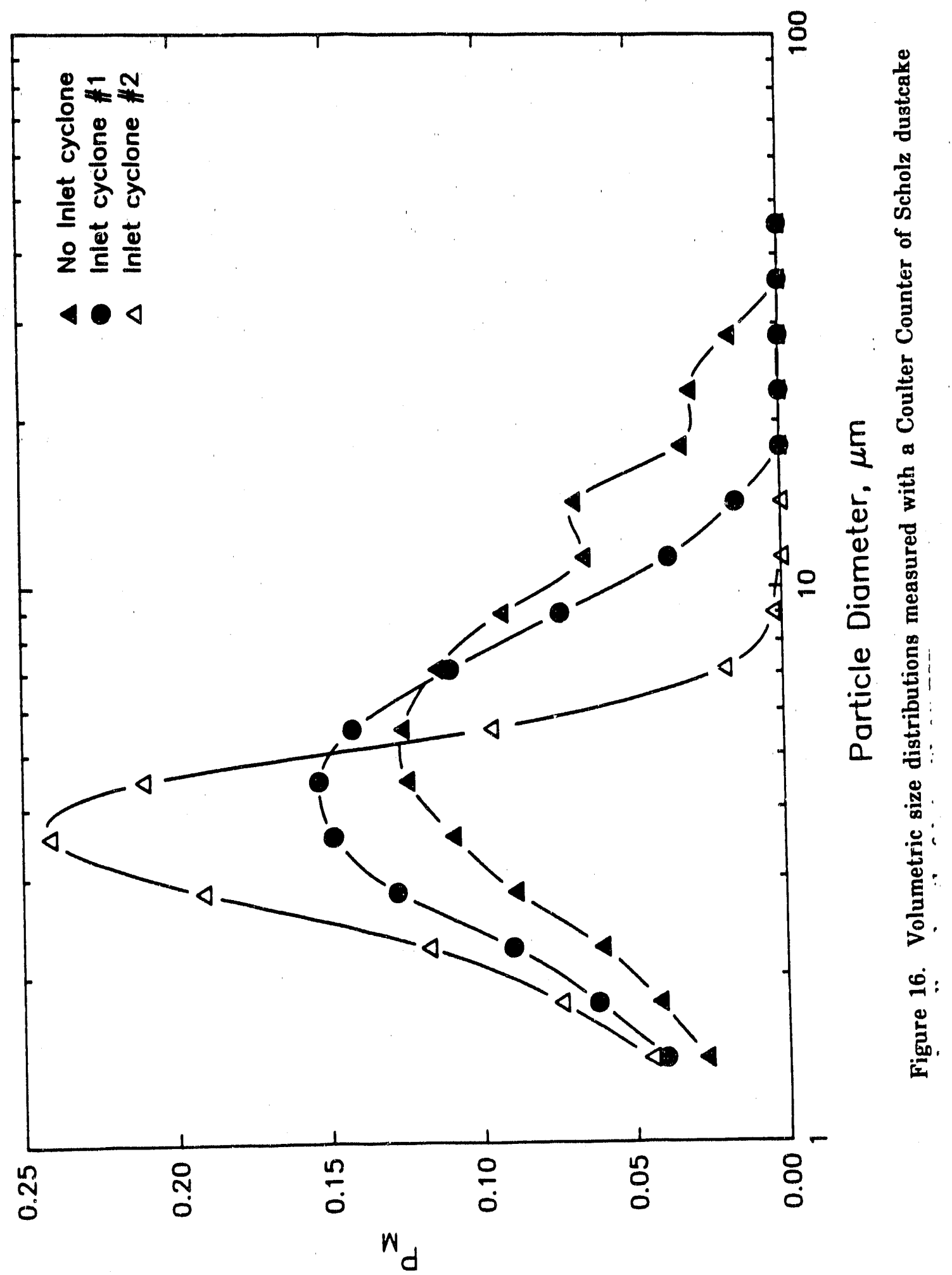



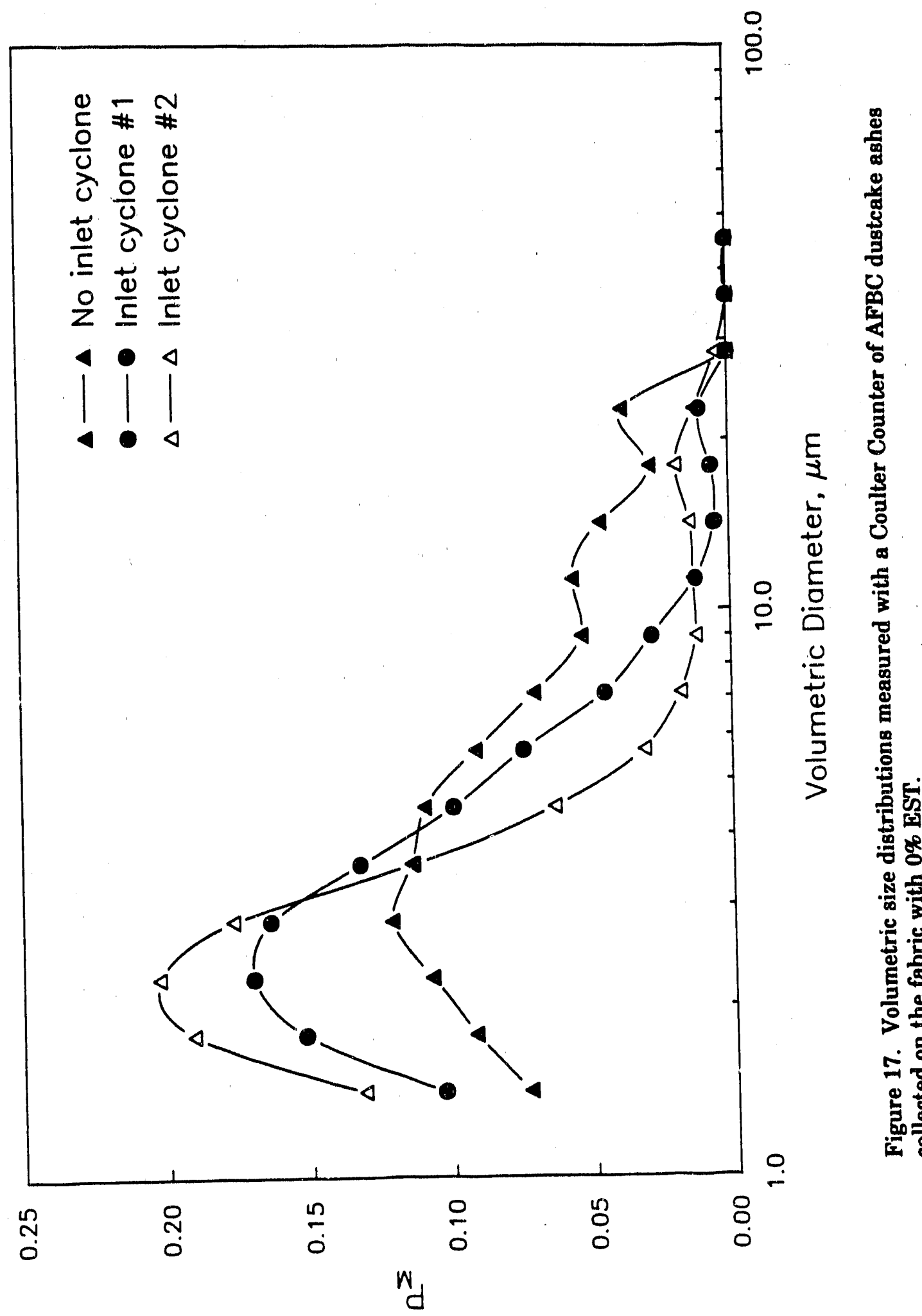
the dustcake. Previous experience has shown significantly different characteristics of dusteakes and dustcake ashes from Monticello, Scholz and the TVA AFBC. The differences in the cohesivity of the three ashes tested under Task 2 cause differences in the porosity of dustcakes from the three utility baghouses. Dustcakes from Monticello generally have porosities around 57\%, Scholz dustcake porosity has been measured to be about 77\%, and TVA if FBC dustcakes have exhibited porosities around $82 \%$ (5).

\section{Effect of Particle Shane}

In order to determine the effect of particle shape on $S_{6}$ and $K_{2}$, the filtration performance data from the parametric tests have been compared with analyses of the physical properties of the dustcake ashes collected in each test. Table 3 includes filtration data from the FFSS and data from a variety of analyses of the dustcake ashes. Table 3 also contains data for some of the Task 4 filtration tests collecting unconditioned ashes with the fabric with 25\% EST. (The collection efficiencies presented in table 3 are not representative of long-term operation or operation with cleaning, jes. Further data describing the filtration tests listed in table 3 are included in Appendix E.)

Analyses performed on the dustcake ashes include median volumetric size of the dustcake ash particles as measured with a Coulter Counter, and the morphology factor, M, which expresses the sphericity of the ash particles. The morphology factor is described in Appendix D, and is fully defined elsewhere (5). An $M$ value of 1.0 indicates the particles are perfectly smooth spheres. M values are larger for ash particles that are more irregular in shape.

Figure 18 presents the morphology factor as a function of median volumetric size for the dustcalse ashes collected in the parametric tests. These data illustrate that the smallet $=a b$ particles from Scholz and the TVA AFBC are more spherical than the larger ash particles from these plants, and that smaller Monticello ash particles are generally less spherical than larger Monticello ash particles. The apparent dependence of particle shape on particle size indicates that shape and size cannot be considered totally independent for these ashes. A variety of comparisons must be made to clarify the specific influences of particle size and shape, as well as ash cohesivity, on the filtration characteristies of the ash.

The influence of particie shape on $\mathrm{K}_{2}$ can be examined by comparing filtration data for dustcake ashes that have similar size distributions. Tests 2-3A, 2-6, and 2-8 listed in table 3 generated dustcake ashes with similar median diameters but significantly different morphology factors. Dustcake porosity is strongly dependent on particle morphology. The morphology factors of these dustcake ashes are determined to a grest extent by the specific surface area of the ash particles. The $\mathrm{K}_{2}$ values of these dustcakes depend primarily on the dustcake porosity and the surface area of the particles composing the dustcake. Increased particle surface area beneficially increases dustcake porosity but also causes more filtering drag as the gas flows past the particles. The competing effects of increased surface area can be observed in the $\mathrm{K}_{2}$ values measured for these three tests. The smoothness of the Monticello dustcake ash particles provides enough reduction the component of drag ceused by the flow of gas past the ash particles to compensate for the inherently low dustcake porusity that is associated with very smooth ash particles. The higher porosities of the Scholz and AFBC dusicakes do not fully compensate for the increased drags due to the higher surface areas of these ash particles.

\section{Effect of Particle_Size}

One way to clarify the different effects of ash source and particle size on filtration performance is to plot $\mathrm{K}_{2}$ of the various dustcake ashes as a function of their volumetric median diameters. These data are presented in figures 19 and 20. Reducing the median diameter of any of the three asbes produced dustcakes having significantly higher drag coefficients. The rate at 


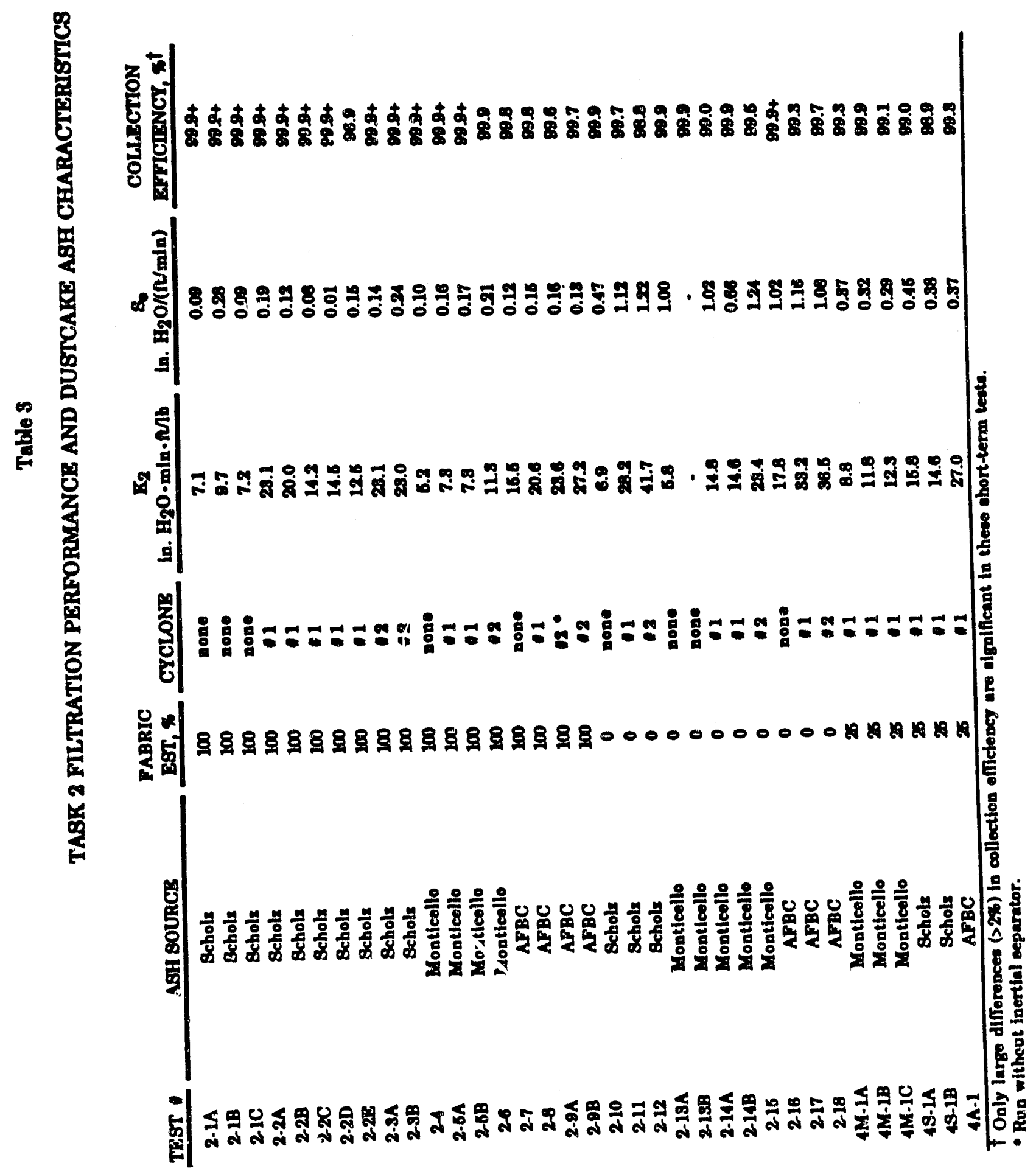




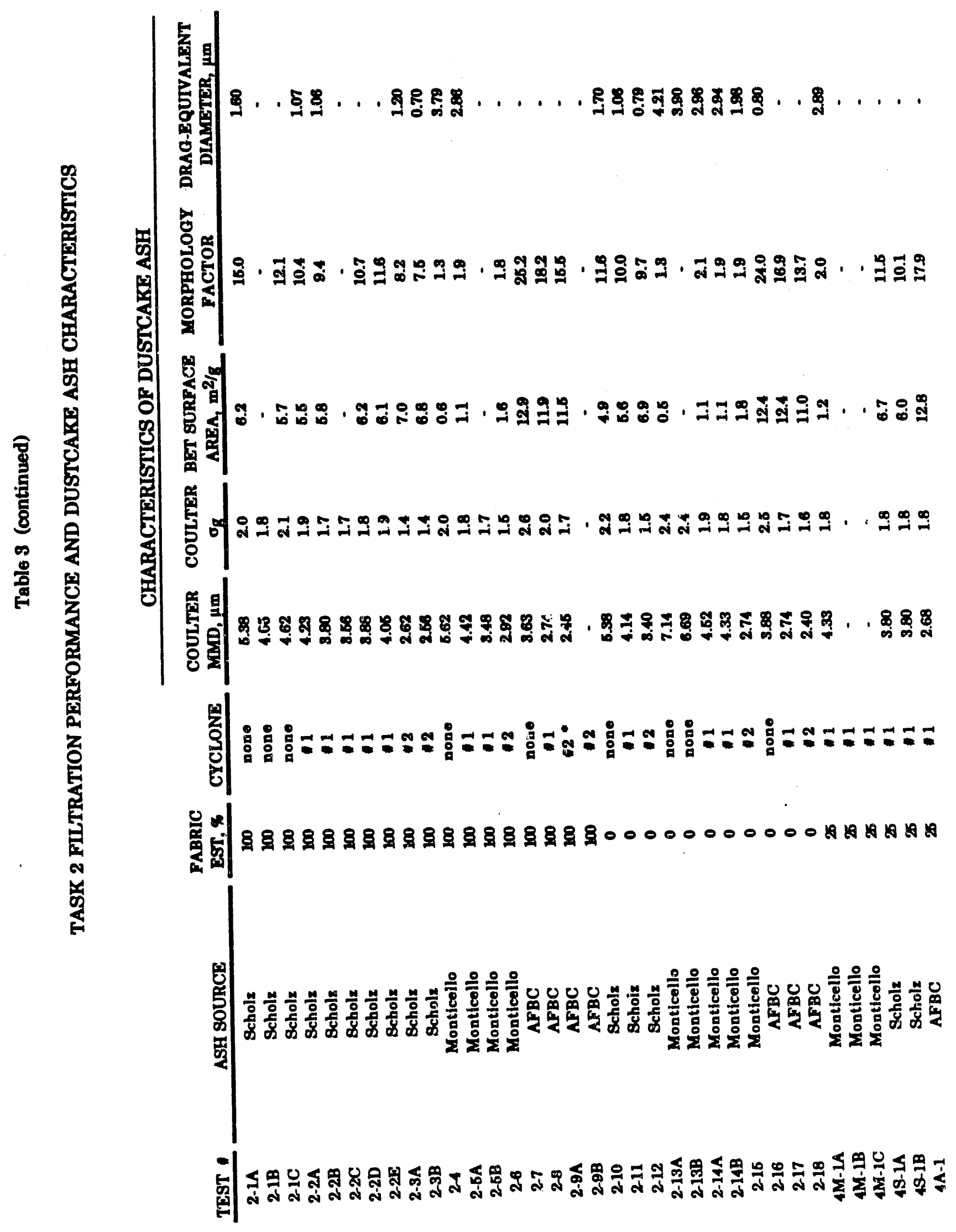




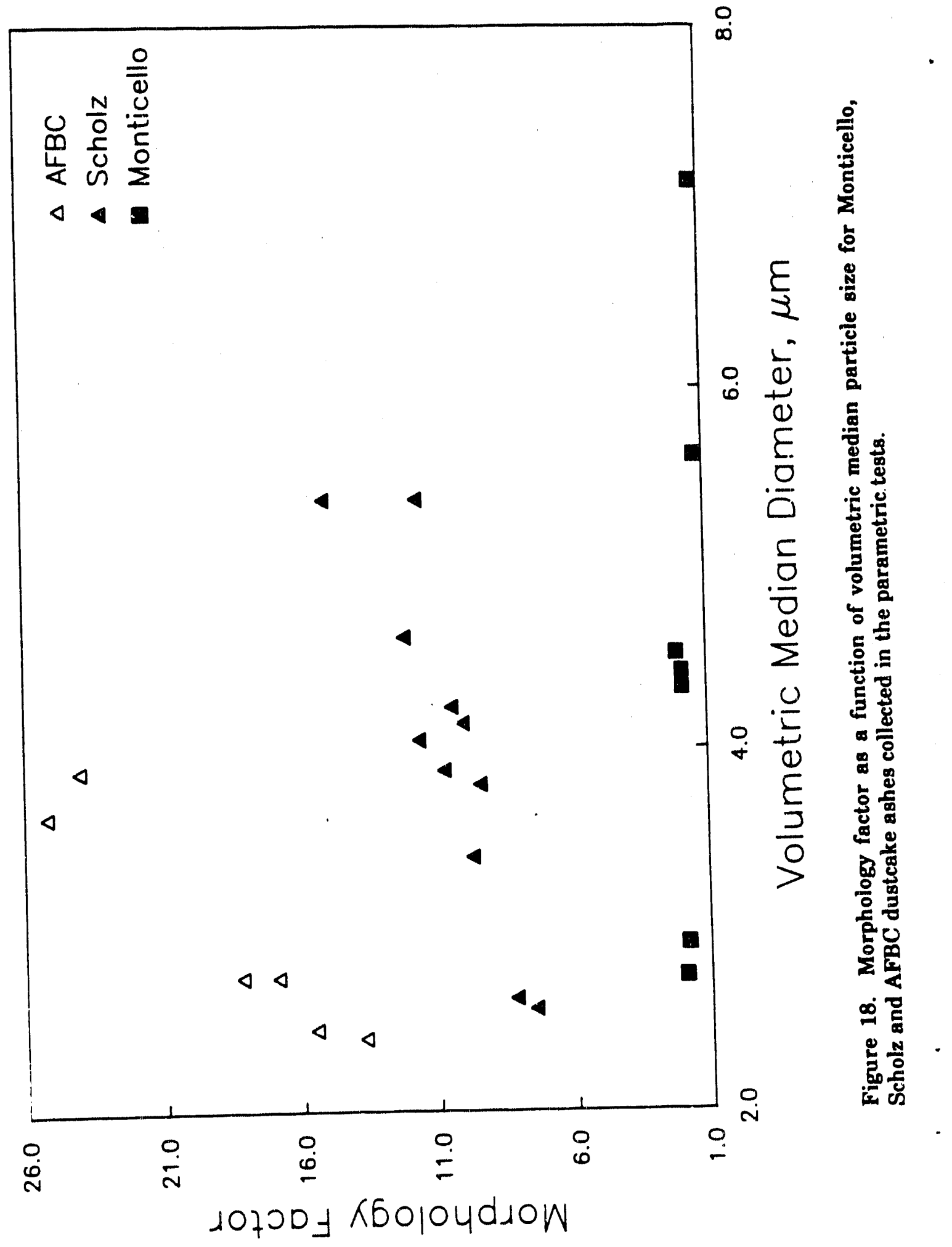




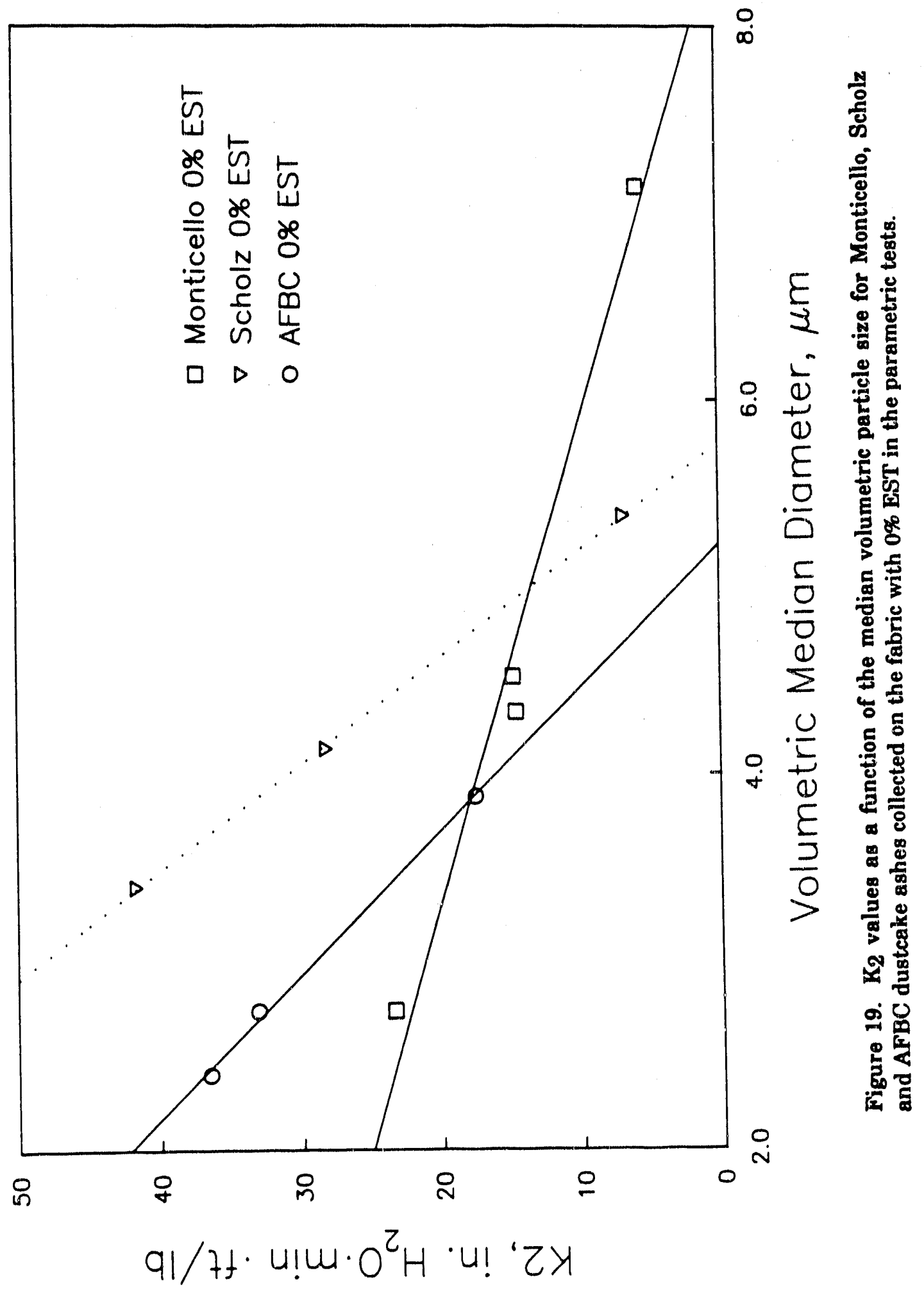




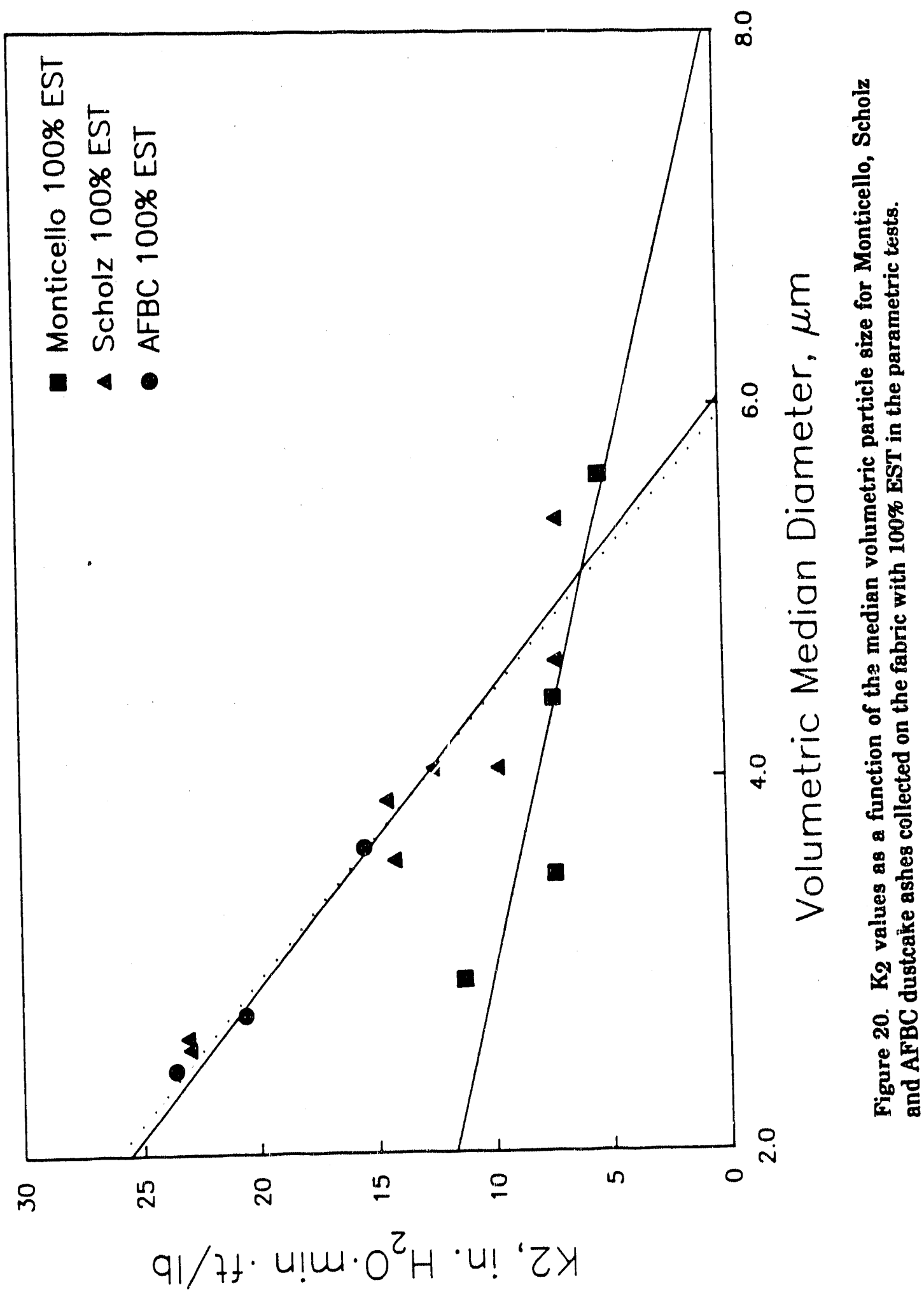


which $\mathrm{K}_{2}$ varies as a function of size is apparently associated with ash source. The Scholz and AFBC ashes exhibit similar rates in this comparison, while the $\mathrm{K}_{2}$ values measured for the tests of the Monticello ash are less sensitive to changes in particle size than the Scholz or AFBC sshes.

The changes in particle shape as a function of particle size noted in figure 18 may have a direct bearing on the trends noted in figures 19 and 20 . Lower dustcake porosity could account for some of the increase in $\mathrm{K}_{2}$ noted for the Scholz and AFBC dustcakes formed from the smaller particles. This effect should not be present for the Monticello ash because the sphericity of the Monticello particles decreases with decreasing size. Dustcakes composed of the smaller Monticello ash particles should exhibit a somewhat greater cohesivity, and consequently a greater dustcake porosity than dustcakes composed of the larger Monticello ash particles. The observed increases in $\mathrm{K}_{2}$ for the Monticello ash in figures 19 and 20 are due primarily to changes in the specific surface area of the Monticello ash particles. The specific surface area of Monticello dustcake ash particles increases by about a factor of 3 between tests run at the unmodified inlet condition and tests run with inlet cyclone 2 (see table 3 ).

\section{Effect of Ash Cohesivity}

Most of the differences in the filtration behavior of the three ashes tested in Task 2 can be attributed to differences in the inherent colvesivity of the ashes. Differences in the inherent cohesivity were induced by differences in the particle size, particle shape, or both. The effects of ash cohesivity on $\mathrm{K}_{2}$ as observed in these parametric tests are defined by the effects of particle size and shape, as discussed above. If the inherent cohesivity of ash particles can be modified by changing the surface characteristics or surface chemistry of the ash particles without introducing detrimental changes in the size or shape of the ash particles, the filtration properties of the ash particles can be improved. These approaches were addressed in Tasks 3 and 4 , which are discussed later in this report.

\section{Effect of Fabric Desien}

The key aspects of fabric design that affected filtration performance in the Task 2 parametric testing are the pore size and the areal pore distribution. Texturized fabric yarns containing indiridual fibers which protrude from the surface of the fabric should improve the collection and retention of ash particles. The fabrics used for the Task 2 tests have very different pore sizes and pore distributions. The backlit photographs shown in figure 5 illustrate the differences between the fabrics used in the FFSS tests. The only pores in the fabric with 0\% EST are at the interstices of the yarn bundles, which show up distinctly in the photographs. The fabric with $100 \%$ EST has more numerous, but smaller pores through the yarn bundles. The areal distribution of the pores in the fabric with $25 \%$ EST represents an intermediate condition between the fabrics with $0 \%$ and $100 \%$ EST.

During the initial stages of filtration, the first ash particles that reach the clean fabric are deposited in the fabric pores. The degree to which the ash particles infiltrate the pores depends primarily on the cohesivity of the ash, and also on the pore sizes and the velocity of the gas through the pores. Because the velocity of the gas passing through the pores is much greater than the superficial face velocity of the gas, the ash particles that fill or bridge over the pores have a disproportionately large contribution to the total filtering drag. This contribution is generally contained in the $S_{e}$ value, and is determined experimentally using the process described in Appendix C. A pore that has been infiltrated with ash particles essentially contains a small dustcake structure, through which the filtered gas must pass. The filtering drag through this pore is directly dependent on the relative gas flow resistance of the ash in the pore. Although the ash particles that are deposited in the pore have the same physical characteristics (size distribution, surface area and drag-equivalent diameter) as the ash particles collected during the later stages of filtration, the ash particle structure in the pore is subjected to a greater local 
gas velocity and therefore a greater compressive force. The increased gas velocity through the pore might provide enough force to compress this particle structure to a lower porosity than the poronity characteristic of the dustcake deposited during later stages of filtration. If the cohesivity of the ash is low enough, the force of the gas passing through the pore can prevent the formation of a stable particle structure within the pore. This situation promotes the formation of pinholes through the dustcake that can significantly reduce collection efficiency. Dustcake structures that contain pinholes provide examples of the effects of nonuniform flow and nonuniform dustcake structure. These pinholes also provide pathways for a disproportionate amount of the gas to pass through. Because less of the filtered gas generates flow resistance by passing through the porous dustcake, the apparent value of $\mathrm{K}_{2}$ is lowered by the presence of pinholes. The effect of pinholes on $\mathrm{K}_{2}$ was observed for some of the proof-of-concept tests, which are discussed later.

In the data collected from the parametric tests, $S_{0}$ values for dustcakes collected on fabric with 0\% EST are up to an order of magnitude greater than corresponding values for fabric with 100\%

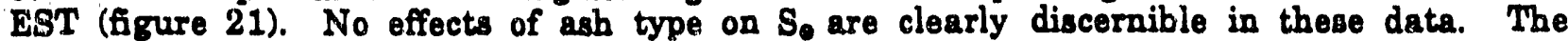
overwhelming determizants of $S_{\theta}$ in these Task 2 tests are the sizes and arrangement of pores in the fabric due to differences in the designs of the fabrics.

The influence of the fabric design and pore geometry on filtration characteristics of the dustcake can extend beyond the point when the pores are completely filled or bridged over. Although the $S_{\theta}$ value may be determined after a very brief filtration period in the FFSS filtration tests (figure 3), the pores can still influence the waiformity of flow through the dustcake. Since all the filtered gas must pass through the fabric pores, the location of the pores influences the distribution of flow through the portion of the dustcake very close to the fabric surface. The flow resistance through a uniform porous medium increases as the flow distribution through the medium becomes less uniform. This effect may account for differences in $\mathrm{K}_{2}$ for cests run on the two different fabrics with inlet cyclone \#1 and inlet cyclone \#2 (figures 22, 23 and 24). $K_{2}$ values differed significantly between dustcakes collected on the fabric with 0\% EST and those collected on the fabric with 100\% EST. This effect of fabric EST on $K_{2}$ was not observed for the unmodified size distributions.

\section{REVERSE-GAS CLEANING TESTS}

Filtration tests involving repeated reverse-gas cleaning cycles were performed with each of the three ash types. These tests were run with inlet cyclone \#1 and fabric with 25\% EST. Figure 25 presents the filtration data from these tests in terms of drag as a function of time. The removal of previously collected ash from the fabric during the cleaning cycles prevented determination of areal density values during the tests. $S_{6}$ and $K_{2}$ values could not be derived for these tests because areal density data could not be presented as a function of time. Although the data in figure 25 cannot provide the $\mathrm{K}_{2}$ or $\mathrm{S}_{0}$ associated with any of these tests, the data do show that for each ash, the $\mathrm{K}_{2}$ values appear to return to a given value (proportional to the slopes of the curves in figure 25) following cleaning cycles. This result was expected, since the slope of the linear portions of these curves should be dependent only on the characteristics of the ash reaching the dustcake.

For the Monticello and Scholz ashes, reverse-gas cleaning decreased system collection efficiency, although no drop in collection efficiency was noted for the AFBC ash. Reverse-gas cleaning disturbs the dustcake structure, allowing previously collected ash pa-ticles to break free and move through the fabric pores during the next filtration cycle. Apparently the cohesivity of the AFBC ash was sufficiently high to prevent this from occurring. 


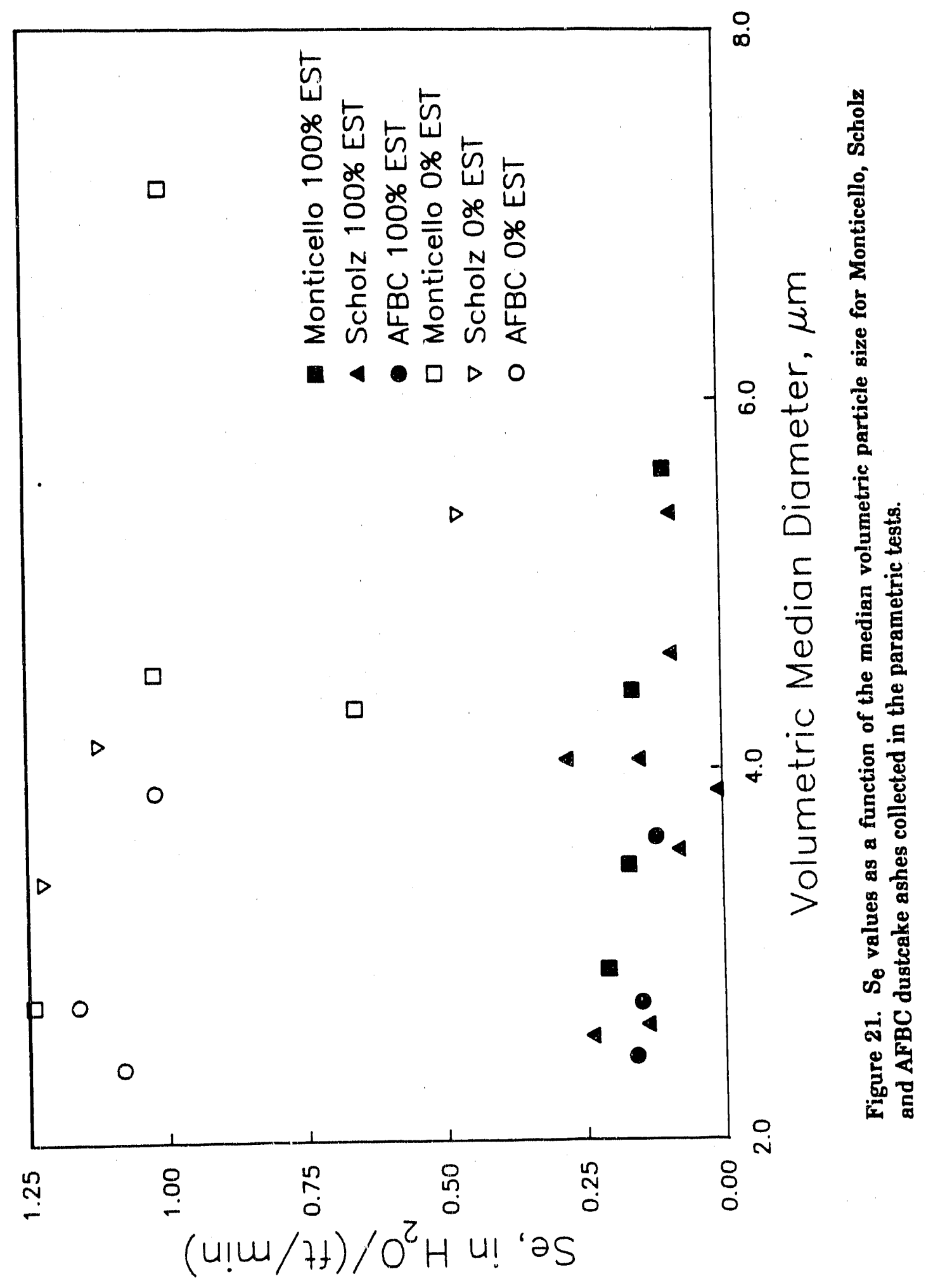




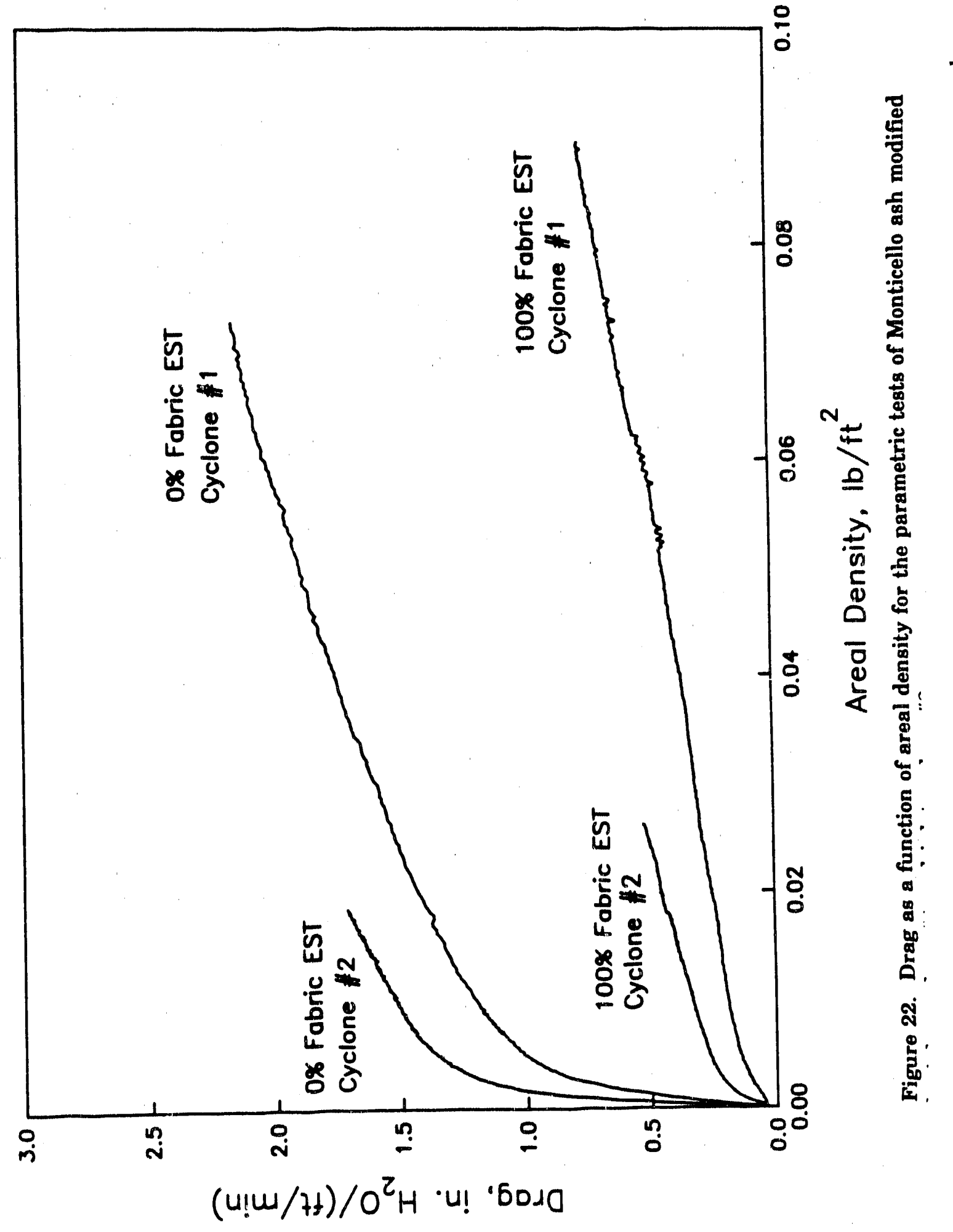




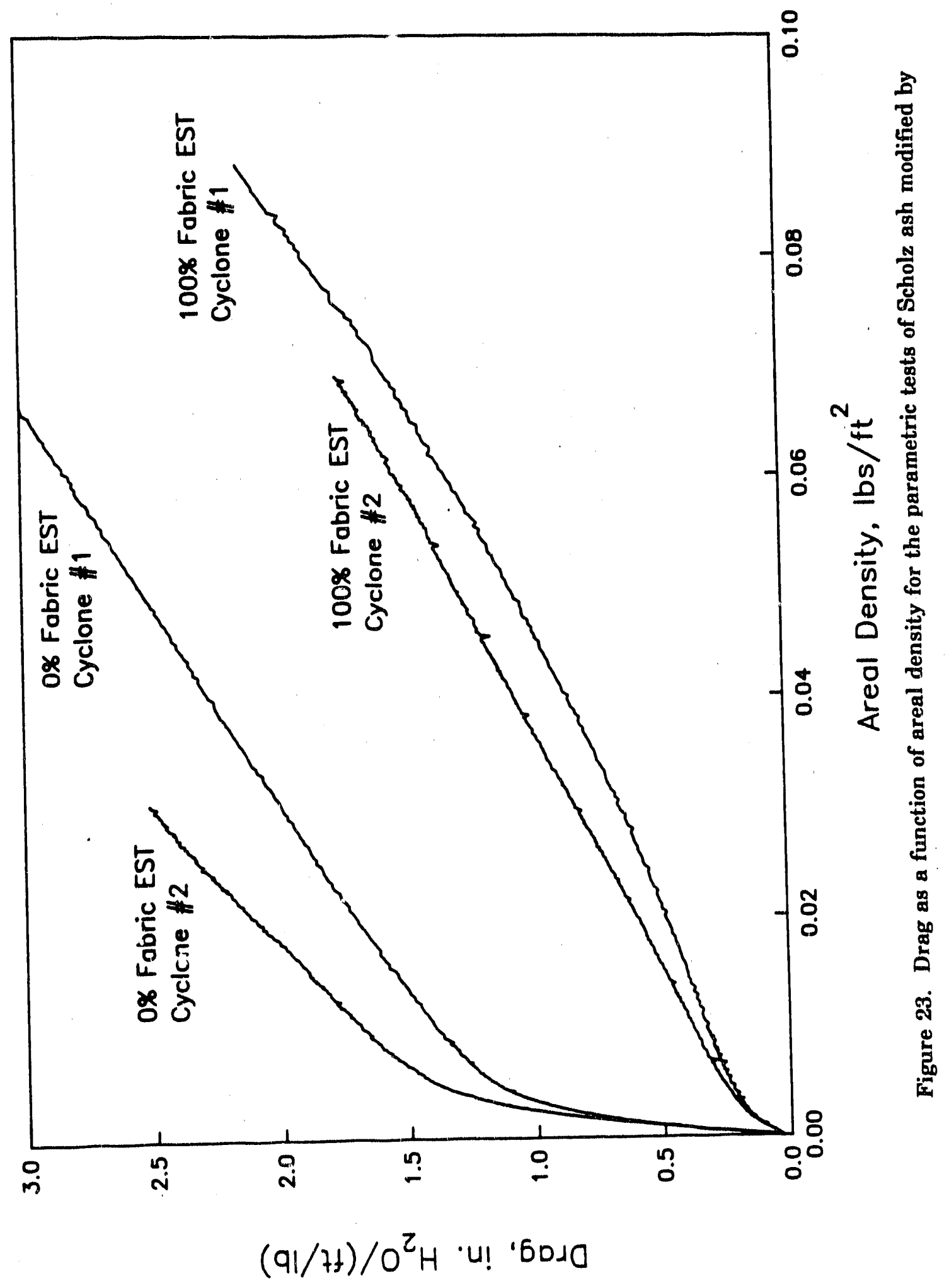




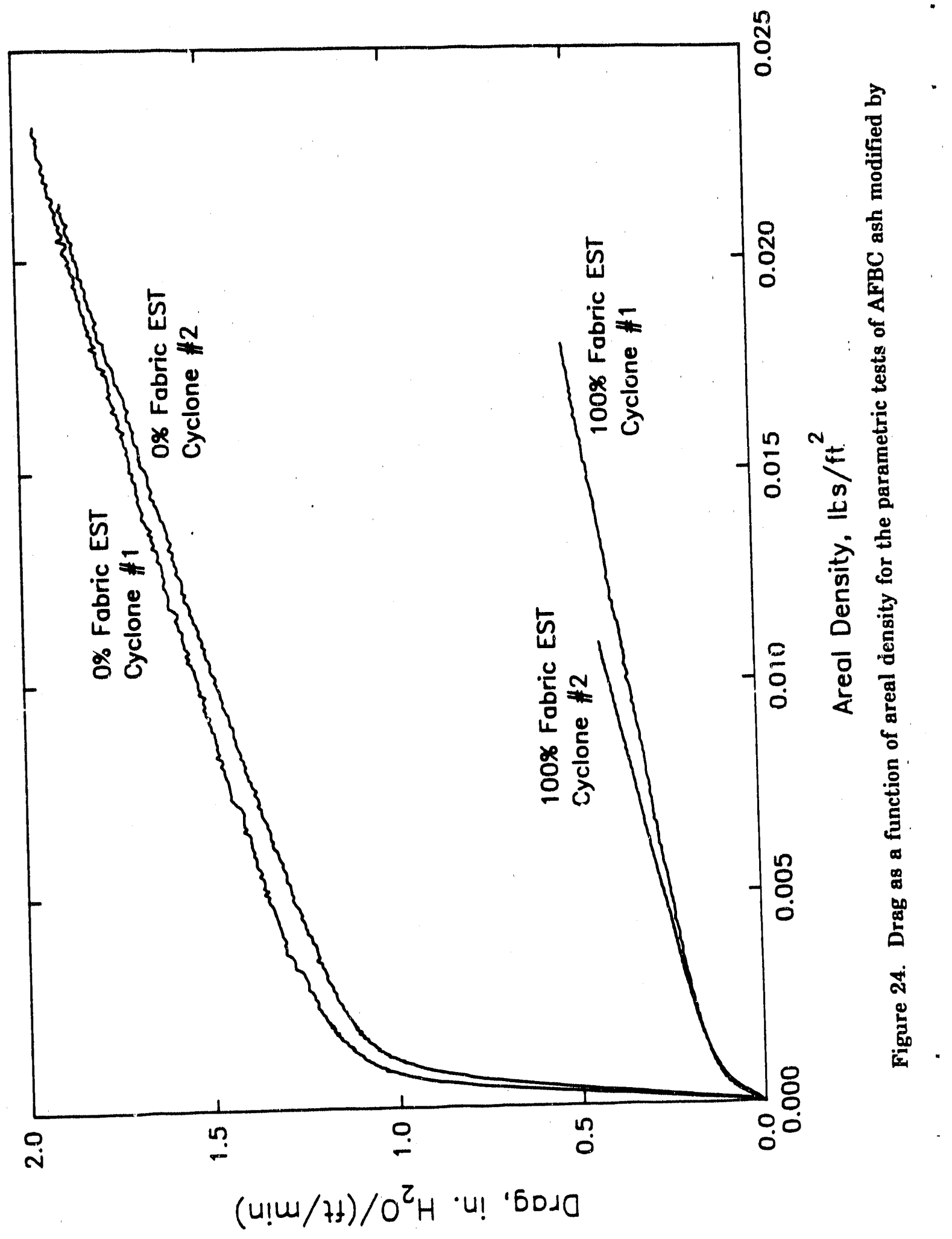



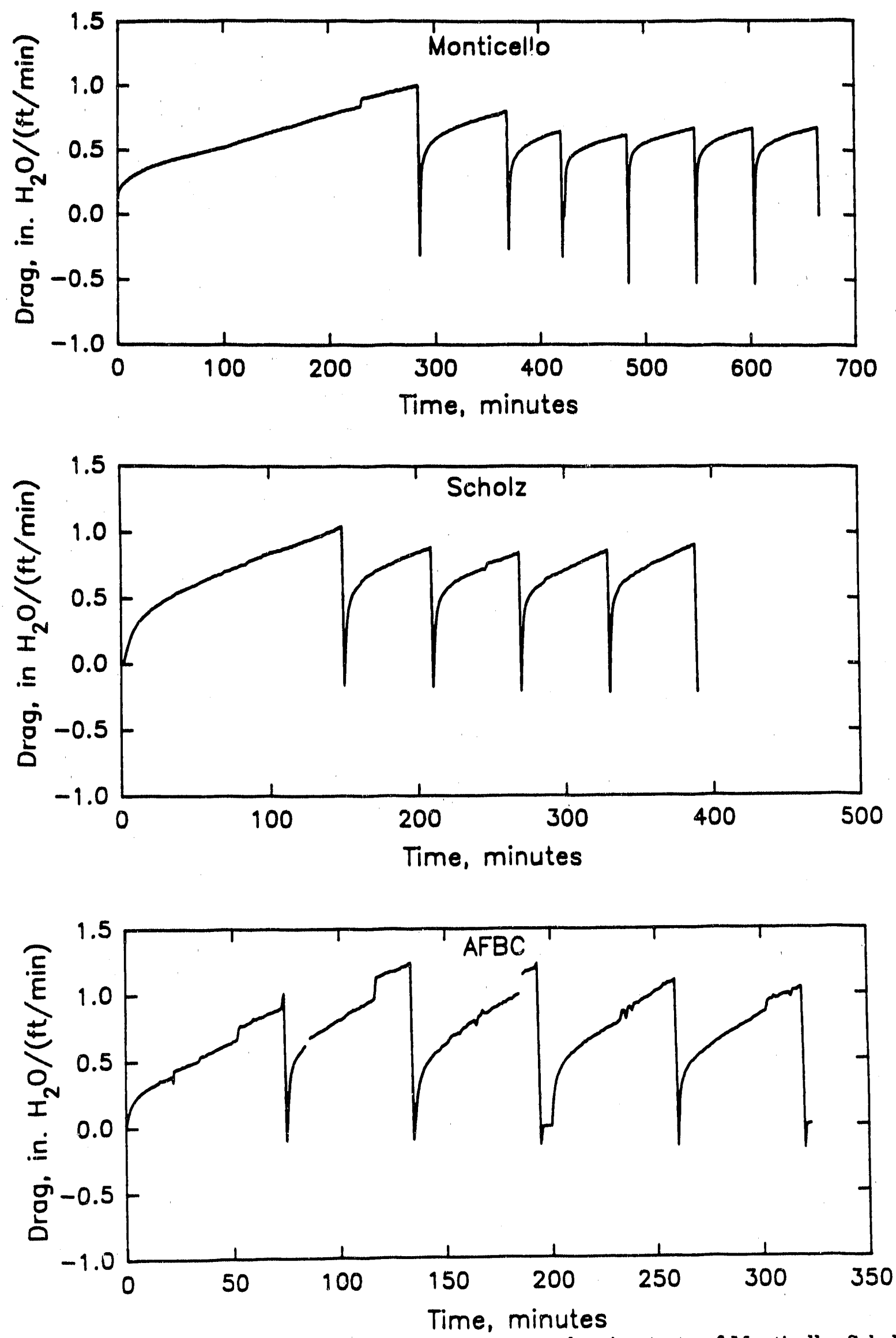

Figure 25. Drag as a function of time for reverse-gas cleaning tests of Monticello, Scholz and AFBC ashes collected on fabric with $25 \%$ EST. 
The parametric tests performed under Task 2 verified that inherent ash cohesivity is primarily determined by ash particle shape and size.

Ash particle size and shape are the main determinants of the $\mathrm{K}_{2}$ value associated with filtering that ash. The relationship between particle shape and $\mathrm{K}_{2}$ is relatively complex, involving the competing effects of altered particle roughness on specific surface area and dustcake porosity.

Ash particle shape can be dependent on particle size. Although this relationship is sometimes weak, it can be significant in determining the overall characteristics of ashes with modified size distributions.

When filtering ash with an initially clean fabric, $S_{\theta}$ is much more dependent on the size and arrangement of pores in the fabric than on the characteristics of the collected ash.

$\mathrm{K}_{2}$ can also be dependent on fabric pore characteristics when the collected dustcake is very thin, or when the combination of low ash cohesivity and fabric pore characteristics generate a nonuniform dustcake structure containing pinholes. Both of these conditions affect $K_{2}$ because they tend to result in nonuniform flow through the dustcake.

For a given fabric design, the inherent cohesivity of the ash being filtered is the primary determinant of filtration performance for unconditioned or unmodified ashes.

The benefits of high inherent ash cohesivity on dustcake porosity can be attenuated by too much particle surface area.

The low surface area characteristic of smooth particles can induce beneficial reductions in filtering drag if dustcake porosity can be kept high.

The Task 2 studies provide baseline information which will aid in the evaluation of various conditioning agents and methods. 
An innovative part of this research project was the Survey of Methods to Modify Filtration Properties to improve the flow reaistance, and collection efficiency. The objective was to find or develop conditioning agents that could be used to optimize the filtration performance of any ash. Numerous powder conditioning agents are used in powder transport and to promote wiform mixing of powders. These agents may be useful for filtration, or they may provide important clues as to the charactoristics of other usefu' conditioning agents.

\section{TE JHNICAL APPROACH}

A major portion of this taak was review of technical literature. TI , literature review was carried out through the DIALOG Information Services, a computer-based network allowing rapid access to specific topics writhin a broad range of sources by the use of selected search parameters. Search procedures that we used are presented in Appendix F. The reviews of the articles were directed toward finding descriptions of the mechanisms governing particle-toparticle interaction, and prospective ash conditioning agents. Summaries of the most useful articles reviewed are presented in Appendix G. (In addition to summaries of the articles obtained through the DIALOG search, Appendix G includes summaries of a trade brochure and an interaal SRI memorandum.)

The second part of the Task 3 work involved the scquisition and preliminary evaluation of potential conditioning agents with quick s reening tests. Agents were selected based on the findings of the literature review, past field experience, and consultations with other researchers. The laboratory sereenirig tests included most of the tests described in Appendix D. The results of these screening tests were used to select several of the conditioning trials performed under Takk 4.

\section{FINDINGS FROM THE LITERATURE REVIEW}

The literature review indicates that the primary particle attraction mechanisms that determine the cohesiveness of powders are electrostatic attraction, van der Waals forces, and adsorbed surface films. Particle characteristics that are of primary importance for these mechanisms are particle size and shape. The generic importence of particle aize and ahape in governing powder cobesivity was anticipatod from the results of the atudy of dustceke asb properties conducted for the Electric Power Research Institute $(E)$. The van der Waals force is the predominant attrective force between particles in the same size range as fly ash particles collected by fabric filters.

The van der Waals force is strongly influenced by particle size and shape, particle closeness, and contact area. These factors can be influenced by the introduction of relatively small amounts of submicron particles anto the surfaces of the host particles. Small additive particles act as lubricants between the larger host particles, allowing the conditioned mixture to flow more freely than the original host powder would. The literature reviewed suggests there is an optimum mixing ratio of conditioning agent to host substrate on a weight-to-weight $(w / w)$ basis. Though the majority of the articles dealing with this subject did not specifically discuss fly ash, the optimum $w / w$ values cited for conditioning agents applied to other materials were usually between 0.1 and $2.0 \%$. In general, the addition of conditioning agents in this proportion tends to place asperities on the surfaces of the host particles. These asperities then influence the strength of the interparticle forces by changing the number and nature of the contact points between particles; that is, by altering the particle morphology.

Many of the articles reviewed emphasize the importance of moisture content and relative humidity in the vicinity of powder particles for the determination of bulk powder cohesivity. 
Liquid films adsorbed onto the surfaces of particles may increase particle adhesion by as much as five-fold. The existence of chemical bonds, in the form of liquid or crystalline bridges between fly ash particles, has been implied by fabric filter field data relating passages through acid and water dew points to dustcake properties. Figure 26 illustrates the geometry of a contact point between two particles that has been strengthened by the presence of a liquid bridge.

Experiences at SRI and at the University of North Dakota indicate that ammonia and sulfur trioxide can be used in combination to increase ash cohesivity $(8,11)$. The mechanism responsible for this increase in cohesivity had not been fully identified. It was not known whether the products formed from the reaction of these two chemicals altered ash particle morphology by attachment as asperities to the substrate particle surfaces, or if the chemical composition of the reaction products directly modified the bonding strength of the particles by providing a liquid bridging mechanism at the particle contact points. Determining the dominant mechanism by which the $\mathrm{NH}_{3}+\mathrm{SO}_{3}$ product modifies ash cohesivity was identified as an intermediate goal that would guide the investigation of alternate conditioning agents.

In consultation with Dr. E.B. Dismukes on the identification of substances that might be able to alter the cohesiveness of fly ash, several types of compounds were discussed. The primary sroups of compounds identified were amine sulfates, surfactants/dispersants, flocculating or coagulating agents, silanizing agents, and deliquescent compounds. Excerpts from Dr. Dismukes' summary of potentially useful compounds are included in Appendix G.

\section{RESULTS OF SCREENING TESTS}

Two basic types of laboratory screening tests were performed under Task 3 . One set of screening tests consisted of various methods of mixing a wide selection of dry powders with unconditioned ash samples to induce changes in ash cobesivity. The other set of screening tests included several experiments deaigned to gain a better understanding of the mechanism by which the reaction products of ammonia and sulfur trioxide increased the cohesivity of fly ash. The uncompacted and compacted bulk porosities of conditioned ash samples were measured to indicate the degree to which the conditioning process had changed the cohesivity of the source ash. The uncompacted bulk porosity test was considered to be the most reliable indicator of changes in cohesivity. In most cases, the compacted bulk porosity values measured for the conditioned ashes did not show significant changes in ash cohesivity due to the addition of the conditioning powders. This may be due to the high degree of stress placed on the bonds between the ash particles during the compaction process involved in the measurement of compacted bulk porosity. This stress may overcome the effects of van der Waals forces, and the resulting strain may become primarily dependent on host ash particle morphology and size distribution.

\section{Conditioning Fly Ashes with ury Powders}

A variety of dry powders were evaluated as conditioning agents for modifying the cohesivity of the fly ashes. Table 4 lists these conditioning agents and some of their pertinent characteristics. Three methods were used to mix unconditioned fiy ash samples with 1 powders for the Task 3 evaluations. The three basic methods used and the most importa: results of the mixing tests are presented in the following discussions. Further details of th procedures of each method and full presentations of the mixing test results are given in various Appendices $\mathrm{H}$ through $\mathrm{N}$.

Mixing Ashes with Dry Powders in the Mixine and Conditioning Chamber. The first mixing method was used for several tests performed in the miring and conditioning chamber described in Appendix $H$. Turbulence induced by a large $\mathrm{fan}$ in the chamber was used to redisperse unconditioned ash samples. The unconditioned ash particles were exposed to various conditioning agents while suspended in the air within the chamber. At the conclusion of many of these tests, conditioned ash samples were collected from the inner walls of the chamber (wall ash). Analyses of unconditioned source hopper ashes exposed to this mixing process without 


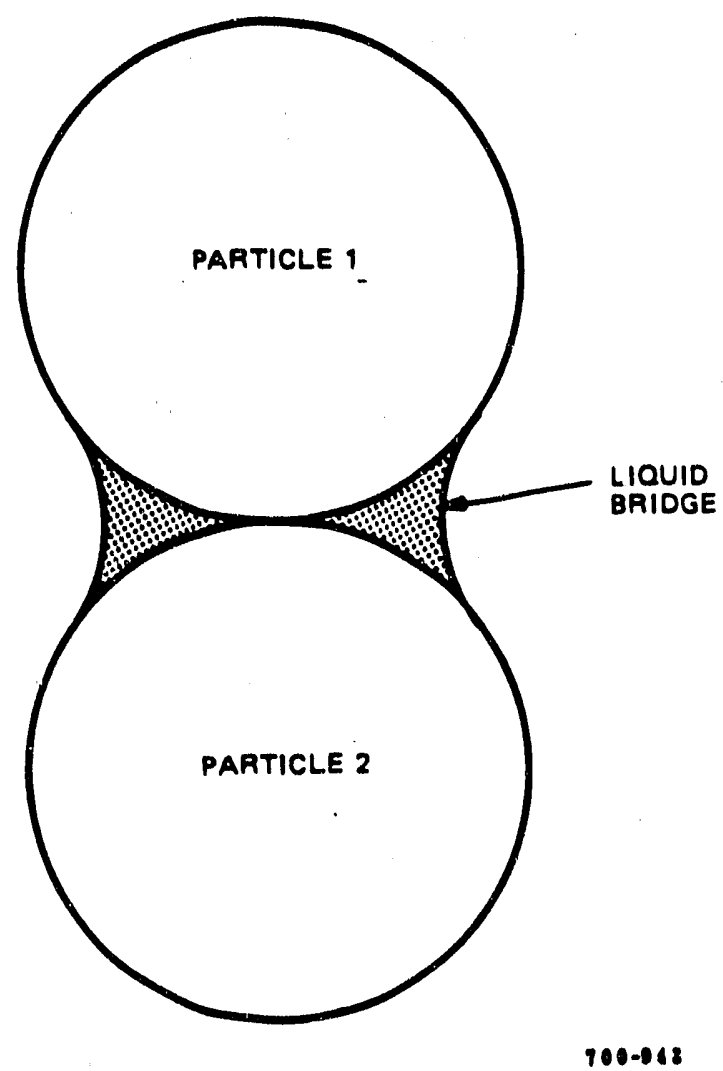

Figure 26. Schematic drawing showing the bond between two particles enhanced by the presence of a liquid bridge. 
Table 4

CHARACTERISTICS OF DRY POWDER CONDITIONING AGENTS

EVALUATED IN TASK 3

CONDITIONING AGENT

Cab-O-Sil silice L90

Cab-O-Sil silica M5

Cab-O-Sil silica EH5

AGSCO Novaculite silica

$\mathrm{NaHCO}_{3}$

High-Calcium Dolomitic Lime

Gasifier Char

Glass Fibers

Monticello hopper ash

Scholz hopper ash

AFBC hopper ash

Aluminum silicate
PRIMARY CHARACTERISTICS

$100 \mathrm{~m}^{2} / \mathrm{g}$; low bulk density; white powder; $99.8 \% \mathrm{SiO}_{2}$;

hydrophilic amorphous agcregates

$200 \mathrm{~m}^{2} / \mathrm{g}$; low bulk density; white powder; $99+\% \mathrm{SiO}_{2}$; very hydrophilic amorphous aggregates

$380 \mathrm{~m}^{2} / \mathrm{g}$; low bulk density; white powder; $99+\% \mathrm{SiO}_{2}$; extremely hydrophilic amorphous aggregates

$1.7 \mathrm{~m}^{2} / \mathrm{s} ; 4.0 \mu \mathrm{m} \mathrm{MMD} ; 99.5 \% \mathrm{SiO}_{2} ;$ well-rounded crystalline dises

$6.7 \mathrm{~m}^{2} / \mathrm{g} ;-20 \mu \mathrm{m}$ MMD; low-medium bulk density; soluble white powder

$13.0 \mathrm{~m}^{2} / \mathrm{g} ;-4-6 \mu \mathrm{m} \mathrm{MMD;}$ medium bulk density; soluble white powder; $\mathrm{Ca}(\mathrm{OH})_{2}+\mathrm{Mg}(\mathrm{OH})_{2}$

$278 \mathrm{~m}^{2} / \mathrm{g}$; low bulk density; black powder; very irregular particle shapes; high Carbon content

$<5 \mu \mathrm{m}$ diameter by $<20 \mu \mathrm{m}$ long strands of fiberglass insulation

low cobesivity ash (soe table 2)

medium cohesivity ash (see table 2)

high cohesivity ash (see table 2)

$1.4 \mathrm{~m}^{2} / \mathrm{g}$, low bulk density; white powder; irregular particle shapes 
any added conditioning agent established that this process removes the larger ash particles from the wall ash. This size classification produces wall ashes with median particle sizes that more closely approximate the particle sizes of corresponding dustcake ashes than do the source hopper ashes (table 5). The effectiveness of conditioning agents and the ability of the screening. tests to identify effective agents may depend on the size distribution of the conditioned ashes.

\section{Table 5}

MEDIAN DIAMETERS OF UNCONDITIONED ASH SAMPLES

Agh

Median Diameter ${ }^{\dagger}, \mu \mathrm{m}$

Monticello source hopper ash

52.29

Monticello dustcake ash (range)

Monticello wall ash

Scholz source hopper ash

14.15

Scholz dustcake ash (range)

$4.05-5.38$

Scholz wall ash

Terodynamic mass median diameters are presented for the source hopper ashes. Volumetric median diameters are presented for the dustcake and wall ashes.

Many of the conditioning tests performed in the mixing and conditioning chamber were designed to mix resuspended Monticello fly ash together with resuspended Scholz fly ash in various ratios. Laboratory analyses were performed to determine if the cohesivity of either of the two types of fly ash was significantly modified by a relatively small addition of the other ash. Although the cohesivities of the two fly ashes tested were modified by the addition of specific amounts of the other ash (figure 27), the amounts of additive ash required to significantly modify the host ash cohesivity are probably too large to warrant full-scale application of this type of ash conditioning.

A second group of tests performed in the mixing and conditioning chamber was intended to deposit the fine silica powder Cab-O-Sil M5 on the surfaces of the source hopper asbes. These test were performed at $300^{\circ} \mathrm{F}$, with a $0.2 \%$ weight/weight ratio of silica to hopper ash, and the mixed product was collected on the inner walls of the mixing and conditioning chamber. Using this mixing method, the addition of the Cab-O-Sil M5 silica to the Scholz hopper ash apparently caused only a minor decrease in the uncompacted buik porosity of the wall ash (from 78.1\% to $76.4 \%$ ). The addition of the silica to the hopper ash increased the uncompacted bulk porosity of the Monticello wall ash from $66.3 \%$ to $69.6 \%$. The apparent ability of the fine silica to increase the cohesivity of the Monticello ash in these screening tests led to several of the proof-of-concept filtration tests performed under Task 4.

Mixing Ashes with Dry Powders in a Blender. To allow mixing tests to be performed more rapidly, and to eliminate the uncertainty of collection of consistent ash samples from the inner wall of the mixing and conditioning chamber, an alternative mixing method was developed. This method was used for a large number of the evaluations of dry powders as conditioning agents. The basic procedure for this method consisted of combining $400 \mathrm{~g}$ of source ash with the desired anrount of additive powder (usually between 0.02 and $8.0 \mathrm{~g}$ ) in a 1-quart jar. This mixture was then hand shaken for approximately 3 minutes, and then blended at medium speed in a Waring blendor ${ }^{\mathrm{TM}}$ for 3 additional minutes.

The various additive products tried in tisese tests were intended to physically alter the contact points between the host hopper ash particles to change the bulk cohesivity of the ash. Altered cohesivity would then be reflected in changes in the uncompacted bulk porosities of the 


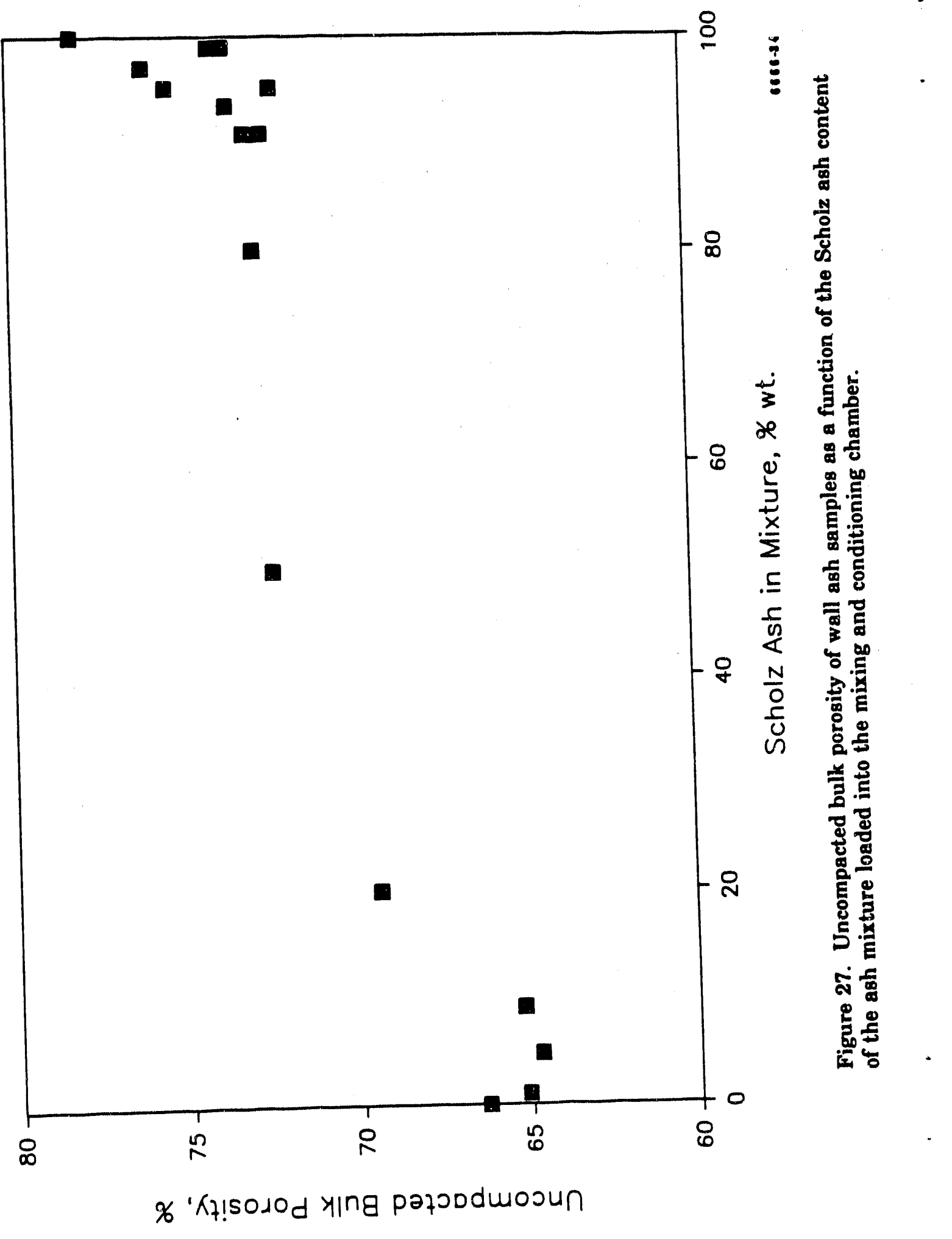


conditioned ash. One inherent limitation of conditioning evaluations performed on hopper ash samples is the difference in the size distribution of the hopper ashes and the size distributions of the dustcake ashes that are derived from them. It is possible that the effectiveness or ineffectiveness of a particular combination of conditioning agent and hopper ash may be due to the presence of the large particles in the hopper ash. Consequently, not all of the results of these conditioning evaluations may carry over to the proof-of-concept filtration testing.

Many different combinations of hopper ash and additive were produced in this set of screening tests. Monticello and Scholz hopper ashes were combined with Cab-O-Sil M5, EH5, and L90, sodium bicarbonate, chemical hydrated lime, gasifier char, glass beads, glass fibers, and Novaculite (silica powder approximately $4 \mu \mathrm{m}$ mean diameter). Selections of data from these tests are shown graphically in figures 28 and 29 . The mixture ratios and the compacted and uncompacted bulk porosities for the various mixtures produced are presented in Appendix M.

None of the additives blended with the Scholz ash appeared to have a significant effect on the ash cohesivity. Several additives apparently decreased the cohesivity of the Monticello ash (figure 28). These additives were the three Cab-0-Sil fine silica powders, the chemical hydrated lime, and the gasifier char. We believe the mechanism responsible for the decrease in cohesivity of the Monticello ash when mixed with these additives is the reduction in van der Waals forces due to an increase in the particle separation distance. The Monticello ash particles basically resemble smooth spheres. The smaller Monticello ash particles, for which van der Waals forces definitely predominate, even more closely resemble smooth spheres than do the larger particles. When small additive particles are mixed with the host ash particles, they become deposited on the surfaces of these particles, preventing close interparticle contact. In the case of the Scholz ash, however, the surfaces of the host ash particles are relatively rough. In this application the relatively small additive particles present on conditioned Scholz ash particles are unable to increase the particle separation distance. Instead, they become effectively obscured among the irregular asperities already present on the surfaces of the Scholz ash particles.

The results of the uncompacted bulk porosity tests of the Monticello ash conditioned with sodium bicarbonate indicate that an increase in cohesivity may have been induced. The uncompacted bulk porosity tests indicate that the optimum concentration of sodium bicarbonate is approximately $1.0 \%$ by weight. These results led to proof-of-concept filtration testing under Task 4.

Mixing Ashes with Dry Powders by Manual_Shaking. Results of the blender mixing method indicated that agitating the hopper ashes without any additives lowered the bulk porosity of the hopper ashes. We are not sure what mechanism was responsible for this effect. Therefore a less energetic mixing method was developed for combining powdered conditioning agents with the ash samples. This method consists of placing the desired proportion of each component in a jar and shaking the mixture by hand.

Table 6 presents the most significant results of these tests. In these evaluations, sodium bicarbonate did not produce a significant change in the cohesivity of the Monticello ash. The EH5 silica, however, did have a beneficial effect (increased porosity) on the Monticello and Scholz ashes. These results led to proof-of-concept testing under Task 4, discussed later in this report. Inability of the EH5 silica or the aluminum silicate to induce any significant increase in the porosity of the AFBC ash was probably due to the irregular shapes of the AFBC ash particles. Small amounts of the aluminum silicate were able to increase the cohesivity of the Monticello ash (as indicated by increased values of uncompacted bulk porosity). The data indicated that proof-of-concept testing of the aluminum silicate material would probably be worthwhile. (Results of FFSS testing of the aluminum silicate are discussed under Task 4.)

Characteristics of Aluminum Silicate. To obtain a general description of the aluminum silicate, several basic laboratory tests were performed. Figure 30 presents SEM photographs of the aluminum silicate at four magnifications. The aluminum silicate has a specific surface area of $1.4 \mathrm{~m} 2 / \mathrm{g}$, a drag-equivalent diameter of $0.9 \mu \mathrm{m}$, an uncompacted bulk porosity of $95 \%$, 


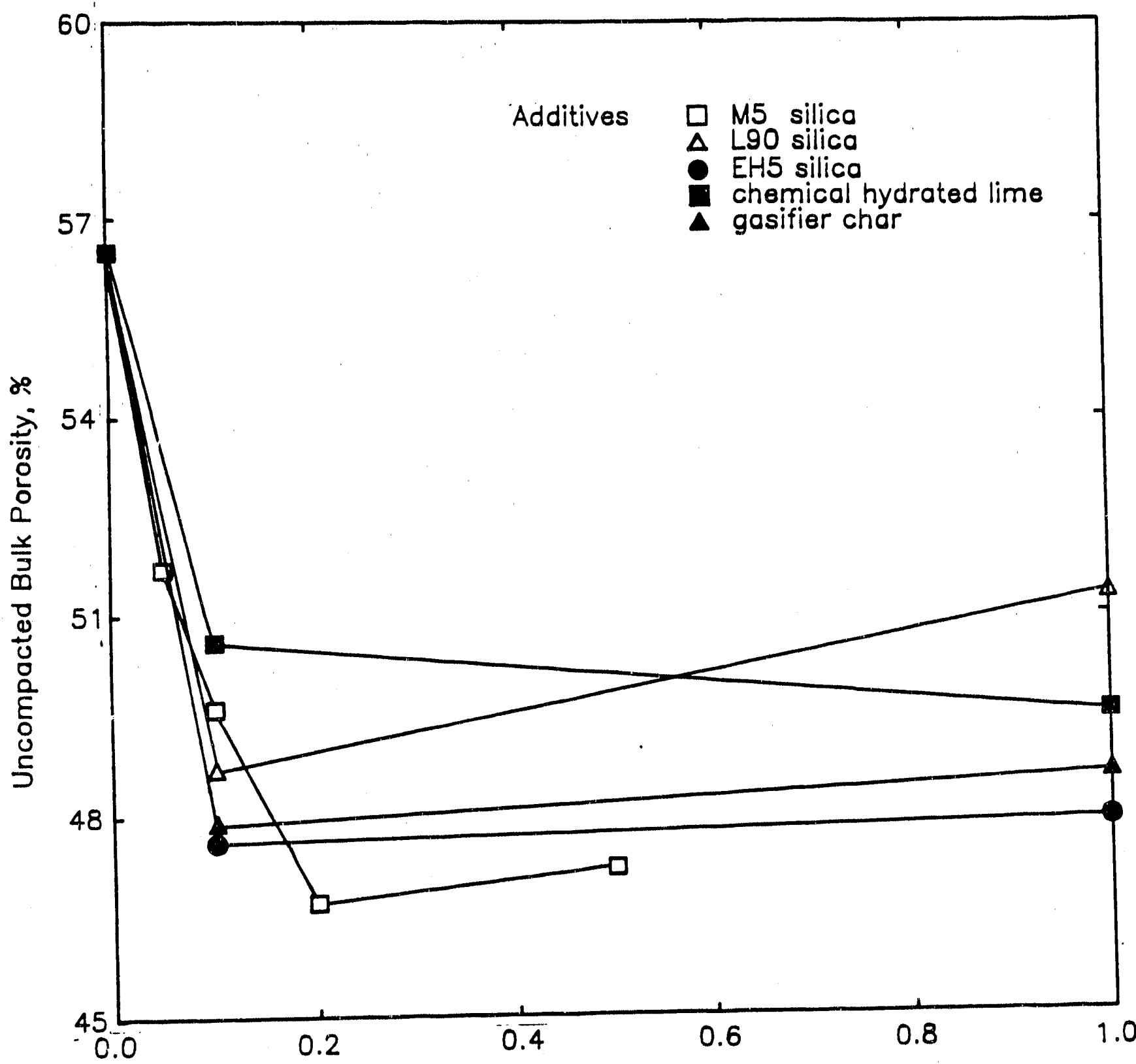

Additive in mixture, $\%$ wt.

Figure 28. Results of uncompacted bulk porosity measurements of mixtures produced in the Waring blendor ${ }^{\mathrm{TM}}$ of Monticello ash and selected conditioning agents. 


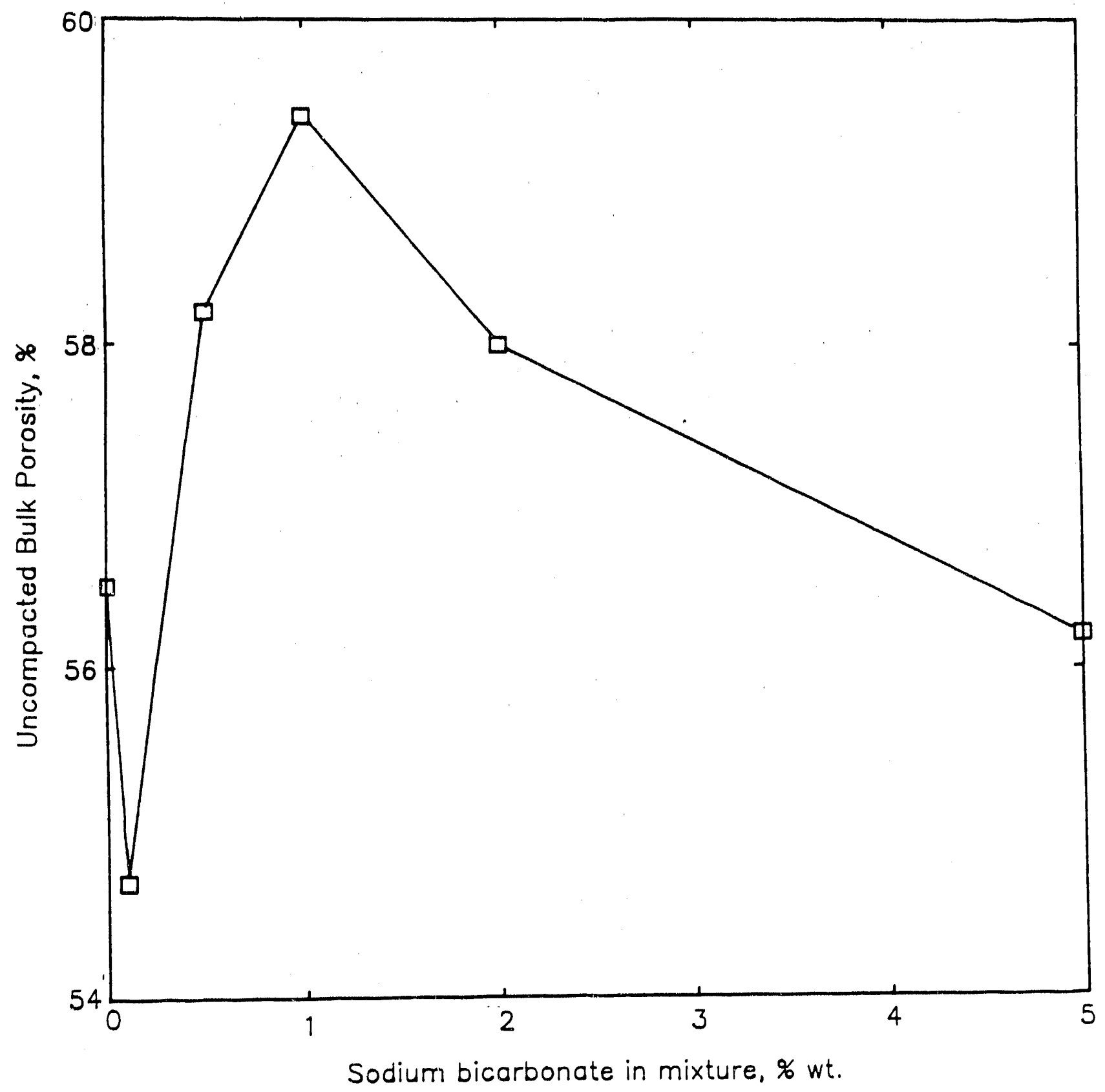

6666.88

Figure 29. Results of uncompacted bulk porosity measurements of mixtures produced in the Waring blendor ${ }^{T M}$ of Monticello ash and sodium bicarbonate. 
Table 6

SELECTED ANALYSES OF HAND-SHAKEN MIXTURES $†$

\begin{tabular}{|c|c|c|c|}
\hline Base ash & Additive & $\begin{array}{l}\text { \% wt. additive } \\
\text { in mixture }\end{array}$ & $\begin{array}{l}\text { uncompacted } \\
\text { bulk porosity, \% }\end{array}$ \\
\hline $\begin{array}{l}\text { Monticello } \\
\text { Monticello } \\
\text { Monticello } \\
\text { Monticello } \\
\text { Monticello }\end{array}$ & $\begin{array}{l}\text { sodium bicarbonate } \\
\text { sodium bicarbonate } \\
\text { sodium bicarbonate } \\
\text { sodium bicarbonate } \\
\text { sodium bicarbonate }\end{array}$ & $\begin{array}{l}0 \\
0.5 \\
1 \\
2 \\
5\end{array}$ & $\begin{array}{l}51.4 \\
50.2 \\
51.0 \\
50.9 \\
51.2\end{array}$ \\
\hline $\begin{array}{l}\text { Monticello } \\
\text { Monticello } \\
\text { Monticello } \\
\text { Monticello } \\
\text { Monticello } \\
\text { Monticello }\end{array}$ & $\begin{array}{l}\text { EH5 silica } \\
\text { EH5 silica } \\
\text { EH5 silica } \\
\text { EH5 silica } \\
\text { EH5 silica } \\
\text { EH5 silica }\end{array}$ & $\begin{array}{l}0 \\
0.05 \\
0.1 \\
0.2 \\
0.5 \\
1\end{array}$ & $\begin{array}{l}51.4 \\
48.0 \\
47.4 \\
47.4 \\
50.2 \\
54.5\end{array}$ \\
\hline $\begin{array}{l}\text { Monticello } \\
\text { Monticello } \\
\text { Monticello } \\
\text { Monticello }\end{array}$ & $\begin{array}{l}\text { aluminum silicate } \\
\text { aluminum silicate } \\
\text { aluminum silicate } \\
\text { aluminum silicate }\end{array}$ & $\begin{array}{l}0 \\
0.1 \\
0.5 \\
1.0\end{array}$ & $\begin{array}{l}51.4 \\
55.7 \\
55.1 \\
56.6\end{array}$ \\
\hline $\begin{array}{l}\text { Scholz } \\
\text { Scholz } \\
\text { Scholz } \\
\text { Scholz } \\
\text { Scholx }\end{array}$ & $\begin{array}{l}\text { EH5 silica } \\
\text { EH5 silica } \\
\text { EH5 silica } \\
\text { EH5 silica } \\
\text { EH5 silica }\end{array}$ & $\begin{array}{l}0 \\
0.1 \\
0.2 \\
0.5 \\
1\end{array}$ & $\begin{array}{l}75.2 \\
76.7 \\
77.0 \\
77.0 \\
79.1\end{array}$ \\
\hline
\end{tabular}

tComplete results of these tests are presented in Appendix 0. 


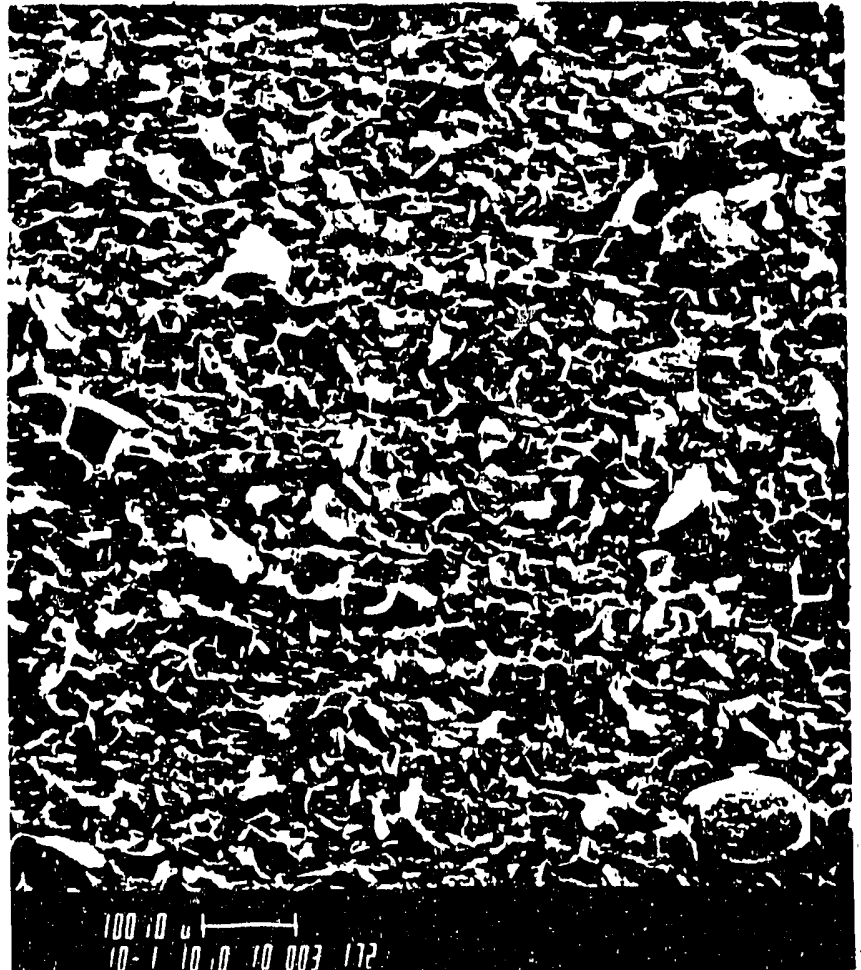

(a)

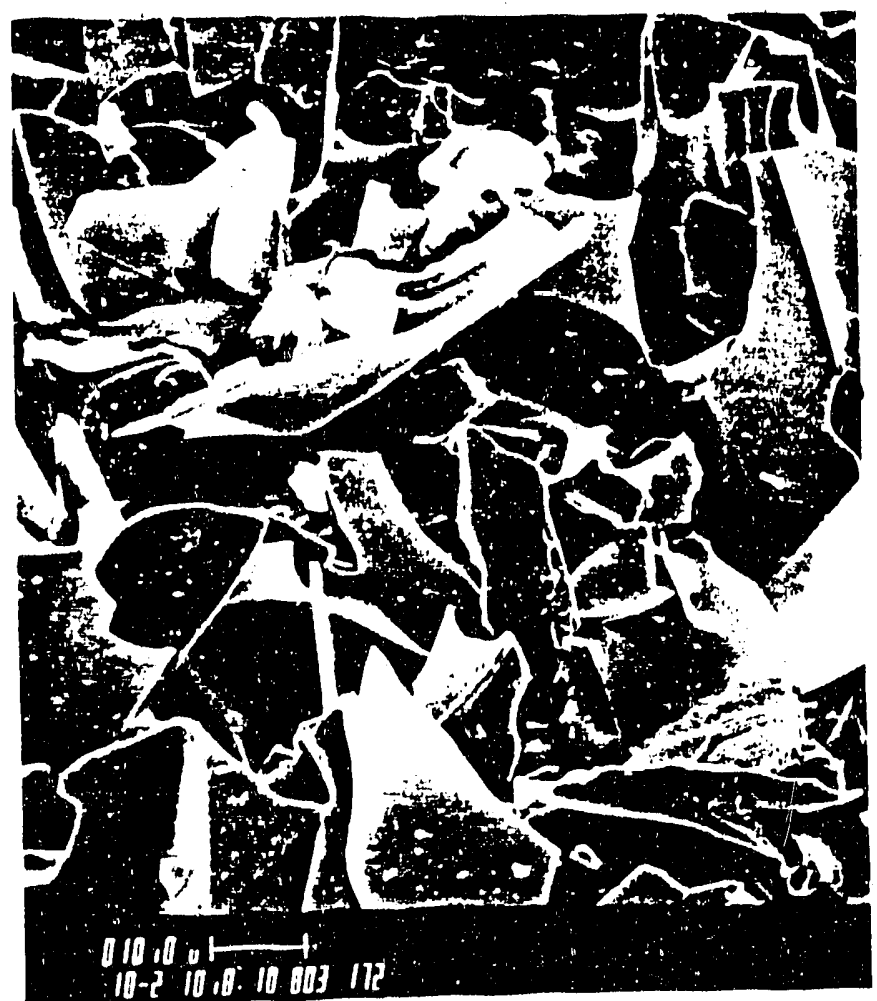

(c)

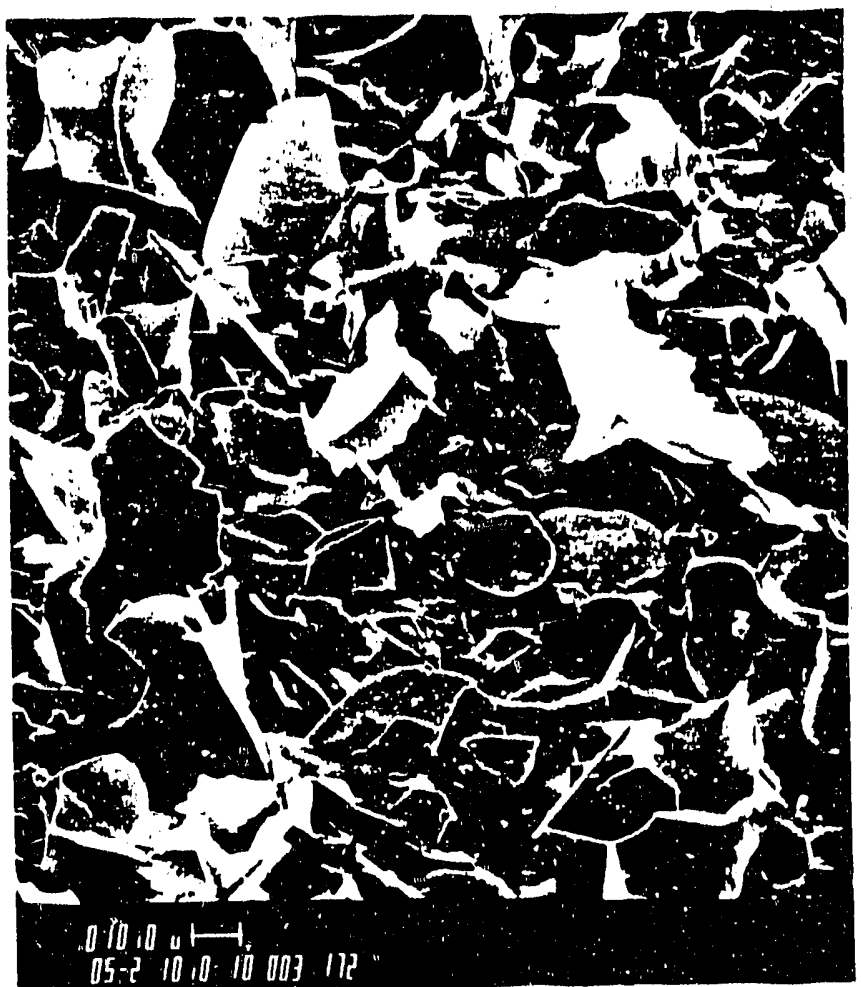

(b)

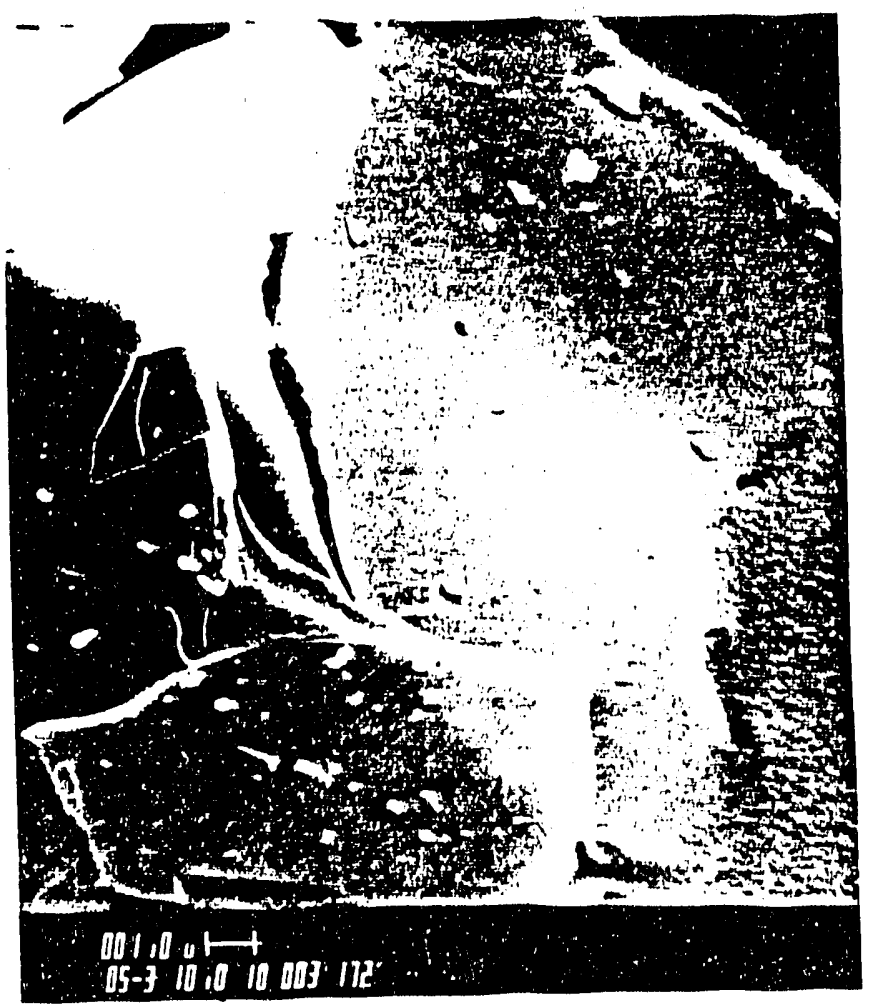

(d)

$6666-41$

Figure 30. SEM photographs of the aluminum silicate powder taken at a) $100 \mathrm{x}$ b) $500 \times \mathrm{c}$ ) $1000 \mathrm{x}$ and d) $5000 x$. 
and a relative gas flow resistance of $1.7 \mathrm{in} \mathrm{H}_{2} \mathrm{O} \mathrm{min} \mathrm{ft} / \mathrm{b}$. The low relative gas flow resistance of this material suggests its viability as a precoat material to reduce $S_{\theta}$. (Testa of the aluminum silicate as a precoat are discussed under Task 4.)

\section{Investigation of Ammonia/Sulfur Trioxide Reactions}

Laboratory tests were performed to form fine particulate aerosols of ammonium sulfate $\left(\left(\mathrm{NH}_{4}\right)_{2} \mathrm{SO}_{4}\right)$ and ammonium bisulfate $\left(\mathrm{NH}_{4} \mathrm{HSO}_{4}\right)$ in a temperature-controlled environment for subsequent collection and analysis. The objectives of these tests were to determine if these compounds could be produced consistently in the form of a fine aerosol and to establish the techniques necessary for this production. The compounds were analyzed to determine their physical and chemical characteristics.

Five separate laboratory tests were performed with the apparatus pictured in figures 31 and 32 . For each of these tests, gaseous sulfur trioxide was produced from temperature-controlled fuming sulfuric acid with the device shown in figure 31. Gaseous ammonia was obtained from a commercially-obtained tank. The injection systems for the sulfur trioxide and the ammonia were calibrated so that desired stoichiometric ratios of $\mathrm{NH}_{3}$ to $\mathrm{SO}_{3}$ could be set. Each test was carried out at $300^{\circ} \mathrm{F}$. In each test, the two gases were introduced into the chamber shown in figure 32, and a particulate fume was produced. This product was then collected on a glass fiber filter. The tests were concluded by purging the chamber, cooling the filter assembly, and removing the filter for analysis.

The filters used in the five tests were submitted for wet chemistry measurements of the concentrations of soluble $\mathrm{SO}_{4}=$ and soluble $\mathrm{NH}_{3}$, and for SEM photographs of the collected ammonium sulfate compounds. The results of these chemical analyses are presented in table 7, along with information describing the conditions for each of the tests. SEM photographs of the product collected on the filter in tests $1,2,4$, and 5 are shown at two magnifications in figures 33 and 34 . (Test 3 produced a product essentially identical in appearance to that produced in test 5.)

Table 7

TEST RESULTS OF GAS-PHASE REACTIONS BETWEEN $\mathrm{SO}_{3}$ AND NH3

\begin{tabular}{clcc} 
Test \# & $\begin{array}{c}\text { Purge air } \\
\text { condition }\end{array}$ & $\begin{array}{c}\text { Target Ratio } \\
\mathrm{NH}_{3}: \mathrm{SO}_{3}\end{array}$ & $\begin{array}{c}\text { Measured Ratio } \\
\mathrm{NH}_{3}: \mathrm{SO}_{3}\end{array}$ \\
\hline 1 & moist & $1: 1$ & 0.88 \\
2 & moist & $2: 1$ & 1.31 \\
3 & dry & $2: 1$ & 1.54 \\
4 & dry & $1: 1$ & 1.03 \\
5 & dry & $4: 1$ & 1.96 \\
\hline
\end{tabular}

Two different compounds were formed as a function of the molar ratios of $\mathrm{NH}_{3}$ and $\mathrm{SO}_{3}$. The effect of humidity on the structure of the compounds is apparent in the photographs in figures $33(\mathrm{a}), 33(\mathrm{~b}), 34(\mathrm{a})$, and $34(\mathrm{~b})$. The ammonium bisulfate product has a melting point of about $293^{\circ} \mathrm{F}$. The bisulfate product was formed and deposited on the filter at a temperature of $300^{\circ} \mathrm{F}$, so the spheres seen as the product of test 4 are the result of collection of liquid droplets. Ammoniuin sulfate is expected to be a solid particle which, when formed by a gas-phase reaction as in the case of tests 3 and 5 , has a mean equivalent diameter of $1-3 \mu \mathrm{m}$ (12). The products of tests 3 and 5 are not discrete particles, though the dimensions of the components of the structures seen in figures 33(d) and 34(d) are the order of magnitude expected. It is possible 


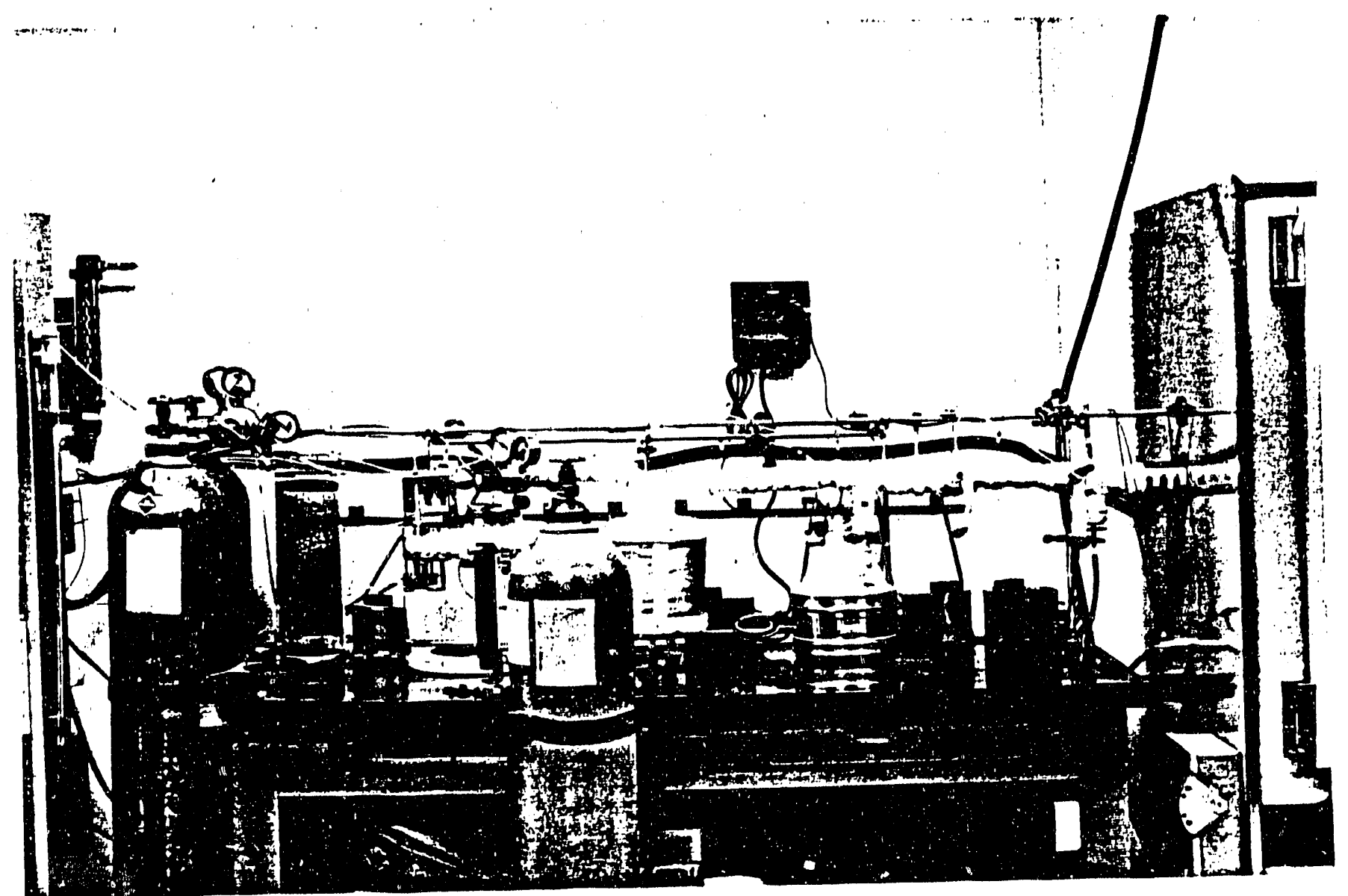

0660.14

Figure 31. System used for generating gaseous $\mathrm{SO}_{3}$ from temperature-controlled fuming sulfuric acid. 


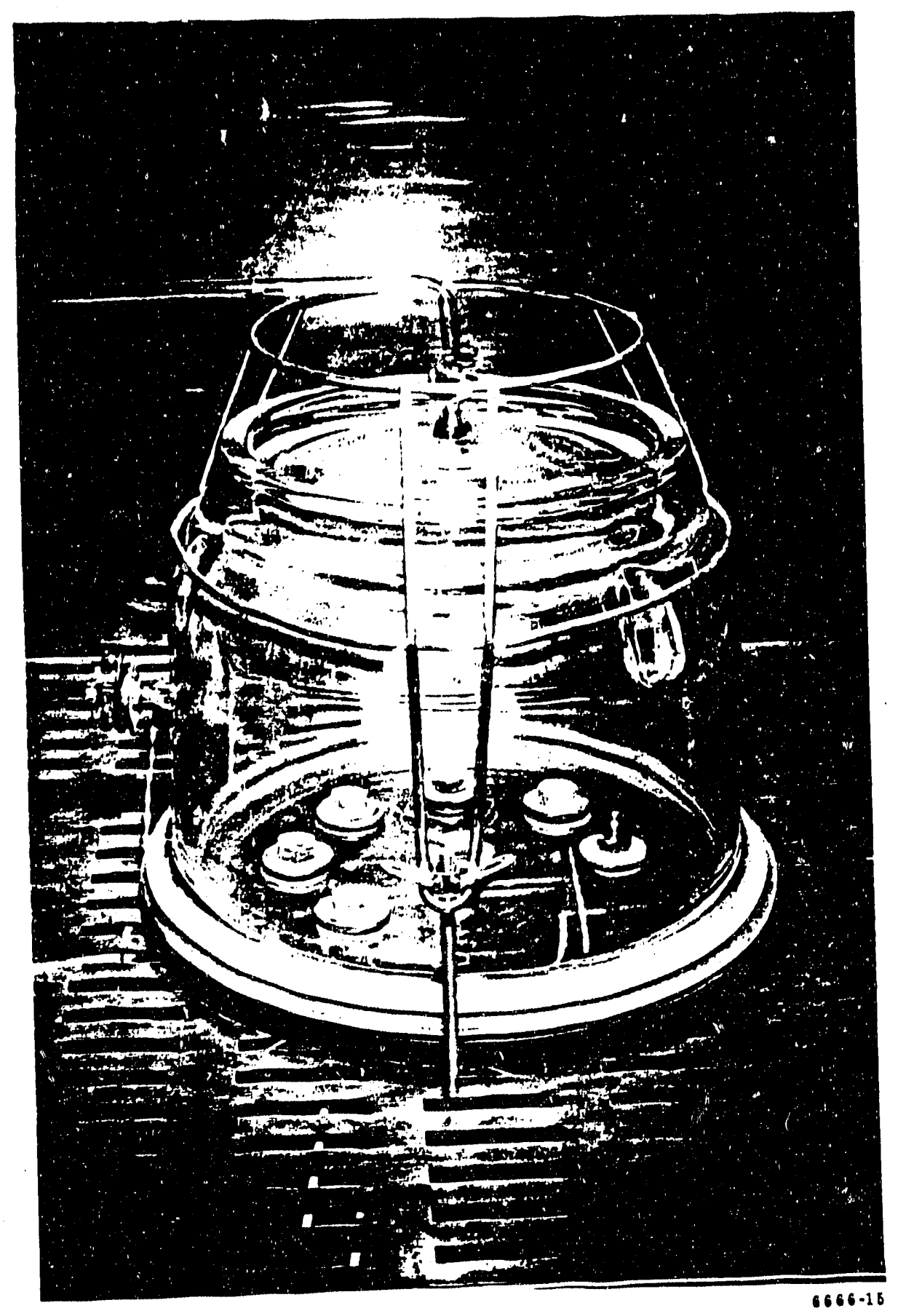

Figure 32. Chamber for mixing gaseous $\mathrm{SO}_{3}$ and $\mathrm{NH}_{3}$. 


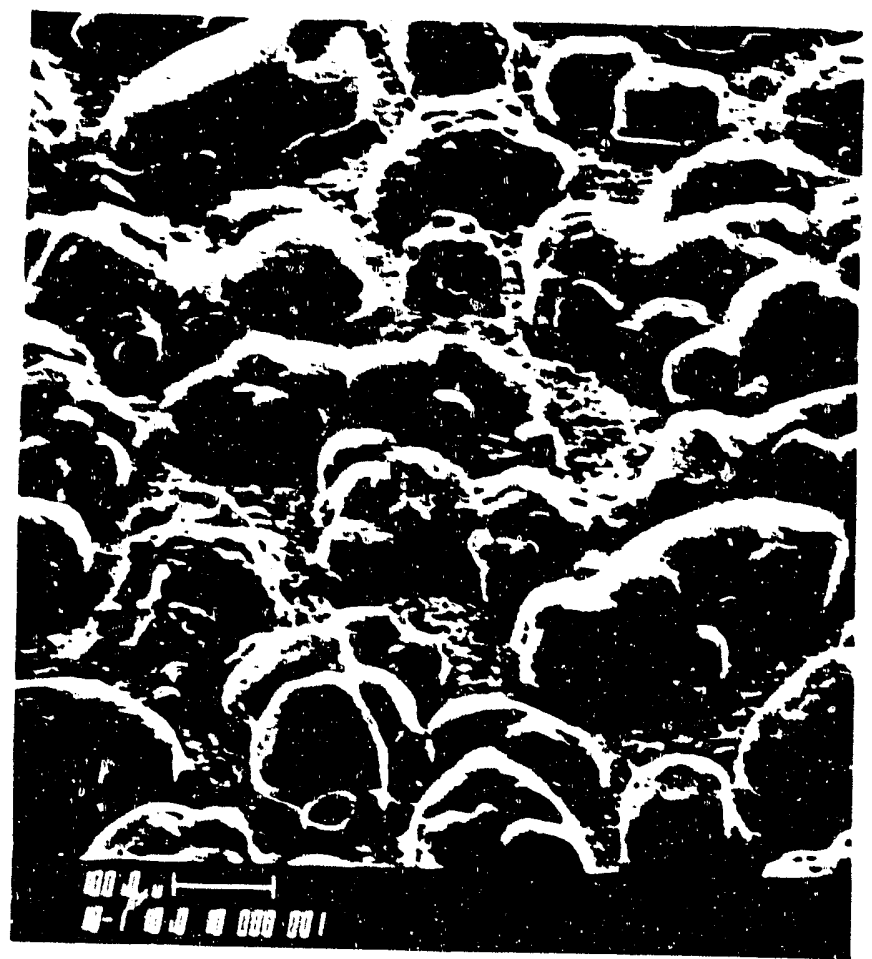

(a)

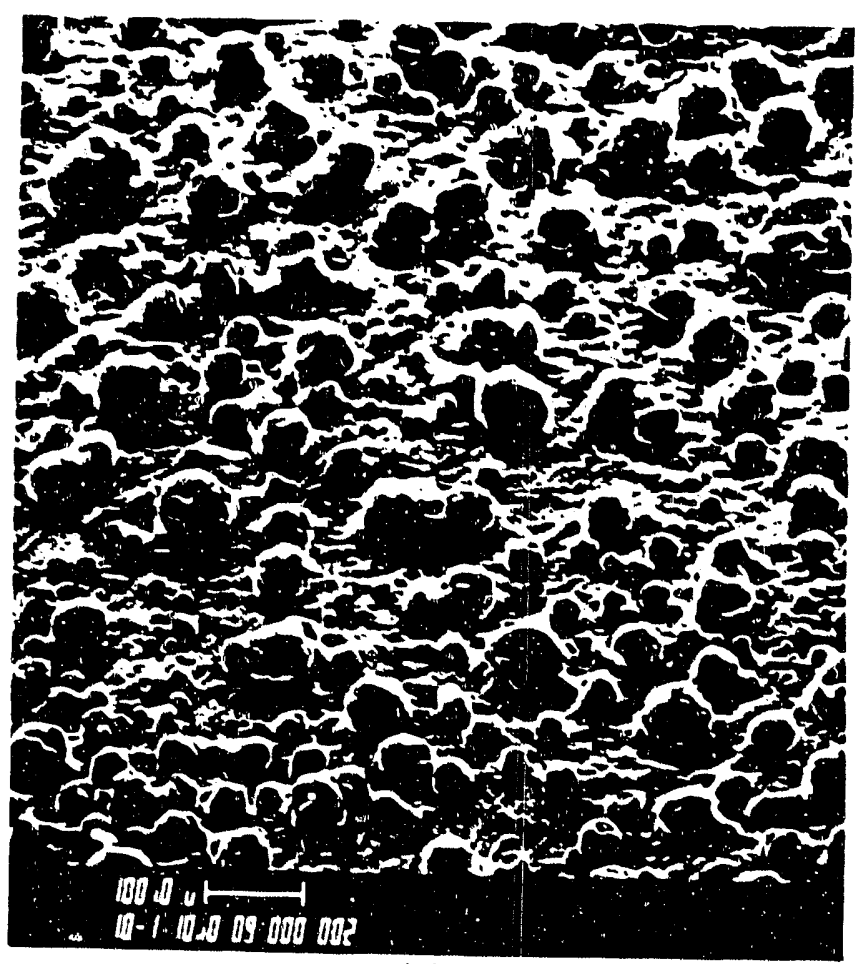

(b)

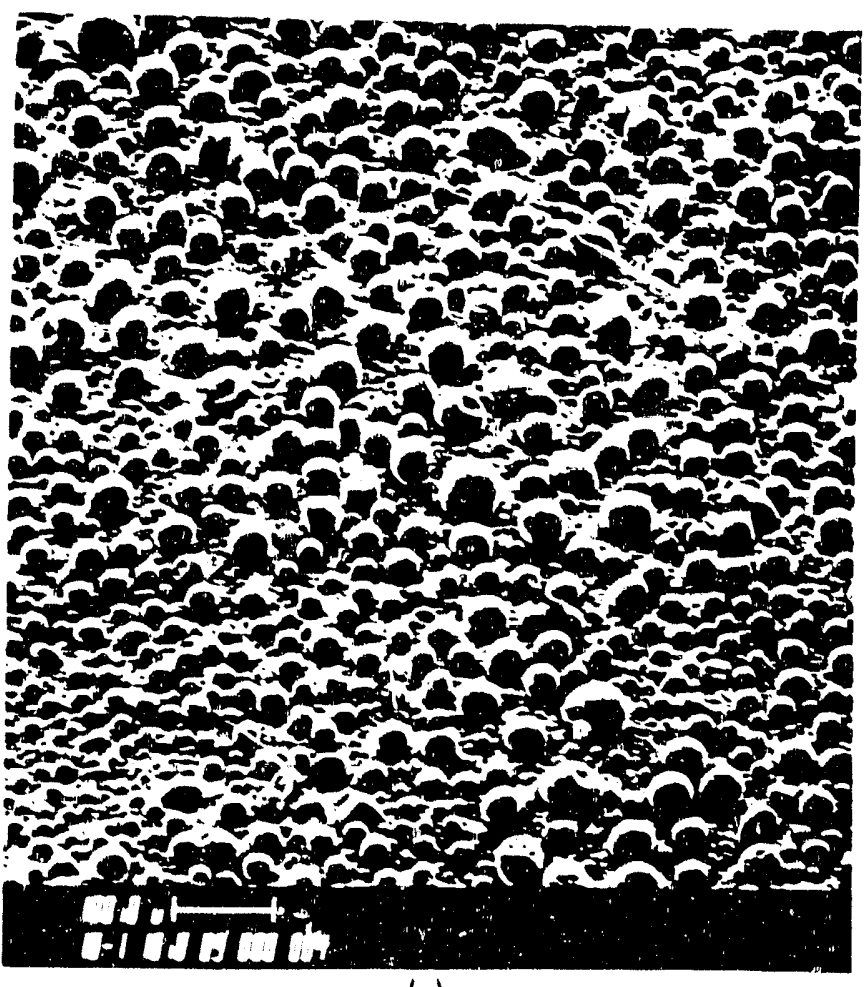

(c)

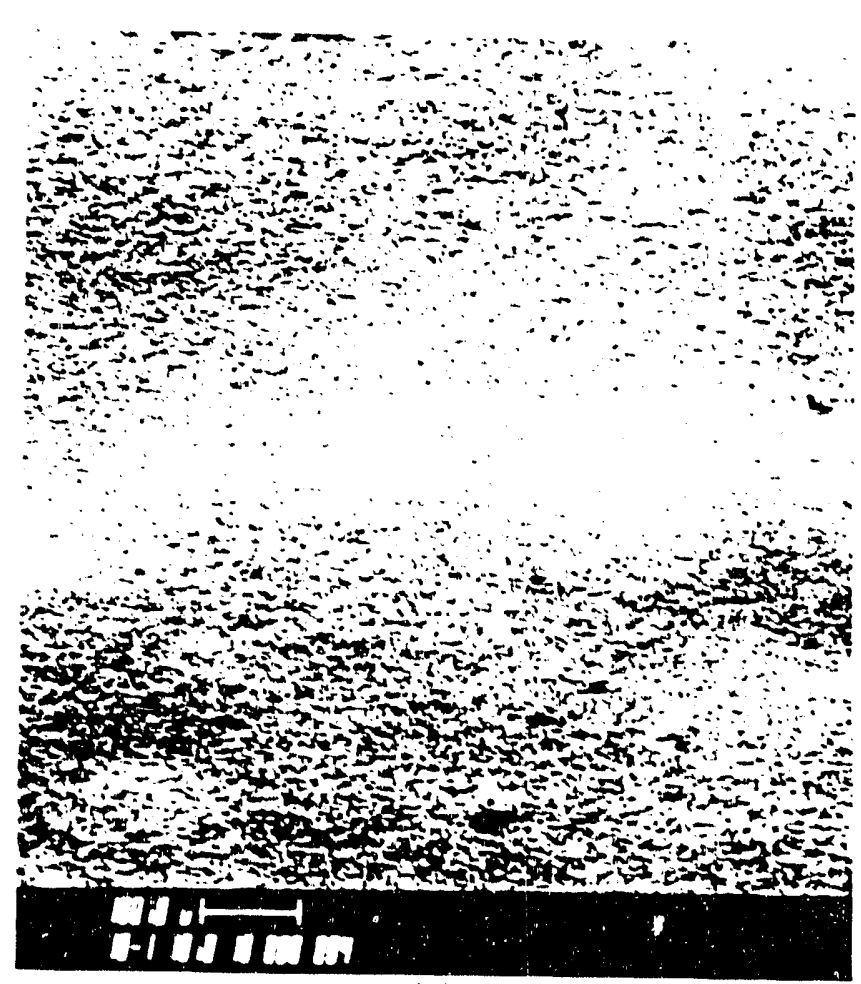

(d)

$6666 \cdot 6$

Figure 33. SEM photographs taken at a magnification of $100 x$ of reaction products of tests a) 1, b) 2 , c) 4 , d) 5 . 


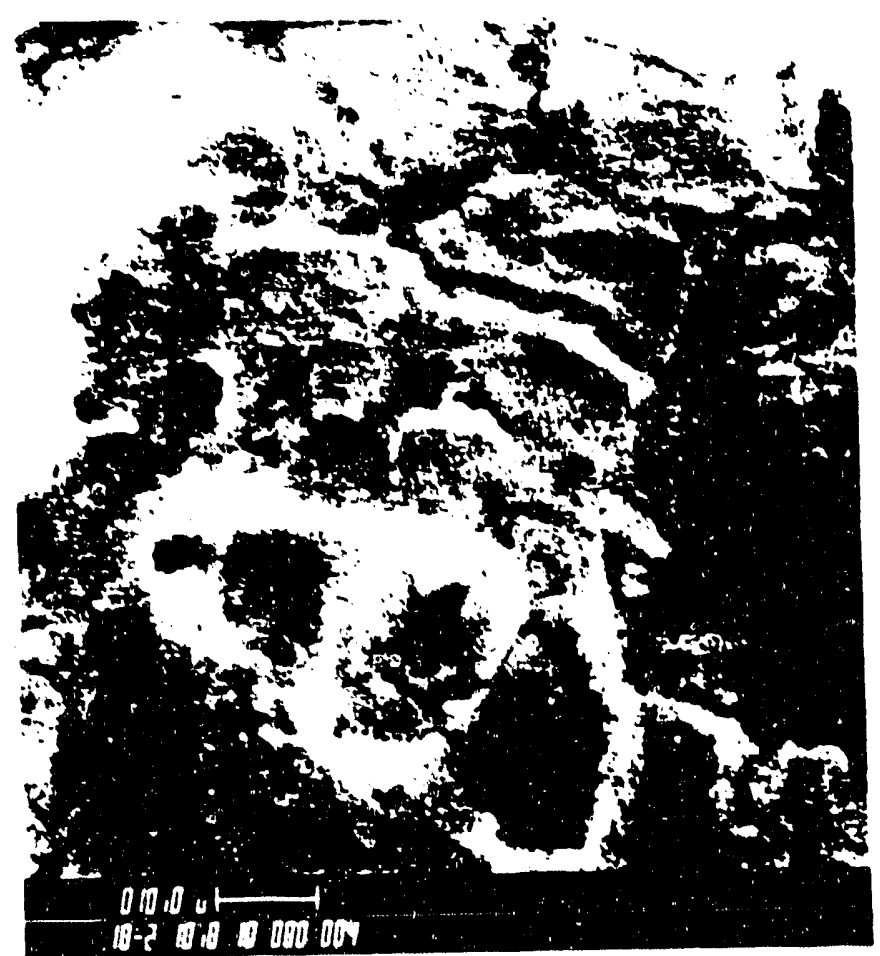

(a)

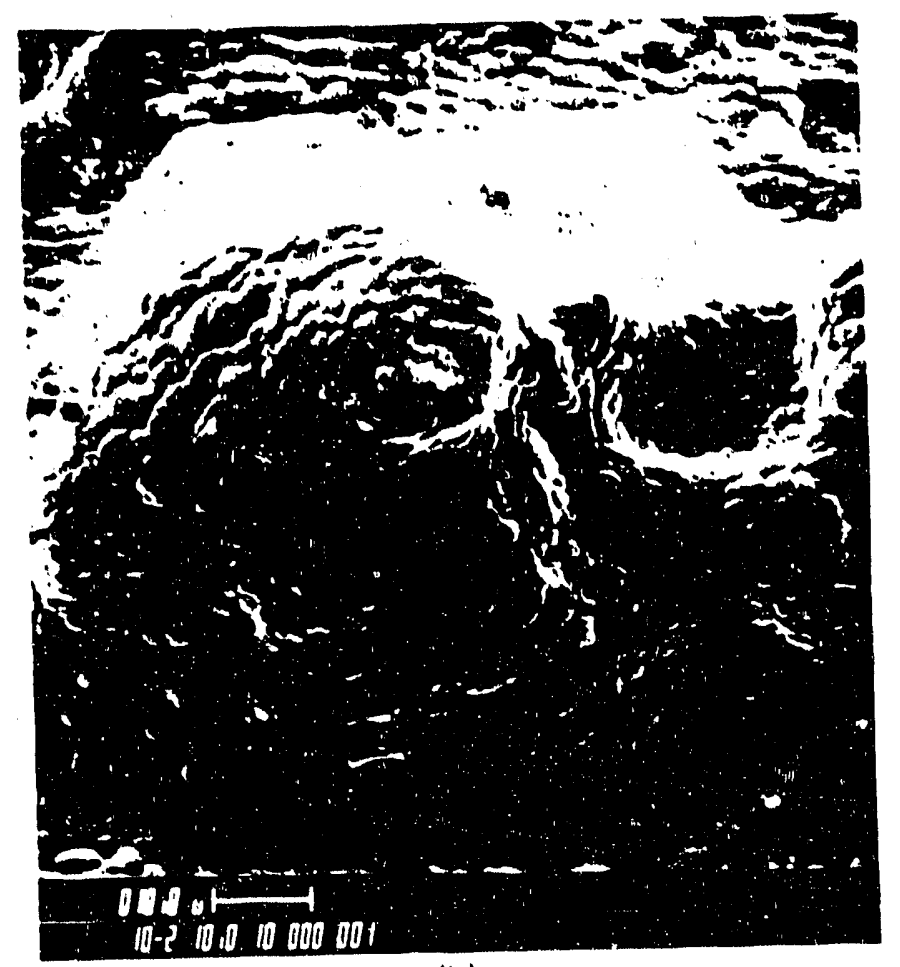

(b)

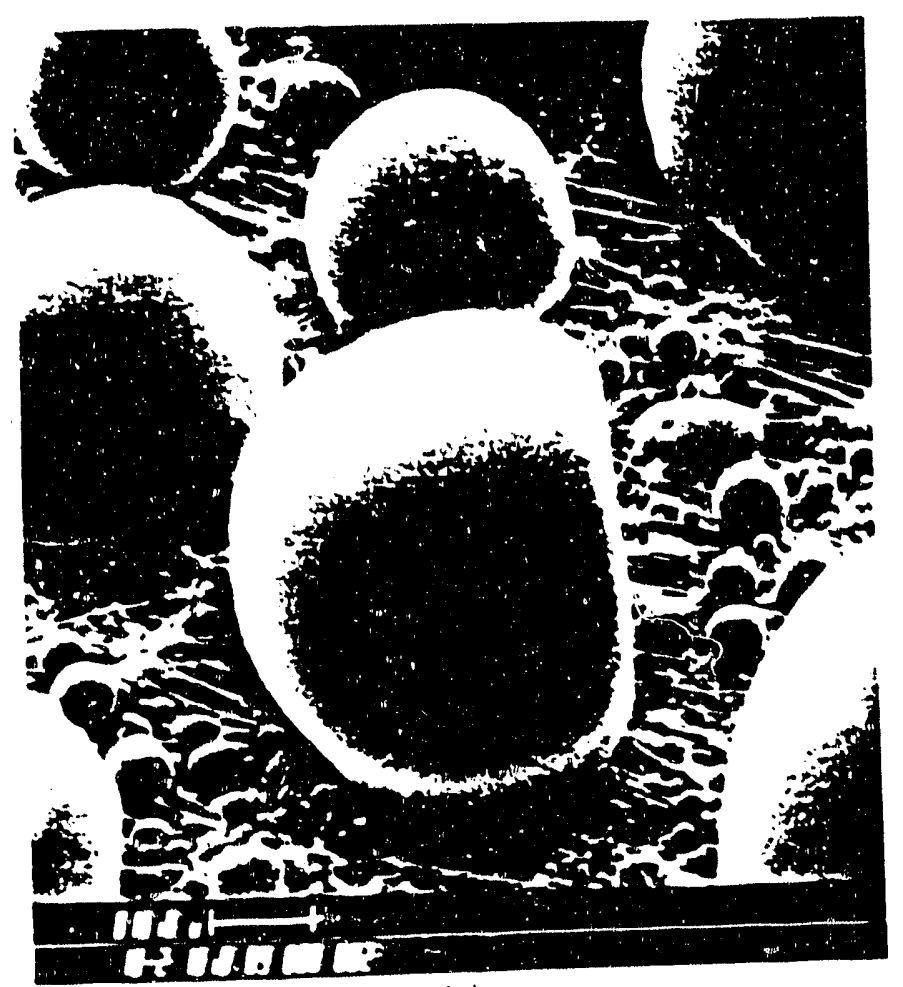

(c)

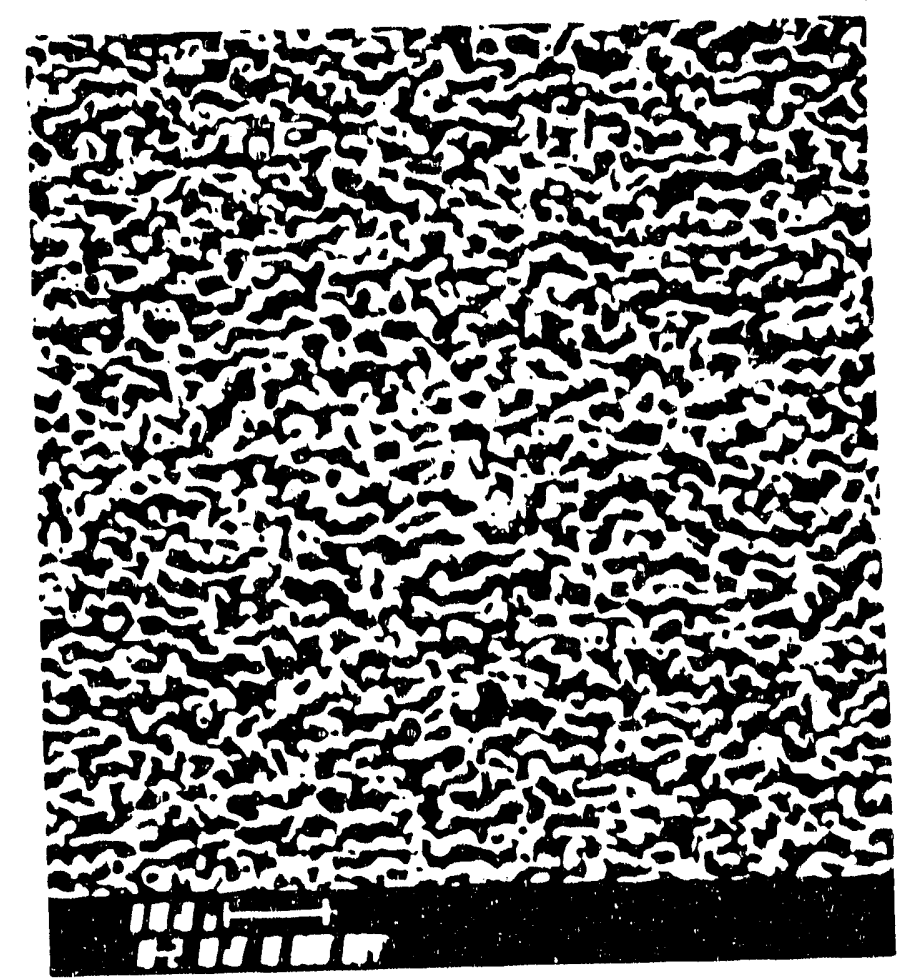

(d)

$6666 \cdot 2$

Figire 34 SEM photographs taken at a magnification of 1000 of reaction products of tests a) $1, b) 2$, c) 4 , d) 5 . 
that the agflomerated structure of the deposited ammonium sulfate is due to a time-dependent reaction in the test apparatus that precluded the complete formation of the ammonium sulfate product before it was collected on the filter. The reaction to yield ammonium sulfate procoeds in two atopa:

$$
\begin{aligned}
& \mathrm{NH}_{8}(\mathrm{~g})+\mathrm{SO}_{3}(\mathrm{~g})+\mathrm{H}_{2} \mathrm{O} \rightarrow \mathrm{NH}_{4} \mathrm{HSO}_{4}(\mathrm{l}, \mathrm{s}) \\
& \mathrm{NH}_{4} \mathrm{HSO}_{4}(\mathrm{l}, \mathrm{s})+\mathrm{NH}_{3} \rightarrow\left(\mathrm{NH}_{4}\right)_{2} \mathrm{SO}_{4}(\mathrm{~g})
\end{aligned}
$$

The first reaction produces the bisulfate that is a liquid above $293^{\circ} \mathrm{F}$. The bisulfate will tend to continue to react with available ammonia to form the stable ammonium sulfate, which is a solid up to $437^{\circ} \mathrm{F}$. The data in table 7 show that, at the injected molar ratio of $2: 1 \mathrm{NH}_{3}$ to $\mathrm{SO}_{3}$, the product had a measured molar ratio of 1.3:1. This result may indicate incomplete reaction of the intermediate bisulfate with the ammonia. The amorphous-looking product from test 5 may result from deposition of ammonium bisulfate on the filter, instead of a completely reacted ammonium sulfate particulate, whereon further reaction with ammonia gas is occurring. The appearances of the products of $\mathrm{NH}_{3}$ and $\mathrm{SO}_{3}$ were apparently affected by the moisture content of the air used to purge the system and possibly by the residence time available for the reactions to occur.

Figure 35 presents a phase diagram which describes the effects that temperature and stoichiometric ratios have on the types and phases of reactants producsd from the combination of sulfur trioxide and ammonia at 1 atm pressure. This diagram is based on the work of Margulis et al (13) and illustrates that differing compounds of various phases can be created from the combination of these two reactants.

The phase diagram shows three different solid compounds: $1: 1$ or $\mathrm{NH}_{4} \mathrm{HSO}_{4}$ (ammonium bisulfate), 2:1 or $\left(\mathrm{NH}_{4}\right)_{2} \mathrm{SO}_{4}$ (ordinary emmonium aulfate), and 3:2 or $\left(\mathrm{NH}_{4}\right)_{3} \mathrm{H}\left(\mathrm{SO}_{4}\right)_{2}$ (known as letovicite). The 3:2 compound has two different crystalline modifications: alpha, which is stable below $140^{\circ} \mathrm{C}$, and beta, which is stable above $140^{\circ} \mathrm{C}$. The effect of temperature on equilibrium in the system is strongly dependent upon composition. Complete liquifaction occurs as low as $110^{\circ} \mathrm{C}$ if the mole ratio of $\mathrm{NH}_{3}: \mathrm{H}_{2} \mathrm{SO}_{4}$ is between 1.1 and 1.0 , but only above $360^{\circ} \mathrm{C}$ if the mole ratio is abuve 1.2 . Only the $1: 1$ compound melts congruently; ite melting point is between $140^{\circ} \mathrm{C}$ and $150^{\circ} \mathrm{C}$. (In congruent melting the product of melting has the same composition as the solid.) The $3: 2$ compound melts incongruently near $225^{\circ} \mathrm{C}$, producing the $2: 1$ solid and a liquid such as the 1:1 compound. Shifting composition toward a higher mole ratio at a fixed temperature converts liquid material to liquid-plus-solid and then solid alone. At $100^{\circ} \mathrm{C}$, for example, beginning at the ratio $\mathrm{NH}_{3}: \mathrm{H}_{2} \mathrm{SO}_{4}=\mathrm{O}$ (i.e. pure sulfuric acid), adding $\mathrm{NH}_{3}$ first produces the solid $1: 1$ compound, then the solid $3: 2$, and finally the solid $2: 1$.

A second group of tests were performed to determine the effect of ammonia plus sulfur trioxide conditioning on Monticello ash. In this test Monticello ash was exposed to $40 \mathrm{ppm}$ sulfur trioxide in the mixing chamber and then exposed to ammonia gas with a $>2: 1 \mathrm{NH}_{3}: \mathrm{SO}_{3}$ stoichiometry. The details for the test procedures for this experiment are presented in Appendix $P$. The uncompacted bulk porosity of the Monticello ash increased from $66.3 \%$ to $73.3 \%$ because of the $\mathrm{NH}_{3}$ reaction with $\mathrm{SO}_{3}$ on the particles. This increase in porosity translates to a decrease in flow resistance by a factor of two (see figure 36). Exposing ash to preformed ammonium sulfate was less effective for increasing porosity (also shown in figure 36). This result, along with data from field tests and in light of the literature review, suggests that the mechanism by which ammonia gas modifies the how resistance of ashes is particle surface wetting which creates liquid bridges where particles corstact. The $\mathrm{NH}_{3}$ gas reacts with $\mathrm{SO}_{3}$ adsorbed on the particle surfaces to form ammonium bisulfate, which is a sticky liquid at $300^{\circ} \mathrm{F}$. The reaction may continue to completion, forming ammonium sulfate, after the particles bave stuck together in the dustcake. 


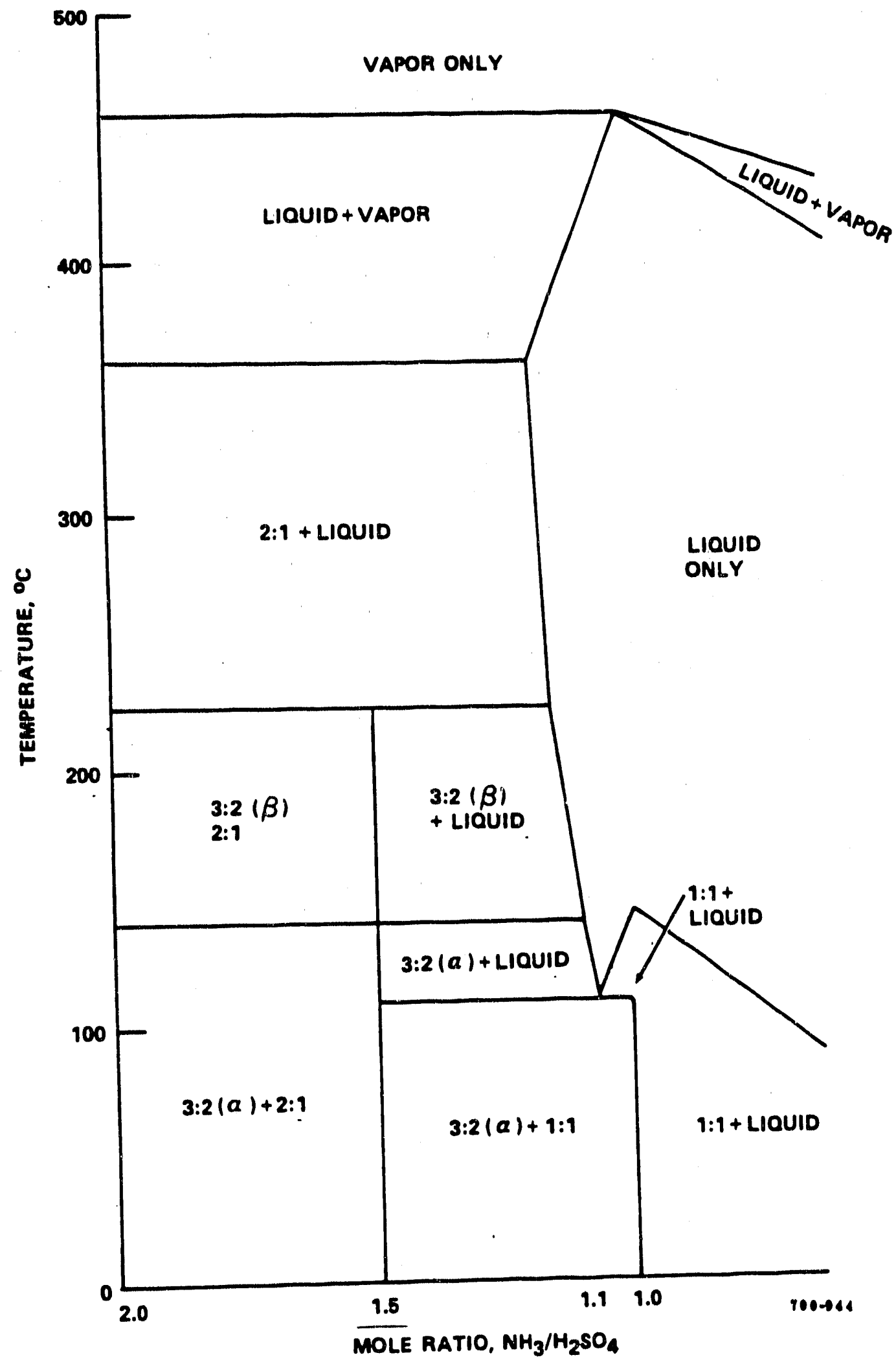

Figure 35. Phase diagram showing the effects of temperature and stoichiometric ratios on the

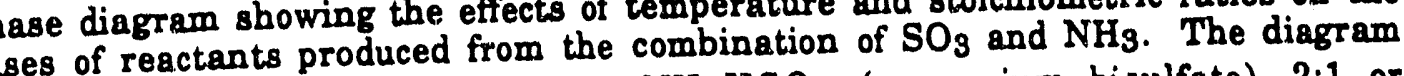
shows three different solid compounds: $1: 1$ or $\mathrm{NH}_{4} \mathrm{HSO}_{4}$ (ammonium bisulfate), 2:1 or $\left(\mathrm{NH}_{4}\right)_{2} \mathrm{SO}_{4}$ (ordinary ammonium sulfate), and $3: 2$ or $\left(\mathrm{NH}_{4}\right)_{3} \mathrm{H}\left(\mathrm{SO}_{4}\right)_{2}$ (known as letovicite). The 3:2 compound has two different crystalline modifications: $\alpha$ and $\beta$. 


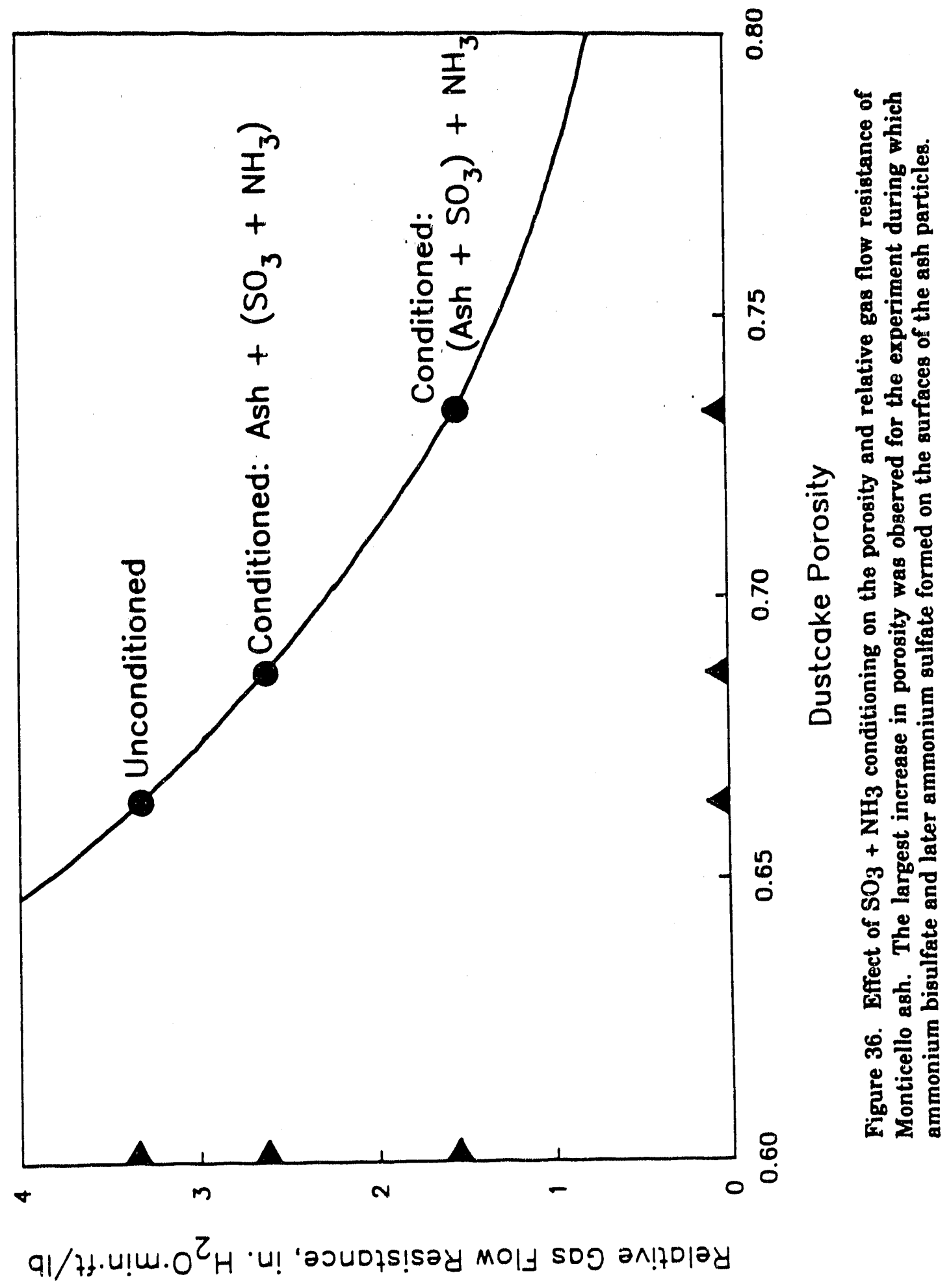




\section{SUMOMARY OF SURVEY OF METHODS TO MODIFY PARTICLE FILTRATION PROPERTIES}

The literature review identified particle size and shape, van der Waals forces, and adsorbed surface films as the primary factors determining fly ash cohesivity.

Van dor Waals forces are heavily influenced by particle size, shape, closeness and contact area.

Prospective dry powder conditioning agents identified in the literature review included fly ashes, fine silica, lime, and aluminum silicate.

In general, the higher the surface area of the dry powder conditioning agent, the larger the apparent change in cohesivity.

Dry powders have the greatest conditioning effect on relatively smooth, spherical particles. Surface irregularities tend to obscure the effects of dry powder conditioning agents.

Blending very small amounts of fine powders with ash generally decreases bulk ash cohesivity. The fine particles act as lubricants, separating particles and decreasing the van der Waals attractive force.

The uncompacted bulk porosity test is a good indicator of ash cohesivity and provides a quick way to screen the effects of conditioning agents.

The mechanism by which adsorbed surface films increase particle cohesivity is the generation of liquid bridges between particles at their points of contact.

Particle wetting agents identified in the literature review included ammonium bisulfate, water vapor, and reaction products of triethylamine and sulfur trioxide.

Exposing ash having adsorbed sulfur trioxide to ammonia gas increases bulk ash cohesivity. At temperatures above $293^{\circ} \mathrm{F}$ ammonium bisulfate is a liquid that wets the particles, increasing the adhesive forces. Exposure to dry ammonium sulfate fume was less effective for increasing ash cohesivity. 


\section{PROOF-OF-CONCEPT TESTS OF METHODS TO MODIFY PARTICLE FILTRATION PROPERTIES}

Based on the findings from the literature review and the screening tests, a series of filtration tests were performed to evaluate conditioning agents. One group of tests evaluated agents for modifying the cohesivity of ashes. Another group of tests evaluated agents for use as precoat materials to modify the filtering surface. The filtration tests were performed with the same basic test apparatus used for Task 2 tests, and followed the same basic procedure. Conditioning agents were mixed with the ash prior to injection into the wind tunnel, injected into the wind tunnel to mix with the ash, injected into the FFSS inlet to condition the ash, or injected into the wind tunnel prior to ash injection to coat the fabric filter before sampling the ash. Each conditioning agent was evaluated by comparing its performance (in terms of $S_{\theta}, K_{2}$, and collection efficiency) with baseline data.

These proof-of-concept tests resulted in recommendations for FFSS field trials of selected technologies that may generate significant improvements in the performance of full-scale fabric filter installations. Additional laboratory proof-of-concept tests have been suggested to evaluate other conditioning agents that were identified in the Task 3 work.

\section{TESTS DESIGNED TO MODIFY ASH COHESIVITY}

As we discussed at the beginning of this report, changes in dustcake porosity resulting from modified cohesivity can significantly alter the filtering drag of an ash. Therefore, the agents selected for these tests were chosen for their potential ability to modify ash cohesivity. Agents were selected from both categories investigated in Task 3: dry powders and various liquids.

\section{Eine Powders as Conditioning_Agents}

Many of the laboratory screening tests indicated that fine powder additives would lower the cohesivity of fly ash. This would lower dustcake porosity and $\mathrm{K}_{2}$. However, some of the screening tests indicated that some fine silica powders and the aluminum silicate porwder could increase the cohesivity of the Monticello and Scholz ashes. Tests were performed to determine the effects of fine powder additives on dustcake filtration characteristics. The results of these filtration tests are summarized in table 8. Additional data describing these tests are presented in Appendix Q.

Initial testing under Task 4 was performed with fabric with $0 \%$ EST. The addition of $0.2 \% \mathrm{w} / \mathrm{w}$ EH5 silica to the Monticello ash resulted in a more than $20 \%$ reduction in $\mathrm{K}_{2}$ and a very large drop in collection efficiency (test $4 \mathrm{M}-2$ vs tests $2-14 \mathrm{~A}$ and $2-14 \mathrm{~B}$ ). The data obtained in Task 3 (Appendix M) suggest the ash cohesivity, as indicated by the uncompacted bulk porosity values, would be lower for the Monticello ash conditioned with EH5 silica than for the unconditioned ash. A reduction in ash cohesivity was expected to result in lower dustcake porosity and a higher $\mathrm{K}_{2}$. The dustcake collected after test $4 \mathrm{M}-2$ contained many pinholes approximately 125 $\mu \mathrm{m}$ diameter (figure 37 ). The presence of numerous pinholes accounts for the observed changes in $\mathrm{K}_{2}$ and collection efficiency. Unobstructed gas flow through the pinholes masked the higher gas flow resistance of the conditioned dustcake ash. We believe the dramatic decrease in collection efficiency for the conditioned ash was due to the direct passage of suspended ash particles through these pinhole openings.

The data in table 8 indicate that the drag-equivalent diameter of the conditioned Monticello ash was less than the drag-equivalent diameter of the unconditioned ash. This difference is probably due to the increased specific surface area of the conditioned dustcake ash. (Drag 


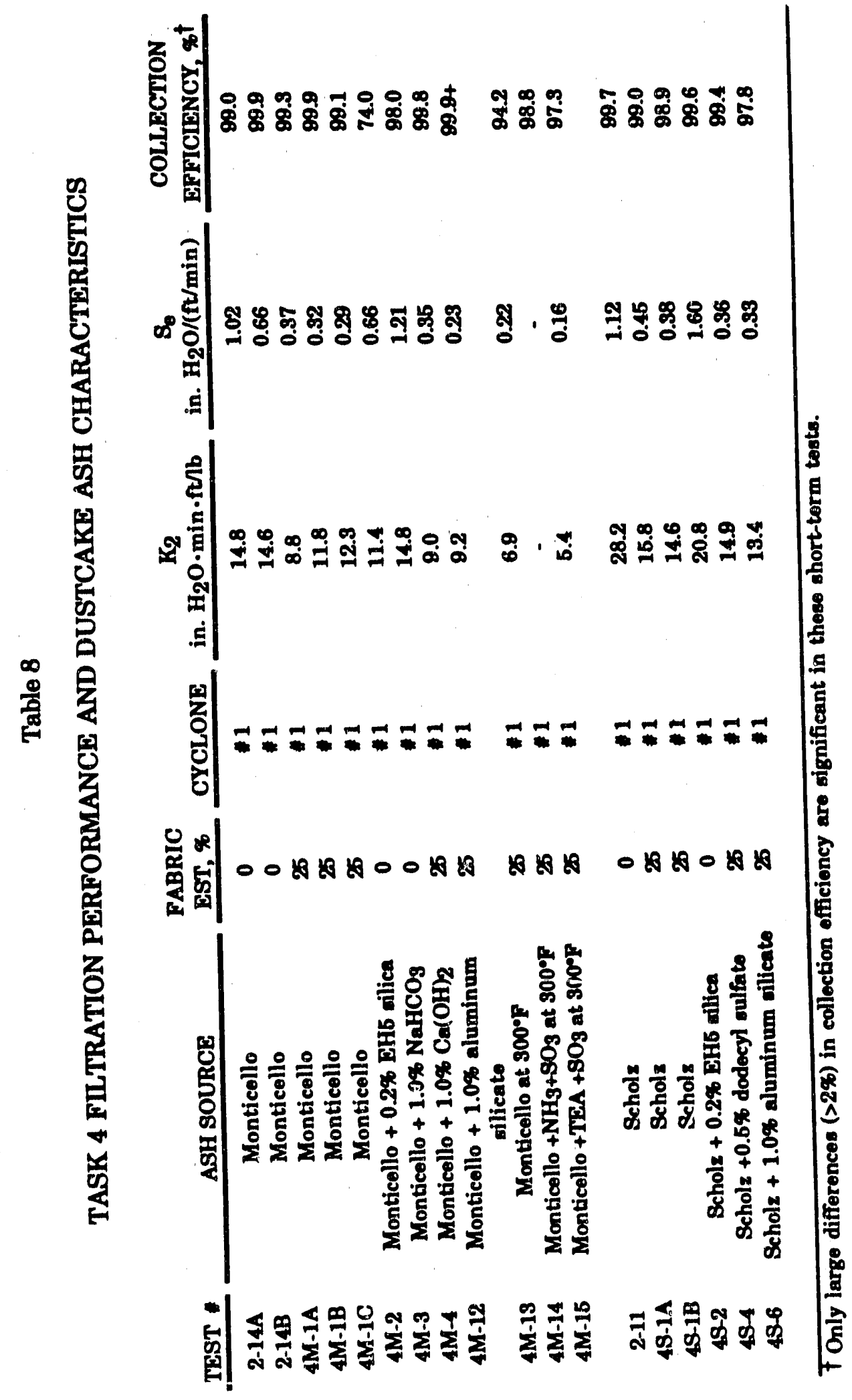




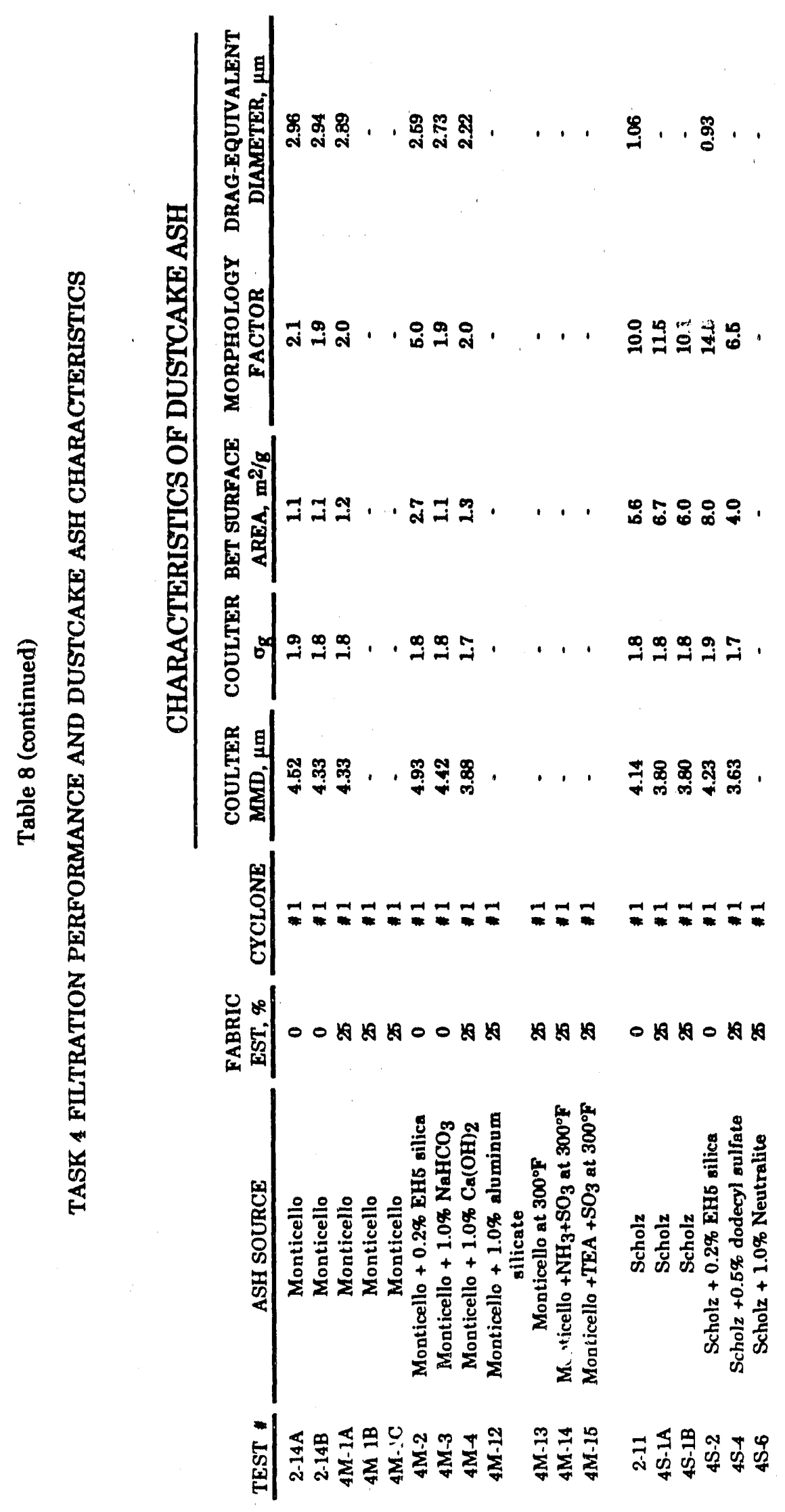




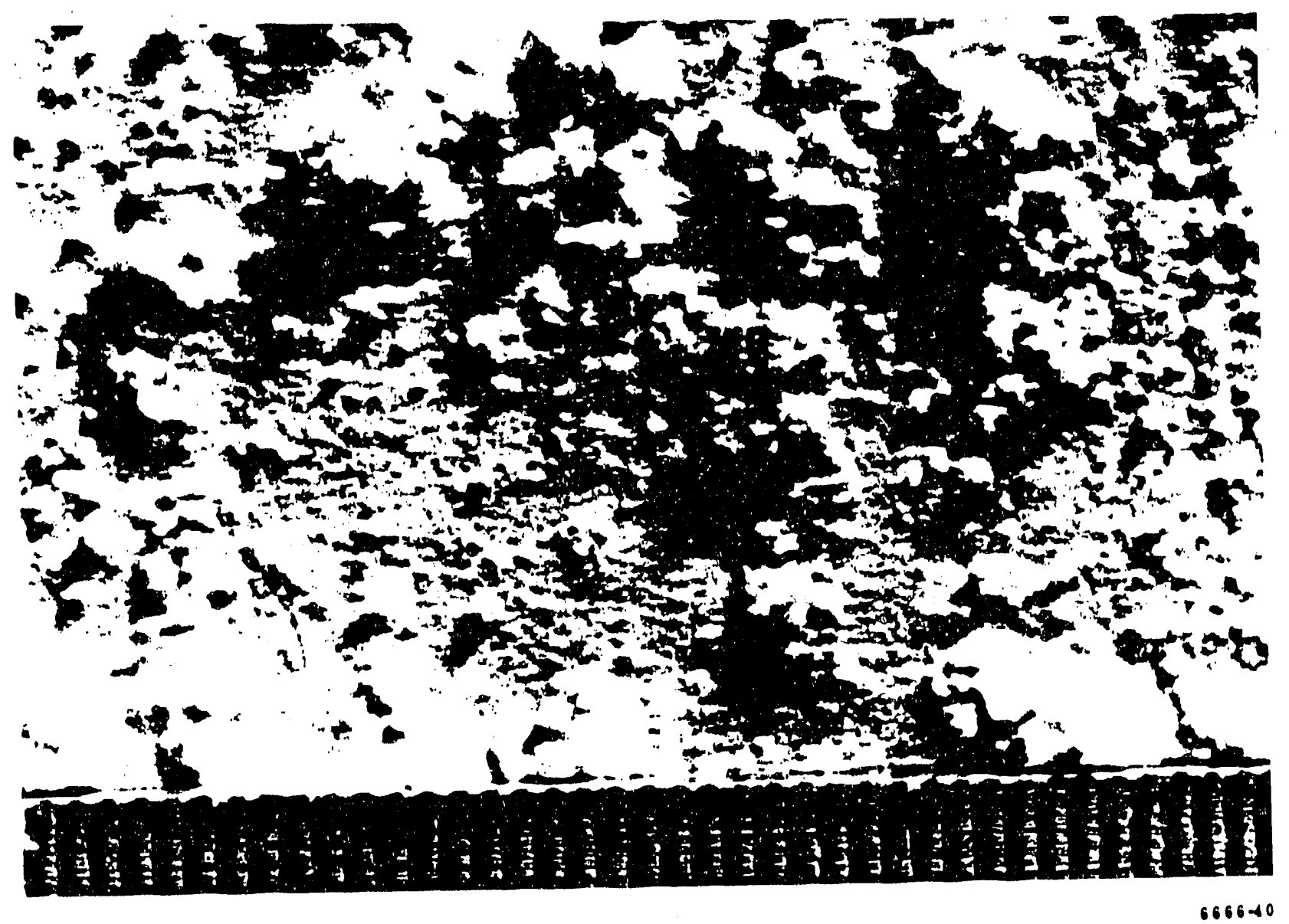

Figure 37. Photographs showing pinholes in the dustcake comprising Monticello ash conditioned with $0.2 \%$ EH5 silica collected on fabric with 0\% EST. (Ruler divisions shown on the bottom of the photograph are 0.01 inches.) 
equivalent diameter normally decreases with increasing surface area.) The increase in specific surface area is due to the high specific surface area of the EHE silica ( $380 \mathrm{~m} 2 / \mathrm{g}$ ).

A similar test was performed with the Scholz ash conditioned with $0.2 \%$ w/w EHS silica collested on fabric with 0\% EST (test 4S-2). The silica induced a reduction in $\mathrm{K}_{2}$, apparently due to the existence of pinholes in the dustcake. However there was no significant drop in collection efficiency for this test. The conditioned dustcake ash from this test also showed an increase in specific surface area due to the added silica.

Sodium bicarbonate was also used to condition Monticello ash collected on fabric with 0\% EST (test $4 \mathrm{M}-3$ ). The $\mathrm{K}_{2}$ value remainod essentially unchunged from the $\mathrm{K}_{2}$ values measured in tests 2-14A and 2-14B. Screening tests indicated that the sodium bicarbonate might increase the ash cohesivity. The sodium bicarbonate had a relatively large mean particle size $(\sim 20 \mu \mathrm{m})$. Therefore, much of the sodium bicarbonate used to condition the ash may have been collected in the inlet cyclone or settled out in the FFSS transform.

Additional Task 4 tests were performed with fabric with 25\% EST because of limited supplies of the fabric with 0\% EST. Tests $4 \mathrm{M}-1 \mathrm{~B}$ and $4 \mathrm{M}-1 \mathrm{C}$ established baseline data for the further conditioning trials of the Monticello ash. (Data from test $4 \mathrm{M}-1 \mathrm{~A}$ was not considered to reliably represent the baseline condition.) Tests 4S-1A and 4S-1B established baseline data for the further conditioning trials of the Scholz ash. The $S_{e}$ values for these 25\% EST baseline tests lie between the corresponding values for tests perforned on the fabric with 0\% EST and the fabric with $100 \%$ EST. These results agree with the trends noted in the discussion presented under Task 2 of the effects of fabric design.

Conditioning the Monticelii ash with hydrated lime (test $4 \mathrm{M}-4$ ) resulted in an unexplained drop in $\mathrm{K}_{2}$ of about $25 \%$. Further testing of lime is recommended to identify the chemical or physical mechanism(s) responsible for this beneficial change.

Proof-of-concept tests of the aluminum silicate as an additive to modify ash cohesivity were performed with the Monticello and Scholz ashes. Figure 38 presents filtration data from tests 4M-1B and 4M-12 with the Monticello ash and tests 4S-1A and 4S-6 with the Scholz ash. The aluminum silicate induced a drop in $\mathrm{K}_{2}$ greater than $20 \%$ when used with the Monticello ash and a drap in $\mathrm{K}_{2}$ greater than $10 \%$ when used with the Scholz ash. As with the hydrated lime results, the mechanism(s) responsible for these improvements have not been identified. The high bulk porosity of the aluminum silicate may have directly contributed to the changes in $\mathrm{K}_{2}$.

The EH5 silica evaluated in the screening tests and in filtration tests performed on fabric with $0 \%$ EST was also evaluated in filtration tests performed on fabric with $25 \%$ EST. This test (4S. 3) was run to obtain additional information on the interaction of fabric design, ash cohesivity, and pinhole formation. The dustcake formed in this test also contained numerous pinholes. Apparently the increased texturization of the fabric with 25\% EST was not sufficient to overcome the forces that cause pinholes to form. Although pinholes were present in this test, the $K_{2}$ value was significantly higher than the values measured for the baseline condition indicating a lower dustcake porosity.

One of the anionic surfactants mentioned in the review surnmarized in Appendix $G$ was dodecyl sulfate. Test $4 \mathrm{~S}-4$ was performed as a preliminary test of this compound. The results, included in table 8 , indicate that this compound had no significant effects on the filtration of Scholz ash in the configuration tested. Due to time constraints, none of the other dry powder compounds discussed in Appendix G were tested.

\section{Formation of Liauid Bridges to Condition Ashes}

The information obtained from the literature review and the screening tests described the ability of liquid bridges to increase the cohesivity of powders. The second set of filtration tests 


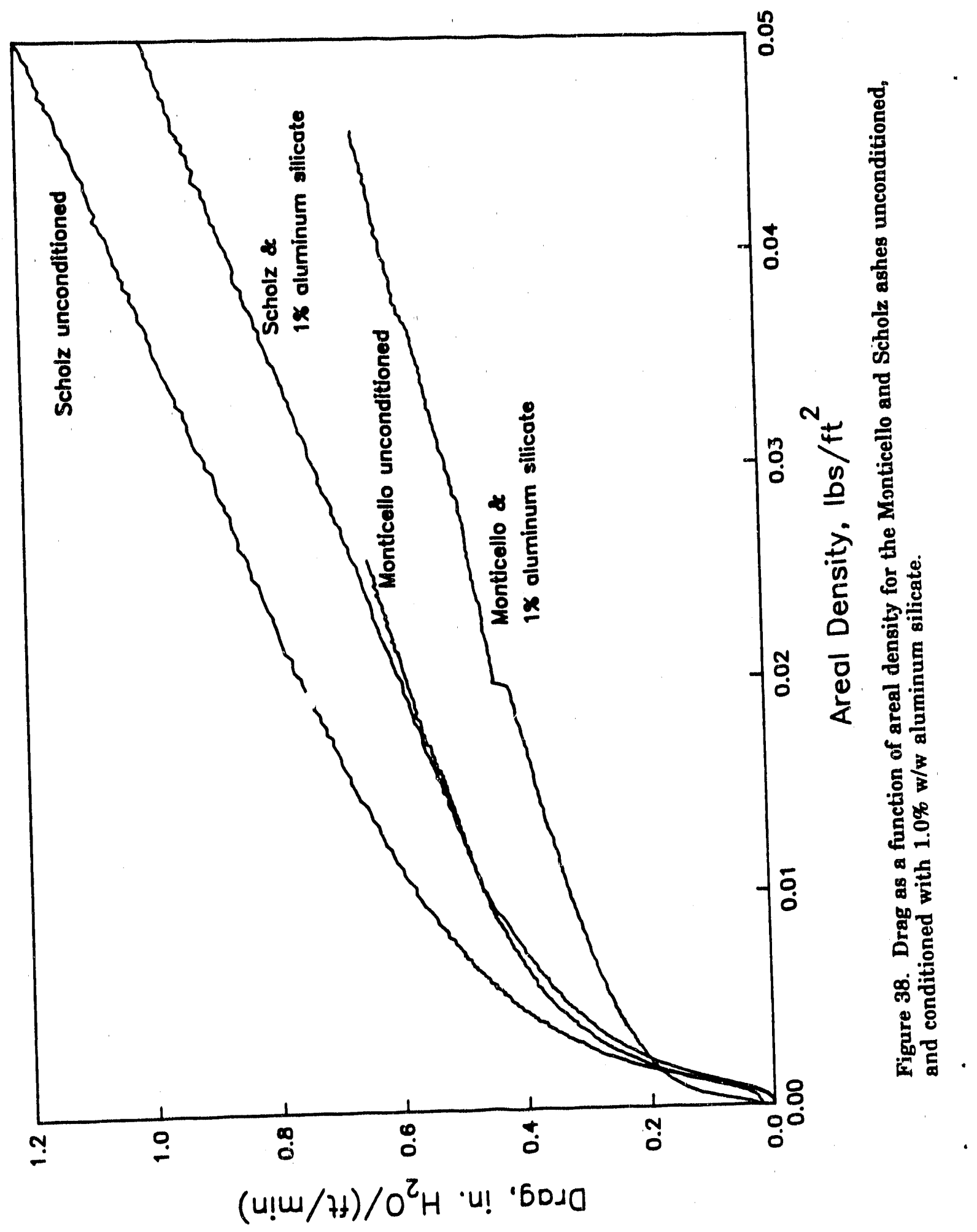


intended to modify ash cohesivity were designed to create liquid bridges at the particle contact points. Four different mechanisms for creating these liquid bridges were investigated in these tests.

Elevated Humidity Levels. Tests 4 M-7 and 4M-8 were performed to determine the effects of increased relative humidity on the filtration characteristics of the Monticello ash. Moist air produced by bubbling metered air through a controlled-temperature water bath was injected into the FFSS chamber to mix with the ash-laden air sampled from the wind tunnel. Different humidity levels were produced by maintaining different water bath temperatures. Figure 39 compares the filtration data from test $4 \mathrm{M}-7$ and test $4 \mathrm{M}-8$ with the baseline test $4 \mathrm{II}-1 \mathrm{~B}$. These data indicate that increased levels of relative hunidity caused significant reductions in $S_{\theta}$ and $\mathbf{K}_{2}$ values.

Fine Oil Mist. Proof-of-concept itsts were also performed to evaluate the effectiveness of depositing a thin layer of oil on the surface of the fly ash particles prior to their collection on the fabric. The oil chosen for these tests was di(2nechylhexyl) sebacate because it is non-toxic, a supply was readily available, and because it had been successfully generated as a fine mist with an existing spray nozzle. The nozzle was used to spray the oil mist into the mixing and conditioning chamber to allow the larger oil droplets to settle out. The oil droplets exiting the chamber had a median diameter of $\sim 0.8 \mu \mathrm{m}$. These fine sebacate particles were injected into the FFSS through a port adjacent to the inlet tube through which the fly ash particles enter the FFSS.

In the first test with oil droplet injection (4M-9), the oil injection began as soon as fly ash entered the FFSS chamber. The data from this test were inconclusive because the plot of drag as a function of areal density did not achieve a linear slope by the conclusion of the test. For the next two tests, oil injection began after enough unconditioned Monticello ash had been sampled to coat the fabric. The data in table 8 show that the $K_{2}$ value measured during test $4 \mathrm{M}-11$ after the oil injection had begun was approximately $30 \%$ lower than the baseline value.

The degree of mixing and uniformity of deposition of oil on the Monticello ash particles is not known for these tests. It might have been possible to decrease $\mathrm{K}_{2}$ even further if the oil droplets had been smaller or if the oil had been present as a vapor, or if more mixing had been possible between the oil and the ash particles. We believe oils other than the sebacate should produce similar effects if they have approximately the same viscosity.

Reactants Formed from Ammonia or Triethylamine and Sulfur Trioxide. To provide baseline data for subsequent filtration tests of sulfur trioxide with ammonia or triethylamine, test $4 \mathrm{M}-13$ was performed at $300^{\circ} \mathrm{F}$. Pinholes observed in the dustcake collected in this test may account for the significant drop in the system collection efficiency to $94.2 \%$ from the collection efficiencies of greater than $99 \%$ measured for the room temperature tests. The $\mathrm{K}_{2}$ value measured for this test was also significantly lower than the values measured at room temperature. Several factors may have influenced this change in $\mathrm{K}_{2}$. The pinholes provided a low-resistance flow path through the dustcake. The increase in temperature may have induced enough of an increase in ash cohesivity to form a more porous dustcake structure. These two possible explanations may also have been affected by the slight increase in gas viscosity due to the increase in gas temperature. The data from test $4 \mathrm{M}-13$ provide baseline data for evaluation of the following two tests.

Test 4M-14 was run to determine the effects of ammonia and sulfur trioxide conditioning of the Monticello ash on FFSS filtration performance. The conditioning system used for this test (and test $4 \mathrm{M}-15$ ) is shown schematically in figure 40 . The basic approach was to condition the fly ash particles with ammonia prior to their entry into the FFSS transform. This conditioning took place in the wind tunnel and in the sampling line. Once the ash particles entered the FFSS transform, they were exposed to sulfur trioxide (or sulfuric acid vapor) injected at a constant rate into the FFSS. During tests $4 \mathrm{M}-14$ and $4 \mathrm{M}-15$, the $\mathrm{SO}_{3}$ concentration in the FFSS transform was approximately $16 \mathrm{ppm}$. The concentration and flow rate of the ammonia were maintained 


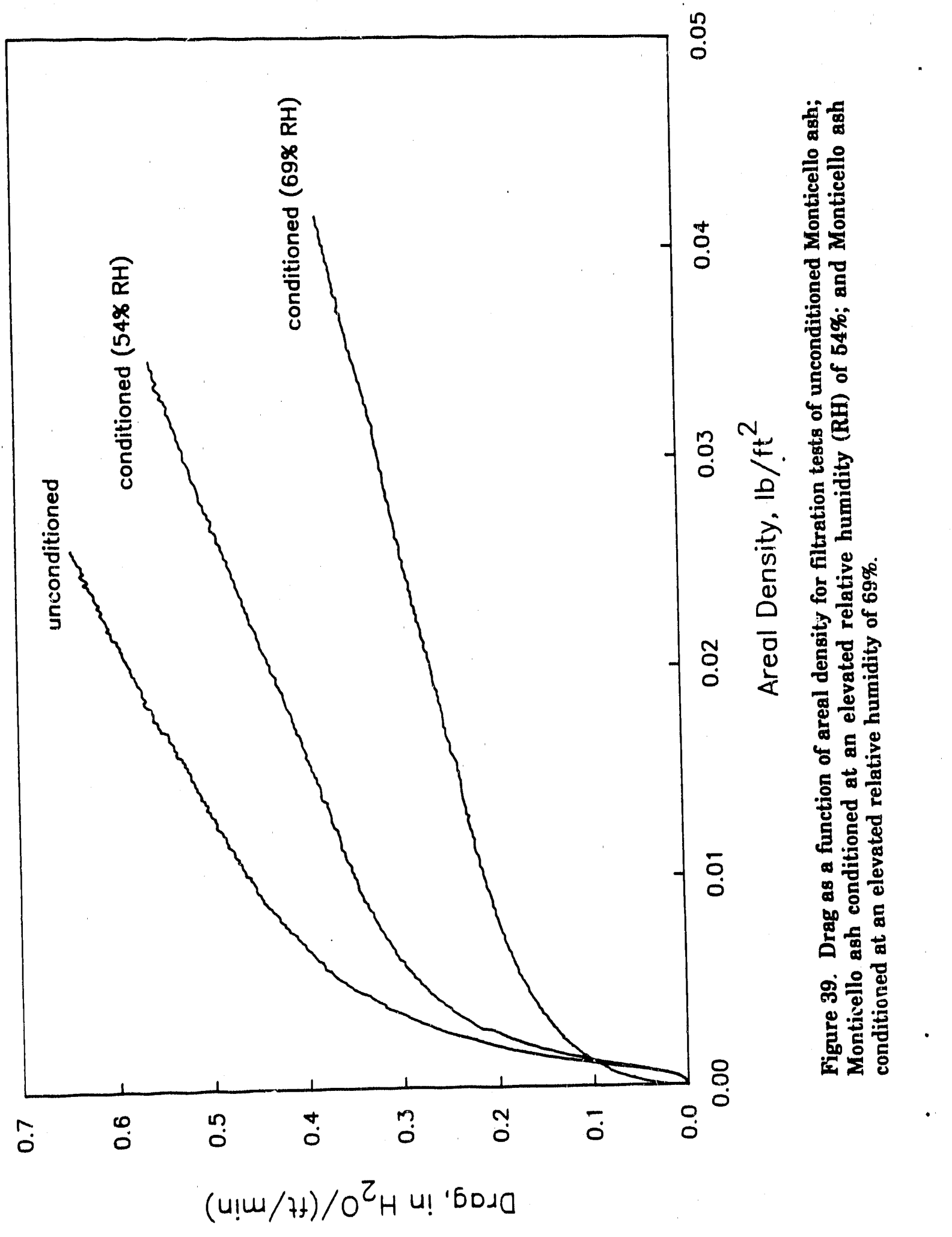




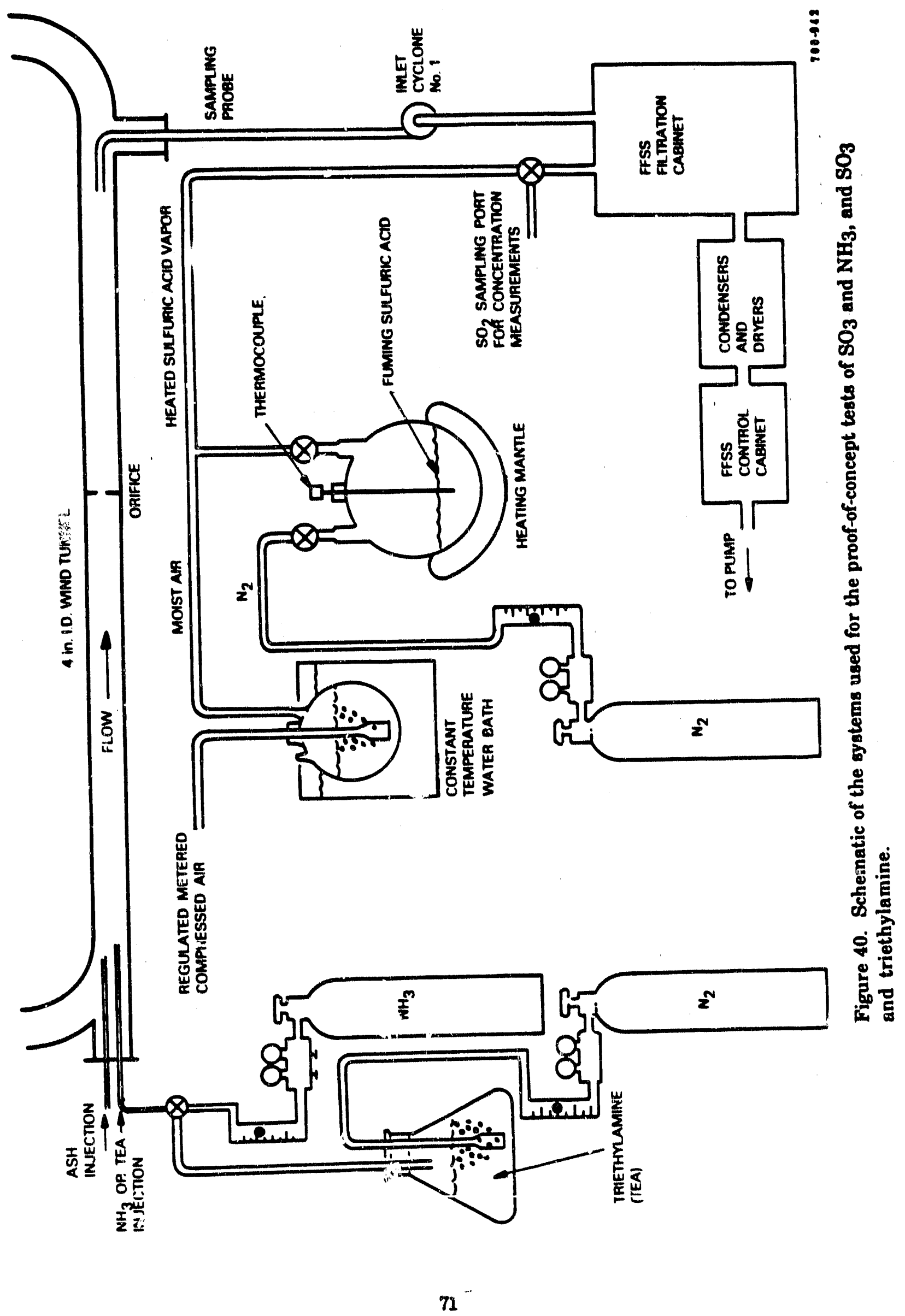


at levele required to provide a stoichiometry greater than $2: 1$ in the ratio of $\mathrm{NH}_{3}$ to $\mathrm{SO}_{3}$. The conditioning procedures used in these tests are summarised in Appendix $R$.

The dustcake formed in test 4M-14 did not contain any pinholes. The rnlationahip botween drag and areal denaity for this tost included in foure 41 shows that a line: relationship we nisver fully establiwhed. Because of this, $K_{2}$ and $S_{0}$ values could not be determined for thim tast. However, the date for teat $4 \mathrm{M}-14$ do seem to indicate that the conditioning with $\mathrm{NH}_{3}$ and $\mathrm{SO}_{3}$ in combination did aignificantly improve the filtration characteriatic of the collected duatcake. By the conclusion of the tost, the slope of the relationship between drag and areal density $\left(K_{2}\right)$ appears to have dropped well below the slope for the baseline test. The conditioned dustcake ash removed from the fabric followink the test appe ared to be more cohesive than the unconditioced dustcake ash. The conditioning process used in test $4 \mathrm{M}-14$ turned the fabric and the dustiake ash a medium brown color. We do not know the reason for this discoloration, though previous experience has revealed selenium as a possible source. The apparently increased ash cohesivity and reduced flow resistance ohserved for test $4 \mathrm{M}-14$, along with the absence of pinholes in the conditioned dustcake, indicate that $\mathrm{NH}_{9}$ and $\mathrm{SO}_{9}$ conditioning did increase the cohesivity of the Monticello ash collocted in this FFSS teat.

Triethylamine (TEA) was evaluated in test $4 \mathrm{M}-16$ as abstitute for ammonia because of differences in the thermodynamic and kinetic properties of the reactants of the two gases with $\mathrm{SO}_{3}$. The expected reactions of TEA with $\mathrm{SO}_{3}$ are shown in the following two equations.

$$
\begin{aligned}
& \mathrm{N}\left(\mathrm{CH}_{3} \mathrm{CH}_{2}\right)_{3}(\mathrm{~g})+\mathrm{SO}_{3}(\mathrm{~g})+\mathrm{H}_{2} \mathrm{O} \rightarrow \mathrm{NH}\left(\mathrm{CH}_{8} \mathrm{CH}_{2}\right)_{3} \mathrm{HSO}_{4}(?) \\
& \mathrm{NH}\left(\mathrm{CH}_{3} \mathrm{CH}_{2}\right)_{3} \mathrm{HSO}_{4}(?)+\mathrm{N}\left(\mathrm{CH}_{3} \mathrm{CH}_{2}\right)_{3}(\mathrm{~g}) \rightarrow\left(\mathrm{NH}_{(}\left(\mathrm{CH}_{3} \mathrm{CH}_{2}\right)_{3}\right)_{2} \mathrm{SO}_{4}(?)
\end{aligned}
$$

The TEA was injected into the wind tunnel in sufficient quantity (> 2:1 TEA:SOs stoichiometry) to fully react with the sulfur triaxide in the FFSS.

As with the test performed with ammonia, the dustcake formod in test 4M-16 did not contain any pinhoies. Tho relationship between drag and areal density for this test is included in figure 41 . Compared with the baseline data, the $S_{\theta}$ and $K_{2}$ values decreased by ove- $20 \%$ (see table 8). It appeared from the color a and qualitative cobesivenese of the ash collected on the fabric that there had been incomple .. aixing of the conditioning agents in the FFSS. Ash collected in the region of the fabric directly opposite the $\mathrm{SO}_{3}$ injection port was noticeably darker and more cohesive than ash in other regions. We presume that botter mixing of the agents and the ash would yiel t greater reductions in $\mathrm{K}_{2}$ and $\mathrm{S}_{\mathbf{S}}$.

\section{TESTS DESIGNED TO MODIFY THE FILTERING SURFACE}

It is a relatively common practice to cont new filter bags with dry particulate matter before hecinning filtration of flue gas. This is pecially true of the starturs of new, full-scale utility baghouses, and is a requirement by some baghouse vendors. In most, if not all of these cases, ach collected in anotiner baghouse was used as the precoat material. Aluminum silicate or lime has been used in some industrial baghouses to precoat the bags. The motivation for precoating" has bean to protect the bage from soot, dirt, FBC bed material, or oil ash that would be conveyed in the flue gas during an initial startup.

It is our purpose to use a precoating material to modify the fabric filtering surface as shown in fioure 2. The rationale for this approach is the effect of fabric EST on $S_{0}$. As shown in figure 21 , increasing the fabric testurization can dramptically reduce $S_{0}$ in ahort-term tests. This is attributed to the modification of the pore distribution of the filtering medium unto which the ask is conveyed. However, higher EST leads to bigher residual dustcake areal density nver the losis ters, which raduces or negates the initial benefit to $S_{0}$. Selection of an appropriate 


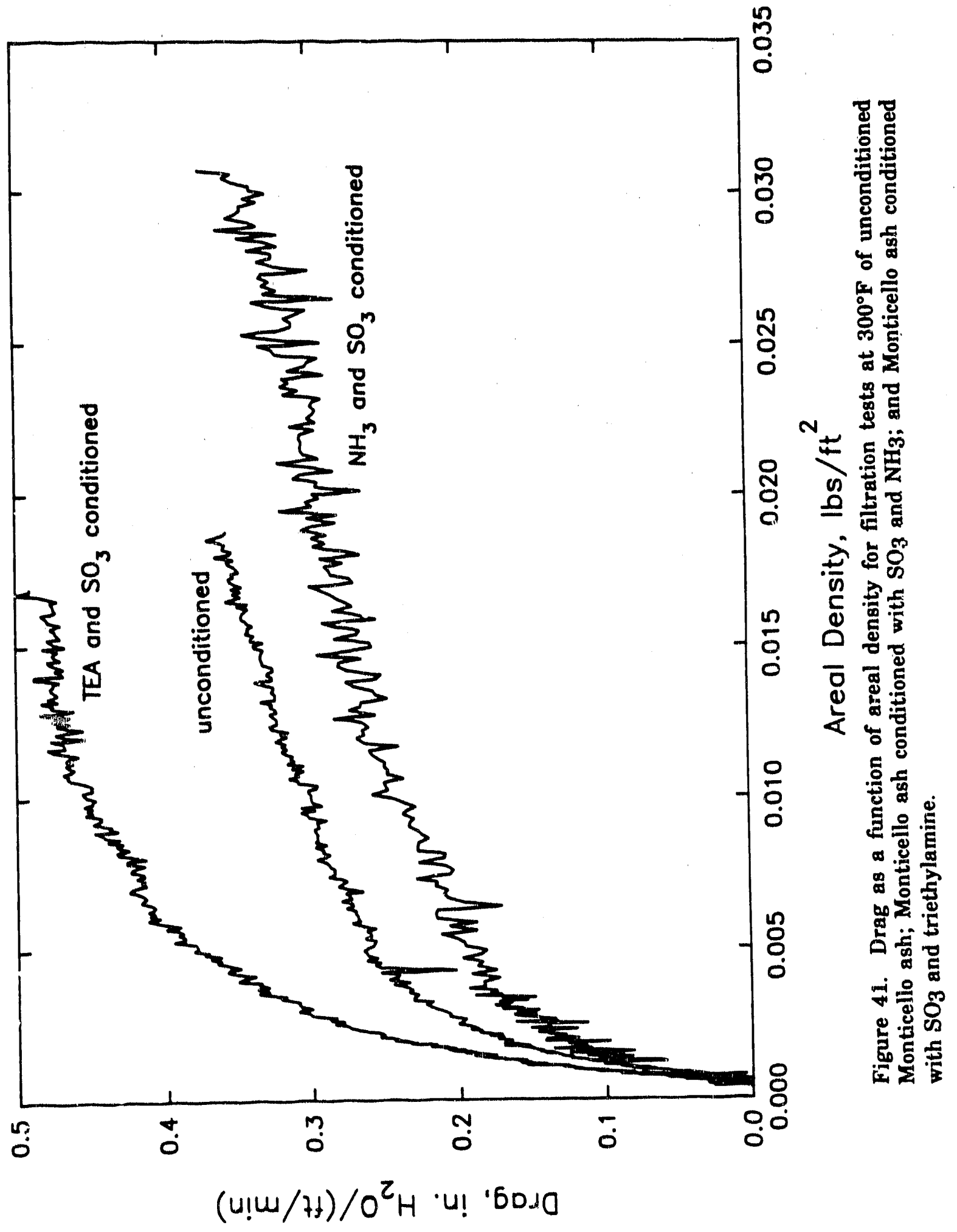


precoating material may yisld the same short-term benefit to $S_{0}$ as higher EST without the negative long-term effect.

The second group of proof-of-concept tests consisted of the application of various powders to the clean fabric surface prior to the collection of the ash. For these tests, the fabric was precoated with the selected material by withbolding ash feed from the screw feeder while feeding the precoat material into the wind tunnel through an eductor. This procedure was continued until the chart of filtering drag indicated that the fabric surface had been completely coated (the rate of change of the drag had become constant). At this point the feeding of precoat material into the eductor was discontinued and the feeding of fly ash from the screw feeder was begun. All of these precoating evaluations were performed on fabric with 25\% EST. Powders selected as precoating materials because of their potential for bridging over the pores in the fabric included hydrated lime, dustcake ash from the Scholz High Sulfur Fabric Filter Pilot Plant (HSFP), and the aluminum silicate. Successful precoating materials were expected to significantly reduce $S_{\theta}$ values.

Based on examination of the plots of drag as a function of areal density presented in figure 42 , the hydrated lime and the Scholz HSFP dustcake ash did not improve the characteristics of the filtering surface. (The algorithm for determining the values of $\mathrm{S}_{\theta}$ and $\mathrm{K}_{2}$ values for these tests was unsuccessful because of nonlinear drag behavior.) The aluminum silicate proved to be a very effective precoat material in tests (4M-11 and 4S-5) performed with the Monticello and Scholz ashes (see the reductions in $S_{\theta}$ noted in table 8). These tests are compared in figure 43 with the bacelise results.

\section{SUMMARY OF PROOF-OF-CONCEPT TESTS OF METHODS TO MODIFY PARTICLE FILTRATION PROPERTIES}

Reductions in ash cohesivity due to the addition of small amounts of fine silica powders can cause pinhole formation and degradation of collection efficiency.

Ash cohesivity is the primary determinant of pinhole formation.

The filtering characteristics of ashes are affected by the specific surface area of fine powder conditioning agents.

Although the responsible mechanism(s) have not been $\mathrm{d}^{\prime}$, jitely identified, a small amount of hydrated lime can be used to condition Monticello ash to reduce the specific drag coefficient, $K_{2}$, of the ash.

Increased levels of relative humidity can significantly decrease $S_{\theta}$ and $K_{2}$ values.

Fine oil droplets have been used to verify the formation of liquid bridges as a mechanism capable of significantly reducing filtering $\mathrm{K}_{2}$.

FFSS tests of the Monticello ash at $300^{\circ} \mathrm{F}$ resulted in pinholes that were not formed during tests at $70^{\circ} \mathrm{F}$.

FFSS tests of Monticello ash at $300^{\circ} \mathrm{F}$ showed that conditioning with sulfur trioxide and ammonia or sulfur trioxide and triethylamine increased ash cohesivity. The increased ash cohesivity prevented pinhole formation and improved the filtering characteristics of the ash.

Using aluminum silicate as a precoating material significantly reduced $S_{\theta}$. 


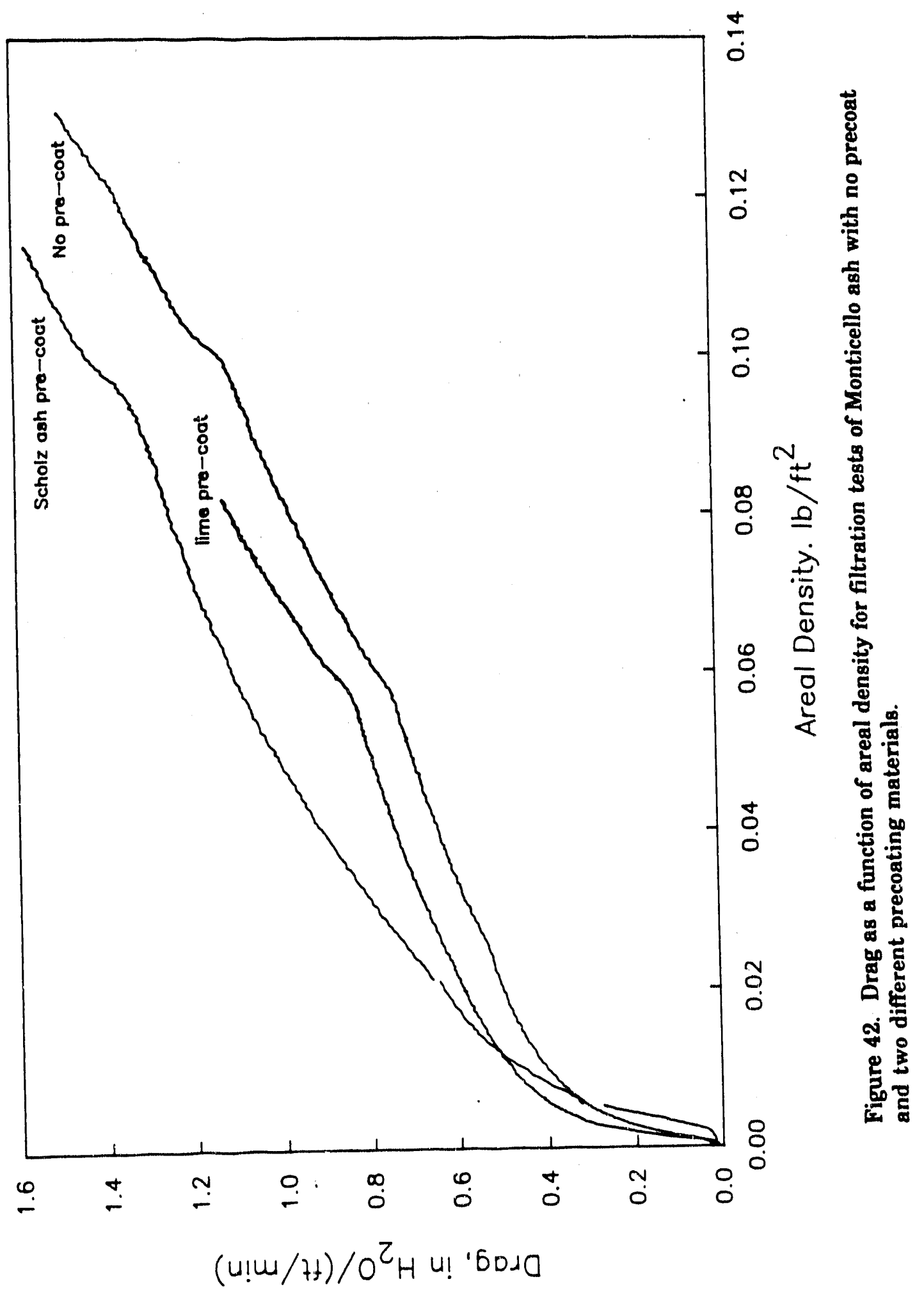




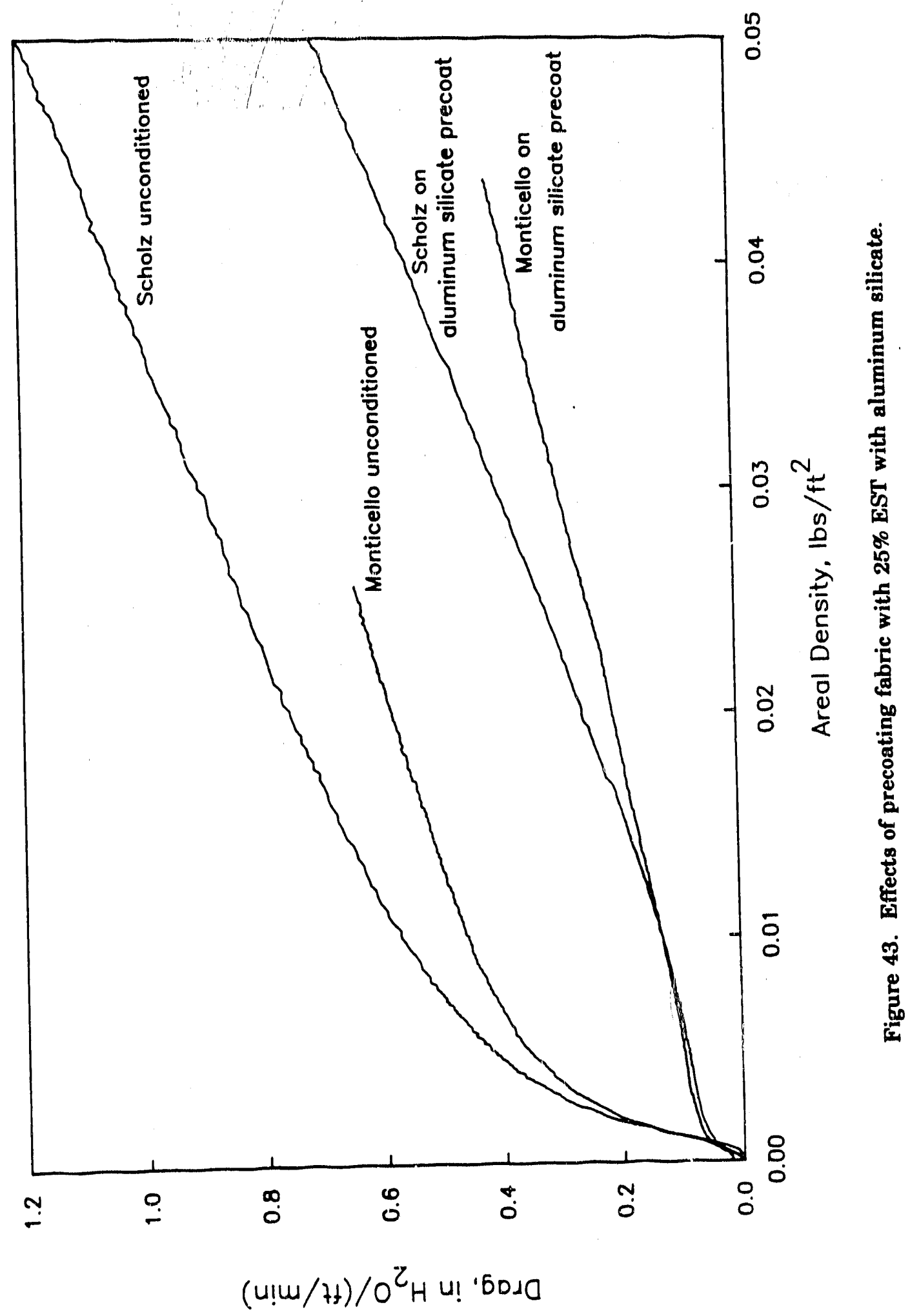




\section{SUMMARY}

This research project utilized a series of parametric tests of three distinct types of fly ash to characterize the key particulate properties that determine their filtration performance. Literature reviews were combined with laboratory screening tests to identify primary mechanisms and potential agents for the modification of these key fly ash properties. Proof-ofconcept filtration tests were then used to evaluate and verify the benefits of various approaches. Several successful conditioning approaches were identified through this process, resulting in substantial improvements in filtration performance. Furthermore, modification of the fabric filtering surface by precoating also yielded significant improvements in filtration performance. We have also identified conditioning agents and processes which warrant further study.

\section{CONCLUSIONS}

Inherent ash cohesivity is primarily determined by ash particle shape and size, which are the main determinants of the $\mathrm{K}_{2}$ value associated with filtering unconditioned ash. The relationship between particle shape and $\mathrm{K}_{2}$ is relatively complex, involving the competing effects of altered particle roughness on specific surface area and dustcake porosity.

When filtering ash with an initially clean fabric, $S_{\theta}$ is much more dependent on the size and arrangement of pores in the fabric than on the characteristics of the collected ash.

$\mathrm{K}_{2}$ can also be dependent on fabric pore characteristics when the collected dustcake is very thin, or when the combination of low ash cohesivity and fabric pore characteristics generate a nonuniform dustcake structure contraining pinhnles. Both of these conditions affect $\mathrm{K}_{2}$ because of the nonuniform flow through the dustcake.

For a given fabric design, the inherent cohesivity of the ash being filtered is the primary determinant of filtration performance for unconditioned or unmodified ashes.

The low surface area characteristic of smooth particles can induce beneficial reductions in filtering drag if dustcake forosity can be kept high.

The literature review identified particle size and shape, van der Waals forces, and adsorbed surface films as the primary factors determining fly ash cohesivity.

Prospective dry powder conditioning agents identified in the literature review included fly ashes, fine silica, lime, and aluminum silicate. In general, the higher the surface area of the dry powder conditioning agent, the greater its potential effect on cohesivity. Dry powders have the greatest conditioning effect on relatively smooth, spherical particles. Surface irregularities tend to obscure the effects of dry powder conditioning agents.

Blending very small amounts of fine powders with ash generally decreases bulk ash cohesivity. The fine particles act as lubricants, separating particles and decreasing the van der Waals attractive force. Dustcakes composed of ashes conditioned with fine powders often contain pinholes induced by the lowered ash cohesivity.

The mechanism by which adsorbed surface films increase particle cohesivity is the generation of liquid bridges between particles at their points of contact. Particle wetting agents identified in the literature review included ammonium bisulfate, water vapor, and reaction rroducts of triethylamine and sulfur trioxide.

Exposing ash having adsorbed sulfur trioxide to ammonia gas increases bulk ash cohesivity. At temperatures above $293^{\circ} \mathrm{F}$ ammonium bisulfate is a liquid that wets the particles, increasing 
the adhesive forces. Exposure to dry ammonium sulfate fume was not as effective in increasing ash cohesivity.

Filtration teats indicated that increased levels of relative humidity can significantly decrease $S_{\bullet}$ and $K_{2}$ values.

FFSS teats of Monticello ash at $300^{\circ} \mathrm{F}$ showed that conditioning with sulfur trioxide and ammonia or sulfur trioxide and triethylamine increased ash cohesivity. The increased ash cohesivity prevented pinhole formation and improved the filtering characteristics of the ash.

At loant part of the explanation for the effact of dow point excursions on fabric filtor operation is the formation of liquid bridges between particles that increase cohesivity and result in more porous dustcakes.

Using aluminum silicate as a precoating material significantly reduced $S_{0}$.

Appropriate modification of the ash can result in substantial improvements in filtration performance. Furthermore, modification of the fabric filtering surface by precoating can potentially yield significant improvements in filtration performance.

\section{CONDITIONING RECOMMENDATIONS}

We feel that several approaches studied in this project merit further investigation. Liquid bridges were apparently successfully created between Monticello ash particles by increased relative bumidity. Additional laboratory evaluations of various humidity levels followed by field trial performed with the FFSS are recommended to pursue this potentially beneficial approach. In full-scale applications the reduction in flue gas temperature that would be associated with water injection to increase relative humidity would also decrease total flue gas volume. Reducing flue gas volume flow rate would reduce filtering pressure drop. An additional benefit would result from a reduction in the viscosity of the flue gas due to the drop in temperature (pressure drop is proportional to gas viscosity). Although the full implications of conditioning with increased humidity levels need to be examined in more detail, this approach holds significant promise.

The application of a suitable precoat material to the clean fabric was also shown to successfully reduce $S_{\theta}$ values. Field trials of this technology are recommended to test its viability in flue gas environments and for repeated cleaning and filtration cycles. Precoat materials may be capable of protecting the fabric surface and residual dustcake from the detrimental effects of condensation often associated with cyclic behavior.

We also recommend the evaluation of additional chemicals as conditioning agents. Several categories of chemicals hold promise as potential conditioning agents. These categories include amine sulfates, surfactants and dispersants, flocculating or coagulating agents, silanizing agents and deliquescent co-npounds. More detailed descriptions of these compounds are found in Appendix G. Chemically active compound such as these may be able to alter ash cohesivity by inducing chemical bonds between fly ash particles. 


\section{RECOMMENDATIONS FOR FIELD TRLALS}

The following discussion identifies the conditioning approaches that are recommended for FFSS testing on flue gases from utility boilers. The advantages of these tests are presented, along with a discussion of the planned test procedures.

\section{Inherent Limitations of the Laboratory Finvirunment}

All of the parametric and proof-of-concept tests performed in the saboratory were carried out within certain inherent limitations. The constituents of the laboratory air filtered in these experiments differ significantly from the consisituents of flue gases. The laboratory experiments utilized redispersed fly ashes originally collected from hoppers at the source plants. The true inlet particle size distributions present at the source plants (especially the submicron particles suspended in the flue gas) were not precisely reproduced in the wind tunnel used in the laboratory experiments. The laboratory tests were necessarily of relatively short duration. This limitation affects the interpretation of efficiency data and residual dustcake formation. The laboratory tests were also not able to simulate the dew point excursions often encourtered at operating baghouses, because of the constraints placed on test duration and the constituents of the laboratory air being filtered.

\section{Technical Questions Addressed by On-Site_Sidestream Testing}

- Can the predicted beneficial effects of a aluminum silicate precoat withstand the presence of flue gas constituents, system cycling through water dew points, and repeated fabric cleanings?

- Can lime perform as well as aluminum silicate as a precoat?

- Can elevated humidity produce beneficial effects in the presence of flue gas constituents and true inlet particle size distributions?

- What are the potential costs, benefits, and technical implications of fullscale applications of the proposed approaches?

\section{Broposed Field_Trials at Monticello}

Site Descriotion. Monticello Steam Electric Station, located near Mt. Pleasant, Texas, is owned and operated by TU Electric Company of Dallas. Monticello is a base-loaded plant consisting of two 575-MW units and one 750-MW unit, all burning locally-mined lignite coal. The fly ash generated during combustion has a low inherent cohesivity. The low cohesivity of the Monticello ash causes the ash particles to infiltrate into the pores in the filtering fabric. This infiltration leads to the poor collection efficiency and contributes to the high filtering pressure drops that are characteristic of filtration of this ash (11). Another important characteristic of this ash is its tendency to build dustcakes with very low porosity. This characteristic is the primary cause of high filtering pressure drops experienced at this plant.

Proposed Tests. A series of tests (table 9) is proposed for Monticello that will address both the problem of the infiltration of ash intn the fabric pores and the low dustcake porosity. All of the tests at Morticello will be performed on fabric with 25\% EST. Reverse-gas cleaning cycles in the sidestream will be on a timed basis, occurring every 60 minutes. 
Table 9

MONTICELLO SIDESTREAM TRIATS
Condition 1:
Test 1a - baseline (one filtration cycle only - no cleaning).
Test $1 \mathrm{~b}$ - baseline (repeated filtration/cleaning cycles)
Condition 2:
Test $2 \mathrm{a}$ - humidification level 1 (one filtration cycle only - no cleaning)
Test $2 \mathrm{~b}$ - humidification level 1 (repeated filtration/cleaning)
Condition 3:
Test 3a - humidification level 2 (one filtration cycle only)
Test 3b - humidification level 2 (repeated filtration/cleaning cycles)
Condition 4:
Test 4 - aluminum silicate precoat (repeated filtration/cleaning cycles)

The two levels of relative humidity evaluated in test conditions 2 and 3 will be determined through preliminary tests conducted in the laboratory. For each of the first three test conditions where no precoat is applied, a brief preliminary test $(1 a, 2 a, 3 a)$ will be run to establish a $K_{2}$ value for the condition. These brief tests will be run in the same manner as the parametric and proof-of-concept tests performed in the laboratory. Tests $1 \mathrm{~b}, 2 \mathrm{~b}, 3 \mathrm{~b}$, and 4 will run for five or six days each, and will include numerous filtration and cleaning cycles.

The first of these test conditions will establish baseline data for evaluation of the following three sidestream test conditions. The next two conditions will evaluate the effects of elevated humidity. Humidity levels will be increased within the sidestream by the injection of moist, beated air directly into the sidestream transform. This mothod for increasing humidity was used successfully in the laboratory proof-of-concept tests. The humid air will enter the FFSS transform through a port located next to the flue gas sample port. The humid air will mix with the flue gas prior to filtration of the mixture by the fabric. The total flow through the FFSS will be set to account for the added volume of humid air. For the tests of elevated humidity, the FFSS will be operated at temperatures below the temperature of the Monticello duct. This reducedtemperature operation is designed to account for the reduction in temperature that would be experienced in the Monticello duct due to the evaporative cooling effects of water iniection. Therefore the FFSS oven temperature setpoints for tests $2 a, 2 b, 3 a$, and $3 b$ will be calculated based on the evaporative cooling that would occur in full-scale use of water injection to raise the flue gas humidity. Tests 1 and 4 will be carried out at $360^{\circ} \mathrm{F}$, the flue gas temperature in the Monticello duct.

The fourth Mont cello test condition will begin with the deposition of a thin layer of aluminum silicate on the clsan fabric. The aluminum silicate will be injected through a port next to the port through which the flue gas sample enters the FFSS transform. Application of the aluminum silicate precoat will discontinue once the pressure drop data indicate that the pores in the fabric have been bridged over. Normal filtration of the Monticello ash will proceed as in the baseline condition once this alv inum silicate precoat is deposited.

\section{Broposed Field Trials_at_Schola}

Site Description. Scholz Steam Plant is owned and operated by Gulf Power Company, utility member of the Southern Company. The plant is located near Sneads, Florida and consists of two 40-MW units. The burning of high-sulfur bituminous coal at Scholz produces a fly asn with relatively high cohesivity. Experiments have been performed at the EPRI High Sulfur Fabric Filter Pilot Plant to evaluate the effects of cycling the baghouse through water dew points. Measurmd $\mathrm{K}_{2}$ values at this plant are significantly lower when the system cycles through water dew poiats. This beneficial effect is offset by the tendency of successive passages through the dew points to increase residual dustcake weight (3). If the effects of wycling on $\mathrm{K}_{2}$ can be maintained while controlling the tendency to increase residual dustcake weight, filtering pressure drop should be significantly reduced.

Prooosed Tests. Sidestream field trials of suitable precoat materials at Scholz are recommended to address the effects of system cycling on dustcake behavior. The most 
important function of a precoat material at this facility would be its ability to eliminate or reduce dustcake buildups associated with cycling through water dew points. A series of four sidestream test conditions are proposed at Scholz to evaluate the effectiveness of aluminum silicate and lime as precoating materials (table 10). Baseline tests will be run with and without cycling.

\title{
Table 10 \\ SCHOLZ SIDESTREAM TRLALS
}

\author{
Condition 1: Test 1a - baseline (one filtration cycle only - no cleaning) \\ Test $1 \mathrm{~b}$ - baseline (repeated filtration/cleaning cycles) \\ Test 1c - baseline with daily cycling (repeated filtration/cleaning cycles) \\ Condition 2: Test 2 - aluminum silicate precoat without daily cycling (repeated \\ filtration/cleaning cycles) \\ Condition 3: Test 3 - aluminum silicate precoat with daily cycling (repeated \\ filtration/cleaning cycles) \\ Condition 4: Test 4 - lime precoat (repeated filtration/cleaning cycles)
}

For the baseline condition a brief preliminary test (1a) will be run to establish a $\mathrm{K}_{2}$ value for the ash. This brief test will be run in the same manner as the parametric and proof-of-concept tests performed in the laboratory. Tests $1 b, 1 c, 2,3$, and 4 will run for approximately five days $6 a c h$, and will include numerous filtration and cleaning cycles.

As with the Montivello trials, the first test condition will provide baseline data for the evaluation of the three tests that will follow. Each application of precoat material will be made with the method described for the Monticello trials. For the test of the aluminum silicate precoat without daily cycling, an initial precoating will be followed by normal filtration of the Scholz ash as in the baseline test $1 \mathrm{~b}$. Test 3 will begin like test 2 , but will involve periodic cycling of the sidestream test chamber thrnugh the water dew point. This cycling will be carried out by shutting off the sample flow just after a cleaning cycle, and letting the sidestream test chamber cool to below the was dew point. Just prior to the reintroduction of hot flue gas into the sidestream, an additional coating of aluminum silicate will be applied to the fabrie/dustcake aggregate. This freshly added precoat is intended to present a barrier between the residual dustcake and the ash that will be collected during the next filtration cycle. Without this berrier, the freshly deposited ash particles would become attached to the residual dustcake with very strong bonds derived from the water, and possibly condensed acid, present after the temperature excursion below the water dew point. By preventing these strong bonds from forming between these ash particles, the rapid rise in residual dustcake weight normally observed with cycling operation should be avoided. Test 4 will evaluate the effectiveness of lime as a precoating material. The procedure followed for this tesi will be the same as either test 2 or 3 , depending on the results of the aluminum silicate evaluations.

The tests at Scholz will be performed on fabric with $25 \%$ EST, and will be carried out at $300^{\circ} \mathrm{F}$, the flue gas temperature in the Scholz du.t. As with the Monticello tests, reverse-gas cleaning cycles in the sidestream will be on a timed basis, occurring each 60 minutes. 
This work work was supported by the U.S. Department of Energy under Contract No. DE-AC2288PC88868. We would like to thank Dr. Perry Bergman, Project Manager, and Chuck Schmidt of the Pittsburgh Energy Technology Center for their contributions to this work. We are also indebted to Dr. E. B. Dismukes of Southern Research In.situte for his aid in identifying and evaluating various conditioning agents. John Hester, Brenda Rinehart and Marvin Steele performed some of the analytical tests we have reported. BHA group supplied the aluminum silicate powder (Neutraliterm) and Cabot corporacion provided the Cab-O-Sil fine silica used in the sereering and filtration tests. 


\section{REFERENCES}

1. K. M. Cushing, R. R. Wilson, Jr., W. B. Smith, "Arapahoe Low-Sulfur Coal Fabric Filter Pilot Plant Volume 2: Characterization and Reverse-Gas Cleaning Tests," EPRI Report Cs $3862,1985$.

2. L. J. Felix, C. J. Bustard, G. E. Kenniston, D. V. Giovanni, R. L. Chang, "Parametric Testing of Filtration Fabrics for Low-Sulfur-Western Coal Fly Ash," presented at Seventh Symposium on the Transfer and Utilization of Particulate Control Technology, 1988.

3. R. F. Heaphy, R. R. Wilson, Jr., R. P. Gehri, R. F. Altman, "Fabric Filter Options for HighSulfur Coal," presented at Seventh Symposium on the Transfer and Utilization of Particulate Control Technology, 1988.

4. G. M. Blythe, J. M. Burke, R. L. Glover, "Evaluation of a 2.5-MW Spray Dryer /Fabric Filter SO2 Removal System," EPRI Report CS 3953, 1985.

5. P. V. Bush, T. R. Snyder, R. L. Chang, "Determination of baghouse performance from coal and ash properties: part I," JAPCA 39: 228 (1989).

6. P. V. Bush, T. R. Snyder, R. L. Chang, "Determination of baghouse performance from coal and ash properties: part II," JAPCA 39: 361 (1989).

7. P. V. Bush, F. G. Pohl, W. B. Smith, T. R. Snyder, "Laboratory Determination of the Characteristic Drag of Various Fly Ashes Collected in Utility Baghouses," presented at 80th APCA Annual Meeting and Exhibition, 1987.

8. D. L. Laudal and S. J. Miller, "Flue Gas Conditioning for" Improved Baghouse Performance," In proceedings of the Sixth Symposium on the Transfer and Utilization of Particulate Control Technology, EPRI CS-4918 Vol. 3, 1986, p. 14-1.

9. O. Molerus, "Theory of yield of cohesive powders," Powder Technology 12:259 (1975).

10. P. V. Bush, T. R. Snyder, W. B. Smith, "Filtration properties of fly ash from fluidized bed combustion," JAPCA 37: 1292 (1987).

11. L. G. Felix, R. L. Merritt, K. Duncan, "Improving baghouse performance at the Monticello Generating Station," JAPCA 36: 1075 (1986).

12. R. Kiyoura, "Studies on the removal of sulfur dioxide from bot flue gases to prevent air pollution," JAPCA 16: 488 (1966).

13. E. V. Margulis, N. I. Kopylov, L. I. Beisekeeva, "Thernal decomposition of ammonium sulphate in the $\left(\mathrm{NH}_{4}\right)_{2} \mathrm{SO}_{4}-\mathrm{H}_{2} \mathrm{SO}_{4}$ system," Russian Journal of Inorganic Chemistry Vol 11, No. 7: 893 (1966). 
APPENDICES

A-1 


\section{APPENDIX A}

\section{FLY ASH SUPPLY SYSTEM}

The fly ash supply system comprised two main functions: redispersion of the fly ash obtained from the source plants (Monticello, Scholz, or Shawnee AFBC) into the gas stream of the wind tunnel; and isokinetic sampling and subsequent modification of the size distribution of the ash sample (when required). The ash redispersion system consistod of a constant-rate screw feeder in combination with an aspirator to inject the ash into the wind tunnel gas stream. The wind tunnel provided the environment for the redispersion and mixing of the fly ash needed for Tasks 2 and 4, and a conditioning chamber for the resuspended fly ash for come of the Task 4 tests. After being isokinetically sampled from the wind tunnel gas stream, the size distribution of the fly ash was modified (if desired) by selecting one of two different inlet cyclone configurations. The arrangement of the major components of the ash supply system are shown in figure A-1.

Preparation of the wind tunnel included general maintenance and repair, lubrication, leak checks, velocity calibration, and checkout of controls and temperature and pressure readouts. The SRI wind tunnel is a closed-loop system. The wind tunnel has a duct diameter of 12.4 inches, can be operated at temperatures between ambient and $400^{\circ} \mathrm{F}$, pressures from 0.7 to 1.0 atm, and stable gas velocities from 5 to $60 \mathrm{ft} / \mathrm{s}$. A venturi is available for monitoring the gas velocity.

Modifications were made to the SRI wind tunnel to allow high concentrations of ash at the sampling nozzle and reduce the total amount of ash required for the filtration tests. A 4-inch diameter wind tunnel was attached as a sidestream to the main wind tunnel. A variable baffle was inserted in the main wind tunnel. A 4-inch ID pipe exited the wind tunnel upstream of the baffle and rentered the wind tunnel downstream of the baffle in a closed loop. The pressure drop induced by the baffle drove flow through the 4-inch $\mathrm{DD}$ pipe at $20 \mathrm{ft} / \mathrm{s}$. Ash and $80 \mathrm{me}$ of the conditioning agents used in Task 4 were injected into this 4-inch ID pipe 20 feet upstream of the FFSS sampling port. An orifice located between the ash injection point and the FFSS sampling port was used to monitor the flow rate in the 4-inch ID pipe. The sampling port was located near the point at which the 4-inch pipe reentered the main wind tunnel. The particulate material remaining in the wind tunnel gas stream was then removed from the circulating gas stream by a fabric filter.

The wind tunnel and ash injection system were calibrated prior to testing. After the 4-inch ID wind tunnel configuration was instailed, twelve pitot measurements were run to determine the orifice constants for the orifice in the 4-inch ID wind tunnel. The pitot traverses indicated that the velocity of gas in the 4-inch pipe was very nearly constant across the pipe at the sampling location. The weight scale on the ash feed hopper was calibrated twice in the course of the parametric tests to insure against drift in the weight scale.

A sampling probe was made for the FFSS so that the optional cyclones could be inserted in the sample train. The configuration used to modify the inlet size distribution of the ash with inlet cyclone $\# 2$ is shown in figure A-2. The suspended ash sample, at a flow rate of 1.3 acfm, passed either through an unobstructed length of tubing (when no size modification was desired), or through one of the two cyclone configurations.

When inlet cyclone \#2 was used, a pre-collecting container was also put in line upstream of the cyclone as an auxiliary inertial separator to insure that the collection cup of the cyclone did not become overloaded during the filtration test. The inertial separator was an air-tight cylinder 12.5-inches tall by 3-1nches in diameter. Tests indicated that the inertial separator had a cut point greater than $2.5 \mu \mathrm{m}$. 


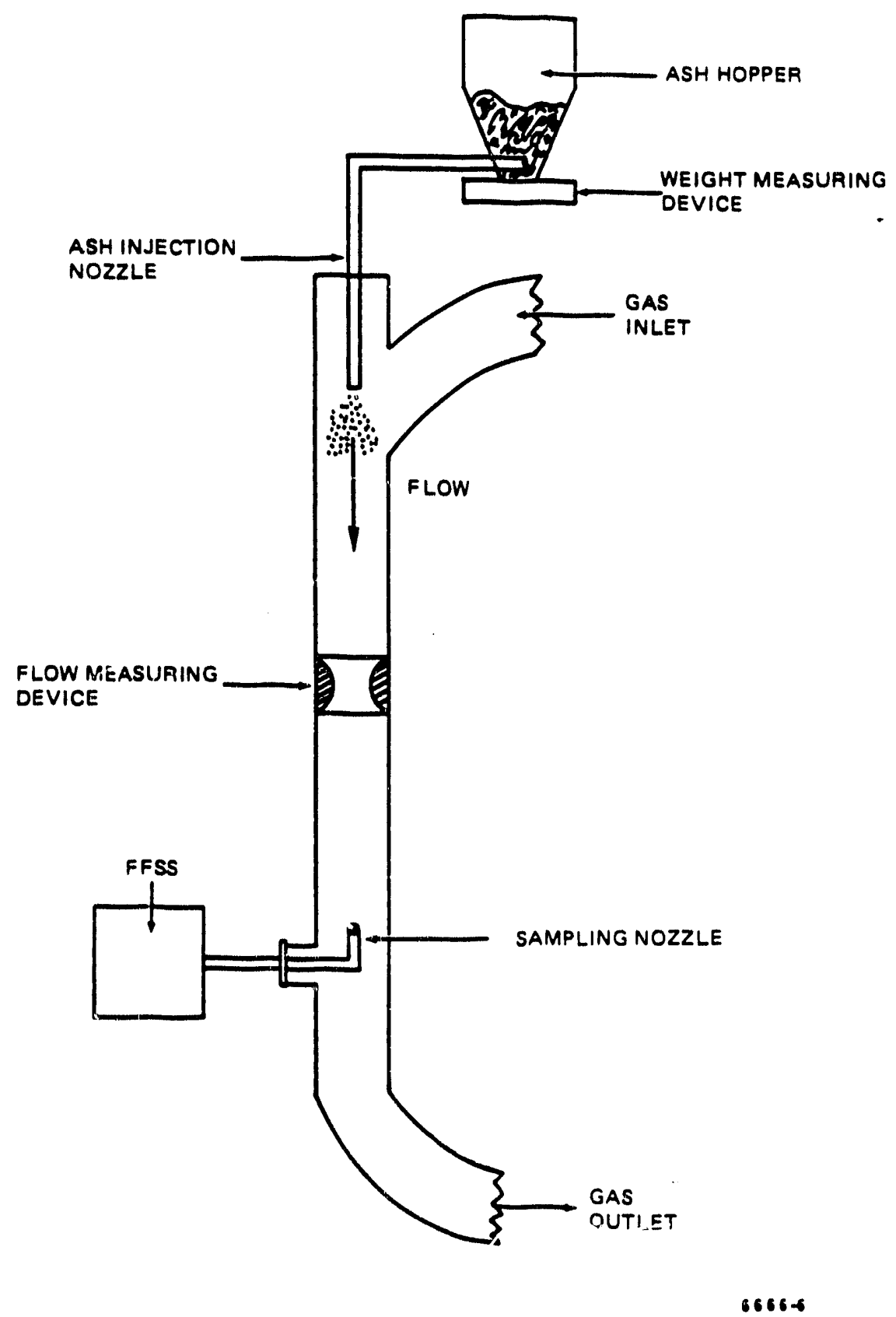

Figure A-1. Schematic diagram of the SRI wind tunuel, ash injention system and FFSS. 


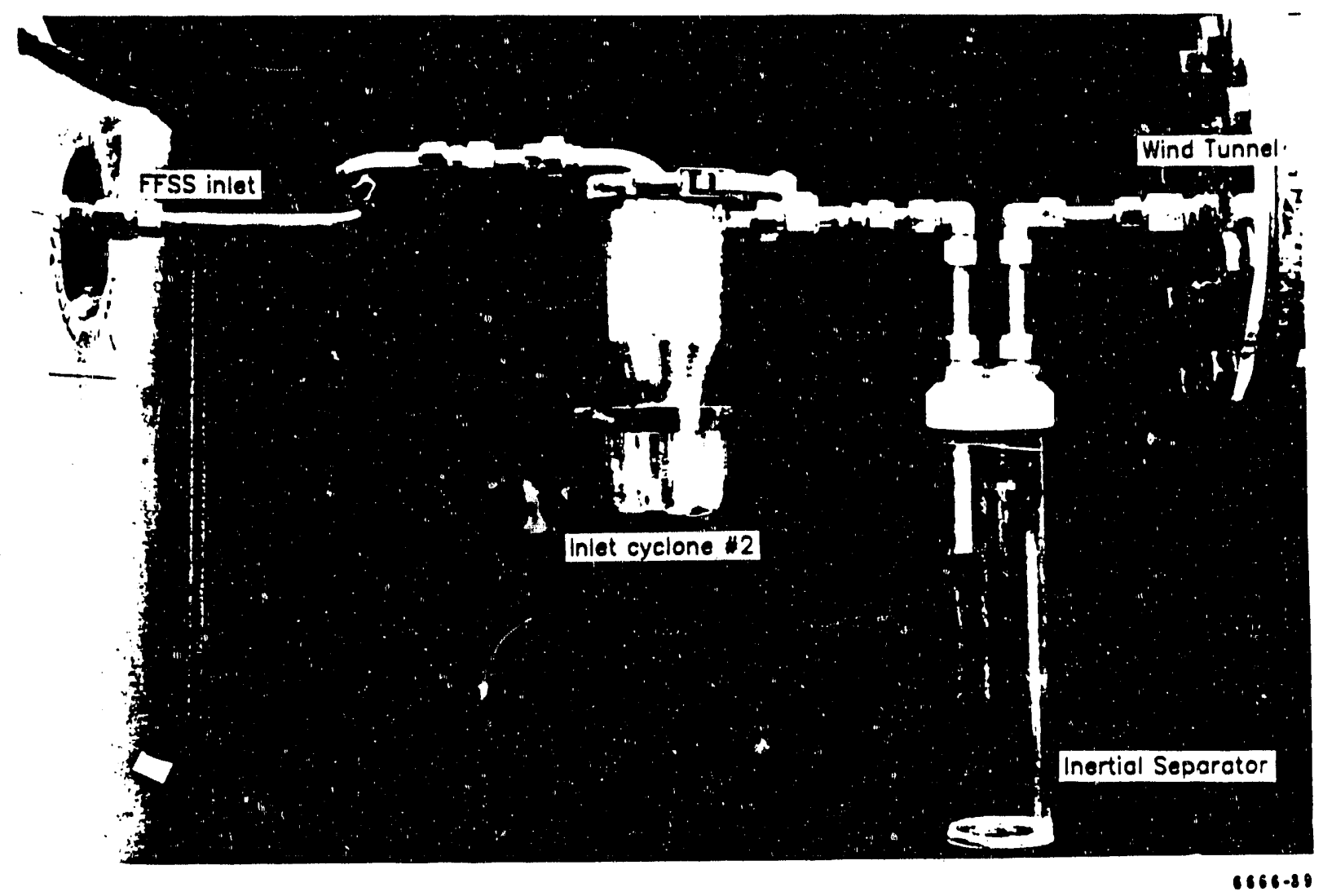

Figure A-2. Photograph of the inlet cyclone \#2 sampling train arrangement. The dust-laden sample air passed through the inertial separator, inlet cyclone $\# 2$, and finally into the FFSS. 
The characteristics of the ash entering the FFSS were determined to assess the effects of modifications of ash particle size distribution on filtration performance. These characterizations included size distribution determinations made with a cascade impactor and inlet mass concentration determinations made with a modified Method 17 mass train. Volumetric size determinations were also performed on inlet ash samples with a Coulter Counter. These measurements were made for each combination of ash source and configuration for optional size modifications. Several EPA Method 17 mass measurements were made for each combination of ash source and sire fraction used in the testing. Mass measurements were run at isokinetic conditions for $3 \mathrm{~min}$ to 1 hour using either a $63 \mathrm{~mm}$ filter or a $19 \times 90 \mathrm{~mm}$ thimble. The particular sampling conditions were chosen 80 as to run for as long as possible without overloading the filter. Consistent mass train results were obtained. Two University of Washington Mark V impactor runis were made for each of the three ash source/size fraction conditions. The impactor data were also accurately reproduced. The total mass collected in the Method 17 tests were used to calculate an inlet mass loading as a check on the accuracy of the impactors. The impactor mass loadings agreed with the mass measurement resu'ts and are included in the reported mass concentration which is an average of all measured mass concentrations.

A specialized plumbing arrangement was required to run the impactor downstream of the inlet cyclone. Because the cut point of the cyclone depends on its flow rate, it was necessary to pull 1.32 acfm through the cyclone to measure the size distribution entering the FFSS. The impactor however, is not accurate at flow rates ereater than $0.75 \mathrm{acfm}$. The solution was to split the flow exiting the cyclone into two legs using a Y-shaped tube. One leg of the $Y$ went through the impactor to a pump pulling $0.66 \mathrm{acfm}$, the other leg went through a mass filter to a pump pulling $0.66 \mathrm{acfm}$, for a total flow through the cyclone of $1.32 \mathrm{acfm}$. The results of both impactor runs were nearly identical, and good agreement was observed between the inlet mass loading measured by the Method 17 tests and by the impactor. As a further check the leg of the $Y$ from which the impactor sampled was switched with the mass measurement and the procedure repeated. The results of this arrangement agreed with the first configuration. Characterizations of the inlet ash were made for each combination of ash source and configuration for optional inlet size modification. 


\section{APPENDDX B}

\section{DESIGN AND OPERATION OF THE FABRIC FILTER SAMPLING SYSTEM}

The fabric filter sampling system (FFSS) was central to the execution of Tasks 2 and 4 and was used to simulate the operation of a fabric filter with reverse-gas cleaning. The FFSS is relatively complex, involving automated electrical sequencing, mechanical flow control, and computerdriven data acquisition and storage. The FFSS consists of modules for holding the filter media, controlling and monitoring flow and temperature in the system, cooling and drying the flue gas after it has been filtered, and acquiring and analyzing data. The various modules and their functions are specified below.

Eiltration cabinet. A schematic diagram of the filtration cabinet is shown in figure B-1. Pressure taps located upstream and downstream of the fabric were used to monitor the pressure drop across the fabric and dustrake. Orifices are mounted in the flow stream in the filtration cabinet to monitor the sample and reverse-gas flows. Four pressure taps located on the side of the filtration cabinet provided access to monitor press ures on the upstream and downstream sides of these two orifices. A high efficiency cyclone located downstream of the fabric collected ash that penetrated the fabric. Heating elements located in the filtration cabinet can maintain the cabinet at temperatures up to $400^{\circ} \mathrm{F}$. If required, the air used for reverse-gas cleaning can be beated to the temperature of the filtration cabinet by passage through a coil of copper tubing mounted inside the cabinet.

Centrol cabinet. A central control box was used to control and monitor temperature, flow rate, pressures, and operating mode of the system. Three modes of operation are provided: manual, automatic, and idle. In manual mode the state of the system (filtering or reverse-gas cleaning) is chosen by means of a two-way paddle switch. In the automatic mode the system switches between filtering and reverse-gas cleaning using a timer set by the operator. The timer allows for setting the duration of both the filtration cycle and the reverse-gas cycle. No gas flows through the system in the idle mode. Temperature monitoring and control is provided for the filtration cabinet heaters and two probes by type-J thermocouples. Temperature monitoring without control is also provided for up to seven auriliary type-J thermocouples.

Pressure drop was monitored across the fabric and across the flow-metering orifice, and static pressure was monitored at the orifice. Solenoid valves automatically select which orifice is monitored, depending on whether the FFSS is filtering or cleaning. Transducers in the FFSS control cabinet monitored these pressures and output a signal to the data acquisition system.

Coarse and fine adjustment valves located in the sample flow line and in the reverse flow line enabled the air-to-cloth ratio to be set independently for forward and reverse flows. Flow of both the flue gas and reverse air through the FFSS is driven by an electric pump powered from the control cabinet. A timer measures total elapsed sample time.

Gas cooline and dryinemedule. After the flue gas exits the filtration cabinet it passes through a condenser. The coolant for the condenser is continuously cycled through a liquid chiller. The flue gas then passes through a particulate filter and a drying column charged with silica gel. This process assures that the flue gas at this point is completely clean and dry. The flue gas then passes on to the control cabinet.

Data acauisition and analysis system. A computer utilizing Labtech NotebookC software served as a data acquisition system for the FFSS. The orifice static pressure, pressure drop across the orifice, and orifice (filtration cabinet) temperature were continuously monitored and used to calculate the flow rate and the air-to-cloth ratio. The pressure drop across the fabric was also 


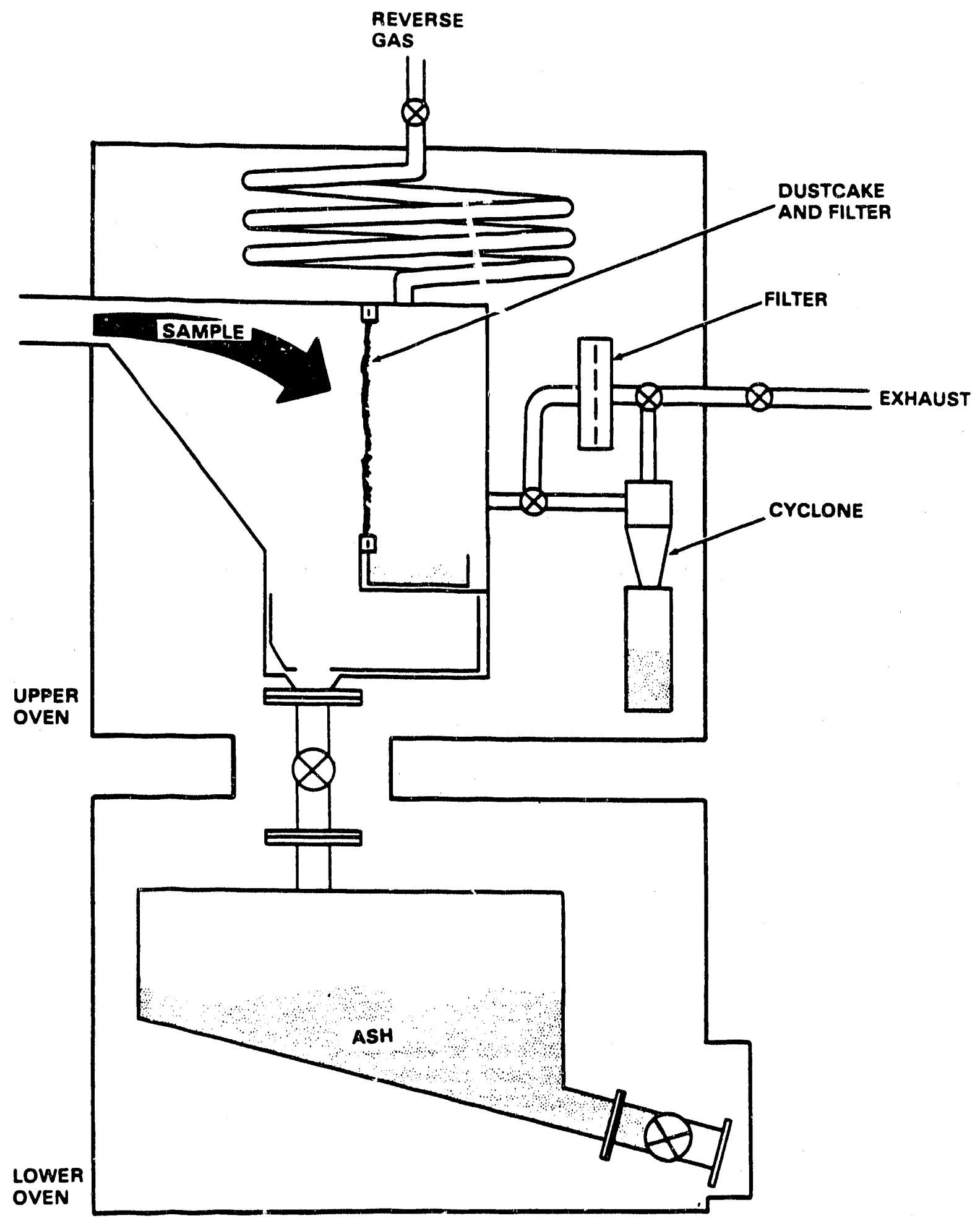

Figure B-1. Schematic diagram of the FFSS filtration cabinet. 
monitored continuously and, along with the air-to-cloth ratio, was used to calculate the drag. These values were displayed on the computer monitor during the test along with a real-time graph of drag as a function of time.

Standard operating procedures for the SRI FFSS. The following outline provides a summary of the operating procedures used during the filtration tests.

\section{FFSS proparation}

A. Clean FFSS components of any rosidual fly ash

1. Inlet cyclone

2. Iniet tubing

3. Inside of sampling transform

4. Outlet cyclone

B. Install fabric and seal the FFSS

C. Connect to sampling cabinet the inlet cyclone (if desired)

II. Ash feed system preparation

A. Turn on ash feed system control panel

B. Set reentrainment air pressure to $40 \mathrm{psi}$

C. Set the ash feed rate

D. Check to see that the ash hopper is full

III. Wind tunnel start-up

A. Turn on wind tunnel control system

B. Start wind tunnel fan

C. Set fan speed so that $\Delta P$ orifice $=0.5$ in WC

IV. Control cabinet and computer system start-up

A. Turn on control cabinet main power

B. Turn on control cabinet heater power

C. Set temperature of sampling cabinet for test

(not used for Task 2 tests)

D. Turn on computer system

E. Check computer clock and reset if necessary

F. Run initialization program

G. Run Labtech Notebooke

H. Input the barometric pressure to Labtech Notebooke

V. Start sampling

A. Set flow rate through FFSS

1. Start data acquisition system

2. Start forward flow through sampling cabinet

3. Adjust flow rate as displayed on computer screen

4. Stop forward flow through sampling cabinet

5. Stop data acquisition system

B. Start reverse gas through sampling cabinet

C. Start ash feed system into wind tunnel

D. Check ash feed system for any sign of blockages

E. Start data acquisition system

F. Stop reverse gas through sampling cabinet

G. Start forward flow through sampling cabinet

VI. Sampling

A. Check instruments for any snomalous readings 
B. Check the ash hopper and refill as needed

C. Check the ash feed system for blocksoges

VII. End sampling

A. After prescribed time for the test turn off ash feed

B. Stop data acquisition

C. Open FFSS and remove fabric

D. Recover and weigh ash collected by the

1. Inlet cyclone

2. Hopper

3. Fabric

4. Outlet cyclone

VIII. Shut down

A. Control cabinet

1. Turn off forward flow

2. Turn off heater power (if on)

3. Turn off main power

B. Computer system

1. Exit Labtech Notebook 0

2. Recover data from temporary file on hard disk and store on floppy disk

3. Park hard disk heads

4. Turn off power

C. Ash feed system

1. Turn off reentrainment air

2. Turn off control panel

D. Wind tunnel

1. Reduce fan speed to zero

2. Turn off power to fan

3. Turn off control panel 


\section{APPENDIX C}

\section{TECHNIQUES USED TO ANALYZE FABRIC FILTER SAMPLING SYSTEM DATA}

After the completion of each test, the mature dustcake/fabric aggregate was removed for determinations of dustcake areal density. Samples of dustcake ash were also subjected to a variety of laboratory analyses to compare the characteristics of the ash collected on the fabric with the filtration behavior recorded for the test.

Because of the flue gas decr ased in velocity as it passed through the FFSS transform, the larger size fraction of the fly ash fell out into the hopper located below the transform. The collection efficiency values presented in tables 3 and 8 represent the total colisction efficiency of the FFSS s) stem. This overall system collection efficiency is the percentage of the ash entering the FFSS (including the hopper fallout) that did not penetrate the fabric. The collection afficiency of the fabric is defined as the fraction of the ash that gets to the fabric and does not penetrate to the outlet cyclone.

The standard way to compare filtering data is to normalize the pressure drop by tine filtering face velocity (or air-to-cloth ratio), yielding the quantity called drag. Drag is then presented as a function of the dust loading (or dustcake areal density) on the filtering fabric throughout the filtration test. One of the two principle characteristics of the drag-areal density relationship is the specific drag coefficient, $K_{2}$, which is defined as the slope of the curre after ash particles have filled the pores in the fabric or dustcake. The relationship is expected to become linear after these pores have been filled, and theoretically does for idealized porous beds. The other principle characteristic of the drag-areal density relationship is the effective residual drag, $S_{e}$ which is the value of drag of the intercept of the linear part of the curve extrapolatec' back through the drag axis. These two characteristics are shown graphically in figure 3, an idealizid data set.

Two types of curve fits were performed on the data from each test relating drag to areal density. To obtain the $\mathbf{K}_{2}$ value, a linear least squares fit procedure was applied co the linear portion of the relationship between drag and areal density. The slope of this fitted line was defined as the $K_{2}$ value for that test. To obtain the $S_{e}$ value, a second-order fit was applied to the same portior of the curve chosen for the first order fit. $S_{e}$ is the $Y$ intercept of this second-orcer curve. Using a secondorder fit for the calculation of $S_{e}$ eliminated eitoneous $S_{e}$ values obtrined with first-order fits $f($ S some of the early illtration tests.

Sudden increases in fabric pressure drop were observed in some of the filtration tests. We believe these increases were due to dustcake compaction resulting in a decrease in porosity. These perturbations were factored out of the data for the purposes of our analyses. Adjustments were made to the data to allow comparisons between different tests. In some tests a sudden increase in pressure drop occurred only during the last few minutes of the test, in which case onl"y the data collected prior to the event was reported. Where many increases in pressure drop uscurred througlaout the test, the effects were removed by subtracting the magnitude of the increase from all data adter each increase. 


\section{APPENDIX D}

\section{LABORATORY TESTS USED TO CHARACTERIZE FLY ASH SAMPLES}

The following tests were used to sharacterize fly ash samples:

1) Aerodynamic size distribution (Bahco classifier)

2) Volumetric size distribution (Coulter Counter)

3) Specific surface area (Brunaeur-Emmett-Teller analyzer)

4) Compacted bulk porosity

5) Uncompacted bulk porosity

6) Dustcake porosity

7) True particle density (Helium pyenometer)

8) Permeability (gas flow resistance, drag-equivalent diameter)

9) Morphology factor

10) Effective angle of internal friction (ring shear device)

11) Scanning Electron Microscope (SEM) photographs

12) Mineral analyses

13) Sciuble $\mathrm{SO}_{4}=$

14) Soluble $\mathrm{NH}_{4}+$

15) Equilibrium $\mathrm{pH}$

The following discussion provides a brief summary of each of these laboratory tests.

Bahco mass median diameter - This standaro technique provides a measurement of the median diameter of the fly ash size distribution based on aerodynamic classification of fly ash particles. The results of this test indicate whether the ash is typically sized (in comparison to other ashes tested, or abnormally fine or coarse. An abnormal size distribution can have significant effects on filtration behavior. In general, dustcakes composed of extremely fine ash particles exhibit abnormally high filtering drags.

Coulter volumetric median diameter - This standard technique provides a measurement of the median diameter of the fly ash size distribution based on volumetric classification of the fly ash particles. The results of this test are used in the same way as the Bahco data and also in the calculation of the morphology factor, described below.

Specific eurface area - This measurement utilizes the Brunaeur-Emmett-Teller (BET) technique for determining the total surface area of a known mass of fly ash sample. Ashes that exhibit abncrmally high specific surface areas are usually highly cotesive, and form dustcakes with relatively high porosities. Abnormally low specific surface area values can indicate potential bleea-through problems.

Compacted bulk porosity - This value expresses the porosity of a column of ash compressed under a given load. Ashes exhibiting a relatively high bulk porosity value are generally highly cohesive.

Uncompacted bulk porosity - This value expresses the porosity of container of sifted, unpacked dustcake ash. A fairly strong direct sorrelation exists between this value and the porosity of actual dustcakes formed on fabric filters.

Dustcake porosity - This value is the measured porosity of the actual dustcake formed on the fabric filter. Dustcake porosity is dependent on the ash particle size distribution and the ash cohesivity. 
Density - This standard measurement is obtained with a helium pycnometer. The value obtained with this technique is the true density, or specific gravity of the ash particles in the sample tested. Ash particle density is a factor in calculating porosity, aerodynamic particle diameter and the morphology factor.

Gas flow resistance - This value is obtained by filtering air at a known flow rate through a simulated dustcake of known porosity in a laboratory test device while measuring the resistance to the air flow (permeability). When this measurement is made with the porosity of the simulated dustcake equal to the estimated characteristic dustcake porosity of the ash, the resultant gas flow resistance is defined as $R$. The $R$ value is the resistance that this simulated dustcalse (with an areal loading of $1.0 \mathrm{lb} / \mathrm{ft}^{2}$ ) exhibits for an air flow of $1.0 \mathrm{acfm} / \mathrm{ft}^{2}$.

Drag-equivalent diameter - This quantity is not a measurement of physical size, but rather a fitted parameter ranking the characteristic gas flow resistances of ashes at equal porosities. Larger values of drag-equivalent diameter indicate a lower resistance to gas flow at a given porosity. Measurements of physical size (Bahco and Coulter median diameters) generally correlate with this expression; however, the drag-equivalent diameter best expresses the fineness of an ash as it relates to its effect on gas flow resistance. Ashes with smaller values of drag-equivalent diameter are generally more cohesive. Drag-equivalent diameter generally decreases with increasing specific surface area.

Morphology factor - This quantity is derived from Coulter sizing data, density of the ash particles and BET specific surface area determinations. The Morphology factor expresses to what degree the ash particles resemble smooth spheres. A murphology factor of 1.0 indicates the particles are perfectly smooth spheres. Morphology factor values are larger for ash particles that are more irregular in shape. Ashes with low morphology factor values (less than 2.0) are more likely to bleed througt the filtering fabric.

Effective Angle of Internal Friction - This quantity is measured at Southern Research Institute with a specially-developed Ring Shear Device, and expresses the relative cohesivity of an ash sample. Ashes that are more cohesive exhibit higher values of the effective angle of internal friction. Effective angles below 39 degrees indicate ashes with very low cohesivity.

Scanning Electron Microscope (SEM) photograpls - This conventional technique is used to obtain a physical description of the ash particles. Variations in particle size and shape can be qualitatively judged from observation of SEM photographs.

Mineral analyses - Conventional techniques are used to determine the elemental concentrations of the primary chemical components of the fly ash.

Soluble $\mathrm{SO}_{4}=-$ This test measures the percentage by weight of soluble $\mathrm{SO}_{4}=$ in the ash sample.

Soluble $\mathrm{NH}_{3}$ - This test measures the percentage by weight of soluble $\mathrm{NH}_{3}$ in the ash sample. 
APPENDIX E

ADDITIONAL DATA FCR FILTRATION TESTS OF UNCONDITIONED ASHES 


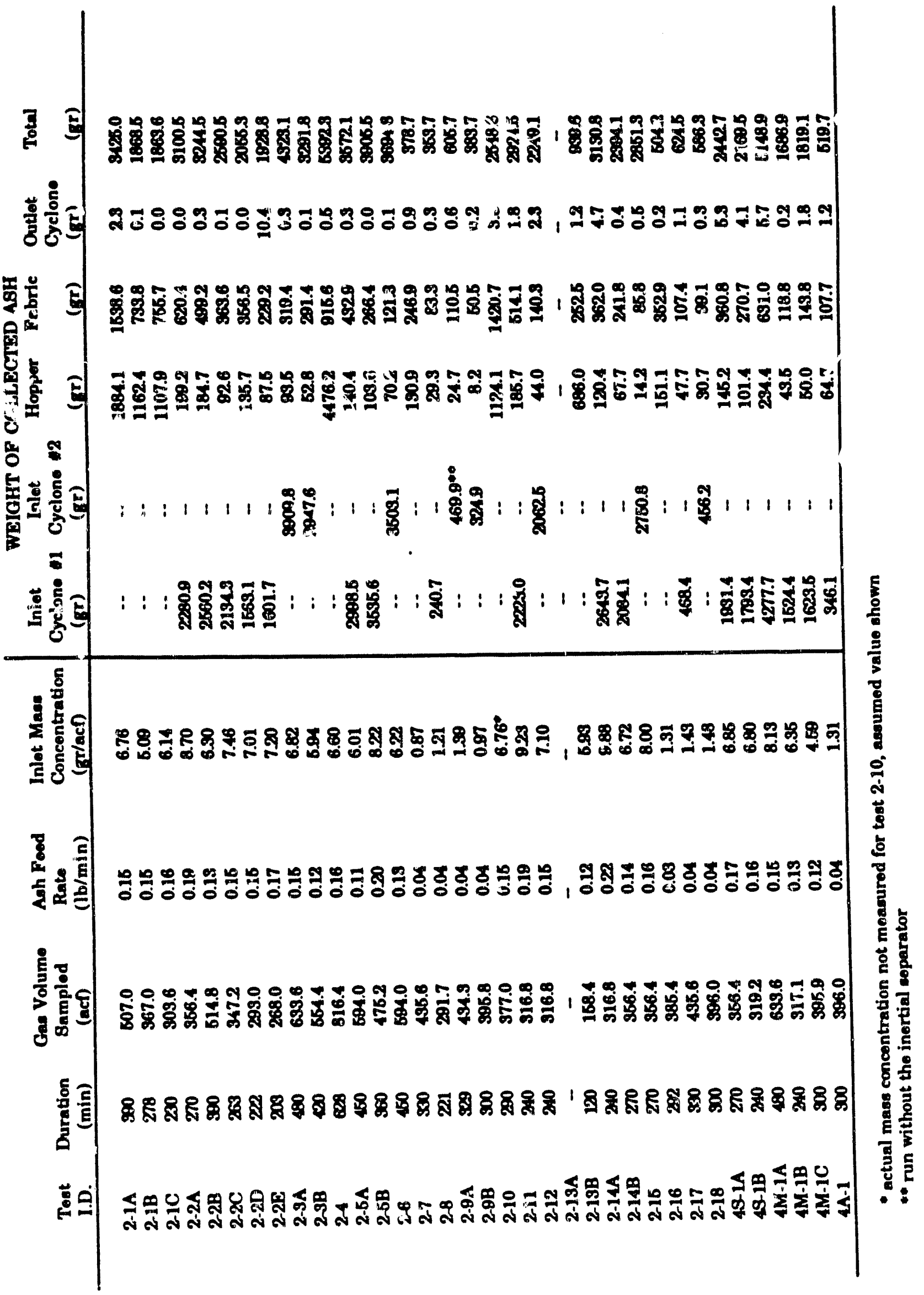


PROCEDURES AND PARAMETERS USED TO GENERATE THE IITERATURE SEARCH

Two separate search procedures w ore carried out using the DLALOG information service. The firnt procedure was a search of titles frem the Chemical Abstracts database conducted on Octo'ser 15, 1988. 679 titles were returned from this search which was rus with the following sets and key words:

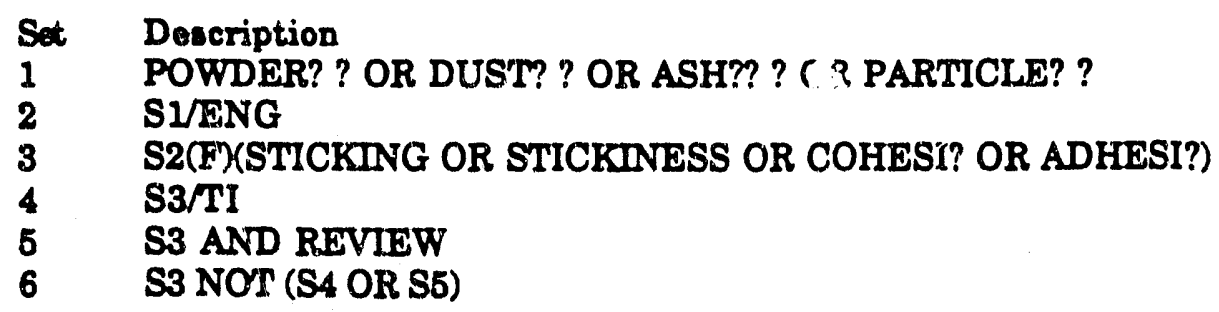

The recond procedure performed through the DLALCG Information Services was a search of abstracts contained in the National Technical Information Service (NTIS), COMPENDEX PLUS, and Searchable Physics Information Notices (SPIN) databases. The NTIS database consists of unclassified government-sponsorgd research, development and engineering reports, and other analyses prepared by government age.scies. The COMPENDEX PLUS database provides coverage of the world's significant engineering and technical literature. This database corresponds to the printed publication, "Engineering Index", plus additional conference records from the Engineering Meetings file. The SPIN database provides the most current indexing and abstracting of the major American, Russian, and Chinese physics and astronomy journals.

1632 abstracts were returned from the NTIS database, 3504 abstracts were retumed from the COMPENDEX PLUS database, and 480 abstracts were returned from the SPIN database. This procedure was performed March 10, 1989 with the following sets and key words.

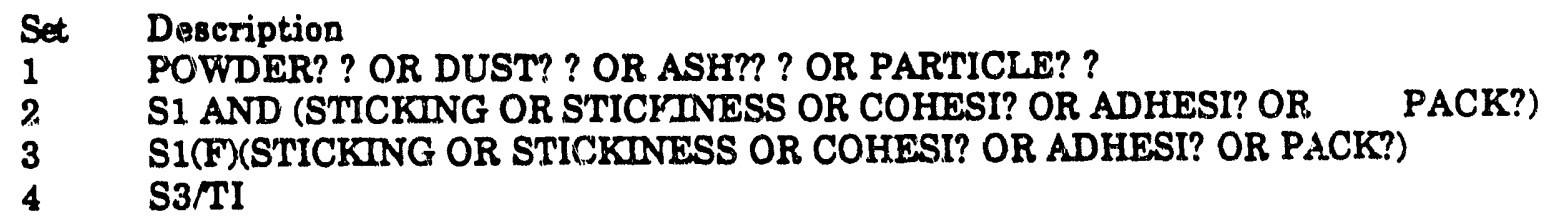

All the abstracts and titles received were examined, and orders were placed for articles that appeared to contain informstion applicable to this project. A total of 134 articles were obtained and examined thoroughly. The reviews of these articles were directed toward finding descriptions of the mechanisms governing particle-to-particle interaction, and prospective ash conditioning agents. Appendix $G$ summarizes the most useful of these articles. 


\title{
APPENDLX G
}

\section{SUMMMARY OF PERTINENT ARTICLES AND ADDITIONAL INFORMATION OBTAINED THROUGH THE ITTERATURE SEARCH}

\begin{abstract}
A total of 134 articles were obtained through the literature searches described in Appendix F. These articles were examined thoroughly for descriptions of the mechanisms governing particle-toparticle intoractions and prospective ash conditioning agents. The most useful of these articles are summarized below. Also included in this appendix are excerpts from a memorandum by Dr. E. B. Dismukes concerning several types of substances that might be useful for altering the cohesivity of fly ash.
\end{abstract}

1. Abbott, M.F. and I. G. Austin. Studies on slag deposit formation in pulverized-coal combustors. 4. Comparison of sticking behavior of minerals and low-temperature and ASTM high-temperature coal ash on medium carbon steel substrates, 5uel 61: 765 (1982).

This aricle contsins some data contrasting Texas lignite and two other coals and coal ashes. Slag sticking behavior may not correlate with the results of sticking tests performed on bulk minc rals or cosl ashes. Results in this paper are limited to the sticking behavior of minerals and ashes on steel substrates, and are generally presented in terms of contact angle and adhesion strength. None of tis data presented in this article show direct application to this projest.

2. Downtou, G.E., J.L. Flores-Luna and C.J. King. Mechanism of stickiness in hydroscopic, amorphous powders, Ind. Eng. Chem. Fundam. 21: 447 (1982).

This article deals mainly with high-molecular-weight food compounds, and the problems ancountered due to stickiness of these compounds. Moisture content of the powders was the primary concern of the work. Some minor mention is made to the surface tension of liquid on particle surfaces. The Karl Fischer titration method for the determination of moisture is referenced.

3. Geldart, D. and A.C.Y. Wong. Fluidization of powders showing degrees of cohesiveness - II. Exporiments on rates of de-aeration, Chemical Engineering Science 40 (4): 653 (1985).

The rrimary objective of this work was to identify differences between powders in Geldart's groups A and C. Sizes of the powders considered ranged from 3 to $125 \mu \mathrm{m}$, which are probably too large for application as conditioning agents. In these studies of powder bed collapse, the authors note that the bed of powder should be absolutely dry as to avoid extraneous cohesive forces.

4. Booth, S.W. and J.M. Newton. Experimental investigation of adhesion between powders and surfaces, J. Pharm. Pharmacol. 39: 679 (1987).

The results of the studies covered in this article are quite specific to two powders used in the pharmaceutical industry: (poly(ethylene glycol) 4000 and Sta-Rx 1500). The introduction does indicate that several different mechanisms cause adhesion: van der Waals' forces, electrostatic forces, isquid bridges, and contact melting.

5. Otsuka, A, K. Iida, K Danjo and H. Sunada. Measurement of the adhesive force between particles of powdered materials and a glass substrate by means of the impact separation 
method. III. Effect of particle shape and surface asperity, Chem. Pharm. Bull. 36 (2): 741 (1988).

This article discusses the effects particle shape and the presence of surface asperities have on adheaive force. These discussions are based on the assumption that the adhesive force is solely due to the van der Waals force. Although the sample powders used are significantly larger (25 to $60 \mu \mathrm{m}$ diameter) than potential conditioning agents, the general effects of particle shape and surface asperity may be valid for the modification of fly ash cohesivity by the introduction of relatively small asperities in the form of a fine powder to the fly ash particles. Two interesting procedures were used in this study to alter particle surface mo:phology: calcium carbonate was treatsd with various concentrations of hydrochloric acid to smooth the particle surface; and small calcium carbonate particles were added to larger, smootín calcium carbonate particles to introduce surface asperities onto the larger particles. Adhesive force decreased rapidly as asperities were added to the larger, smooth particles. Aftor about $0.3 \% \mathrm{w} / \mathrm{w}$ of asperities were added, the measured adhesive force of the resultant miz reached its relative minimum at about 10 to $20 \%$ of the adhesive force of the "clean", large, smooth particles.

This article also discussed the geometry of the contact point watroen the particles and the glass substrate used by the investigators. Angular particles contacted the substrate with the tip or short edge of the particle, resulting in a decreased area of contact as compared with sph rical particle/substrate surface contact area. The adhesive bond with the substrate was weaker for the more irregularly-shaped particles. The authors also postulated that the effects of surface asperities on particle adhesion are dominated by the larger of the surface asperities, with the - smaller asperities having much less significance.

7. Cartilier, L.H. and AJ. Moes. Effect of flowing adjuvants on the homogeneity and the kinetics of mixing of low dosage cohesive powder mirtures, Drug Development and Industrial Pharmacy 12 (8 \& 9): 1203 (1986).

This article deals with the addition of powders having very small mean diameters (flowing adjuvants) to larger powders in order to break apart powder agglomerates. The first, adjuvant tested was colloidal aluminum oxide (Degussa, Frankfurt, R.F,A.). This powiter is reported to have very good antistatic properties, and has exhibited a specific surface area of $100+/ .15$ $\mathrm{m}^{2} / \mathrm{g}$ and a mean diameter of $0.020 \mathrm{\mu m}$. The second adjuvant was Aerosil-200 (Degussa, Frankfurt, R.F.A.) has a specific surface area of $200+1.25 \mathrm{~m} 2 / \mathrm{g}$ and a mean diameter of 0.012 $\mu \mathrm{m}$. The authors concluded that the aluminum oxide facilitates the breakdown of drug agglomerates and prevents reagglomeration.

8. York, P. Application of powder failure testing equipment in assessing effect of glidants on flowability of cohesive pharmaceutical powders, Journal of Pharmaceutical Sciences 64 (7): 1216 (1975).

Three glidants were investigated in this article: fine silica, magnesium stearate, and purified talc. Each glidant exhibited an optimum w/w concentration in mixes with two host powders (lactose, calcium hydrogen phosphate) for increasing flowability. The following reasons are postulated for the effectiveness of glidants: 1) removal of electrostatic charges on the surface of the host powder; 2) collection of very fine cohesive host particles onto glidant particle surfaces (host size << glidant size); 3) selective adsorption of gases and vapors otherwise adsorbed onto the host powders; 4) reduction of van der Waals forces by separation of bost powder particles; and 5) reduction of interparticle friction and surface roughness by glidant particles adhering to the surface of the host powder. 
The authors discounted the simple angle of repose test for cohesive powder/glidant mixtures. Shear flow factors were used to assess the cohesiveness of the various powder mirtures tested. Optimum $w / w$ concentrations for fine silica were $0.85 \%$ for lactose and $1.45 \%$ for calcium hydrogen phosphate. (Similar trends for optimum concentration were observed with the other two clidant - talc 2.25\%, and 2.45\%, and magnesium stearate $1.75 \%$ and $2.20 \%$.) The difference between hydrophobic and hydrophilic powders coems to alter the mechanism for cohesivity.

9. Muller, V.M., V.S. Yushchenko and B.V. Derjaguin. General theoretical consideration of the influence of surface forces on contact deformations and the recifrocal adhesion of elastic apherical particles, Journal of Colloid and Interface Science 92 (1): 9 ; (1983).

This article is a theoretical treatise of the effects of surface forces determining adhesion between particles.

10. Tangsathitkulchai, M. and L.G. Austin. Nature of the surface involved in fly ash adtesion on boiler steel, Fuel 64: 1764 (1985).

This article covers the adhesion of molten coal ash particles to steel surfaces. Chemical bonding, not mechanical microporosity, was identified as the primary determinant of adhesive strength.

11. Uno, H. and S. Tanake. Adhesion of suspension particles on the wall surface of the container - IV. Effect of additives on particle adhesion, Kolloid-Zeitschrift und Zeitscrift fur Polymere 245: 519 (1971).

This article examines the adhesive properties in liquid suspensions, and is therefore not directly applicable to fly ash conditioning; however, several of the conclusions derived from these studies may apply to a dry conditioning system. The authors concluded that all the effects due to additives are due to the adsorption of the additives on the surface of the host particles, and that van der Waals forces can explain the surface forces.

12-15. Gillespie, T. and W.J. Settineri. The effect of capillary liquid on the force of adhesion between spherical solid particles, Journal of Colloid and Interface Science 24: 199 (1967).

Along with attached responses (13-15) from various readers, this article (12) is a mathematically-based study of the effect of capillary liquid on the adhesive force between two identical spherical particles.

16. Pilpel, N. Cohesive pharmaceutical powders, Advan. Pharm. Sci. 3: 173 (1971).

This discussion provides a general trestment of the cohesivity of fine powders. Pilpel notes that only a few powders with mean particle diameters greater than $300-400 \mu \mathrm{m}$ exhibit cohesive behavior, although the application of Aerosil (silica: mean diameter $<10 \mu \mathrm{m}$ ) as glidant can still improve flowability characteristics of a host powder. The shear cell is identified as a appropriate testing method for fine powders (less than $100 \mu \mathrm{m}$ mean diameter). A significant discussion is provided on equipment for the measurement of cohesive strength and the data reduction techniques that are used with these measuring devices. Brief discussions cover the effects of particle size and shape, and bulk moisture content on powder cohesivity. Cohesivity increases as particle size decreases, as particle shapes become more irregular, and as moisture content increases.

Pilpel states that acidition of a giidant to a powder can affect the powder's cohesiveness through several factors: chemical or physical affinity for the powder, the glidant particles' size and 
shape in relation to the host powder, and the concentration and degree of miredness of the glidant with the powder. Pilpel also states that a hydrophilic glidant such as silica tends to more effective on a hydrophilic powder because the glidant achieves a more uniform distribution on the hydrophilic host particle surface than this same hydrophilic glidant would achieve on hydrophobic powder. In this latter case the glidant would tend to accumulate in the void spaces between the particles.

Glidants are most effective when they are significantly smaller than the host particles, allowing the host particles to be coated completely. Pilpel also notes the existence of an optimum glidant concentration, above which cohesivity may increase. Talc, starch, magnesium stearate, fly ash, and aerosil are identified as glidants, and ranges of optimum concentration for these materials are shown when mixed with particular host powders. A discussion of anti-caking agents notes that this effect may be produced through several mechanisms. These include selective adsorption of moisture, the rupturing of moisture films, physical separation of particles, neutralization of electrostatic charges, and reduction in van der Waals forces and coefficient of friction. Finally, Pilpel notes that elevated temperature can improve the compressibility of powders, thereby indicating reduced powder cohesivity.

17. Whikazawa, M., T. Kanazawa and T. Yamaguchi. The role of adsorbed water on adhesion force of powder particles, Kona 2: 54 (1984).

In the introduction to this article, the relative strengths of the adhesion forces due to water vapor adsorption and van der Waals forces are briefly discussed. For hydrophilic powders, the adhesion force due to water adsorptior. is generally considered to be greater than the van der Waals force. The main body of the article is directed toward the mechanism of the adhesion force due to water vapor adsorption at relatively high humidities.

19. Bohme, G., W. Kling, H. Krupp, H. Lange, G. Sandstede and G. Walter. Measurement of the adhesion of small particles. Chem. Phys. Appl. Surface Active Subst., Proc. 4th Int. Congr., J. Overbeek, editor. 2: 429 (1967).

In this general discussion of the factors influencing the adhesion of small particles, the authors determine that adhesion strength incieases with increasing particle smoothness (or size for the spherical particles used in these tests), time of contact, and adsorbed water. An equation is also given describing the influence of adsorbed water on adhesive force. This equation may be useful in assessing the effects of liquid conditioning agents, and will be covered in greater detail during the evaluation of any liquid agents used.

2.2. York, P. and N. Pilpel. The effect of temperature on the frictional, cohesive and electrical conducting properties of powders. Materials Science and Engineering 9: 281 (1972).

The authors describe the interactions that occur between contacting particles when these particles are subjected to high pressure or temperature. Although the pressures required to induce the melting or plastic deformations the authors discuss in this article are unlikely to be encountered in fabric filter applications, some of the mechanisms described may occur with conditioning agents.

23. Adams, M.J. and V. Perchard. The cohesive forces between particles with interstitial liquid. Inst. Chem. Eng. Symposium Series No. 91: 147 (1985).

The authors provide many detailed calculations of the cohesive forces due to interstitial liquid. 
24. Rao, AS. Cohesive strength of alumina powder compacts. Ceramics International, 13: 139 (1987).

The author investigates the cohesive strength of eight commercial submicron alumina powder compacts. The most important factor was surface charge level. If the powders are moderately charged, the powder compact tensile strength was governed by van der Waals forces.

25. Rumpf, H. Particle adhesion. Agglomeration, 2nd Proc. Int. Symp., K. Sastry, editor. : 97 (1977).

This article discusses various mechanisms involved in particle adhesion, and provides comparisons of these mechanisms. Van der Waals forces, liquid bridges, salt bridges, and electrostatic effects are each covered in separate discussions. The author states that the st-ength of salt bridges is highly dependent on drying conditions and salt contents. Rumpf states that the primary influence on particle adhesion is the particle shape.

28. Larsson, N. and J.C. Eriksson. Acthesion of $\mathrm{Fe}_{2} \mathrm{O}_{3}$ and $\mathrm{SiO}_{2}$ particles to some chemically modified polymer surfaces, Microscopic sspects of adhesion and lubrication. Elsevier Scientific Publishing Company 1982.

The authors state that $\mathrm{Fe}_{2} \mathrm{O}_{3}$ particles they studied carried a positive surface charge, while the $\mathrm{SiO}_{2}$ particles carried a negative charge. (These two compounds are generally the two most common compounds found in fly ash.) The rest of the article is not highly useful to the project goals.

29. Schutz, W. Influence of pressing forces and of atmospheric humidity on particle adhesion, Deposition and Filtration of Particles from Liquids and Gases, Symposium of the Society of Chemical Industry, 1978.

In this article, adhesion is noted to become important for particles less than $100 \mu \mathrm{m}$ diameter, with adhesion tahing the prominent role for particles less than $50 \mu \mathrm{m}$ diameter. Van der Waals forces and liquid bridges are highlighted in this article. The effects of roughness on these two forces are discussed. Van der Waals forces are decreased by small degrees of surface roughness, but can be increased for certain geometries involving increased roughness. (The type of roughness, or surface morphology, determines the degree of this eftect.) The effect of roughness on adhesion due to liquid bridges is strongly affected by the amount of liquid in the bridges. Increased liquid decreases the influence of roughness on adhesion. Since the contacts between fly ash particles will certainly differ from the idealized systems investigated in this article, the data reported by Schutz only provides general trends.

31. Rosner, D.E. and R. Nagarajan. Toward a mechanistic theory of net deposit growth from ashladen flowing combustion gases: self-regulated sticking of impacting particles and deposit erosion in the presence of vapor deposited - or submicron mist - 'glue', Heat Transfer, AIChE Symposium, 1987.

The mathematical modeling approach of this work precludes its direct application toward identification and evaluation of conditioning agents. This article may prove useful if a conditioning agent is located which acts in the same manner as the 'glue' described by the authors. 
32. Rafailidis, S.V. and J.A. Reizes. Determination of the adhesivity of acrylics on fresh coal fly ash particles, Part. Part. Syst. Charact. 5: 130 (1988).

Specific tests performed in this article highlight the effect of the electrostatic charge on fly ash particles on their adhesivity to acrylic fibers. If some charging technique is used to modify the cohesivity of the ash particles, or if some conditioning agent modifies the existing charge on the fly ash particles significantly, the authors' description of some testing techniques may prove useful.

36. Scarlett, B. Measurement of particle size and shape, some reflections on the BCR reference material programme, Part. Charact. 2: 1 (1985).

This article provides a good discussion of some of the most critical, and most often overlooked, aspects of particle sizing measurements. This background information places various sizing measurements in perspective.

39. The Surface Chemistry of Solids, 2nd edition, 1961.

This work deals mainly with macroscopic interactions between solids. The importance of deformation at contact points is stressed, with adhesion and cohesion increasing with increasing deformability.

40. Sutton, H.M. Flow properties of powders and the role of surface character.

This work provides an extensive background on many of the factors that affect particle cohesion. In general, these factors are discussed in greater detail in the other articles reviewed.

42. Yamashiro, M., Y. Yuasa and K. Kawakita. An experimental study on the relationships between compressibility, fluidity and cohesion of powder solids at small tapping numbers, Powder Technology 34: 225 (1983).

This article focuses on the compressibility of powders, and the relationship of measured compressibility data to on existing formula derived by one of the authors. The tap denser described in this article seems to provide reproducible assessments of powder cohesivity, and could be used to compare the cohesivity of various ash samples.

44. Rafailidis, S. and J.A. Reizes. Measurement of adhesion furces between coal fly ash particles and acrylic fibres, Filtration and Separation 23 (5): 300 (1986).

Staticide was used in these studies to treat acrylic fibers, thereby altering the adhesion of fly ash particles to these fibers. (Staticide, an antistatic solution, is a product of ACL Inc. USA, an consists of an aqueous solution of quaternary compounds used in the electronics industry.) Cleaning of fibers with Staticide caused fine particles to adhere more strongly to the fibers, as did overnight exposure of the ash particles to ambient air. The authors conclude that electrostatics plays a crucial role in the adherence of fly ash particles to filter fibers.

46. Eaves, T. and T.M. Jones. Effect of moisture on tensile strength of bulk solids II: Fine particle-size materials with varying inherent coherence, Journal of Pharmaceutical Sciences 61 (3): 342 (1972).

The effect of moisture on the tensile strength of bulk solids was shown to depend on the inherent cohesivity of the dry bulk solid. van der Waals forces decrease as moisture content increases. Fly ash tensile strength increases as moisture content increases (up to $3 \%$ moisture). Though 
meanurements were not performed at moisture contents above $3 \%$ for fly ash, the authors believe the tensile strength would eventually decrease if the moisture content of the fly ash were inereased enough.

48. Kulvanich, P. and P.J. Stewart. Influence of relative humidity on the adhesive properties of a model interactive system, J. Pharm. Pharmacol. 40: 453 (1988).

Adsorbed moisture was seen to influence the conductivity on the surface of particles, thereby modifying electrostatic effects.

49. Fukuoka, E., S. Kimura, M. Yamazaki, and T. Tanaka. Cohesion of particulate solids. IV. Improvement of apparatus and application to measurement of cohesiveness at various levels of humidity, Chem. Pharm. Bull. 31 (1): 221 (1983).

The authors state that powders that display large cohesiveness under conditions of low humidity must be irregularly shaped, exhibit plasticity, or divelop static charge. The raain portion of this article describes an improved device for the measiurement of cohesivity.

51. Kurihara, $\mathrm{K}$ and I. Ichikawa. Effect of particle characteristics in packing structure, Chem. Pharm. Bull. 21 (10): 2278 (1973).

The authors state that particle shape is less significant for dynamic (flowing) systems than for static systems. Measures of bulk porosity and cohesivity are compared with particle shape information.

52. Molerus, O. Interpretation of Geldart's type A, B, C, and D powders by taking into account interparticle cohesion forces, Powder Technology 33: 81 (1982).

Brief definitions are provided of Geldart's type A, B, C, and D powders. Dustcake ash appears to belong to group $\mathrm{C}$.

53. Hsu, J-P., H-H. Wang and S-Y Yuan. Adsorption of particles on particulate materials, Journal of the Chinese Institute of Chemical Engineering 17 (2): 113 (1986).

The authors state that adsorption capacity (of particles onto particulate materials) is closely related to the shape and size distribution of the particulate materials. The main body of this article is highly statistical in its approach.

55. Eaves, T. and T.M. Jones. Cohesion and tensile strength of bulk solids, Rheol. Acta 10: 127 (1971).

This article describes basic cohesivity measurements, but does not provide any new information specifically applicable to this project.

58. Mastrangelo, C.J. The effects of charge, size, and shape on toner photoconductor adhesion in electrophotographic systems, Photographic Science and Engineering 26(4): 194 (1982).

For the toner particles studied in this paper, adhesion was primarily determined by van der Waals forces and particle charges. The specific nature of this work precludes its direct application to the selection or evaluation of conditioning agents. 
62. Hartley, P.A. and G.D. Parfitt. Analysis of liquid bonding forces in agglomerates of tine particle powders, Proc. Int. Symp. Workshop on Particulate and iultiphase Processes, T. Ariman, editor, 1987.

The authors introduce an equation describing the reduced interparticle force, which takes into account the measured tensile strength, the packing density, and factors virectly determining the van der Waals force. These authors indicate that the influence of van der Waals forces increases significantly for particles less than $10 \mu \mathrm{m}$ in dikmeter, and especially for submicron particles. The authors also state that an adsorbed liquid layer increases the van der Waals force. The authors cite the lack of studies of the effects of liquid layers and packing density on powders containing submicron particles (such as dustcake ash).

63. Kocova, S. and N. Pilpel. The failure of some "simple" and "complez" powders and the significance of their yield locus parameters, Powder Technology 8: 33 (1973).

This lengthy article discusses the application of shear stress information to the classification of powders. Some useful examples of shear data examination are provided; however, the article does net identify any potential conditioning agents.

64. Heinrichs, J. Non-local effects in the macroscopic theory of van der Waals and adhesive forces, Solid State Communications 13: 1595 (1973).

This article provides a mathematical discussion of van der Waals and adhesive forces.

68. Felix, L.G., Merritt, R. and Duncan, K. Improving baghouse performance at the Monticello Generating Station JAPCA 36 (9): 1075 (1986).

This article highlights the use of $\mathrm{NH}_{3}$ to condition Monticello fly ash to increase the inherently low cohesivity of the ash. Conditioning with 10-15 ppm of $\mathrm{NH}_{3}$ reduced particulate bleedthrough without a pressure drop penalty. This work, performed by Southern Research Institute personnel, has had direct influence on the current research project.

69. Miller, S.J., D.L. Laudal and S.S. Kim. Mechanisms of fabric filte: performance improvement with flue gas conditioning, Seventh Symposium on the Transfer and Utilization of Particulate Control Technology, 1988.

The authors have investigated the conditioning of fly ash with small amounts of $\mathrm{SO}_{3}$ and NH3. Results have indicated that the resultant increased cohesivity of low-rank lignite coal ashes accounts for a dustcake structure that is more porous, and contains bridges over pinholes in the fabric. As a consequence, pressur drop and particulate emissions are reduced. 
70. Dimmukes, E.B. Conditioning of tly ash with sulfur trioxido and ammonia, Project Report EPA-600/2-75.015, 1975.

This report is directed towards the conditioning of fly ash for the enhancement of electrostatic precipitator performance; however, much useful information on the basics of these types of conditioning is included. Sulfan (an Allied Chemical product) is mentioned as a source of anhydrous $\mathrm{SO}_{3}$. The key to effective $\mathrm{SO}_{3}$ conditioning was identified to be thorough mixing and even distribution of $\mathrm{SO}_{3}$ on ash particles. The recommended temperature range for $\mathrm{SO}_{3}$ conditioning is identified as between 110 and $160^{\circ} \mathrm{C}$. Below acid and water dew points the mechanism for $\mathrm{SO}_{3}$ deposition on ash is condensation (not desired), while above these dew points the mechanism is adsorption. Chemically basic ash required more $\mathrm{SO}_{3}$ to be effectively conditioned. The author identifies the following mechanism: $\mathrm{SO}_{3}$ reacts with basic components in ash until the surfaces of the particles are covered with sulfate salts, and then additionai $\mathrm{SO}_{3}$ combines witt. water on the particle surface to form $\mathrm{H}_{2} \mathrm{SO}_{4}$. Like $\mathrm{SO}_{3}, \mathrm{NH}_{3}$ increases ash cohesivity. When the compounds are used together, ammonium bisulfate is most likely to increase ash cohesivity because it exists as a liquid below $144^{\circ} \mathrm{C}$.

71. Miller, S.J. and D.L. Laudal. Flue gas conditioning for improved tine particle capture in fabric filters: Comparative technical and eccnomic assessment, final technical report for Fine Particulate Emissions for U.S. Department of Energy, Cooperative Agreement No. DEFC21-86MC10637, 1987.

This extensive survey provides good background and theoretical information in the area of fly ash conditioning. A broad discussion is also provided covering ESP technology, fabric filter basics, and other particulate control technology areas of interest. The authors state that $\mathrm{SO}_{3}$ and $\mathrm{NH}_{3}$ conditioning of ash improves filtration characteristics by increasing ash cohesivity. These two agents were observed to adsorb to a very thin layer on the particle surfaces. The results of extensive short-term pilot tests of $\mathrm{SO}_{3}$ and $\mathrm{NH}_{3}$ conditioning are presented. The authors highlight the need for more research into the mechanisms involved in these types of conditioning applications.

73. Farley, R. and F.H.H. Valentin. Effect of particle size upon the strength of powders, Powder Technology 1 (6): 344 (1968).

For the powders studied, particle size differences were correlated with the shear index. Additionally, tensile strength was corrolated with bulk density. No fly ashes were studied in these tests. Though the general trends represented by these correlations have appeared to be valid for fly ashes and in later studies, the equations provided by the authors describing their correlated data are probably not applicable to fly ashes.

75. Johansen, S.T. Fouling of walls in systems where hot, dusty gases are transported. Sellskapet for Industriell og Teknisk Forskning, Trondheim (Norway) (1988).

This report discusses the mechanisms (electrostatic attraction, van der Waals forces, adsorbed surface films) of adhesion that determine the degree of adhesion between fly ash particles. Though the report deals primarily wi wh the fouling of tubes in hotter environments than fabric filters experience, some of the discussions are useful. The author states that particles can pick up electrostatic charge easily, and that individual particles can carry significant charges. These factors can lead to rapid agglomeration. Increased humidity in the gas can reduce the charging of the particles. The author references Rumpf's discussions of chemical and physical properties of particles, microstructure of particles, temperature, humidity, electrical charges, adsorbed gases, and particle size. 
The author notes that some referances indicate that van der Waals forces are 100 times stronger than electrostatic forces, while other references state they may be of the same magnitude. Young's statement that the adhesion of silica is due to water vapor adsorbtion on silanol sites of the silica surface. A brief discuseion is provided or. physical and chemical adsorbtion of gases on particle interfaces. Chemieorbed layers are often monolayers which are very hard to remove. Adsorbed layers increase the distance betwisen interacting bodies, and thus decrease van der Waals forces. However, some experimenters have demonstrated that the adsorbtion of water increases adhesive forces by up to a factor of 5 .

Contamination of particle surfaces with submicron particles can decrease particle adhesion by decreasing contact area and closeness of approach. Contact area can be increased with softening of particles. Adhesive forces increase proportionally with contact area. Surface roughness also influences adhesion. Some investigators have shown that submicron irregularities sticking to specific sites can increase adhesion. Others have found decreased adhesion. The important factors seem to be primary particle shape and size, and the size and distribution of submicron irregularities. Adhesion depends on particle closeness and contact area.

76. Ahluwalia, R.K., Im, K.H., Haiduk, J.C. Mechanism of pa.ticulate adhesion in coal-fired gas turbine systems. CONF-860154-3 (1986).

The authors state that the primary sources of adhesive energy between particles arise from van der Waals forces and electrostatic attraction. The presence of moisture negates the contribution of electrostatic attrac 'ion.

77. Royal, T.A. Gravity flow of solids engineering handbook. Volume 1. Analysis of pressurization of lock hoppers and typical measured flow properties of coal. Final technical report phase 2. DOE/MC/14101-2054-V.1 (1986).

This report contains extensive information on the interpretation of shear measurements made on cohesive powders

83. Miller, B., Lamb, G., Constanza, P., Saville, D., Oak, M. Studies of dustcake formation and structure in fabric filtration. EPA-600/9-81-023 (1983).

This report covers early work on the feasibility of electrically stimulated fabric filtration (ESFF). The data indicated that the effect of electrically charged dust on dust deposition was more pronounced for more texturized, or nappier fabrics.

85. Powder coatings and their applications. January 1976 - August 1981 (Citations from the paper and board, printing, and packaging industries research associations data base) NTIS (1981).

Only one article in this bibliography may be of interest. This article mentions the use of Cab0 -Grip 11 as an anti-slip agent. This is a silicon dioxide product from the Cabot corporation.

88. Ranade, M.P., Goyal, A. Research on coatings or surface treatment of metal powders (Final report June 1, 1975 - May 31, 1976). RADC-TR-76-355 (1976).

The authors provide some discussion of the theoretical mechanisms that are thought to govern interparticle attraction, however, they stress the need for experimental verification of the effects of additives on powder properties. They added Cab-O-Sil and a similar product, Silanox, to aluminum powder and tested the tensile strength, flowability, and general characteristics of the resultant mix. Addition of up to $2 \%$ Cab-O-Sil and Silanox noticeably improved flow properties but did not decrease the effect of the interparticle forces. The authors 
speculate that these additives act as $\varepsilon$ oscers and ball bearings under shear conditions. This report aleo describes some tochniques for assessing the strength of the interparticle forces.

89. Hedley, W.H., Feairheller, W.R., Richardson, G.A., Zanders, D.L. Studies oî surface chemistry of solids in dissemination (Quarterly progress report no. 2, Nov 67 - Jan 68). (1968).

The authory estimate that a temperature of approximately $400 \mathrm{C}$ would be required to completely remove tipghtly-bound water from Cab-O-Sil.

91. Berg, T., Nilunkins, M., Stansbury, M. Investigation of the force of adhesion between powder particles. AGC-0395-04(04)SP (1963).

This early report discusses the force of adhesion betwoen solid particles in contact with one another with emphasis on the effect of humidity. The researchers found isut water was instrumental in adhesion. For monomolecular layers of water on particles $r$.nd surfaces, the hydrogen bonds between the water and the solids were responsible for the ooserved adhesion. The authoris did not cet_ct ihe influence of van der Waals forces. They determined that the furce of adhesion is proportinnal to the surface area of the particles. The authors stated that below 3\% humidity, electrostatic forces caused the observed adhesion. From 3 to $8 \%$ humidity, hydrogen bonds were responsible for adhesion. Above $20 \%$ humidity, water coverage of the particles or solids was approxinately $500 \%$.

94. Kendoll, KL Agglomerate strength. Powder Metallurgy 31:1 (1988).

Kendall states that Rumpfs theory of agglomerate cohesion is in error and that real agglomerates are imperfect and weak because they contain small internal agglomerates that act as defects. When these small agglomerates are broken apart, powder compact strength increases substantially. Compaction can breakdown small agglomerates.

96. Coury, J.R., Thambimuthu, K.V., Clift, R. Capture and rebound of dust in granular bed gas filters. Powder Technology 50:3 (1987).

The authors show how electrostatic effects can aid adhesive forces. They also indicate that the adhesive forces responsible for the bonding of dry dust and the filter are dominated by van der Waals forces. The rest of this article deal with methods by which particles are captured and retained in granular bed filtern.

99. Hsieh, H.P. Effect of particle size distribution and shape on bulk properties of calcined alumina. Journal of Powder and Bulk Solids Technology 10:2 (1986).

The author provides a simple formula for the compressibility of a powder in terms of the packed and loose bulk densities.

101. Steeneken, P., Woortman, A, Gerritsen, A, Poort, H. Influence of flow conditioners on some mechonical properties of potato starch powder. Powder Technology 47:3 (1986).

The authors modified the cohesivity of potato starch powder with the addition of small $(.01-.10$ wt.\%) amounts of fine silica. The presence of fine silica on the surfaces of the much larger starch particles causes the starch powder to pack more tightly and flow more freely. This effect is due to the extra space between the larger particles caused by the introduction of the smaller conditioning particles. Some of the wording used in this article is ambiguous, however the experimental information contained may provide some basis for setting initial concentrations of fine silica for use in conditioning experiments. 
103. Cottaar, E., Rietema, K. Theoretical study on the influence of gas adsorption on interparticle forces in powders. Journal of Collnid and Interface Science 109:1 (1986).

The authors conclude that gas adsorption can quite heavily influence the interparticle forces and cohesion (increase up to a factor of three). Cohesion is stated to be practically independent of the hardness of the particles involved.

104. Takahashi, M., Suzuki, S., Kosakai, M. Dependence of intergranular fracture strength of a compact of pressed granules on their deformation characteristics. Journal of American Ceramic Society 69:1 (1986).

This article states that the cohesive force between compacted granules can be assumed to be proportional to the corresponding contact area. The authors develop an equation that predicts how the tensile strength of a compact is affected by the comfraction pressure, intergranular porosity, and granule size. The authors also state that the tensile strength depends rnt only on the porosity of a compact but also on the compacting pressure.

106. Nikolakakis, I., Pilpel, N. Effect of particle shape on the tensile strengths of powders. Powder Technology 42:3 (1985).

Tensile strength depends on packing fraction, moisture content, temperature, length of period of consolidation, and particle size and shape. Tensile strength increases with more irregular particle shape. The effect of shape on tensile strength is increased for smaller particles.

107. Hartley, P.A., Parfitt, G.D., Pollack, L.B. Role of van der Waals force in the agglomeration of powders containing submicron particles. Powder Technology 42:1 (1985).

Van der Waals force is dominant for some agglomerates tested in this work (carbon black) while adsorbed water or liquid bridges provide the dominant force for titanium dioxide. The authors state that as particle size decreases, the cohesivity of the powder increases. Mechanical forces resulting from the interlocking of irregularly shaped particles can also influence cohesion. More tightly packed powders exhibit groater tensile strength.

109. Molerus, O., Nywlt, M. Influence of the fine particle content on the flow behavior of bulk materials. Powder Technology 37 (1983).

The authors reference earlier work by Kurz and Munz that indicates that small changes in the fine particle content give measurable changes in cohesiveness. The author's work described in this paper deals with mixtures of particle types (coarse and fine) that contain a much greater fine particle conient than would be used to condition fly ashes. This article does contain some useful discussions of the techniques for reducing shear data.

112. Nosker, R.W., DiMarco, L.A, Williams, R. Deliquescence as the mechanism for strong dust adhesion. Applied Physics Letters 38:12 (1981).

Water soluble salts were seen to serve as adhesives, causing dust particles to strongly adhere to a substrate. This strong adherence was generated by storage of the dust-laden substrate above $80 \%$ humidity for several hours.

113. Chudleigh, P.W. Fabric filter performance: effect of dust charge and cleaning efficiency. Filtration and Separation 19:5 (1982).

The author achieved a reduction in filtering pressure drop in a laboratory-scale fabric filter device by increasing the residual charge on the particles prior to their deposition on the filter 
cake. The more highly charged particles form a more porous dustcake. Cake cleanability was not adversely affected. The author attributes this to the relatively rapid dissipation of charge in the dustoake structure.

114. Enumby, N., Jaskeon, I. Effect of mointure on powder mixing proceswes. Presented at the fourth European Conference on Miring, Noordwijkerhout, Netherlands (1982).

Though the work described in this paper concerns particles with larger mean size than fly ash colloetod on fabric filtere, the authors provide an observation on the effectiveness of impeller miring. When interparticle forces are strong, segregation will be inhibited. If the interparticle forces are relatively weak, segregation will be enhenced as mixing progresses. For all mires, an equilibrium cegregation will be obtained after a sufficient amount of mixing.

115. ter Borg, L. Evaluation of shear test results on bulk solids in chemical industry. German Chemical Engineering 5:1 (1982).

The author added flow additives (zinc stearate, sodium mersolate) to various bulk samples of chemicals. Fowability was seen to increase with additive contents between 2 and $5 \%$ for some combinations. (These values are somewhat higher than have been reported by others.)

117. Castle, G.S.P. Mechanisms involved in Ay ash precipitation in the presence of conditioning agents - a review. IEEE Traneactions on Industry Applications IA-16:2 (1980).

This article reviews the use of water vapor, $\mathrm{SO}_{3}, \mathrm{NH}_{3}$, and triethylamine as fly ash conditioning agents. $\mathrm{NH}_{3}$ is stated to increase ash cohesivity and thereby aid ash agglomeration. The effects of ammonia on ash cohesivity are believed to be due to the ammonium sulfate produced in the conditioning application. Mechanisms for cohesivity modification are not discussed in detail in this article; however, several references are listed that may provide more usaful information.

118. Alince, B., Lepoutre, P. Plastic pigments in paper coatings - the effect of particle size on porosity and optical properties. Tappi 63:5 (1980).

The authors report that blends " 0.5 and $0.2 \mu \mathrm{m}$ synthetic particles with platelike clay resulted in increased porosity, and the similar mixtures of the clay with 0.1 and $0.03 \mu \mathrm{m}$ particles caused decreased porosity. In blends with spherical celcium carbonate, a decrease in porosity was noted.

121. Cheremisinoff, P.N. Advanced flyash conditioning technology. Power Engineering 81:11 (1977).

This article revisws some of the methods by which fly ash has been cunditioned for improved ESP performance. $\mathrm{SO}_{3}$ and $\mathrm{NH}_{8}$ are briefly discussed, and their potential for increasing ash cohesivity is mentioned. No further details are included.

123. Chattopadhyay, A.K. Whittemore, O.J.Jr. Powder compaction in systems of bimodal distribution. American Ceramic Society Bulletin 52:7 (1973).

The compacting forces used in the experiments described in the article are far too great to apply to dustcake formation. The particle sizes used are significantly larger than the size of dustcake ashes. Consequently, no useful information was obtained from the article. 
128. Dalmon, J., Tidy, D. The cohesive properties of fly ash in electrostatic precipitation. Atmospheric Environment 6 (1972).

The authors appliod ammonium sulfate, sulfuric asid, $\mathrm{SO}_{3}, \mathrm{SO}_{2}$ and $\mathrm{HCl}$ in liquid or gaseous forms to two types of fly ash. Although relative coherivity was assessed with tensile strength measurements, most of the article deals with ESP operatis. No information is provided on the effects of difiering amounts of conditioning agents, ir on the details of cohesivity modification.

129. Dalmon, J., Tidy, D. Effect of ammonium sulfate and related compounds on the performance of an experimental electrostatic precipitator. Central Electricity Generatiigg Board (internal publicativis) 1968.

The authors injected ammonium sulfate as a aqueous solution with some success for their objectives. Injection of solid ammonium sulfate was required to be as a fine particulat:

130. Dalmon, J., Tidy, D. A comparison of chemical additives as aids to the electrostatic precipitation of fly ash. Atmospheric Environment 6 (1972).

The additives included ammonium sulfate, sulfuric acid, $\mathrm{SO}_{3}$, and $\mathrm{NH}_{3}$. (Other additives were ineffective.) The discussions and evaluations are heavily weighted to ESP operation.

131. Hollenbach, A, Peleg, M., Rufner, R Interparticle surface affinity and the bulk proparties of conditioned powders. Powder Technology 35 (1983).

The authors assess the effect of four conditioning powders on three substrate powders. In most cases, the achievement of scattered adherence of the conditioner on the surfaces of the larger particles reduces cohesivity and bulk porosity. The nature of the adherence between conditioner and substrate depends on the particular species involved. For some conditioner/substrate combinations, the conditioner tended to aggregate with its own species, rather than disperse on the substratc. The authors used Cab-O-Sil EH5 silica. A $2 \% \mathrm{w} / \mathrm{w}$ mirture of Cab-O-Sil EH5 with fine sodium chloride exhibited an increased bull porosity over the pure sodium chloride substrate. The authorn tried conditioner concentrations of $0.1,0.5$, 1.0, and $2.0 \% \mathrm{w} / \mathrm{w}$. Mixing was performed in a laboratory mixer. The authors state in their conclusions: "The results of this work demonstrat!! that the bulk properties of conditioned powders are strongly influenced by the kind of surface intersetion between the host powder and the conditioner particles. It appears there are at least three degrees of surfaces affinity in such systems expressed by complete adherence, partial adherence and no adherence at all. The magnitude of the change in the bulk properties also appears to be associated with the degree of surface coverage. This is evident from the relationship between the magnitude of the change and the conditioner concentration. Where surface affinity is strong, large effects are noticeable already at concentrations of $0.1-0.5 \%$. Where there is little affinity, the effects become appreciable only at higher concentrations, i.e. at about 1 - $2 \%$."

132. Cab-O-Sil fumed silica properties and functions. Cabot Corporation (1987).

This brochure describes the uses and properties of Cab-0-Sil. Cab-0-Sil fumed silica is produced by the hydrolysis of silicon tetrachloride vapor in a flame of hydrogen and oxygen. The following reaction occurs at $1800 \mathrm{C}: \mathrm{SiCl} 4+2 \mathrm{H} 2+\mathrm{O} 2 \longrightarrow \mathrm{SiO} 2+4 \mathrm{HCl}$. Molten spheres of silica are formed in the combustion process. The diameters of the silica spheres are varied through process parameters from .007 to $.030 \mu \mathrm{m}$. (These sizes are estimated from measurements of specific surface area, which range from 400 to $100 \mathrm{~m}^{2} / \mathrm{g}$.) The molten spheres collide and fuse with one another to form branched, three dimensional aggregates. As these aggregates cool, reversible mechanical entanglement and agglomeration take place. 
The bull properties of the final product are quite unique. The bulk porosity of the uncompacted fumed suce is near $98 \%$ (approximately $2 \mathrm{lbs} / \mathrm{ft}^{3}$ ), and the silica is highly hydrophilic. The brochure describes in great detail the chennical reactions that occur between the fumed silica and water vapor. Uses of Cab-O-Sil in lipuid systems are discussed, as well as uses in dry systems. The Cabot Corporation emphasizes the ability of tine fumed silica to cause powders to flow more freely. The silica apgregates probably form a coating on the larger host particles, and act mobile "ball bearings" for the free movement of the large particles. The fumed silica reportedly neutralizes the electrostatic charge on the host particles, and can make caked powders free flowing by adsorbing the moisture from the surfaces of the host particles.

133. Visser, J. An invited review: Van der Waals and other cohesive forces affecting powder fluidizetior. Powder Technology 58 (1989).

This article includes discussion of cohesive forces present in powders between 1 and $100 \mu \mathrm{m}$ diameter. The author identifies the van der Waals forces as the dominant forces influencing powder cohesivity. The van der Waale forces are only noticeable at separation distances of less than $1 \mathrm{~nm}$. For particles greater than a few microns in diameter, the van de Waals forces become insignificant compared to the gravitational force. Gravitational force is proportional to the cube of the diameter while the van der Waals forces are proportinnal to the diameter. The author states that results of tests on one class of powder (A, B, C, or D, secording to Geldart) cannot be extrapolat d to other classes of powders. Also powder behavior can vary' significantly as temperature and pressure are varied. The author also mentions the importance of other forces, including capillary, magnetic and electrostatic, and partisle characteristics such as surface asperities, hardness, humidity, conductivity and magnetic susceptibility. If asperities found on the particle surfaces are of the order of $1 \mu \mathrm{m}$, then the separation distance between particles becomes too great for the action of van der Waals forces. Particles can be irregularly shaped in such a way as to allow the particles to come closer together, increasing the van der Waals attraction. This author also notes the ability of the addition of fine particles to increase particle separation, and reduce cohesivity.

The author states that the results of small-scale experiments should not be extrapolated to large-scale industrial operations bycause of the effects of pressure and temperature on powder behavior. Visser notes that tise dimensions (size, shape) of fine particles used as spacers are critical to their success. Visser references the work of Piepers, et al., who note that physically adsorbed gases increase the cohesion of powders. The type of gas used has a large influerce on the results. Gas adsorption can also alter the separation distance between particles. Visser also referencea Bailey, who states that electrostatic charging of powder particles invariably occurs during powder-handling operations due to tribo-electrification. This usefis article concludes with the statement, that a basic understanding of the underlying mechanisms of powder cohesivity is still lacking, however, theories for the various mechanisms are available.

134. Kono, H.O., Huang, C.C. Fundamental principles of flow conditioners for very fine powders. paper presented at Powder and Bulk Solids Conference at Rosemont, 1989.

This paper was intended to define the flowability of fine, bu:k powder under low loading pressure. The particle structures formed under this level of stress (compacting force) is relatively delicate, and should correspond relatively well to dustcake structure. The authors tested calcium stearate and polysaccaride as flow conditioning agents for type $C$ powders (according to Geldart). The calcium stearate used had a mean diameter around $4 \mu \mathrm{m}$. When mixed with coal powder, a relative minimum of flowability was achieved at $.5 \%$ by weight concentration of calcium stearate. At concentrations greater than this critical point, the flowability of the coal powder/additive mix increased. These tensile measurements were 
performed with a device developed by Hartley. The authors reported that uncompacted bulk powder density measurements were not sensitive to different additive concentrations.

\section{EXCERPTS FROM A MEMORANDUM FROM DR. E. B. DISMUKES \\ Septomber 6, 1989}

SUBJECT: Substances to alter the cohesiveness of fly ash

This memo has been prepared in response to our meeting on August 30. The information contained in the memo has the slant that you want mainly to increase cohesion. There is negative commentary on some materials with respect to this objective. Where the comments are negative in this sense, they may imply that the materials would be useful for lowering cohesion when you have that alternative purpose in mind.

This memo deals with most of the subjects that came up in our meeting. It still leaves some items not attended to, such as ordering certain materials, depending on your decision.

\section{AMINE SULFATES (REACTION PRODUCTS OF AMINES AND SULFURIC ACID)}

My finding in the literature, contrary to my expectation, is that amine hydrochlorides are not much more stable that $\mathrm{NH}_{4} \mathrm{Cl}$ and thus are not much more likely to form at low concentrations of $\mathrm{HCl}$ vapor than is $\mathrm{NH}_{4} \mathrm{Cl}$. I spent several hours in the library without finding out anything about the stability of amine sulfates. It took some time erren to find out how Chemical Abstracts (CA) indexes information for these compounds. The conimon name is amine sulfate, but CA uses nomenclature such as the following:

Methanamine compounds, sulfates (for sulfates of monomethyl-amine)

Ethanamine compounds, sulfates (for sulfates of monoethyl-amine)

There are entries for 1:1 sulfates and 2:1 sulfates, which are illustrated by the following compounds:

$$
\begin{aligned}
& \mathrm{CH}_{3} \mathrm{NH}_{3} \mathrm{HSO}_{4} \text {, a bisulfate } \\
& \left(\mathrm{CH}_{3} \mathrm{NH}_{3}\right)_{2} \mathrm{SO}_{4} \text {, a normal sulfate }
\end{aligned}
$$

The cumulative index for 1982-86 contained 15 citations for sulfates of the three methyl amines and the three ethyl amines (mono-, di-, and trialkyl). No useful material was to be found in any of these citations, however. A computer search for the period 1967-date, looking primarily for vapor pressure data or any other basic data on physical properties of amine sulfates in general was unsuccessful.

I failed in the library to do what I wanted to do: to obtain basic data so that I could say something about the concentrations of amines and $\mathrm{H}_{2} \mathrm{SO}_{4}$ that will lead to the to mation of amine sulfates at flue gas temperatures, or say something about the physical states of the 1:1 and 2:1 sulfates that are analogous to $\mathrm{NH}_{1} \mathrm{HSO}_{4}$ and $\left(\mathrm{NH}_{4}\right)_{2} \mathrm{SO}_{4}$.

Despite the failure of my library work, I feel fairly comfortable in suggesting that you go ahead and explore the use of amine sulfates for ash conditioning. I say this mainly on the basis of tome 
prior research on amines for conditioning fly ash and other dust materials with respect to collection in ESPs. I will cite two examples:

1. In the $1940 \mathrm{~s}$ Joseph Chittum at Western Precipitation investigated a variety of conditioning agents including amines. My recollection is that he regarded ammonia and amines as useful for acidic dusts (for example, boric acid) and acids such as SOg as useful primarily for basic dusts (for example, fly ash). There is nothing in Chittum's work that I can recall to tie the performance of amines to $\mathrm{SO}_{3}$, but the precedence for using amines for conditioning is there.

2. In the 1970s Edmund Potter at the CSIRO in Australia touted triethylamine : IEA, as it became known) for conditioning the troublesome fly ashes in Australia. Other investigators have looked at TEA in Great Britain, Canada, and South Africa. My recollection is that the track recsrd of TEA is somewhat spotty and the mechanism of action obscure. I do remeinlser, however, that Pottor was always something of a septic or iconoclast on the role of resistivity and claimed that TEA was an agglomerating agent. Maybe this idea is a grod signal to you with respect to fabric filtration. I was never able to be convinced that TEA would have much affinity for fly ash in the absence of anything' else, just as I had the same doubt about ammonia having affinity for ash. Maybe the true story on TEA, as it has been on occasion for ammonia, is that combination with $\mathrm{SO}_{3}$ is involved.

\section{SURFACTANTS/DISPERSANTS}

There is a technical distinction between surfactants and dispersants that I am not entirely sure about. I believe, however, that, by definition, surfactants have "amphipathic" molecular structures in which polar and nonpolar functions are clearly separated, as in a long-chain carbaxylic acid with the polar-COOH group at one end of the molecule and the hydrocarton tail at the other end, whereas dispersants have polar or ionized groups located more or lesis randomly throughout their structures. Another point, I believe, is that surfactants have the typical action of causing a reduction in the surface tension of water, whereas dispersants may not do this. In the group of materials discussed below, the lignin derivative and the two phosphates are to be regarded as dispersants, whereas the remainder are surfactants.

We investigated a number of these materials as additives to $\mathrm{Ca}(\mathrm{OH})_{2}$ as part of the super-sorbent project. The one that we did the most work with was the culcium salt of sulfonated lignin (a natural byproduct of the wood industry); the specific material was Georgia Pacific's product known as Lignosite. This material had one major advantage in addition to being effective - low cost. My recollection is that this feature of the material, as well as work being done at the same time at EPA, was a compelling reason for concentrating on it.

The idea behind work with the surfactants/dispersants was to obtain more freely flowing powders of $\mathrm{Ca}(\mathrm{OH})_{2}$ and thus to obtain better dispersions of the lime when it was injected into a furnace. The features of a material that were favorable for this application may be different from ones that are favorable for your application. In fact, I suspect that surfactants and dispersants are more likely to cause particle separation than to cause cohesion. Furthermore, I suspect that the related materiais known as flocculants or coagulants are more likely to accomplish your goal, as discussed below. I don't know how to answer this question, however, except to try both groups of materials.

I have found leftover samples of the following materials from our work on the super-sorbent project: 
1. Witcolate D5-10, a tradename for an anionic surfactant known as 2-ethylhexyl sulfate (probably the $\mathrm{Na}$ salt).

2. Witconate AOS, a tradenamn for an anionic surfactant known as an alpha-olefin sulfonate (also probably a $\mathrm{Na}$ salt).

3. Aldrich's form of the anionic surfactant named dodecyl sulfate, Na salt.

4. The chemical $\mathrm{Na}$ tripolyphosphate, in which three phosphate groups are bonded together in a chain.

5. The chemical $\mathrm{Na}$ herametaphosphate, in which a much longer string of phosphate groups are bonded together.

In addition to the above, we purchased the following, which I cannot find, from Aldrich:

6. Dodecylbenzenesulfonic acid, $\mathrm{Na}$ salt. This is another classical example of an anionic surfactant.

We can also purchase the following from Aldrich:

7. Cetyltrimethylammonium chloride or bromide. Either halide would be a representative cationic surfactant.

The first six materials listed above are anionic. The last is cationic. I am less familiar sith nonionics but know that linear polymers of ethylene oxide, with repeating oxygen bridges and terminal OH groups, are representative examples. I do not know immediately where to find a nonionic ard don't think we have one on hand. We did not try any nonionics with lime, but had no reason not to, as far as I can remember.

My suggestion is that you evaluate one surfactant in each of the three categories - anionic, cationic, and nonionic - and one dispersant. One of the sulfates or sulfonates on hand will suffice as ail anionic. I can order the cationic named above and will find a source of an anionic. I also suggest that you try one dispersant - probably the herametaphosphate.

\section{FLOCCULATING AGENTS OR COAGULATING AGENTS}

These agents seem to make more set ,e than surfactants/dispersants when your purpose is to agglomerate particles. Strangely, however, some of the agents in the class of flocculants are similar in structure to agents that are dispersants. It is said that a given type of polymeric structure may be a dispersant if the molecular weight is low and the electrical charge density is high, whereas otherwise the structure will be a flocculant.

The use of these agents that I am familiar with is to change small particles dispersed in water to large particles so that the water can be purified by sedimentation. For a long time, alum (aluminum sulfate) was the primary product for this application. Thirty years ago we had a project for Allied Chemical on the development of polymeric flocculants as a substitute for alum.

Alum, if I can recall, operates by altering the electrical double layer around particles, which maintains a stable suspension through repulsive forces. Polymers, on the other hand, work as bridging agents; that is, they tie the individual particles together through the action of ionic groups located throughout the polymeric structure. An example of a cationic polymeric flocculating agent from the time of our work was poly(ethylenimine): 


\section{$\left(-\mathrm{CH}_{2} \mathrm{CH}_{2}-\mathrm{NH}\right) \mathrm{n}$}

The positive charges came from protons that were abstracted by the basic nitrogen from the water in which the polymer operatod. Another cationic polymer from that time was developed by a Prof. Butler at the University of Florida. This polymer had quaternary amine groups and thus was permanently charged.

Kirk-Othmer has what appears to be a good review article on polymeric flocculants, from which we might find one or more to try as a bridging agent.

\section{SILANIZING AGENT}

This type of material puts a hydrophobic shield aroung the material to which it is applied and may not be any more attractive for your purpose than a surfactant. However, if want to look at a material of this type, a preparation can be bought from Thomas Scientific. The product is called Prosil-28, an organosilane that coats glass with a water-repellant film to reduce abrasion and adhesion of foreign matter.

\section{DELIQUESCENT COMPOUNDS}

One way to get water to condense in the capillary constrictions between particles and increase cohesion would be to have a deliquescent compound present. By definition, this type of compound has such a strong affinity for water that it will cause water vapor to condense at a partial pressure far below the saturation value. The driving force for condensation under these conditions is the high solubility of the compound and the attendant marked lowering of the equilibrium vapor pressure of the condensate.

Calcium chloride is one of the best known deliquescent compounds. It will draw water vapor out of the atmosphere if the relative partial pressure (ratio of actual partial pressure to the saturation value) is as low as 0.2 . Other examples - I believe $\mathrm{NaOH}$ is one - will do this at a relative partial pressure around 0.05 .

Consider what the relative partial pressure of water vapor is in five gas. At $150 \mathrm{C}$ the actual partial pressure is around $76 \mathrm{mmHg}$ at a concentration of $10 \%$ by volume. At this temperature the saturation vapor pressure of wator is $3570 \mathrm{mmHg}$. Thus, the relative partial pressure is $76 / 3570$ or 0.02. Clearly, therefore, finding a compound that will be deliquescent under the relevant conditions would be a formidable task. Sulfuric acid is the only probable example I can name.

Calcium chloride would not necessarily fail to meet the requirement because of what was said earlier about the relative partial pressure at which it becomes deliquescent. On going from room temperature, where the form of the salt in equilibrium with the saturated solution is the hexahydrate, to $150 \mathrm{C}$, where the form of the salt changes to the dihydrate or perhaps even the anhydrous compound, the relative partial pressure required for deliquescence changes. My conclusion from an analysis made on an Ogden-Martin project was nevertheless that calcium chloride is not deliquescent in flue gas at $150 \mathrm{C}$ at usual water vapor concentrations. 


\section{APPENDIX H}

\section{DESCRIPTION OF MIXING AND CONDITIONING CHAMBER}

A schematic diagram of the mixing and conditioning chamber used in several of the Task 3 and Task 4 tests is shown in figure E-1. Figure E-2 shows the chamber located in an oven for controlled temperature operation. The following discussion presents some of the design and operating parameters established for the use of this system. The chamber is a cylinder composed of 316 Staiuless Steel and has an inner diameter of 17.75 inches and an inner height of 28.75 inches. A 16-inch diameter five-blade variable speed fan is located approximately 9 inches from the top of the chamber and forces air flow towards the bottom of the chamber when rotated. Six 3/4inch female NPT ports spaced 60 degrees apart are located approximately 6 inches from the top of the chamber. One 4-inch female NPT port is located approximately 9 inches from the top of the chamber. These ports are used for the injection of conditioning agents, collection of samples, and preparation of the chamber for testing. Ash samples can be loosely placed in the bottom of the chamber prior to a test, or injected through one or more of the ports during the test. The environment inside the chamber can be prepared for testing by purging with moist or dry air (or other gas, if desired) and heating the chamber to a specific temperature.

During conditioning tests, the fan can be operated intermittently or constantly, and at various speeds to achieve different turbulence levels within the chamber. Conditioning agents can be supplied to the chamber during turbulent mixing, or provided in the chamber prior to the startup of the conditioning test. Ash samples can be collected during the test with extractive samplers (filters, cyclones, etc.) or at the conclusion of the test from the removable collection reservoir which forms the lower region of the mixing and conditioning chamber. Ash samples have also been collected from deposition on the inner walls of the chamber. The chamber can be easily disassembled for cleaning and sample collection bitween tests. 


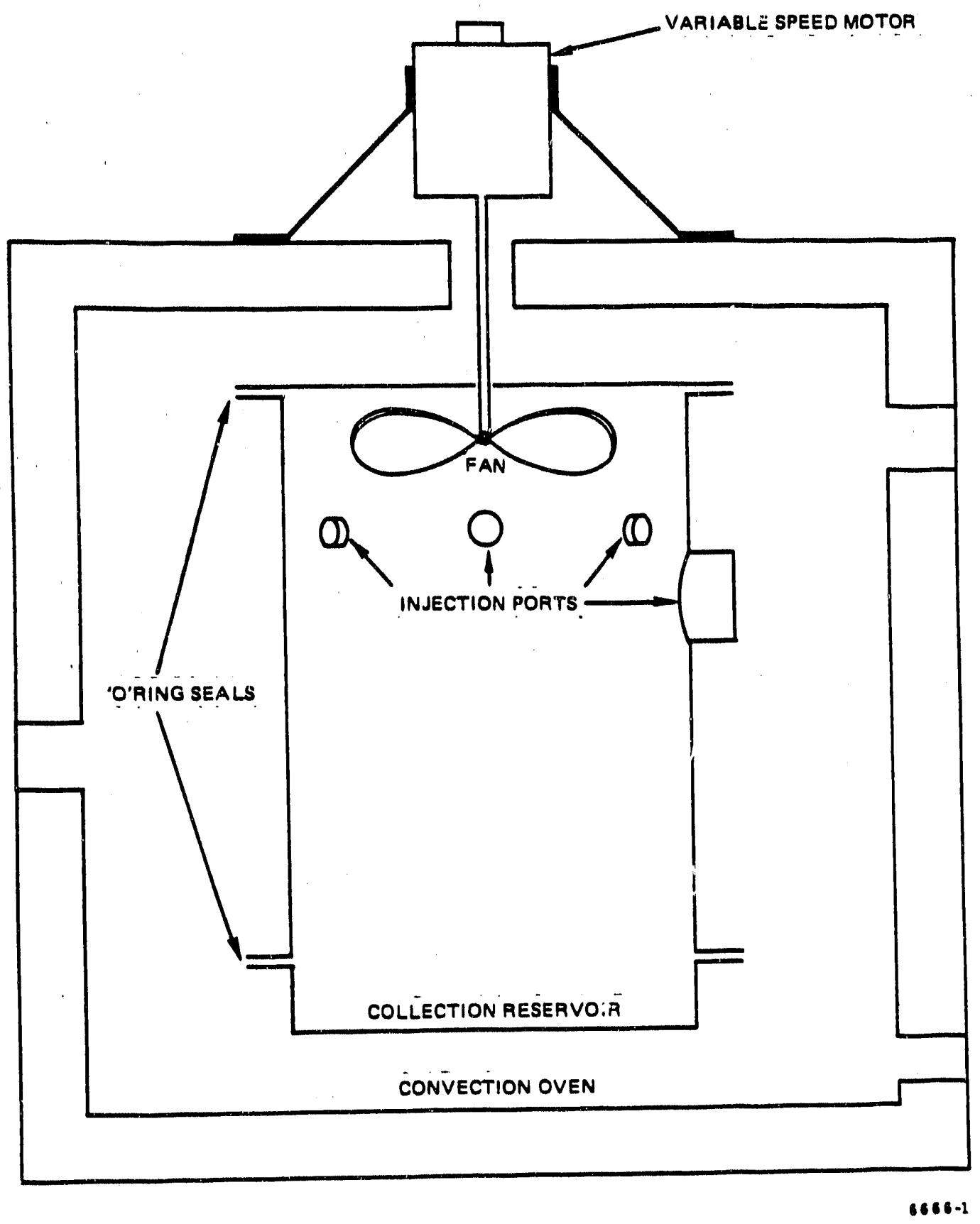

Figure E-1. Schematic diagram of the mixing and conditioning chamber located in the thermally controlled oven. 


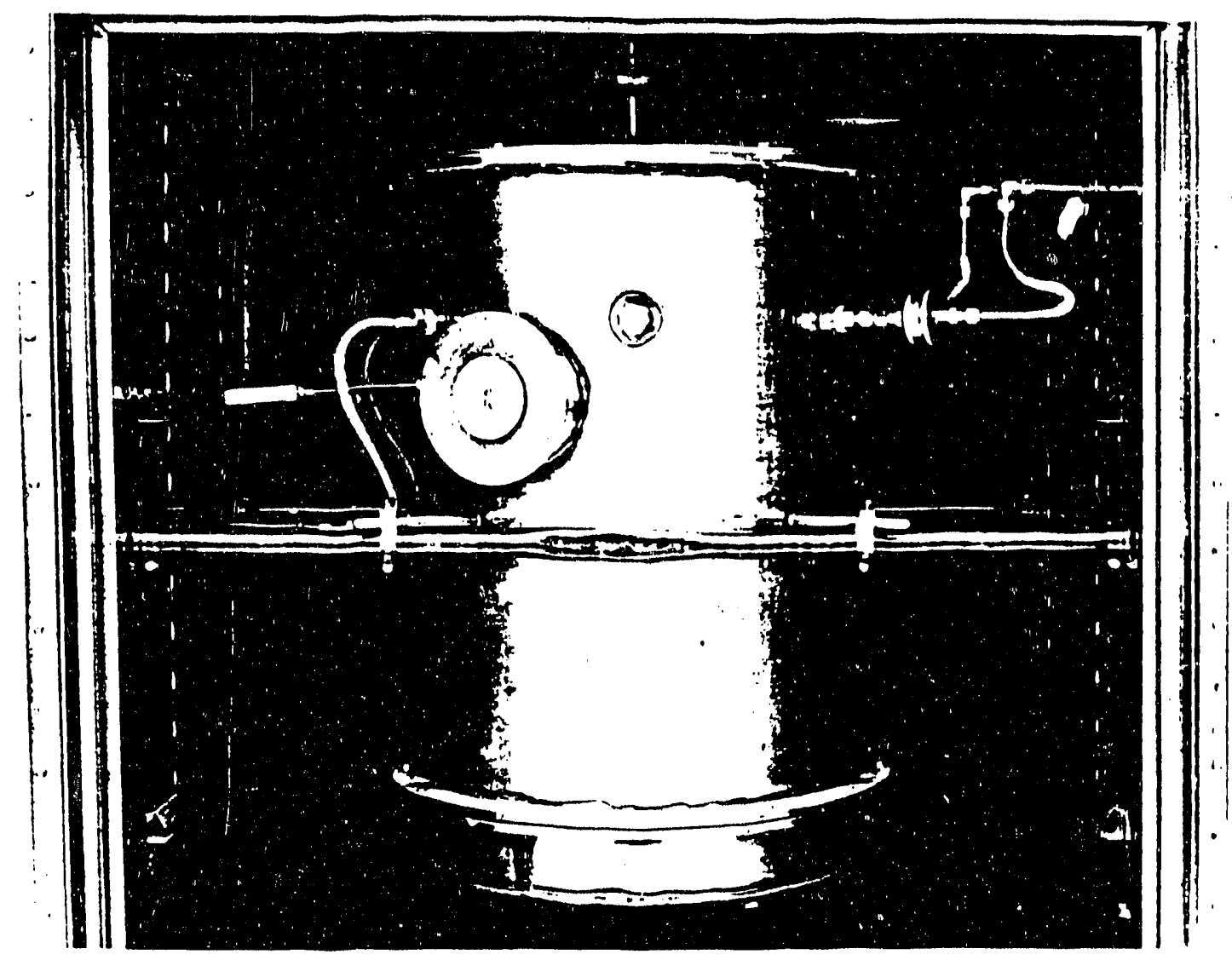

$6686-17$

Figure E-2. Photograph of the mixing and conditioning chamber located in the thermally controlled oven. 
PROCEDURES USED FOR PRODUCING CONDITIONED MIXTURES

OF TWO FLY ASH TYPES IN THE MIXING AND CONDITIONING CHAMBER

Tims

h:mm:ss Action

Pro-test Mix dissimilar ashes in desired ratio

Pro-test Load ash into removable collection reservoir

Pre-test Load 47 mmfilter holder and connect to conditioning chamber

Pro-test Preheat oven and chamber to $155 \mathrm{C}$

0:00:00 Initiate air flow with $4 \%$ moisture into chamber at $4 \mathrm{liter} / \mathrm{min}$

2:05:00 Initiate and adjust exhaust vacuum to 1" negative

2:10:00 Turn on fan at 75\% power

2:40:00 Turn off fan

2:40:15 Pull resuspended ash sample through $47 \mathrm{~mm}$ filter

2:43:15 Disengage filter

2:43:15 Switch inlet air flow to dry air

2:53:00

Shut off exhaust vacumm, open exhaust bleed

2:53:00

Shut off ovan heaters

2:53:00

Reduce dry air flow to less than 1 liter/min to compensate for air volume decrease due to chamber cooling

4:10:00 remove $47 \mathrm{~mm}$ filter with ash sample remove, clean, and remount collection reservoir rap chamber to release wall ash into collection reservoir remove collection reservoir and retrieve wall ash sample clean chamber for next test 


\title{
APPENDIX J
}

CHARACTERISTICS OF ASHES COLLECTED FROM THE MIXING AND CONDITIONING CHAMBER

DRY POWDER CONDITIONING TESTS

\begin{abstract}
Although the objective of these conditioning tests was to mix two different ash types, the procedure was run once with $100 \%$ Monticello ash and once with $100 \%$ Scholz ash. A variety of analyses were run on the wall ashes collected from these two runs (table J-1). Analyses run on mixtures of these two ashes combined in various ratios are presented in table J-2. Table J-2 provides a summary of mixing ratios of the two hopper ashes, as well as the measured particle densities and results of two laboratory measurements of relative cohesivity of the wall ash collected at the conclusion of each test.
\end{abstract}




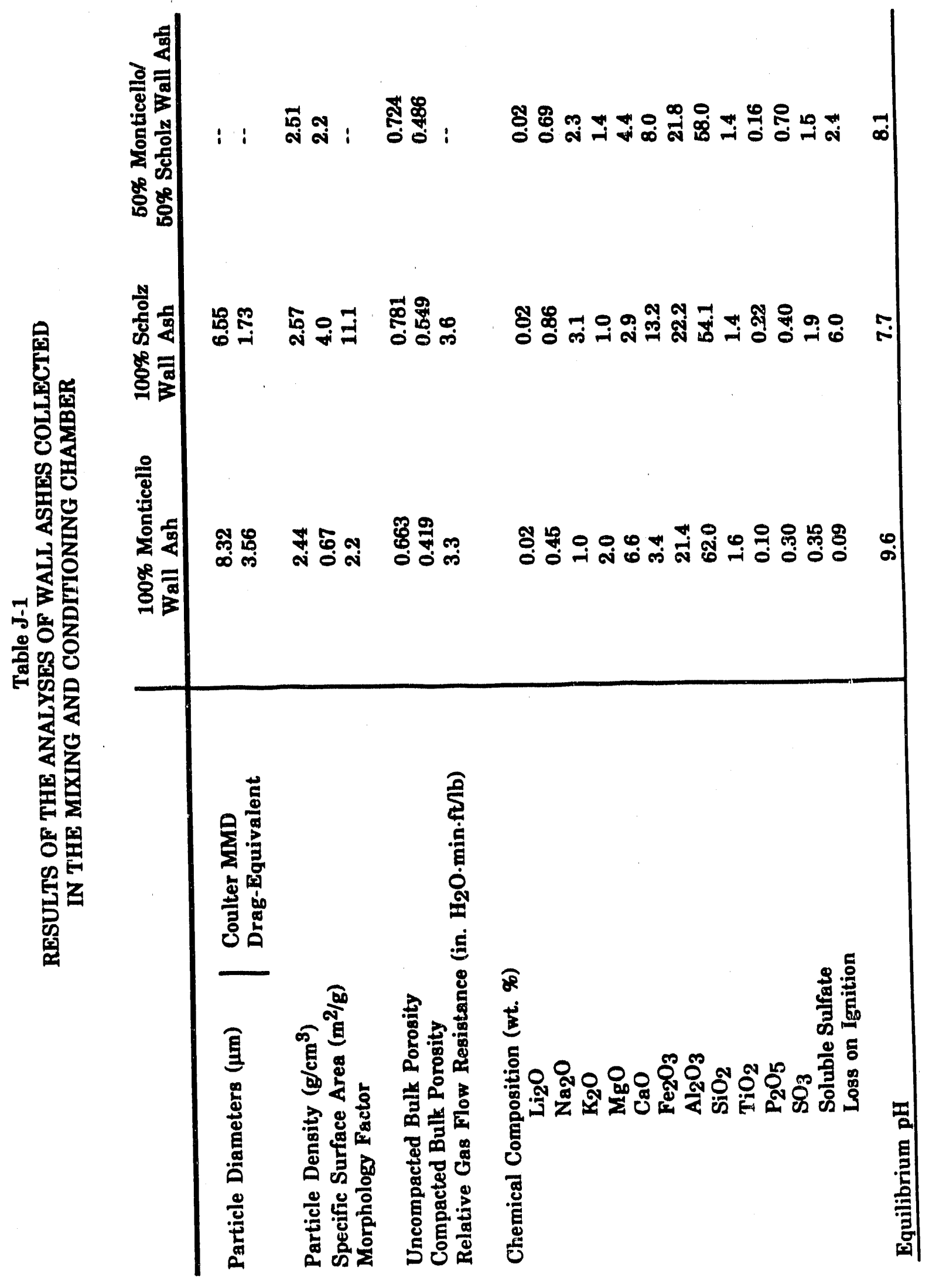


Table J-2

CONDITIONING TESTS ON MLXTURES OF MONTICELLO AND SCHOLZ HOPPER ASHES

\begin{tabular}{|c|c|c|c|c|}
\hline Test & $\begin{array}{l}\text { \%o wt of Scholz } \\
\text { Ashin mixture }\end{array}$ & $\begin{array}{l}\text { Compacted Bulk } \\
\text { Pomosity } \%\end{array}$ & $\begin{array}{l}\text { Uncompacted } \\
\text { Bulk Porosity. \% }\end{array}$ & $\begin{array}{l}\text { Particle } \\
\text { Density } \mathrm{g} / \mathrm{cm}^{3}\end{array}$ \\
\hline 11 & 0.00 & 41.9 & 66.3 & 2.44 \\
\hline 16 & 0.99 & 42.2 & 55.1 & 2.47 \\
\hline 17 & 4.76 & 42.7 & 64.7 & 2.45 \\
\hline 18 & 9.09 & 44.0 & 65.2 & 2.45 \\
\hline 19 & 20.0 & 45.8 & 69.4 & 2.48 \\
\hline 20 & 50.0 & 48.6 & 72.4 & 2.51 \\
\hline 25 & 80.0 & 50.3 & 72.8 & 2.53 \\
\hline 24 & 90.9 & 52.0 & 73.0 & 2.53 \\
\hline 23 & 95.2 & 50.4 & 72.2 & 2.55 \\
\hline 22 & 99.0 & 51.6 & 73.6 & 2.54 \\
\hline 21 & 100.0 & 54.9 & 78.1 & 2.57 \\
\hline
\end{tabular}




\section{APPENDIX $\mathbf{K}$}

TEST PROCEDURES FOR THE CONDITIONING OF FLY ASH WITH CAB-U-SIL SILICA IN THE MIXING AND CONDITIONING CHAMBER

Time

h.mmise Action

Proteat Lad and install $47 \mathrm{~mm}$ filter holder

Proted

Load $400 \mathrm{~g}$ of ash into removable collection reservoir

Protect

Load silica storage cell with $0.8 \mathrm{~g}$ of silica

Pro-tect

Seal chamber

Pro-tect

Pro-heat oven to $155 \mathrm{C}$ overnight

0.00500

Initiate \&ry air flow into chamber at 4 liter/min

2.00200

zurn off dry air flow

$1.00: 30$

Turn on fan at $75 \%$ power

1:01:00

1.0130

Turn off fan

Blow silice frrm storage cell into miring and conditioning chamber with brief blast of dry air

102.00

Begin agitation of fan slowly (moving belt back and forth by hand)

1:12:00

Cease agitation of fan

1:12.00

Turn on fan at 75\% power

1:12:30

Turn off fan

1:1230

Initiate dry air flow into chamber at 4 liter/min

1:12:45

Switch outlet flow through $47 \mathrm{~mm}$ filter

1:16:00

Bypass outlet flow around filter

$1: 16.00$

Turn off dry air flow

$1.36: 00$

Initiate moist air flow into chamber at 4 liter/min

2:36:00

Turn off moist air flow

$2: 36.00$

Turn on fan at $75 \%$ power

2:44:30

Turn off fon

2:45.00

Shut off oven heaters

3:45:00

Collect $47 \mathrm{~mm}$ filtur with conditioned ash sample

Post-test Collect wall ash sample 


\section{APPENDLX L}

TEST PROCEDURES FOR THE CONDITIONING OF BASE FLY ASH WITH FINE POWDERS IN THE WARING BLENDORTM

Time

h:mm:ss Action

Pro-test Load $400 \mathrm{~g}$ of base ash into 1-quart jar

Pro-test Load desired amount of conditioning powder into same 1-quart jar

0:00:00 Place lid on jar and hand mix contents by shaking jar

0:03:00 Cease hand-mixing of contents of jar

0:04:00 Load contents of jar into Waring Blendor ${ }^{\mathrm{TM}}$

0:10:00 Turn on blender at 50\% power

0:13:00 Turn off blender

0:17:00 Remove sample from blender 


\section{APPENDIX M}

SUMMMARY OF ANALYSES OF MIXTURES PRODUCED IN THE BLENDER

\begin{tabular}{|c|c|c|c|c|}
\hline Base Ash & $\begin{array}{l}\text { Additive } \\
\text { in Mixture }\end{array}$ & Additive & $\begin{array}{l}\text { Uncompacted } \\
\text { Bulk Porosity, \% }\end{array}$ & $\begin{array}{l}\text { Compacted } \\
\text { Bulk Porosity, } \%\end{array}$ \\
\hline $\begin{array}{l}\text { Scholz } \\
\text { Scholz } \\
\text { Scholz } \\
\text { Scholz } \\
\text { Scholz } \\
\text { Scholz }\end{array}$ & $\begin{array}{l}\text { M5 silica } \\
\text { M5 silice } \\
\text { M5 silica } \\
\text { M5 silica } \\
\text { M5 silice } \\
\text { M5 silica }\end{array}$ & $\begin{array}{l}0 \\
0.05 \\
0.1 \\
0.2 \\
0.5 \\
1\end{array}$ & $\begin{array}{l}70.2 \\
68.1 \\
68.8 \\
68.7 \\
68.5 \\
69.4 \\
\end{array}$ & $\begin{array}{l}53.0 \\
53.4 \\
53.6 \\
53.5 \\
54.1 \\
53.6\end{array}$ \\
\hline $\begin{array}{l}\text { Monticello } \\
\text { Monticello } \\
\text { Monticello } \\
\text { Monticello } \\
\text { Monticello }\end{array}$ & $\begin{array}{l}\text { M5 silica } \\
\text { M5 silica } \\
\text { M5 silica } \\
\text { M5 silica } \\
\text { M5 silica }\end{array}$ & $\begin{array}{l}0 \\
0.05 \\
0.1 \\
0.2 \\
0.5\end{array}$ & $\begin{array}{l}56.5 \\
51.7 \\
49.6 \\
46.7 \\
47.2\end{array}$ & $\begin{array}{l}34.7 \\
34.0 \\
34.2 \\
34.1 \\
34.9\end{array}$ \\
\hline $\begin{array}{l}\text { Scholz } \\
\text { Scholz } \\
\text { Scholz } \\
\text { Scholz }\end{array}$ & $\begin{array}{l}\text { L90 silica } \\
\text { L90 silica } \\
\text { L90 silica } \\
\text { L90 silica }\end{array}$ & $\begin{array}{l}0 \\
0.1 \\
0.5 \\
1\end{array}$ & $\begin{array}{l}70.2 \\
69.2 \\
69.8 \\
70.8\end{array}$ & $\begin{array}{l}53.0 \\
53.2 \\
53.6 \\
53.8\end{array}$ \\
\hline $\begin{array}{l}\text { Monticello } \\
\text { Monticello } \\
\text { Monticello }\end{array}$ & $\begin{array}{l}\text { L90 silica } \\
\text { L90 silica } \\
\text { L90 silica }\end{array}$ & $\begin{array}{l}0 \\
0.1 \\
1\end{array}$ & $\begin{array}{l}56.5 \\
48.7 \\
513\end{array}$ & $\begin{array}{l}34.7 \\
35.5 \\
36.1\end{array}$ \\
\hline $\begin{array}{l}\text { Scholz } \\
\text { Scholz } \\
\text { Scholz }\end{array}$ & $\begin{array}{l}\text { EH5 silica } \\
\text { EH5 silica } \\
\text { EH5 silica }\end{array}$ & $\begin{array}{l}0 \\
0.1 \\
1\end{array}$ & $\begin{array}{l}70.2 \\
69.6 \\
70.3\end{array}$ & $\begin{array}{l}53.0 \\
53.0 \\
54.0\end{array}$ \\
\hline $\begin{array}{l}\text { Monticello } \\
\text { Monticello } \\
\text { Monticello }\end{array}$ & $\begin{array}{l}\text { EH5 silica } \\
\text { EH5 silica } \\
\text { EH5 silica }\end{array}$ & $\begin{array}{l}0 \\
0.1 \\
1\end{array}$ & $\begin{array}{l}56.5 \\
47.6 \\
47.9\end{array}$ & $\begin{array}{l}34.7 \\
38.0 \\
36.1\end{array}$ \\
\hline $\begin{array}{l}\text { Scholz } \\
\text { Scholz } \\
\text { Scholz } \\
\text { Scholz } \\
\text { Scholz }\end{array}$ & $\begin{array}{l}\text { Novaculite } \\
\text { Novaculite } \\
\text { Novaculite } \\
\text { Novaculite } \\
\text { Novaculite }\end{array}$ & $\begin{array}{l}0 \\
0.05 \\
0.2 \\
0.5 \\
1\end{array}$ & $\begin{array}{l}70.2 \\
68.7 \\
69.6 \\
69.8 \\
69.9\end{array}$ & $\begin{array}{l}53.0 \\
53.4 \\
52.7 \\
52.7 \\
52.1\end{array}$ \\
\hline $\begin{array}{l}\text { Scholz } \\
\text { Scholz } \\
\text { Scholz }\end{array}$ & $\begin{array}{l}\text { sodium bicarbonate } \\
\text { sodium bicarbonate } \\
\text { sodium bicarbonate }\end{array}$ & $\begin{array}{l}0 \\
0.06 \\
1\end{array}$ & $\begin{array}{l}702 \\
70.6 \\
702\end{array}$ & $\begin{array}{l}53.0 \\
53.3 \\
53.5\end{array}$ \\
\hline
\end{tabular}




\begin{tabular}{|c|c|c|c|c|}
\hline Base Ash & $\begin{array}{l}\text { Additive } \\
\text { in Mirture }\end{array}$ & dditive & $\begin{array}{l}\text { Uncompacted } \\
\text { Bulk Porosity, \% }\end{array}$ & $\begin{array}{l}\text { Compactod } \\
\text { Bulk Porosity, \% }\end{array}$ \\
\hline $\begin{array}{l}\text { Monticello } \\
\text { Monticello } \\
\text { Monticello } \\
\text { Monticello } \\
\text { Monticello } \\
\text { Monticello }\end{array}$ & $\begin{array}{l}\text { sodium bicarbonate } \\
\text { sodium bicarbonate } \\
\text { sodium bicarbonate } \\
\text { sodium bicarbonate } \\
\text { sodium bicarbonate } \\
\text { sodium bicarbonate }\end{array}$ & $\begin{array}{l}0 \\
0.1 \\
0.5 \\
1 \\
2 \\
5\end{array}$ & $\begin{array}{r}56.5 \\
54.7 \\
58.2 \\
59.4 \\
58.0 \\
562\end{array}$ & $\begin{array}{l}34.7 \\
34.6 \\
35.6 \\
38.6 \\
38.9 \\
38.0\end{array}$ \\
\hline $\begin{array}{l}\text { Scholz } \\
\text { Scholz } \\
\text { Scholz }\end{array}$ & $\begin{array}{l}\text { chemical hydrated lime } \\
\text { chemical hydrated lime } \\
\text { chemical hydrated lime }\end{array}$ & $\begin{array}{l}0 \\
0.1 \\
1\end{array}$ & $\begin{array}{l}702 \\
702 \\
698\end{array}$ & $\begin{array}{l}53.0 \\
53.6 \\
53.5\end{array}$ \\
\hline $\begin{array}{l}\text { Monticello } \\
\text { Monticello } \\
\text { Monticello }\end{array}$ & $\begin{array}{l}\text { chemical hydrated lime } \\
\text { chemical hydrated lime } \\
\text { chemical hydrated lime }\end{array}$ & $\begin{array}{l}0 \\
0.1 \\
1\end{array}$ & $\begin{array}{l}56.5 \\
50.6 \\
49.5\end{array}$ & $\begin{array}{l}34.7 \\
35.3 \\
35.5\end{array}$ \\
\hline $\begin{array}{l}\text { Scholz } \\
\text { Scholz } \\
\text { Scholz }\end{array}$ & $\begin{array}{l}\text { gasifier char } \\
\text { gasifier char } \\
\text { gasifier char }\end{array}$ & $\begin{array}{l}0 \\
0.1 \\
1\end{array}$ & $\begin{array}{l}702 \\
69.8 \\
69.4\end{array}$ & $\begin{array}{l}53.0 \\
53.4 \\
52.7\end{array}$ \\
\hline $\begin{array}{l}\text { Monticello } \\
\text { Monticello } \\
\text { Monticello }\end{array}$ & $\begin{array}{l}\text { gasifier char } \\
\text { gasifier char } \\
\text { gasifier char }\end{array}$ & $\begin{array}{l}0 \\
0.1 \\
1\end{array}$ & $\begin{array}{l}56.5 \\
47.9 \\
48.6\end{array}$ & $\begin{array}{l}34.7 \\
33.5 \\
33.0\end{array}$ \\
\hline $\begin{array}{l}\text { Scholz } \\
\text { Scholz }\end{array}$ & $\begin{array}{l}\text { glass beads } \\
\text { glass beads }\end{array}$ & $\begin{array}{l}0 . c 5 \\
1\end{array}$ & $\begin{array}{l}70.6 \\
70.4\end{array}$ & $\begin{array}{l}52.8 \\
52.8\end{array}$ \\
\hline $\begin{array}{l}\text { Monticello } \\
\text { Monticello }\end{array}$ & $\begin{array}{l}\text { glass fibers } \\
\text { glass fibers }\end{array}$ & $\begin{array}{l}0 \\
13\end{array}$ & $\begin{array}{l}56.5 \\
54.5\end{array}$ & $\begin{array}{l}34.7 \\
34.2\end{array}$ \\
\hline $\begin{array}{l}\text { Monticello } \\
\text { Monticello } \\
\text { Monticello } \\
\text { Monticello } \\
\text { Monticello } \\
\text { Monticello } \\
\text { Monticello } \\
\text { Monticello } \\
\text { Monticello } \\
\text { Monticello } \\
\text { Monticello } \\
\text { Monticello } \\
\text { Monticello } \\
\text { Monticello } \\
\text { Monticello }\end{array}$ & $\begin{array}{l}\text { AFBC hopper ash } \\
\text { AFBC hopper ash } \\
\text { AFBC hopper ash } \\
\text { AFBC hopper ash } \\
\text { AFBC hopper ash } \\
\text { AFBC hopper ash } \\
\text { AFBC hopper ash } \\
\text { AFBC hopper ash } \\
\text { AFBC hopper ash } \\
\text { AFBC hopper ash } \\
\text { AFBC hopper ash } \\
\text { AFBC hopper ash } \\
\text { AFBC hopper ash } \\
\text { AFBC hopoer ash } \\
\text { AFBC hopper ash }\end{array}$ & $\begin{array}{l}0 \\
0.05 \\
0.1 \\
0.5 \\
1 \\
5 \\
20 \\
50 \\
80 \\
90 \\
99 \\
99.5 \\
99.9 \\
99.95 \\
100\end{array}$ & $\begin{array}{l}56.5 \\
52.9 \\
51.5 \\
53.0 \\
502 \\
52.7 \\
62.1 \\
73.8 \\
81.3 \\
83.7 \\
84.7 \\
84.5 \\
84.6 \\
84.2 \\
84.9\end{array}$ & $\begin{array}{l}34.7 \\
35.8 \\
35.1 \\
35.8 \\
35.0 \\
35.9 \\
39.3 \\
48.5 \\
57.5 \\
61.6 \\
62.9 \\
62.9 \\
63.0 \\
63.2 \\
63.1\end{array}$ \\
\hline
\end{tabular}




\begin{tabular}{lllcc} 
Base Ash & $\begin{array}{l}\text { Additive } \\
\text { in Mixture }\end{array}$ & $\%$ wt. of Additive & $\begin{array}{l}\text { Uncompactod } \\
\text { Bulk Porosity, } \%\end{array}$ & $\begin{array}{l}\text { Compacted } \\
\text { Bull Porosity, } \%\end{array}$ \\
\hline & M5 silica & 0 & 84.9 & 63.1 \\
AFBC & M5 silica & 0.05 & 83.9 & 62.9 \\
AFBC & M5 silica & 0.1 & 83.8 & 62.8 \\
AFBC & M5 silica & 0.2 & 83.1 & 63.1 \\
AFBC & M5 silica & 0.5 & 82.6 & 57.6 \\
AFBC & & 0 & 84.9 & 63.1 \\
& sodium bicarbonate & 0.1 & 83.8 & 63.4 \\
AFBC & sodium bicarbonate & 0.5 & 63.4 \\
AFBC & sodium bicarbonate & 0.5 & 84.1 & 63.4 \\
AFBC & sodium bicarbonate & 1 & 83.6 & $* 3.2$ \\
AFBC & sodium bicarbonate & 2 & 83.4 & \\
AFBC & sodium bicarbonate & 5 & 83.6 & \\
\end{tabular}

* ash sample stuck in compaction cylinder 


\section{APPENDIX N}

PROCEDURES USED FOR PRODUCING CONDITIONED MIXTURES OF ASH AND VARIOUS POWDERS WITH MANUAL SHAKING

Time Action

mm:s8

Pro-test

Load desired mixture ratios of base ash and conditioning agent into 1-quart jar (100 g total weight)

$00: 00$

Begin manual rotary shaking: back and forth rotation with pivot point halfway up the jar at approximately 3 cycles per second

$00: 30$

Cease rotary shaking

$00: 30$

Begin manual vertical shaking: up and down movements (12 inch stroke length) at approximately 3 cycles per second

01:00

Cease vertical shaking 


\section{APPENDIX 0}

SUMMARY OF ANALYSES OF HAND-SHAKTEN MIXTURES

\begin{tabular}{|c|c|c|c|c|}
\hline Base ash & Additive & $\begin{array}{l}\text { \% wt. additive } \\
\text { in mixture }\end{array}$ & $\begin{array}{l}\text { uncompacted } \\
\text { bulk porosity, \% }\end{array}$ & $\begin{array}{l}\text { compacted } \\
\text { bulk porosity, } \%\end{array}$ \\
\hline $\begin{array}{l}\text { Monticello } \\
\text { Monticello } \\
\text { Monticello } \\
\text { Monticello } \\
\text { Monticello }\end{array}$ & $\begin{array}{l}\text { sodium bicarbonate } \\
\text { sodium bicarbonate } \\
\text { sodium bicarbonate } \\
\text { sodium bicarbonate } \\
\text { sodium bicarbonate }\end{array}$ & $\begin{array}{l}0 \\
0.5 \\
1 \\
2 \\
5\end{array}$ & $\begin{array}{l}51.4 \\
50.2 \\
51.0 \\
50.9 \\
51.2\end{array}$ & $\begin{array}{l}35.3 \\
35.5 \\
35.5 \\
35.9 \\
35.9\end{array}$ \\
\hline $\begin{array}{l}\text { Monticello } \\
\text { Monticello } \\
\text { Monticello } \\
\text { Monticello } \\
\text { Monticello } \\
\text { Monticello }\end{array}$ & $\begin{array}{l}\text { EH5 silica } \\
\text { EH5 silica } \\
\text { EH5 silica } \\
\text { EH5 silica } \\
\text { EH5 silica } \\
\text { EH5 silica }\end{array}$ & $\begin{array}{l}0 \\
0.05 \\
0.1 \\
0.2 \\
0.5 \\
1\end{array}$ & $\begin{array}{l}51.4 \\
48.0 \\
47.4 \\
47.4 \\
50.2 \\
54.5\end{array}$ & $\begin{array}{l}35.3 \\
35.5 \\
35.9 \\
36.3 \\
38.3 \\
40.7\end{array}$ \\
\hline $\begin{array}{l}\text { Monticello } \\
\text { Monticello } \\
\text { Monticello } \\
\text { Monticello }\end{array}$ & $\begin{array}{l}\text { aluminum silicate } \\
\text { aluminum silicate } \\
\text { aluminum silicate } \\
\text { aluminum silicate }\end{array}$ & $\begin{array}{l}0 \\
0.1 \\
0.5 \\
1.0\end{array}$ & $\begin{array}{l}51.4 \\
R 5.7 \\
65.1 \\
56.6\end{array}$ & $\begin{array}{l}35.3 \\
33.9 \\
34.2 \\
35.2\end{array}$ \\
\hline $\begin{array}{l}\text { Scholz } \\
\text { Scholz } \\
\text { Scholz } \\
\text { Scholz } \\
\text { Scholz }\end{array}$ & $\begin{array}{l}\text { EH5 silica } \\
\text { EH5 silica } \\
\text { EH5 silica } \\
\text { EH5 silica } \\
\text { EH5 silica }\end{array}$ & $\begin{array}{l}0 \\
0.1 \\
0.2 \\
0.5 \\
1\end{array}$ & $\begin{array}{l}75.2 \\
76.7 \\
77.0 \\
77.0 \\
79.1\end{array}$ & $\begin{array}{l}63.0 \\
63.7 \\
63.1 \\
64.3 \\
64.7\end{array}$ \\
\hline $\begin{array}{l}\text { AFBC } \\
\text { AFBC } \\
\text { AFBC } \\
\text { AFBC } \\
\text { AFBC }\end{array}$ & $\begin{array}{l}\text { EH5 silica } \\
\text { EH5 silica } \\
\text { EH5 silica } \\
\text { EH5 silica } \\
\text { EH5 silica }\end{array}$ & $\begin{array}{l}0 \\
0.05 \\
0.1 \\
0.2 \\
0.5\end{array}$ & $\begin{array}{l}85.3 \\
85.2 \\
85.4 \\
85.4 \\
85.9\end{array}$ & $\begin{array}{l}65.3 \\
65.6 \\
66.1 \\
65.9 \\
67.1\end{array}$ \\
\hline $\begin{array}{l}\text { AFBC } \\
\text { AFBC } \\
\text { AFBC } \\
\text { AFBC }\end{array}$ & $\begin{array}{l}\text { aluminum silicate } \\
\text { aluminum silicate } \\
\text { aluminum silicate } \\
\text { aluminum silicate }\end{array}$ & $\begin{array}{l}0 \\
0.1 \\
0.5 \\
1.0\end{array}$ & $\begin{array}{l}85.3 \\
86.4 \\
86.0 \\
85.9\end{array}$ & $\begin{array}{l}65.3 \\
66.1 \\
67.0 \\
66.9\end{array}$ \\
\hline
\end{tabular}




\section{APPENDIX P}

TEST PROCEDURES FOR THE CONDITIONING OF FLY ASH WTTH AMMONIUM SULFATE IN THE MIXING AND CONDITIONING CHAMBER

Time

h:mm:ss

Action

$\begin{array}{ll}\text { Pro-test } & \text { Load and install } 47 \text { mm filter holder } \\ \text { Pro-test } & \text { Load ash into removable collection reservoir } \\ \text { Pro-test } & \text { Seal chamber } \\ \text { Pro-test } & \text { Pre-heat oven to } 155 \text { C overnight } \\ \text { 0:00:00 } & \text { Initiate air flow with } 4 \% \text { moisture into chamber at 4 liter/min } \\ \text { 0:15:00 } & \text { Initiate } \mathrm{NH}_{3} \text { flow at desired concentration } \\ \text { 0:20:00 } & \text { Initiate } \mathrm{SO}_{3} \text { flow at desired concentration } \\ \text { 0:29:30 } & \text { Turn on fan at 75\% power } \\ \text { 0:30:00 } & \text { Turn off fan } \\ \text { 0:39:30 } & \text { Turn on fan at 75\% power } \\ \text { 0:40:00 } & \text { Turn off fan } \\ \text { 0:49:30 } & \text { Turn on fan at 75\% power } \\ \text { 0:50:00 } & \text { Turn off fan } \\ \text { 0:59:30 } & \text { Turn on fan at 75\% power } \\ \text { 1:00:00 } & \text { Turn off fan } \\ \text { 1:09:30 } & \text { Turn on fan at 75\% power } \\ \text { 1:10:00 } & \text { Turn off fan } \\ \text { 1:19:30 } & \text { Turn on fan at 75\% power } \\ \text { 1:20:00 } & \text { Turn off fan } \\ \text { 1:20:00 } & \text { Turn off SO3 and NH3 flows } \\ \text { 1:21:00 } & \text { Switch outlet flow through 47 mm filter } \\ \text { 1:23:00 } & \text { Bypass outlet flow around filter } \\ \text { 1:53:00 } & \text { Shut off moist air flow } \\ \text { 1:53:00 } & \text { Shut off oven heaters } \\ \text { 2:53:00 } & \text { Collect } 47 \text { mm filter with conditioned ash sample } \\ \end{array}$




\section{APPFAIDIX Q}

ADDITIONAL DATA FOR PROOF-OF-CONCEPT FILTRATION TESTS 


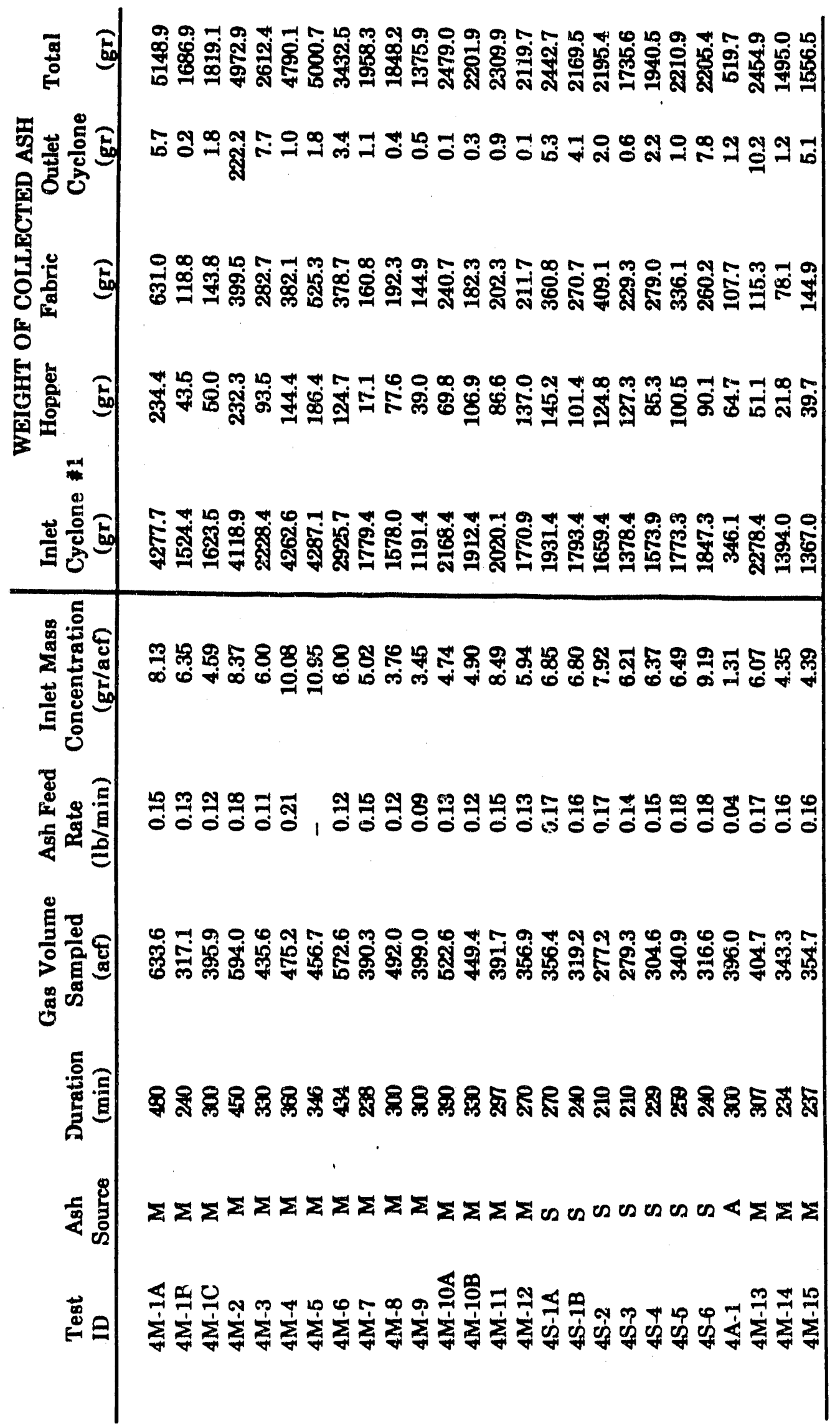




\section{APPENDIX R}

\section{PROCEDURES USED IN PROOF-OF-CONCEPT FILTRATION TESTS OF \\ SULFUR TRIOXIDE COMBBNED WITH AMMONIA AND \\ SULFUR TRIOXIDE COMBINED WITH TRIETHLYAMINE}

Tents 4M-14 and 4M-15 were performed with the conditioning systems shown in figure 40. The following information provides the procedures used in these tests.
1. hoat FFSS to $300^{\circ} \mathrm{F}$
2. heat all conditioning injection lines to $325^{\circ} \mathrm{F}$
3. set wind tunnel velocity to $20 \mathrm{ft} / \mathrm{s}$
4. start ash injection
5. turn ammonia injection (or TEA injection) system on
6. open $\mathrm{SO}_{3}$ bleed line
7. set moist air flow through $\mathrm{SO}_{3}$ line $(.15 \mathrm{cfm})$
8. set FFSS forwand flow to $1.47 \mathrm{~cm}$
9. turn on Nitrogen flow ( $\mathrm{SO}_{3}$ produced at $160 \mathrm{ppm}$ )
10. open $\mathrm{SO}_{3}$ injection line into FFSS transform and close bleed line
11. run filtration test
12. FFSS transform contains $16 \mathrm{ppm} \mathrm{SO}, 40 \mathrm{ppm}$ ammonia (or TEA)
13. shut off ash injection
14. close off fuming sulfuric acid container/stop Nitrogen flow
15. open $\mathrm{SO}_{3}$ test line (serves as bleed for $\mathrm{SO}_{3}$ purging)
16. turn off ammonia (or TEA) injection
17. shut down FFSS heaters
18. purge $\mathrm{SO}_{3}$ line for 10 minutes
19. cool FFSS
20. remove dustcake sample for analysis 

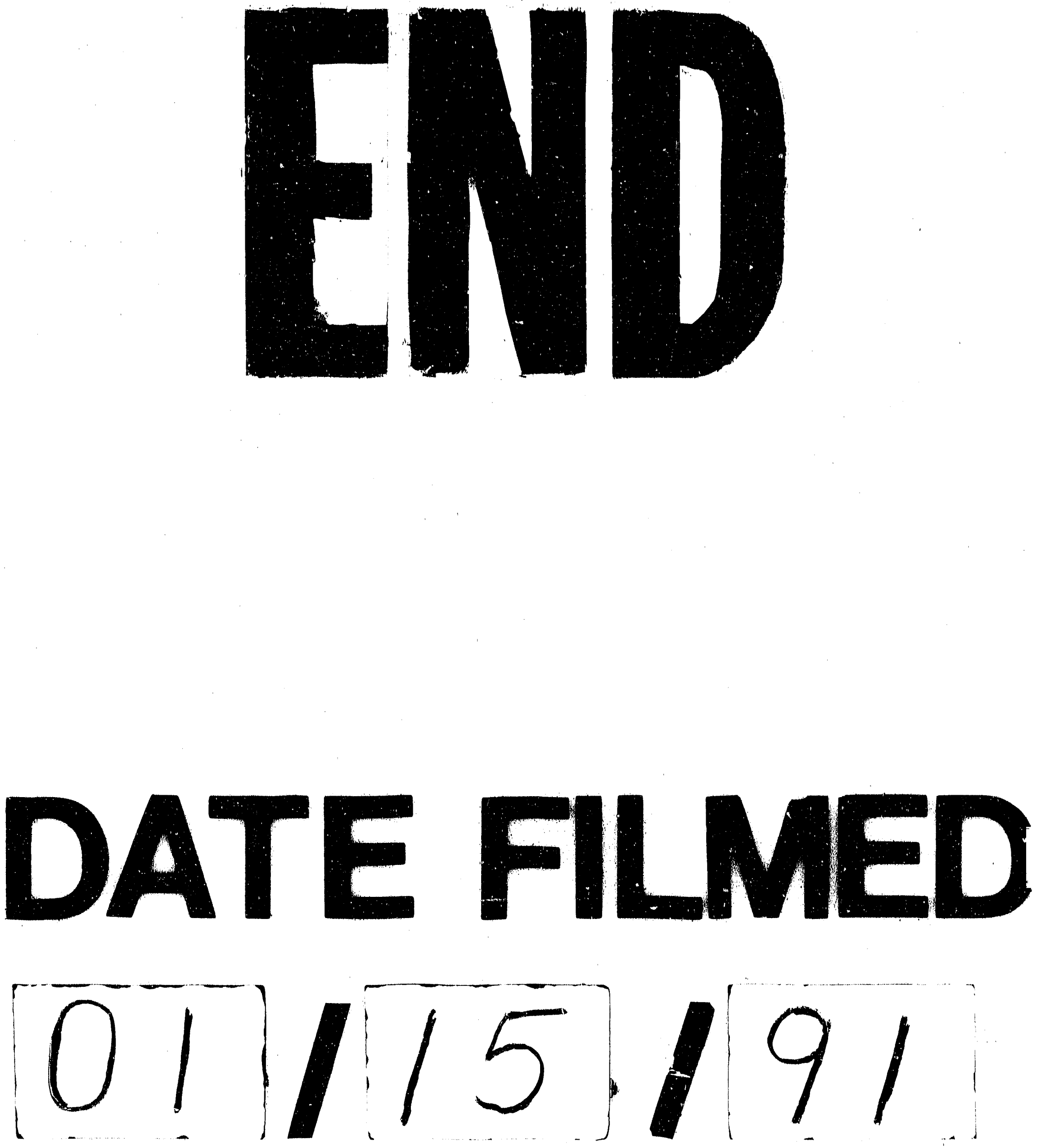
